\title{
Models for Mexican Temperate Forests: A Sustainable Management Approach
}

\author{
Dissertation \\ to attain the doctoral degree Doctor of Philosophy (Ph. D.) \\ of the Faculty of Forest Sciences and Forest Ecology \\ Georg-August-Universität Göttingen
}

\author{
Submitted by \\ Ernesto Alonso Rubio Camacho \\ born on the $25^{\text {th }}$ September 1980 in Jalisco, Mexico
}

Göttingen, September 2021 
1st Referee: Prof. Dr. Jürgen Nagel

2nd Referee: Prof. Dr. Winfried Kurth

Date of oral examination: September $27^{\text {th }}, 2021$ 
"Printed with the support of the German Academic Exchange Service" 



\section{Acknowledgements}

In the first place I would like to thank my family, who have been supporting me since the beginning of the project and are always there at the end of the day. Thank you for all your love, patience, and support: Magnolia, Eric, and Nicolas, this achievement belongs to all of us.

I thank my role model, my mother Tomasa Rubio, for her unconditional love and support, and my brothers Fabian and Carlos. I also thank Rosa Elia Cruz Vargas, who always encouraged me to go on and gave me support, the acknowledgment is extended to her entire family.

Special thanks to Prof. Dr. Jürgen Nagel, who accepted me as a student and has always been a great support. Thank you for all your patience and for all the hours you have spent reading and fixing my code and thesis.

I would like to thank Prof. Dr. Winfried Kurth for agreeing to act as second advisor and for opening the space in the Department Ecoinformatics, Biometrics \& Forest Growth. I also thank Prof. Dr. Achim Dohrenbusch for accepting being the third advisor and for the feedback. Dr. Oscar Aguirre from the Autonomous University of Nuevo Leon, Faculty of Forestry Sciences (UANL-FCF), thank you very much for believing in me and for promoting my research career in Mexico.

In terms of financing, I am very grateful to the National Council of Science and Technology in Mexico (CONACYT) and the Deutscher Akademischer Austauschdienst (DAAD) for the joint grant (91680941) awarded for the doctoral studies. I also thank the Graduate School Forest and Agricultural Sciences (GFA) for the revision grant.

I would like to thank to the National Institute of Research in Forestry, Agriculture and Livestock (INIFAP, Spanish acronym) for all the support to study abroad. A special thank goes to the people from the Pacífico-Centro Regional Research Center (CIRPAC): Dr. Juan de Dios Benavides Solorio, Dr. Antonio Rentería $(†)$, Dr. Moisés Alberto Cortés Cruz (†), Dr. Jorge Armando Bonilla Cárdenas, Deyanira Rodriguez, and Victor Hugo. This acknowledgment is extended to the administration of the Centro-Altos Research Station M. Sc. Ramón Hernández Virgen, Sandra Vega, Francisco Cervantes, and Lupita Morales.

I thank the National Forestry Commission (CONAFOR) Puebla for providing the data, specially to the technical service providers in the region, the Forest 
Management Units (UMAFOR), and the Union of Ejidos of the state of Puebla. This database was collected and structured by Dr. Juan Antonio López Hernández to whom I am especially grateful.

My dear friend Aleksi Tavkhelidze, thank you for the feedback, proofreading, and all those very good moments. I thank Dr. Faustino Hilario Chi and Dr. Christoph Stiehm for the talk and feedback. A special thank to Ms. Ilona Watteler Spang, Agnieszka Melzer, and Dr. Reinhold Meyer for all administrative support during my time in the department. I also thank my friends Ramón and his family; Nadia, Max, and family, thank you Ramón and Max for the proofreading as well; Pablo, Marisela, and Hans; José, Francis, and family; Adriana, David, and Family; Ana and Matthäus; Fernanda and Andres; Christoph Fischer and Wendy; Mariela, Iván, and to all the people I have met during my Ph.D. studies, thank you everybody for joining and sharing this special time with me.

Finally, I would like to thank the developers that have been working on the ForestSimulator software and to the community of free and open source software (R Development Core Team, Linux, and Latex). Certainly, their support was essential to my project. 


\section{Summary}

In Mexico there is a need for technologies that link forest stand dynamics with silviculture systems. Providing these technologies could enhance forest management, not only by making forests more profitable, but by adapting them to climate change. Lately, there has been a debate on forest management for carbon and climate change benefits. Recent studies claim that letting forest grow without management is better for carbon sequestration and storage. However, other researchers argue that harvesting is a better management strategy because of the substitution effects of using wood products instead of carbon-intensive materials. This thesis addresses the subject in a simulation scheme, taking into account the natural conditions of Mexican temperate forests.

For this purpose the ForestSimulator software was adapted to the Mexican standards. The first step was to develop and collect the necessary growth models to be integrated into the software. The developed models were fitted using information of 49 sampling plots located in natural forests of northern Puebla, Mexico (chapters 2-4). The rest of the models were collected from the literature and integrated into ForestSimulator, this process is detailed in chapter 4. Chapter 5 deals with the stand dynamics and the natural drivers of tree mortality in temperate forests, and Chapter 6 integrates the information of previous chapters in a simulation study. The following paragraphs summarize the main findings of each chapter.

In chapter 2, several models for predicting basal area increment (BAI) were fitted using linear fixed and mixed-effects modeling approximations. Mixedeffects models were used to infer about the random effects at plot, elevation, and aspect levels. The results include a set of models for predicting BAI for Pinus patula and other important genera in Central Mexico (Abies, Pinus, Quercus). On each of these models, the logarithm transformation of tree diameter $d$ and the competition index BALMOD were chosen as fixed, while plot, elevation, and aspect were selected as random effects. Therefore, the models presented in this chapter include the fundamental components of BAI prediction models: i) tree size, ii) tree competition, and iii) site characteristics.

Chapter 3 deals with the development of four models to predict tree heightdiameter $(h-d)$ relationships for coniferous and broadleaf species. Non-linear fixed 
and mixed-effects modeling approaches were used to fit generalized versions of the Gompertz function to Pinus patula and Pinus group; Näslund function to Abies religiosa; and Curtis function to Quercus group. These models were also calibrated and validated using cross-validation. All groups showed reliable results with acceptable goodness-of-fit statistics. For the calibration, a sub-sample of three trees is required to make accurate predictions. The newly developed models can be used independently of forest simulators as well.

Chapter 4 is concerned with the methodology used for adapting the ForestSimulator software to the Mexican conditions. Some models were collected from the literature and others were developed to complete the software requirements. The equations from literature were taken primarily from the Forest Biometric System for forest management in Mexico (SIBIFOR) from the forest management unit 2108 (UMF2108) for P. ayacahuite, P. hartwegii, P. leiophylla, P. montezumae, P. patula, P. pseudostrobus, P. teocote, Abies religiosa, and Quercus sp. For this chapter, the models developed were: diameter distribution, crown width, and crown base height models. As a main result, a new Mexican version of ForestSimulator for temperate forests is presented in this thesis.

In chapter 5, spatial point patterns are used to infer about the relationship of forest stand dynamics to disturbances. Tree mortality is an important process of forest dynamics and its knowledge is fundamental to implement adequate management strategies. The aim of this study was to spatially characterize the tree mortality in a mature temperate forest of central Mexico, using information from a unique permanent plot $(300 \times 300, m)$ measured in a 20-year period. Although this plot is different, it was located close to main study area and the information generated can be applicable to similar forests. The results from applying point pattern analysis showed that tree mortality occurs in clusters at different scales, and did not show a strong evidence of mortality by suppression. These results could be explained by the droughts that occurred between measurements and that could have produced clusters of dead trees. The information generated by this study can contribute to implement management strategies and provides novel information regarding tree mortality in Mexican forest ecosystems.

Chapter 6 focuses on the simulation of the carbon balance over a 120-year period, using three different scenarios: 1) Protected; 2) Gaps; and 3) Harvest scenarios. ForestSimulator Mexico was used to perform the simulations. The 
results showed that the largest amount of carbon was stored in situ by the Protected scenario, followed by the Gaps and Harvest scenarios. Although the Protected scenario seemed to be the best option for climate benefits, carbon accumulation in fire-adapted ecosystems increases the risk for more extensive and severe fires, which would release more carbon into the atmosphere, while having a negative effect on forest resilience. The Harvest scenarios turned out to be a better management option due to substitution effects, the avoidance of forest fuel accumulation, and the socioeconomic aspects derived from the sale of timber.

Forest management can affect carbon sequestration and storage, therefore it plays a key role in climate change mitigation. In addition, forestry could also adapt forests to climate change by choosing and selecting a resilient species composition. The results of this thesis were directed to support sustainable forest management in Mexico by integrating models in the ForestSimulator software. Therefore, further use of the knowledge and technologies described in this work could help Mexican foresters, scientists, and decision makers to manage, analyze, and regulate forest ecosystems. 



\section{Zusammenfassung}

In Mexiko besteht ein Bedarf an Technologien, die die Dynamik von Waldbeständen mit Waldbausystemen verbinden. Die Bereitstellung und Anwendung dieser Technologien könnte die Waldbewirtschaftung verbessern. Die Wälder könnten so nicht nur profitabler, sondern auch besser an den Klimawandel angepasst werden. In letzter Zeit gibt es eine Debatte über die Waldbewirtschaftung im Hinblick auf Kohlenstoff und Klimawandel. Neuere Studien behaupten, dass es für die Kohlenstoffbindung und -speicherung besser ist, den Wald ohne Bewirtschaftung wachsen zu lassen. Andere Forscher argumentieren jedoch, dass die Holznutzung eine bessere Bewirtschaftungsstrategie ist, da die Verwendung von Holzprodukten anstelle von kohlenstoffintensiven Materialien Substitutionseffekte mit sich bringt. In dieser Arbeit wird das Thema mit Hilfe von simulierten Waldentwicklungen unter Berücksichtigung der natürlichen Bedingungen beispielhaft für einen mexikanischer Wald der gemäßigten Zone untersucht.

$\mathrm{Zu}$ diesem Zweck wurde die Software ForestSimulator auf die mexikanischen Verhältnisse angepasst. Der erste Schritt war die Entwicklung und Sammlung der notwendigen Wachstumsmodelle, die in die Software integriert werden sollten. Die entwickelten Modelle wurden anhand der Daten von 49 Stichprobenparzellen in Naturwäldern im Norden von Puebla, Mexiko, angepasst (Kapitel 2-4). Die restlichen Modelle wurden aus der Literatur zusammengetragen und in den ForestSimulator integriert, dieser Prozess wird in Kapitel 4 ausführlich beschrieben. Kapitel 5 befasst sich mit der Bestandsdynamik und den natürlichen Triebkräften der Baummortalität in gemäßigten Wäldern, und in Kapitel 6 werden schließlich die Informationen der vorangegangenen Kapitel im Rahmen der Simulationsstudie beispielhaft angewendet. Die folgenden Absätze fassen die wichtigsten Ergebnisse der einzelnen Kapitel zusammen.

In Kapitel 2 wurden mehrere Modelle zur Vorhersage des Basalflächenzuwachses (BAI) mit linearen festen und gemischten Effekten modelliert. GemischteEffekte-Modelle wurden verwendet, um Rückschlüsse auf die zufälligen Effekte von Parzellen-, Höhenlage- und Aspekt-Ebene ziehen zu können. Die Ergebnisse umfassen eine Reihe von Modellen zur Vorhersage des BAI für Pinus patula und andere wichtige Gattungen in Zentralmexiko (Abies, Pinus, Quercus). Bei jedem dieser Modelle wurden die Logarithmus-Transformation des Baumdurchmessers und der Konkurrenzindex BALMOD als fest gewählt, während Parzelle, Höhenlage und Aspekt als zufällige Effekte eingesetzt wurden. Daher 
enthalten die in diesem Kapitel vorgestellten Modelle die grundlegenden Komponenten der BAI-Vorhersagemodelle: i) Baumgröße, ii) Baumkonkurrenz und iii) Standorteigenschaften.

Kapitel 3 befasst sich mit der Entwicklung von vier Modellen zur Vorhersage von Baumhöhe-Durchmesser-Beziehungen $(h-d)$ für Nadel- und Laubbaumarten. Nichtlineare Modellierungsansätze mit festen und gemischten Effekten wurden verwendet, um verallgemeinerte Versionen der Gompertz-Funktion für Pinus patula und die Pinus-Gruppe, die Näslund-Funktion für Abies religiosa und die Curtis-Funktion für die Quercus-Gruppe anzupassen. Diese Modelle wurden ebenfalls kalibriert und einer Kreuzvalidierung unterzogen. Alle Gruppen zeigten zuverlässige Ergebnisse mit akzeptablen Goodness-of-Fit-Statistiken. Zur Kalibrierung ist eine Unterstichprobe von drei Bäumen erforderlich, um genaue Vorhersagen machen zu können. Die neu entwickelten Modelle können auch unabhängig von Waldsimulatoren verwendet werden.

Kapitel 4 befasst sich mit der Methodik, die zur Anpassung der ForestSimulator-Software auf die mexikanischen Bedingungen verwendet wurde. Einige Modelle wurden aus der Literatur entnommen, andere wurden entwickelt, um die Anforderungen der Software zu vervollständigen. Die Gleichungen aus der Literatur wurden hauptsächlich aus dem Forstbiometrischen System für die Waldbewirtschaftung in Mexiko (SIBIFOR) aus dem Forstwirtschaftsgebiet 2108 (UMF2108) UMF2018 für P. ayacahuite, P. hartwegii, P. leiophylla, P. montezumae, P. patula, P. pseudostrobus, P. teocote, Abies religiosa und Quercus sp entnommen. Für dieses Kapitel wurden folgende Modelle neu entwickelt: Modelle für die Durchmesserverteilung, die Kronenbreite und die Kronenansatzhöhe. Als Hauptergebnis wird in dieser Arbeit eine neue mexikanische Version des ForestSimulators für gemäßigte Wälder vorgestellt.

In Kapitel 5 werden räumliche Punktmuster verwendet, um Rückschlüsse auf die Beziehung der Waldbestandsdynamik zu Störungen zu ziehen. Die Baummortalität ist ein wichtiger Prozess der Walddynamik, deren Kenntnis für die Umsetzung geeigneter Bewirtschaftungsstrategien von grundlegender Bedeutung ist. Ziel dieser Studie war es, die Baumsterblichkeit in einem älteren Wald der gemäßigten Zone in Zentralmexiko räumlich zu charakterisieren. Dafür wurden Daten aus einer einzigartigen Dauerbeobachtungsfläche (300 x 300 m) verwendet wurden, die seit 20 Jahren unter Beobachtung ist. Obwohl dieses Plot anders ist, befand es sich in der Nähe des Hauptuntersuchungsgebietes 
und die generierten Informationen können auf ähnliche Wälder angewendet werden. Die Ergebnisse der Punktmusteranalyse zeigten, dass die Baummortalität in Clustern auf verschiedenen Skalen auftritt und keine starken Hinweis auf dichtebedingte Mortalität zu finden war. Die Ergebnisse können durch die Dürreperioden erklärt werden, die zwischen den Messungen auftraten und die Cluster von abgestorbenen Bäumen erzeugt haben können. Die in dieser Studie gewonnenen Informationen sind für die Umsetzung von Managementstrategien nützlich und liefern neue Informationen zur Baummortaltät in mexikanischen Waldökosystemen.

Kapitel 6 befasst sich mit der Simulation der Kohlenstoffbilanz über einen Zeitraum von 120 Jahren unter Verwendung von drei verschiedenen Szenarien: 1) Protected = Geschützt; 2) Gaps = Lücken; und 3) Harvest = Ernte-Szenarien. Zur Durchführung der Simulationen wurde der ForestSimulator Mexico verwendet. Die Ergebnisse zeigten, dass die größte Menge an Kohlenstoff in situ durch das Szenario "Geschützt" gespeichert wurde, gefolgt von den Szenarien "Lücken" und "Ernte". Obwohl das Szenario "Geschützt" die beste Option für den Klimanutzen zu sein schien, erhöht die Kohlenstoffakkumulation in feuergefährdeten Ökosystemen das Risiko für größere und schwerere Brände, die mehr Kohlenstoff in die Atmosphäre freisetzen und sich negativ auf die Widerstandsfähigkeit der Wälder auswirken würden. Die Ernteszenarien erwiesen sich aufgrund von Substitutionseffekten, der Vermeidung der Akkumulation von Totholz und der sozioökonomischen Aspekte als bessere Bewirtschaftungsoption.

Die Waldbewirtschaftung kann die Kohlenstoffbindung und -speicherung beeinflussen und spielt daher eine Schlüsselrolle bei Strategien zur Abschwächung des Klimawandels. Darüber hinaus muss die Forstwirtschaft die Wälder an den Klimawandel anpassen, indem sie widerstandsfähige Artenmischungen fördert und anbaut. Die Ergebnisse dieser Arbeit wurden darauf ausgerichtet, die nachhaltige Waldbewirtschaftung in Mexiko mit Hilfe der Software ForestSimulator zu unterstützen. Die Anwendung, der in dieser Arbeit beschriebenen Kenntnisse und Technologien sollte mexikanischen Förstern, Wissenschaftlern und Entscheidungsträgern helfen, Waldökosysteme besser zu verwalten, zu analysieren und zu regulieren. 



\section{Contents}

$\begin{array}{ll}\text { List of Figures } & \text { XV }\end{array}$

List of Tables $\quad$ xvii

1 Introduction $\quad \mathbf{1}$

1.1 Forest Management in Mexico . . . . . . . . . . . . . . . . . . . . . 1

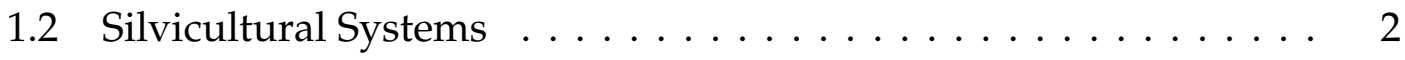

1.3 Forest Growth Models . . . . . . . . . . . . . . . . . . . . . 4

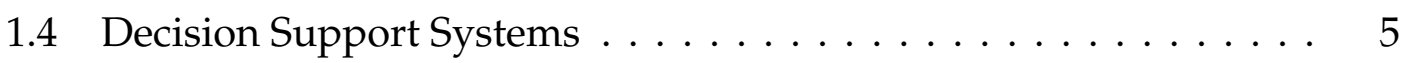

1.5 Forest Dynamics Simulation $\ldots \ldots \ldots \ldots \ldots$

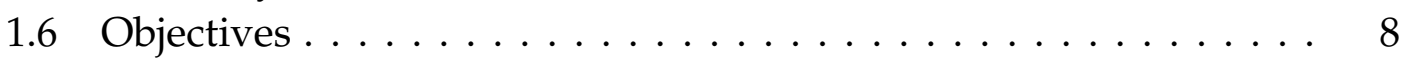

Literature . . . . . . . . . . . . . . . . . . . . 10

2 Testing Random Effects on Basal Area Increment Models for Mexican $\begin{array}{ll}\text { Temperate Forests } & \mathbf{1 5}\end{array}$

2.1 Introduction . . . . . . . . . . . . . . . . . 16

2.2 Materials and Methods . . . . . . . . . . . . . . . . . . . . . . . 19

2.2 .1 Study Area . . . . . . . . . . . . . . . . . . . . 19

2.2 .2 Data collection . . . . . . . . . . . . . . . . . 20

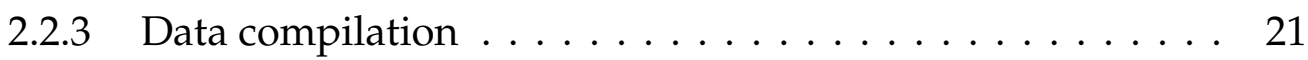

2.2.4 Regression models . . . . . . . . . . . . . . . . . . . . 24

2.2.5 Random effects localization and model validation . . . . . 27

2.3 Results . . . . . . . . . . . . . . . . . . . . . . . . . 29

2.3 .1 Model fitting . . . . . . . . . . . . . . . . . . . . . 29

2.3.2 Random effects localization . . . . . . . . . . . . 35

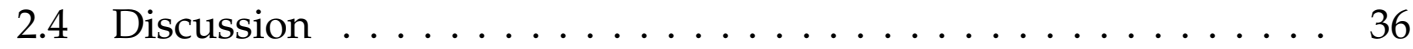

2.4 .1 Tree size $\ldots \ldots \ldots \ldots \ldots \ldots \ldots \ldots \ldots \ldots \ldots$

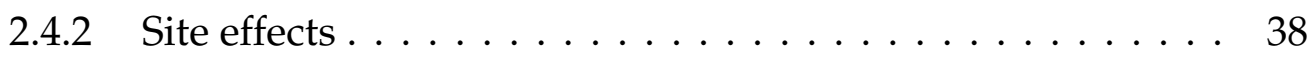

2.4 .3 Competition index . . . . . . . . . . . . . . . 39

2.4.4 Random effects localization and model validation . . . . . 39

2.4 .5 Future applications . . . . . . . . . . . . . . . . . . . . . 40

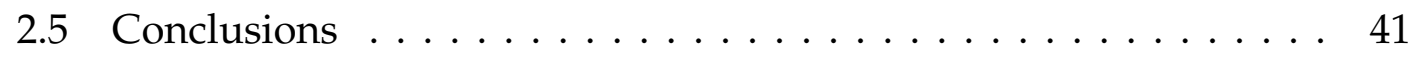


Literature ........................... 42

3 Generalized Height-Diameter Models with Random Effects for Natural $\begin{array}{ll}\text { Forests of Central Mexico } & 47\end{array}$

3.1 Introduction . . . . . . . . . . . . . . . . . . 48

3.2 Materials and Methods . . . . . . . . . . . . . . . . . 50

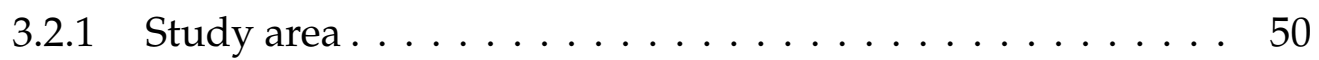

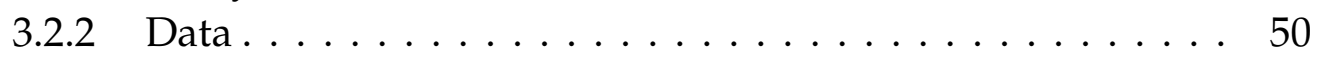

3.2 .3 Model development . . . . . . . . . . . . . . . . 51

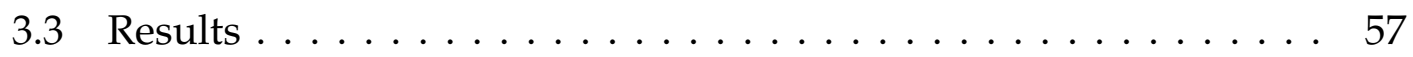

3.3.1 Local fixed-effects models . . . . . . . . . . . . . . . . 57

3.3.2 Generalized mixed-effects models . . . . . . . . . . . . . 58

3.3 .3 Calibration and validation . . . . . . . . . . . . . . 64

3.4 Discussion ......................... 64

3.4.1 Local fixed-effects $h-d$ models . . . . . . . . . . . . . . 65

3.4.2 Tree $h$ - $d$ model generalization . . . . . . . . . . . . 66

3.4.3 Parameter expansion with random effects . . . . . . . . . 66

3.4.4 Random effects calibration . . . . . . . . . . . . . 67

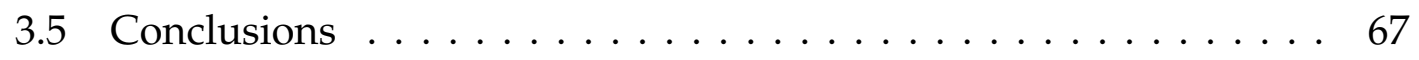

Literature . . . . . . . . . . . . . . . . . . . . . 69

4 ForestSimulator Mexico: Models and Software Settings for Temperate $\begin{array}{ll}\text { Forests } & 73\end{array}$

4.1 Background ... . . . . . . . . . . . . . . . . . 74

4.1.1 Region and Tree Species . . . . . . . . . . . . . . 76

4.1 .2 ForestSimulator Mexico ................ 78

4.2 Forest models . . . . . . . . . . . . . . . . . . . . . 79

4.2 .1 Uniform height curve . . . . . . . . . . . . . . . . . . . . . . 80

4.2 .2 Diameter distribution . . . . . . . . . . . . 80

4.2.3 Weibull parameter prediction models ... . . . . . . . 81

4.2.4 Crown width and crown base height models . . . . . . . . 82

4.2 .5 Volume model . . . . . . . . . . . . . . . . . . . . . . . . . . . . . . . 84

4.2 .6 Taper function . . . . . . . . . . . . . . . . . . . . . . . . . . . . . . . . . . . . 85

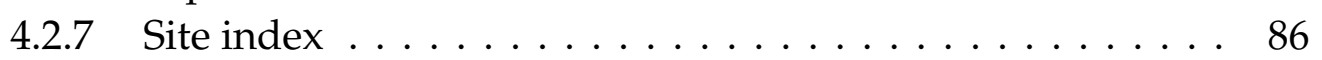

4.2 .8 Index height $\ldots \ldots \ldots \ldots \ldots$

4.2 .9 Potential height increment . . . . . . . . . . . . . . . 88

4.2 .10 Height increment . . . . . . . . . . . . . . . . . . . . . . . . . . . . . . . . . . . 99

4.2 .11 Diameter increment . . . . . . . . . . . . . . . 90

4.2 .12 Maximum density and tree mortality . . . . . . . . . . . . . . . . . . . . . . . . . . . 90

4.2 .13 Competition ... . . . . . . . . . . . . . . . . . . . . . . . . . . . 91

4.2 .14 Biomass models . . . . . . . . . . . . . . . . . . 92 
4.3 Concluding remarks and future work . . . . . . . . . . . 93

Literature . . . . . . . . . . . . . . . . . . . . . . . . . 94

5 Spatial Patterns of Tree Mortality in a Montane Forest of Central Mexico $\quad 97$

5.1 Introduction . . . . . . . . . . . . . . . . . . . . . 98

5.2 Materials and Methods . . . . . . . . . . . . . . . . . . . . 101

5.2.1 Study Area . . . . . . . . . . . . . . . . . . . . . . . . 101

5.2 .2 Data collection . . . . . . . . . . . . . . . . . . . 102

5.2.3 Data Analysis: Spatial Patterns . . . . . . . . . . . . . . . 102

5.3 Results . . . . . . . . . . . . . . . . . . . . . . . . 106

5.3.1 Dead and live trees tracking . . . . . . . . . . . . . . . . . . . . . . . 106

5.3.2 Spatial patterns of dead trees . . . . . . . . . . . . 107

5.3.3 Spatial relationship between dead and live trees . . . . . . 109

5.3.4 Spatial patterns of live trees . . . . . . . . . . . . . . . 111

5.4 Discussion . . . . . . . . . . . . . . . . . . . . . . . . . . . . 114

5.4.1 Spatial patterns of dead trees . . . . . . . . . . . . . 114

5.4.2 Spatial relationship between dead and live trees . . . . . . 115

5.4 .3 Spatial patterns of live trees . . . . . . . . . . . . . . 115

5.4 .4 Concluding remarks . . . . . . . . . . . . . . . 116

Literature . . . . . . . . . . . . . . . . . . . 117

6 Above-Ground Carbon Dynamics in a Mexican Temperate Forest: A $\begin{array}{lr}\text { Simulation Study } & 121\end{array}$

6.1 Introduction . . . . . . . . . . . . . . . . . . . . . . . . . . 122

6.2 Materials and Methods . . . . . . . . . . . . . . . . . . . . . 125

6.2.1 ForestSimulator settings . . . . . . . . . . . . . 125

6.2 .2 Simulation scenarios . . . . . . . . . . . . . . . . . 128

6.3 Results . . . . . . . . . . . . . . . . . . . . . . . . . . . . . . . . . 129

6.3 .1 Stand structure $\ldots \ldots \ldots \ldots \ldots \ldots$

6.3.2 Mean annual increment . . . . . . . . . . . . . . . . . . . . 130

6.3 .3 Stand volume . . . . . . . . . . . . . . . . . 133

6.3.4 Carbon stored in live trees . . . . . . . . . . . . . . . . . . . 134

6.3.5 Carbon storage in dead and removed trees . . . . . . . . . . . . . . . . . . . . . . . . . . .

6.3.6 Substitution effects . . . . . . . . . . . . . . . . . . . . . . 137

6.4 Discussion . . . . . . . . . . . . . . . . . . . . . . . 139

6.4 .1 Forest structure . . . . . . . . . . . . . . . . . . . 140

6.4 .2 Carbon dynamics . . . . . . . . . . . . . . . . . . . . . . . . . . . . . . . . . . .

6.4 .3 Substitution effects . . . . . . . . . . . . . . . 143

6.4 .4 Recommendations . . . . . . . . . . . . . . . . . . . . . . . 144

6.5 Conclusions . . . . . . . . . . . . . . . . . . . . 145 
Literature . . . . . . . . . . . . . . . . . . . 146

$\begin{array}{lll}7 & \text { Conclusion } & 151\end{array}$ 


\section{List of Figures}

1.1 Timeline of major events related to forest management in Mexico . 7

2.1 Study area localization in central Mexico. . . . . . . . . . . . . 20

2.2 Residual plots for P. patula group. . . . . . . . . . . . . . 30

2.3 Residual plots for Pinus group. . . . . . . . . . . . . . . . . . 31

2.4 Residual plots for Abies group. . . . . . . . . . . . . . . . 33

2.5 Residual plots for Quecus group. . . . . . . . . . . . . . . . . . . . 34

2.6 Random effects from Geo models for Pinus patula, Pinus, Abies, and Quercus group. . . . . . . . . . . . . . . . 36

2.7 Number of trees for localization of random effects on new plots. . 37

3.1 Tree height-diameter data used to fit the non-linear fixed and mixed-effects models. . . . . . . . . . . . . . . . . . 53

3.2 Residual plot for Pinus patula generalized mixed-effects model. . . 60

3.3 Residual plot for Pinus group generalized mixed-effects model. . . 61

3.4 Residual plot for Abies religiosa generalized mixed-effects model. . 63

3.5 Residual plot for Quercus group generalized mixed-effects model. 63

4.1 Localization of the UMF2108. . . . . . . . . . . . . . . . . 77

4.2 Species manager. . . . . . . . . . . . . . . . 78

5.1 Study area localization . . . . . . . . . . . . . . . . . . . 101

5.2 Diametric distribution of dead trees . . . . . . . . . . . . . . . . . . . . . . . . . . . . . . . . . 107

5.3 Diametric distribution of live trees . . . . . . . . . . . . . . . . . 108

5.4 Study plot $(300 \times 300 \mathrm{~m})$ showing the spatial distribution of all dead trees . . . . . . . . . . . . . . . . . . . . . . . . 109

5.5 Homogeneous pair-correlation function $g(r)$ applied to all dead

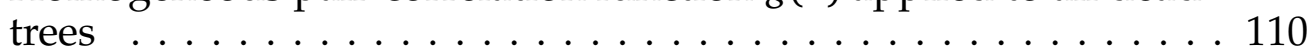

5.6 Thomas cluster process applied to the pair-correlation function $g(r)$ of dead trees . . . . . . . . . . . . . . . . . . 110

5.7 Bivariate mark-connection function $p_{12}(\mathrm{r})$ for testing spatial relationships between dead and live trees at various scales $\mathrm{r}(\mathrm{m}) \ldots 111$ 
5.8 Homogeneous pair-correlation function $g(r)$ applied to all live trees from 1974 and the remaining ones from 1995 by diameter classes . . . . . . . . . . . . . . . . . . . . . . 112

5.9 Thomas cluster process applied to the pair-correlation function $g(r)$ of live trees by class . . . . . . . . . . . . . . . . 113

5.10 Mark correlation function $\mathrm{k}_{m m}(\mathrm{r})$ applied to live trees at the beginning and the end of measurement period using diameter as mark . . . . . . . . . . . . . . . . . . . . . . . 113

6.1 Output of ForestSimulator, only one stand is shown as an example. 131

6.2 Diameter distributions of live trees in all scenarios. . . . . . . . 132

6.3 Volume mean annual increment (MAI) by stand. . . . . . . . . 133

6.4 Volume trend of live trees by simulation scenario. . . . . . . . 134

6.5 Volume extracted in Gaps and Harvested scenarios. . . . . . . . . . 135

6.6 Carbon trends of live trees by stand and simulation scenario. . . . 135

6.7 Cumulative carbon from removed trees and mortality. . . . . . . 137

6.8 Carbon from mortality and removed trees by simulation scenario. 138

6.9 Mean carbon content by scenario and component. . . . . . . . . 139 


\section{List of Tables}

2.1 Summary statistics by group in the study area. . . . . . . . . . . 22

2.2 Classification of the environmental variables used as factor in the models. . . . . . . . . . . . . . . . . . . 23

2.3 Pinus patula $\log (B A I+1)$ models parameters and goodness-of-fit statistic values. . . . . . . . . . . . . . . . . . 30

2.4 Pinus group $\log (B A I+1)$ models parameters and goodness-of-fit statistic values . . . . . . . . . . . . . . . 31

2.5 Abies group $\log (B A I+1)$ models parameters and goodness-of-fit statistic values . . . . . . . . . . . . . . . . 32

2.6 Quercus group $\log (B A I+1)$ models parameters and goodness-of-fit statistic values. . . . . . . . . . . . . . . . . . . 34

3.1 Descriptive statistics of the database by group and stand. . . . . . . 51

3.2 Tree $h$ - $d$ equations analyzed in this study . . . . . . . . . . . . 54

3.3 Root mean square error (RMSE) and Akaike information criterion (AIC) for ONLS fixed-effects $h$ - $d$ local models. . . . . . . . . . . . 58

3.4 Parameter estimates of the generalized mixed-effects models for Pinus patula . . . . . . . . . . . . . . . . . . . . 59

3.5 Parameter estimates of the generalized mixed-effects models for Pinus group. . . . . . . . . . . . . . . . . . 61

3.6 Parameter estimates of the generalized mixed-effects models for Abies religiosa. . . . . . . . . . . . . . . . . . . . 62

3.7 Parameter estimates of the generalized mixed-effects models for Quercus group.......................... 64

3.8 Comparison of the calibration alternatives applied to the selected generalized mixed-effects models. . . . . . . . . . . . . . . . . 65

4.1 Species included in ForestSimulator Mexico . . . . . . . . . . . . . 77

4.2 Example of the XML file input with the species parameters to include in ForestSimulator. . . . . . . . . . . . . . . . . . . . . 79

4.3 Model parameters by group for Equation $4.1 \ldots \ldots$. . . . . . . . 80

4.4 Regression statistics for the Weibull scale parameter. . . . . . . . . . 82

4.5 Regression statistics for the Weibull shape parameter. . . . . . . . . . 82 
4.6 Regression parameters and goodness-of-fit statistics of crown width models by group. . . . . . . . . . . . . . . . 84

4.7 Regression parameters and goodness-of-fit statistics of crown base height models by group. . . . . . . . . . . . . . . . . . 84

4.8 Total volume and stem volume parameters by species. . . . . . . . . 85

4.9 Taper volume parameters by species. . . . . . . . . . . . . . . . . . . . . . 86

4.10 Site index model parameters by species. . . . . . . . . . . . . . 87

4.11 Height increment model parameter estimation results (Lundqvist-

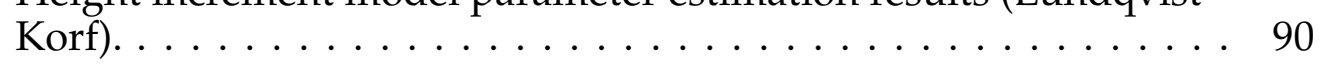

4.12 Diameter increment model parameter by group. . . . . . . . . . . . 90

4.13 Biomass models parameters by species included in the ForestSimulator Mexico: Temperate forests. . . . . . . . . . . . . . . 92

5.1 Summary table for the hypothesis tested and null models applied 106

5.2 Monitoring of the absolute number of live and dead trees by species throughout the plot $(300 \times 300 \mathrm{~m})$ per measurement year . 107

6.1 Initial state, measured in 2012, of the stands used in the simulation. Where $d_{g}=$ quadratic mean diameter, $h_{g}=$ corresponding tree height of the quadratic mean diameter, $H_{o}=$ dominant tree height, $D_{o}=$ corresponding diameter of the dominant tree height, $G=$ basal area, and $V=$ volume. . . . . . . . . . . . . . . 126

6.2 List of product classes with the corresponding decomposition constants. . . . . . . . . . . . . . . . . . . . . . 127

6.3 Carbon content and substitution effects by stand, treatment and product class in $\mathrm{tCha}^{-1}$. . . . . . . . . . . . . . . . . . 140 


\section{Chapter 1}

\section{Introduction}

Mexico, despite considerable progress regarding sustainable forest management, still faces many challenges. These are driven in part by the socio-economic and cultural dimensions related to the diversity of forest ecosystems (Espinosa and Ocegueda, 2008; Jardel-Peláez, 2012; Torres-Rojo et al., 2016). In addition, inefficient forest management practices have historically existed throughout the country (Jardel-Peláez, 2012). This, in turn, enhanced by the lack of technologies to support the decision making process, such as forest growth simulators (Hansen and Nagel, 2014; Moreno-Sánchez and Torres-Rojo, 2010). Therefore, providing such technologies would help forest management by making forests more profitable and adapting them to climate change. Furthermore, these technologies would also help to understand more accurately the contribution of forests to carbon sequestration and storage (Pukkala, 2018; Wördehoff et al., 2017).

\subsection{Forest Management in Mexico}

Mexico's forest land surface is about 66 million hectares, equivalent to $33.6 \%$ of the country's total area. The major ecosystems are temperate and tropical forests, covering roughly 34 and 30 million hectares, respectively (CONAFOR, 2018). These ecosystems are distributed in a diverse range of bioclimatic, topographic, and socioeconomic conditions (Espinosa and Ocegueda, 2008; Jardel-Peláez, 2012). 
Ejidos and agrarian communities own approximately $60 \%$ of forest lands (Madrid et al., 2009). They are entitled to manage their forests and even some communities have been proposed as a global model to other regions (Bray et al., 2006). However, Ejidos and agrarian communities have just recently received the right to manage their own lands, as they had historically been excluded from this entitlement (Bray and Merino-Pérez, 2005).

Forest resources in Mexico, before the Revolution (1910-1917), were usually managed via long-term leasing contracts. The 1926 forestry law intended to regulate this by establishing short-term contracts of up to one year. However, this led to further deforestation, so in the late 1930s the State declared logging bans. In the forestry law of 1943 forest management was turned over to private companies through concessions. These companies were called Industrial Logging Units (ILU) and operated until the mid-1980s. Thereafter, as a result of the agrarian law amendment in 1971, the 1986 forestry law entitled rural communities, and promoted the community-based forest management in Mexico (Merino-Pérez, 2004; Bray and Merino-Pérez, 2005).

Currently, rural communities and Ejidos manage their forests with a certain degree of autonomy from the State. There are communities that own their forest and sell concessions; others that can harvest timber and sell it to private sawmills; and there are also ones that harvest their forest and process timber. Hence, forest management in Mexico is carried out by Ejidos, communities, and private companies (Merino et al., 2008). The adopted silvicultural systems are described in the following sections.

\subsection{Silvicultural Systems}

In Mexico, silvicultural systems have evolved along with forest and land management trends. First, a method of forest regulation was developed for temperate forests, which was promoted in parallel with the forestry law of the 1940s. In the 1970s, another more intensive method was introduced to increase the country's forest production (Ramírez-Maldonado, 2017). Both methods have evolved and adapted to new forest management paradigms (Torres-Rojo et al., 2016). In fact, both approaches are currently used in different regions (Carrillo-Anzures et al., 
2017).

\section{Mexican Method of Forest Regulation (MMFR)}

Método Mexicano de Ordenación de Montes (MMOM)

This uneven-aged method was developed in the 1940s to regulate forest management in Mexico and became the official management system for temperate forests (Bray and Merino-Pérez, 2005; Ramírez-Maldonado, 2017; Torres-Rojo et al., 2016). It was designed primarily to manage old-growth forests and to promote Pinus species. It also attempted to improve forest health by removing damaged, plagued, and diseased trees. MMFR uses the selection method with a minimum target diameter, and established beforehand the maximum harvest intensity, commonly at 30\% of the initial volume stock (Jardel-Peláez, 2012; Ramírez-Maldonado, 2017). To estimate growth and wood volume increment MMFR implemented the compound interest formula, assuming an exponential forest growth, which is difficult to achieve in natural conditions (Torres-Rojo, 2000).

Although the method was widely used in the country, subsequent results were criticized. First, old-growth forests had an excessive pressure and monospecific stands were favored. Second, the selection method did not produce large enough gaps to stimulate pine regeneration (Snook and Negreros-Castillo, 1986). Therefore, it is not recommended for intolerant species, since oaks and broadleaf trees occupied the small open spaces, thus replacing pines (Jardel-Peláez, 2012). Despite these issues, MMFR remained the main method in Mexico for several decades, and in the 1980s an adaptation took place to include multiple forest uses, as well as socioeconomic aspects (Torres-Rojo et al., 2016). By the 1970s an even-aged method appeared to manage temperate forests.

\section{Method for Silvicultural Development (MSD)}

Método de Desarrollo Silvícola (MDS)

The MSD uses seed-trees as regeneration method to produce even-aged stands. It was firstly applied in the north of Mexico in the early 1970s aiming to increase forest production (Bray and Merino-Pérez, 2005; Ramírez-Maldonado, 2017). The MSD is a method of regulation by area and volume, and was designed under 
the assumption that shade-intolerant species need large open spaces to properly regenerate. In general, MSD is an intensive method that includes intermediate thinnings, crop-tree release thinnings, and regeneration harvests or final cuttings (Ramírez-Maldonado, 2017). This method is considered an important advance in Mexican forestry (Jardel-Peláez, 2012). Currently, both systems MSD and MMFR are still in use in some parts of the country (Carrillo-Anzures et al., 2017), and both have evolved allowing to incorporate more complex forest growth models (Torres-Rojo et al., 2016).

\subsection{Forest Growth Models}

Forest models are important elements of forest management, ecology, and forest sciences (Burkhart and Tomé, 2012; Pretzsch et al., 2008; Vanclay, 1994; Von Gadow and Hui, 1999). Generally, these models are represented as tables, graphics, or functions. In forestry, a common use is to predict dominant tree height or site index (Pretzsch et al., 2008). Usually, forest models are classified into whole stand models, size-class models, and single-tree models (Von Gadow and Hui, 1999; Vanclay, 1994).

In Mexico, these three types of models have been used in different ways. Whole stand models have been developed since the 1970s to predict growth in even-aged stands, and more recently a project called SiBiFor released a system of about 6000 different biometric models including site index curves (Vargas-Larreta et al., 2017) applicable to even-aged forests. However, in addition to these, more specific functions are needed, suitable for irregular and mixed stands (Vanclay, 1994) such as many Mexican forest ecosystems are (Návar et al., 2014).

Size-class models are commonly used to provide information about the forest stand, such as diameter distribution (Vanclay, 1994). These models are based on probability density functions ( $p d f$ ) like the Weibull pdf (Burkhart and Tomé, 2012; Vanclay, 1994). In general, size-class models could be considered as a middle course between whole stand and single-tree models (Vanclay, 1994). In Mexico, there are good examples of size-class models, with interesting results (Návar et al., 2014). Nevertheless, more research about other species and regions is needed. 
Single-tree models are more detailed and provide higher resolution of predictions (Burkhart and Tomé, 2012; Weiskittel et al., 2011; Vanclay, 1994). Using the tree as prediction unit, single-tree models have a wider range of application than whole stand and size class models. They can be used to predict single tree growth in even- and uneven-forest stands, and in forests with more than one species. In the northwestern Mexico, single-tree modeling approach has been used to predict basal area (Vargas-Larreta et al., 2010), diameter (Quiñonez-Barraza et al., 2018), and height increment (Briseño-Reyes et al., 2020). However, there is still a need to develop single-tree models in other regions and for other species. There is also a need to explore other modeling approaches such as mixed effects regression (Lindstrom and Bates, 1990), where random effects are taken into account to improve predictions and to make such models more realistic (Fang and Bailey, 2001; Pokharel and Dech, 2012). In addition, as these models become progressively more complex, it is necessary to integrate them into computer systems to facilitate their application.

\subsection{Decision Support Systems}

By the end of the last century, as technology had advanced, forest models had been gradually integrated into computer systems (Moreno-Sánchez and TorresRojo, 2010; Pretzsch et al., 2008). Such 'Decision Support Systems' (DSS) are designed to assist foresters, scientists, and decision makers in managing, analyzing, and regulating forest ecosystems. In Mexico since the 1980s there has been an interest in developing DSS, and many of them were designed based on the country's sivicultural systems (Moreno-Sánchez and Torres-Rojo, 2010). Figure 1.1 represents a summary of the main events related to forest management in Mexico, including the release of DSSs and the most important forestry laws.

Most DSSs in Mexico were developed for temperate forests and SICODESI was the first DSS in the country released in 1986 (Moreno-Sánchez and TorresRojo, 2010). SICODESI is the result of a cooperation program between Mexico and Finland, and it is the most widely used DSS in the country. SICODESI was designed to develop management plans and to simulate annual harvest scenarios (Domínguez-Hernández et al., 2013; Moreno-Sánchez and Torres-Rojo, 2010). 
Currently, Domínguez-Hernández et al. (2013) do not recommend the use of SICODESI because it has some serious flaws regarding software structure.

After SICODESI released several DSSs were launched for different purposes, Moreno-Sánchez and Torres-Rojo (2010) provide a list of 14 DSS that have been used in Mexico since the 1980s. In the country, most DSSs have been designed to assist foresters in the development of forest management plans, SIMBAT (1991) (Moreno-Sánchez and Torres-Rojo, 2010) and more recently SiPlaFor (2013) (Corral-Rivas et al., 2016) are examples of this. However, forest growth simulators have received too little attention in the Mexico. For instance, BwinPro7 was adapted by Vargas-Larreta et al. (2010) for several species, using single-tree models to be applicable only in El Salto, Durango. Therefore, these kind of simulators need to be calibrated to other regions to promote their use.

BwinPro7 or later ForestSimulator (Nagel, 2003; Hansen and Nagel, 2014) is a free and open source software. It was written in Java, what makes it more flexible, since ForestSimulator can run on Windows, iOS, and Linux, keeping the same graphical user interface. ForestSimulator is useful for designing management scenarios, and has currently integrated a new module to estimate carbon content in forest stands and wood products (Wördehoff et al., 2017). However, an interesting use of ForestSimulator is to simulate forest carbon and stand dynamics. 


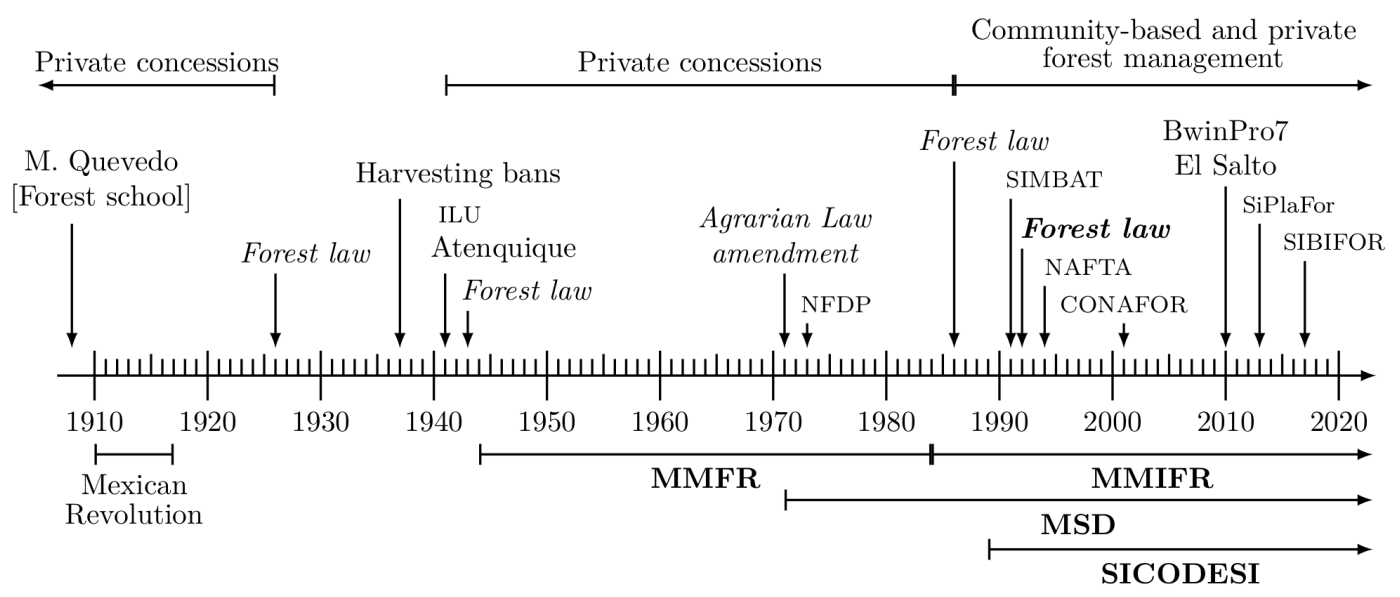

Figure 1.1: Timeline of major events related to forest management in Mexico. Where Miguel Angel de Quevedo is the founder of the first forest school in 1908; Atenquique was the first Industrial Logging Unit and it was located in Jalisco; NFDP is the National Forest Development Program, which was the first document for forest management and planning at national level; SIMBAT and SiPlaFor are some DSSs for planning; SICODESI was the first DSS and BwinPro7 is a forest growth simulator; NAFTA is the North American Free-Trade Area; CONAFOR is the National Forest Commission; SIBIFOR is the forest biometric system, containing about 6000 forest functions; and MMFR, MMIFR, and MSD are the silvicultural systems most used in Mexico.

\subsection{Forest Dynamics Simulation}

Forest growth simulators are useful tools to represent future outcomes of any particular management action. For instance, ForestSimulator can forecast stand growth after the application of certain treatments. It incorporates models to estimate tree growth, mortality, and ingrowth. Therefore, when a specific action has been performed, e.g., cutting trees, ForestSimulator evaluates the new stand structure and implements the prediction models to simulate another time interval (Nagel, 2003; Hansen and Nagel, 2014).

Integration of single-tree models into forest growth simulators makes it possible to emulate natural stand dynamics. ForestSimulator can create different management scenarios, for instance, it is possible to let the forest grow and analyze the carbon dynamics in a given time interval. It is also feasible to simulate carbon dynamics using classical silvicultural treatments, like seed-trees or clear cutting (Wördehoff et al., 2017). 
ForestSimulator could emulate certain effects of natural disturbance regimes, such as tree mortality caused by fire or drought. However, this requires to generate additional information regarding these kind of disturbances. For example, by exploring the spatial aspects of tree mortality using spatial point patterns analysis (Larson et al., 2015).

Spatial point pattern analysis is a powerful tool that helps understand the effects of disturbances on forest stand dynamics (Wiegand and Moloney, 2014). After a certain disturbance, such as fire, the spatial arrangement of trees is modified. It can create gaps or clusters of dead or alive trees, and the scale of these gaps or clusters will depend on the severity of such disturbance (Franklin and Van Pelt, 2004; Franklin et al., 2007). Point pattern analysis help understand this scale-dependent patterns (Brown et al., 2011), and the knowledge of these processes could support in the proper use, conservation, and restoration of forest ecosystems (Franklin et al., 1987, 2002; Larson et al., 2015; Stephens et al., 2008).

With ForestSimulator is possible to use such spatial information and simulate stand dynamics. For instance, users are able to create gaps or cut trees by hand to emulate the effects of fires over a given time interval, e.g., 30 years. The results can then be compared with other traditional silvicultural treatments or with scenarios without forest management. Having this information will provide foresters with valuable knowledge to make better forest management decisions. It will also enable them to make inferences about forest management for carbon and climate change benefits.

\subsection{Objectives}

The purpose of this research is to generate knowledge about forest stand dynamics and the contribution of forest management for carbon and climate change benefits. Currently, there is a debate on whether or not to manage forests in terms of carbon sequestration and storage. In this study, this question is addressed and evaluated in the light of the Mexican forest conditions, i.e., whether protecting and growing Mexican temperate forests is a better management strategy compared to classical silviculture methods. 
This thesis also aims to contribute, even in a small part, to the need for new tools and technologies for sustainable forest management. For this purpose, a new version of ForestSimulator has been developed and is introduced in this study. This would assist foresters, scientists, and decision makers in managing, analyzing, and regulating forest ecosystems.

The specific objectives are: i) to develop and collect the necessary growth models to be integrated into ForestSimulator to calibrate a Mexican version for temperate forests, ii) generate information about tree mortality in temperate forests and its relationship to natural disturbances, and iii) simulate the aboveground carbon dynamics in temperate forests under different scenarios.

Based upon the specific objectives, five manuscripts were prepared and are in the process of being submitted to different journals:

(i) Testing Random Effects on Basal Area Increment Models for Mexican Temperate Forests

(ii) Generalized height-diameter Models with Random Effects on Natural Forests of Central Mexico

(iii) ForestSimulator Mexico: Software Settings for Mexican Temperate Forests

(iv) Spatial Patterns of Tree Mortality in a Montane Forest of Central Mexico

(v) Above-Ground Carbon Dynamics in a Mexican Temperate Forest: A Simulation Study

The manuscripts listed above are presented in the thesis as complete and independent chapters. However, all of them are related in manuscript (v) since it uses ForestSimulator and the models developed in manuscripts (i), (ii), and (iii) to simulate different management scenarios. In addition, the information generated in manuscript (iv) was useful to design a special simulation scenario, where the effects of disturbances on tree mortality are emulated and compared with other management alternatives. Finally, these five manuscripts are framed by a general introduction and conclusion. 


\section{Literature}

Bray, B., Merino-Pérez, L., 2005. La experiencia de las comunidades forestales en México. Instituto Nacional de Ecología (INE-SEMARNAT), Mexico, DF.

Bray, D.B., Antinori, C., Torres-Rojo, J.M., 2006. The Mexican model of community forest management: The role of agrarian policy, forest policy and entrepreneurial organization. Forest Policy and Economics 8, 470-484. doi:10.1016/j.forpol.2005.08.002.

Briseño-Reyes, J., Corral-Rivas, J.J., Solis-Moreno, R., Padilla-Martínez, J.R., VegaNieva, D.J., López-Serrano, P.M., Vargas-Larreta, B., Diéguez-Aranda, U., Quiñonez-Barraza, G., López-Sánchez, C.A., 2020. Individual Tree Diameter and Height Growth Models for 30 Tree Species in Mixed-Species and UnevenAged Forests of Mexico. Forests 11, 429. URL: https://www.mdpi.com/1999-4907/ 11/4/429, doi:10.3390/f11040429.

Brown, C., Law, R., Illian, J.B., Burslem, D.F.R.P., 2011. Linking ecological processes with spatial and non-spatial patterns in plant communities. Journal of Ecology 99, 1402-1414. URL: http://doi.wiley.com/10.1111/j.1365-2745.2011. 01877.x, doi:10.1111/j.1365-2745.2011.01877.x.

Burkhart, H.E., Tomé, M., 2012. Modeling Forest Trees and Stands. Springer Netherlands, Dordrecht. doi:10.1007/978-90-481-3170-9.

Carrillo-Anzures, F., Acosta-Mireles, M., Flores-Ayala, E., Torres-Rojo, J., Sangerman-Jarquín, D., González-Molina, L., Buendía-Rodríguez, E., 2017. Caracterización de productores forestales en 12 estados de la República Mexicana. Rev. Mex. Cienc. Agríc 8, 1561-1573. URL: http://www.scielo.org.mx/scielo. php?script=sci\{_\}arttext $\{\mathcal{E}\}$ pid $=$ S2007-09342017000701561.

CONAFOR, 2018. Inventario Nacional Forestal y de Suelos. Informe de Resultados 2009-2014. Technical Report. Comisión Nacional Forestal. Zapopan, Jalisco, México. URL: https://snigf.cnf.gob.mx/.

Corral-Rivas, J.J., Briseño-Reyes, C., López-Sánchez, C.A., Diéguez-Aranda, U., González-González, J.M., 2016. Sistema de Planeación Forestal para Bosque Templado. (SiPlaFor). MONTE , 24-26URL: https://asmadera.com/wp-content/ uploads/2014/11/TRESEME40web.pdf.

Domínguez-Hernández, F., Mendoza-Briseño, M.A., López-Mata L., 2013. Sistema de conservacion y desarrollo silvicola, lecciones de un caso de aplicacion de manejo forestal en jalisco, Mexico. Juyyaania 1, 85-103.

Espinosa, D., Ocegueda, S., 2008. El conocimiento biogeográfico de las especies y su regionalización natural, in: Capital natural de México, vol. I: Conocimiento actual de la Biodiversidad. Conabio, México, pp. 33-65. URL: https://bioteca. biodiversidad.gob.mx/libros.html. 
Fang, Z., Bailey, R.L., 2001. Nonlinear Mixed Effects Modeling for Slash Pine Dominant Height Growth Following Intensive Silvicultural Treatments. Forest Science 47, 287-300. URL: https://academic.oup.com/forestscience/article/47/3/287/ 4617175, doi:10.1093/forestscience/47.3.287.

Franklin, J.F., Mitchell, R.J., Palik, B.J., 2007. Natural disturbance and stand development principles for ecological forestry. Technical Report. Department of Agriculture, Forest Service, Northern Research Station. Newtown Square, PA: U.S. URL: http://www.nrs.fs.fed.us/pubs/3293.

Franklin, J.F., Shugart, H.H., Harmon, M.E., 1987. Tree Death as an Ecological Process. BioScience 37, 550-556. URL: https://academic.oup.com/bioscience/ article-lookup/doi/10.2307/1310665, doi:10.2307/1310665.

Franklin, J.F., Spies, T.A., Pelt, R.V., Carey, A.B., Thornburgh, D.A., Berg, D.R., Lindenmayer, D.B., Harmon, M.E., Keeton, W.S., Shaw, D.C., Bible, K., Chen, J.., 2002. Disturbances and structural development of natural forest ecosystems with silvicultural implications, using Douglas-fir forests as an example. Forest Ecology and Management 155, 399-423. URL: http://www.treesearch.fs.fed.us/ pubs/6026.

Franklin, J.F., Van Pelt, R., 2004. Spatial aspects of structural complexity in oldgrowth forests. Journal of Forestry 102, 22-28. URL: https://academic.oup.com/ jof/article/102/3/22/4613153, doi:https://doi.org/10.1093/jof/102.3.22.

Hansen, J., Nagel, J., 2014. Waldwachstumskundliche Softwaresysteme auf Basis von TreeGrOSS - Anwendung und theoretische Grundlagen. Universitätsverlag Göttingen, Gottingen, Germany. URL: https://www.univerlag.uni-goettingen.de/ handle/3/isbn-978-3-86395-149-8.

Jardel-Peláez, E., 2012. El Manejo Forestal en México: Estado actual y Perspectivas, in: Chapela, F. (Ed.), Estado de los bosques de México. Consejo Civil Mexicano para la Silvicultura Sostenible en México A.C, Mexico, DF.. chapter 3, pp. 69-115. URL: https://www.ccmss.org.mx/wp-content/uploads/2014/10/Estado_de_ los_bosques_en_Mexico_final.pdf.

Larson, A.J., Lutz, J.A., Donato, D.C., Freund, J.A., Swanson, M.E., HilleRisLambers, J., Sprugel, D.G., Franklin, J.F., 2015. Spatial aspects of tree mortality strongly differ between young and old-growth forests. Ecology 96, 2855-2861. URL: http://doi.wiley.com/10.1890/15-0628.1, doi:10.1890/15-0628.1.

Lindstrom, M.J., Bates, D.M., 1990. Nonlinear Mixed Effects Models for Repeated Measures Data. Biometrics 46, 673. doi:10.2307/2532087.

Madrid, L., Núñez, J., Quiroz, G., Rodríguez, Y., 2009. La propiedad social forestal en México. Investigación Ambiental 1, 179-196.

Merino, L., Rodríguez, J., Ortiz, G., García, A., 2008. Estudio estratégico sobre el sector forestal mexicano. Consejo Civil Mexicano para la Silvicultura 
Sostenible AC, Mexico, DF. URL: https://www.ccmss.org.mx/wp-content/uploads/ Estudio-estrategico-sobre-el-sector-forestal-mexicano.pdf.

Merino-Pérez, L., 2004. Conservación o deterioro: el impacto de las políticas públicas en las instituciones comunitarias y en los usos de los bosques en México. Secretaría del Medio Ambiente y Recursos Naturales, Instituto Nacional de Ecología, Consejo Civil Mexicano para la Silvicultura Sustentable A.C., Mexico, DF. URL: https://www.ccmss.org.mx/acervo/conservacion-o-deterioro/.

Moreno-Sánchez, R., Torres-Rojo, J.M., 2010. Decision Support Systems For Forest Management In Mexico, in: Decision Support Systems in Agriculture, Food and the Environment: Trends, Applications and Advances. IGI Global, pp. 74-100. URL: http://services.igi-global.com/resolvedoi/resolve.aspx?doi=10.4018/ 978-1-61520-881-4.ch004, doi:10.4018/978-1-61520-881-4.ch004.

Nagel, J., 2003. TreeGrOSS: Tree Growth Open Source Software. URL: http: //treegross.sourceforge.net/.

Návar, J., Návar, José, 2014. A Stand-Class Growth and Yield Model for Mexico's Northern Temperate, Mixed and Multiaged Forests. Forests 5, 3048-3069. URL: http://www.mdpi.com/1999-4907/5/12/3048, doi:10.3390/f5123048.

Pokharel, B., Dech, J.P., 2012. Mixed-effects basal area increment models for tree species in the boreal forest of Ontario, Canada using an ecological land classification approach to incorporate site effects. Forestry 85, 255-270. URL: https://academic.oup.com/forestry/article-lookup/doi/10.1093/forestry/cpr070, doi:10.1093/forestry/cpr070.

Pretzsch, H., Grote, R., Reineking, B., Rötzer, T., Seifert, S., 2008. Models for forest ecosystem management: a European perspective. Annals of botany 101, 1065-87. URL: http://www.ncbi.nlm.nih.gov/pubmed/17954471http: //www.pubmedcentral.nih.gov/articlerender.fcgi? artid=PMC2710278, doi:10.1093/ aob/mcm246.

Pukkala, T., 2018. Carbon forestry is surprising. Forest Ecosystems 5, 1-11. URL: https://forestecosyst.springeropen.com/articles/10.1186/s40663-018-0131-5, doi:10.1186/s40663-018-0131-5.

Quiñonez-Barraza, G., Zhao, D., De Los Santos Posadas, H.M., Corral-Rivas, J.J., 2018. Considering neighborhood effects improves individual dbh growth models for natural mixed-species forests in Mexico. Annals of Forest Science 75, 1-11. doi:10.1007/s13595-018-0762-2.

Ramírez-Maldonado, H., 2017. Manual para la elaboración de programas de manejo forestal maderable en clima templado frío. Comisión Nacional Forestal (CONAFOR), Zapopan, Jalisco, México. URL: https://www.gob.mx/cms/uploads/ attachment/file/314226/Manual_para_la_Elaboracion_de_PMFM.pdf. 
Snook, L., Negreros-Castillo, P., 1986. Effects of Mexico's selective cutting system on pine regeneration and growth in a mixed pine-oak (Pinus-Quercus) forest, in: Current topics in forest research: emphasis on contributions by women scientists, USDA Forest Service, Asheville, NC, USA. pp. 27-31.

Stephens, S.L., Fry, D.L., Franco-Vizcaíno, E., 2008. Wildfire and Spatial Patterns in Forests in Northwestern Mexico: The United States Wishes It Had Similar Fire Problems. Ecology and Society 13,1-13. URL: http://www.ecologyandsociety. org/vol13/iss2/art10/, doi:10.5751/ES-02380-130210.

Torres-Rojo, J.M., 2000. Sostenibilidad del volumen de cosecha calculado con el Método Mexicano de Ordenación de Montes. Madera y Bosques 6, 57-72. URL: https://myb.ojs.inecol.mx/index.php/myb/article/view/1335, doi:10.21829/myb.2000. 621335.

Torres-Rojo, J.M., Moreno-Sánchez, R., Mendoza-Briseño, M.A., 2016. Sustainable Forest Management in Mexico. Current Forestry Reports 2, 93-105. URL: http: //link.springer.com/10.1007/s40725-016-0033-0, doi:10.1007/s40725-016-0033-0.

Vanclay, J.K., 1994. Modelling Forest Growth and Yield: Applications to Mixed Tropical Forests. 1 ed., CABI, Wallingford, U.K.

Vargas-Larreta, B., Corral-Rivas, J., Aguirre-Calderón, Ó., Nagel, J., 2010. Modelos de crecimiento de árbol individual: Aplicación del Simulador BWINPro7. Madera y bosques 16, 81-104. URL: http://www.scielo.org.mx/scielo.php?script= sci\{_\}arttext $\{\mathcal{E}\}$ pid=S1405-04712010000400006.

Vargas-Larreta, B., Corral-Rivas, J.J., Aguirre-Calderon, O.A., Lopez-Martinez, J.O., De los Santos-Posadas, H.M., Zamudio-Sanchez, F.J., Trevino-Garza, E.J., Martinez-Salvador, M., Aguirre-Calderon, C.G., 2017. SiBiFor: Forest Biometric System for forest management in Mexico. Revista Chapingo Serie Ciencias Forestales y del Ambiente 23, 437-455. doi:10.5154/r.rchscfa.2017.06.040.

Von Gadow, K., Hui, G., 1999. Modelling Forest Development. Forestry Sciences, Kluwer Academic, Dordrecht. doi:10.1007/978-94-011-4816-0.

Weiskittel, A.R., Hann, D.W., Kershaw, J.A., Vanclay, J.K., 2011. Forest Growth and Yield Modeling. John Wiley and Sons, Chichester, UK. URL: http://doi. wiley.com/10.1002/9781119998518, doi:10.1002/9781119998518.

Wiegand, T., Moloney, K., 2014. Handbook of Spatial Point-Pattern Analysis in Ecology. CRC Press is an imprint of Taylor \& Francis Group, an Informa business, Boca Raton, FL. URL: https: //www.crcpress.com/Handbook-of-Spatial-Point-Pattern-Analysis-in-Ecology/ Wiegand-Moloney/p/book/9781420082548.

Wördehoff, R., Schulz, C., Nagel, J., 2017. Nutzung oder Nutzungsverzicht aus Sicht des Klimaschutzes. AFZ/Der Wald 72, 30-32. URL: https://www.nw-fva. de/fileadmin/nwfva/publikationen/pdf/wordehoff_2017_nutzung_oder.pdf. 



\section{Chapter 2}

\section{Testing Random Effects on Basal Area Increment Models for Mexican Temperate Forests}

Ernesto Alonso Rubio-Camacho ${ }^{1,3}$, Juan Antonio López-Hernández ${ }^{2}$, and Jürgen Nagel $^{1}$

\section{Author details}

${ }^{1}$ Department Ecoinformatics, Biometrics \& Forest Growth, Georg-August University of Göttingen. Busgenweg 4, 37077 Gottingen, Germany.

${ }^{2}$ Facultad de Ciencias Forestales, Universidad Autónoma de Nuevo León. Carretera Nacional 85, Km. 145, 67700 Linares, Mexico.

${ }^{3}$ INIFAP-CIRPAC C.E. Centro Altos: Av. Biodiversidad núm. 2470, Col. Las Cruces, Tepatitlán, Jalisco, México. CP. 47600.

Authors contributions

EARC designed the simulation study, conducted the data analysis and wrote the manuscript; JALH coordinated the field data collection and prepared the database; JN supervised the project and approved the final version.

\section{Status}

The manuscript is being prepared for submission to a scientific journal. 


\title{
Testing Random Effects on Basal Area Increment Models for Mexican Temperate Forests
}

\begin{abstract}
The high demand for forest goods and services increases the need to improve current forest growth models or to even develop new ones. Basal area increment (BAI) is an important variable in forestry and it can be modeled using fixed and mixed effects. So far, the mixed modeling approach has not been applied to predict BAI in Mexico. In this study, we tested how the inclusion of random effects can make BAI models more precise and more realistic. We used mixed-effects models to infer about the random effects at plot, elevation, and aspect levels. For this purpose, we used data from 49 plots $\left(900 \mathrm{~m}^{2}\right)$ and 2771 trees in a temperate forest. The plots were distributed across a $600 \mathrm{~m}$ elevation range to ensure the variability between them.
\end{abstract}

In order to compare mixed-effects models to conventional modeling methods, BAI models were fitted using both linear fixed and linear mixed effects. The results include a set of models for predicting BAI for Pinus patula and other important genera in Central Mexico (Abies, Pinus, Quercus). On each of these models, the logarithm transformation of tree diameter $d$ and the competition index BALMOD were chosen as fixed, while plot, elevation, and aspect were tested as random effects. In all cases, fixed effects parameters resulted in significant predictors of BAI, and random effects improved the model fit. By including $\log (d)$, BALMOD, and site effects, the models presented in this study provide tree size, tree competition, and site characteristics. These are fundamental components of BAI prediction models.

The inclusion of random effects significantly improved the models by increasing the amount of variance explained. Therefore, we recommend the use of random effects when pursuing more accurate and realistic BAI models.

\subsection{Introduction}

Wood consumption, along with other forest goods and services, has increased globally over the last few decades (FAO, 2017; MEA, 2005). Therefore, it is necessary to improve the knowledge of forest dynamics and to optimize forest management with enhanced forestry techniques (Vanclay, 1994; Pretzsch, 2009; Torres-Rojo et al., 2016). This is particularly true for certain developing countries 
such as Mexico since they have to import wood to fulfill the demand. For instance, Mexico had a negative trade balance over a five-year average (2012-16) on wood products (Sawnwood $=1,598.00$, Veneer $=31.00$ and Plywood $=508.00\left[1000 \mathrm{~m}^{3}\right]$ ), (ITTO, 2017). Some important elements that could improve the knowledge of forest dynamics are the forest growth and yield models (Burkhart and Tomé, 2012; Weiskittel et al., 2011). Although forest modeling in Mexico has lately been an important topic in environmental sciences (Vargas-Larreta et al., 2017), there is a need for new technologies to optimize forest production (Torres-Rojo et al., 2016). In this context, more accurate and biologically realistic forest growth models would help improve forest management and minimize environmental impacts in the region.

Forest growth and yield models are essential tools for sustainable management and have a wide range of applications. The first ever used, known as yield tables, were developed in Germany around 200 years ago (Pretzsch et al., 2008); since then, these models have evolved into a comprehensive range of innovative components, from complex and more detailed mathematical functions through advanced graphics to growth simulators (Nagel, 2003; Pretzsch et al., 2008; Salas et al., 2016; Shifley et al., 2017). In a broader sense, forest models could be classified, depending on the scale of application, into: i) whole stand, ii) size class, and iii) single-tree models (Vanclay, 1994).

Of these three, the so-called single-tree models are most detailed and provide higher resolution of predictions (Burkhart and Tomé, 2012; Weiskittel et al., 2011; Vanclay, 1994). Single-tree models are also more specific because they use the individual tree as prediction unit and are mainly driven by four equations: basal area increment (BAI), height increment, crown width, and mortality. BAI models are particularly important in single-tree modeling since they are used to estimate volume (Weiskittel et al., 2011).

BAI models typically include size, site, and competition metrics (Burkhart and Tomé, 2012; Weiskittel et al., 2011; Vanclay, 1994). Tree size, as diameter, height, or even tree crown, is relevant for tree growth modeling because some species have different growing rates depending on their size. For instance, young trees tend to grow faster in height while at maturity stages their growth decreases (Bowman et al., 2013). In the study of Vargas-Larreta et. al., (2010) they developed 
a BAI model using tree crown-cover as size indicator with significant results.

Site effects, such as environmental factors, have significant influences over BAI (Pokharel and Dech, 2012) and are often associated with site index (Uzoh and Oliver, 2008). In a study on Canada by Pokharel and Dech (2012), an ecological land classification was used as random effect for predicting BAI for various species, including black spruce. In other research conducted by Uzoh and Oliver (2008), different site quality indicators such as longitude, latitude, elevation, aspect, site index, and slope were tested. In both studies, the researchers have found significant improvement of the models, including such site characteristics for predicting BAI.

Tree competition is an essential element to develop this class of models since tree growth or the probability to die could be highly influenced by resource competition. For this purpose, competition indices have been proposed for modeling BAI, either spatially or non-spatially dependent (Burkhart and Tomé, 2012; Vanclay, 1994). In the study of Vargas-Larreta et. al., (2010) they included the crown competition index c66 to model BAI in a temperate forest dominated by Pinus. Similar studies showed that the spatial-independent BALMOD-index is suitable to assess competition (Corral-Rivas et al., 2005), and considering spatial interactions in distance-dependent models resulted in more accurate predictions (Quiñonez-Barraza et al., 2018).

Usually, the data used to model BAI are derived from hierarchical structures, e.g., plots of certain dimensions distributed over larger areas. This structure often causes dependency between observations given by the measurement unit (plot) (Gregorie, 1987; Fox et al., 2001). Occasionally, the independence assumption of ordinary least squares regression is ignored. To overcome this problem, mixedeffects models have been proposed in forest growth and yield science (Calama and Montero, 2004; Hall and Bailey, 2001; Mehtätalo et al., 2015; Uzoh and Oliver, 2008). Mixed-effects models allow for hierarchical and longitudinal data by including random effects at different levels (trees, plots, and larger areas). Hence, mixed models include the classical regression parameters, which in this context are called fixed and random effects (Fahrmeir et al., 2013; Pinheiro and Bates, 2000).

While they have been used in other countries, in Mexico, as far as we know, 
there are no studies using mixed effects in BAI modeling. The few examples of the use of mixed models in Mexico are more related to tree $h$ - $d$ functions with non-linear mixed models, where they evaluated the variability among plots, as random effect, for different species of Pinus and Quercus in uneven-aged temperate forests in Durango, Mexico (Vargas-Larreta et al., 2009; Corral-Rivas et al., 2014, 2019). However, including random effects for predicting BAI would contribute to the forest growth and yield science in Mexico.

The aim of the study is to test how the inclusion of random effects in BAI models - as applied to Mexican ecosystems - can make such models more precise and realistic. For this purpose, a temperate forest located in central Mexico was chosen as a case study, where no individual tree BAI models including random effects were found. In this research, it is also discussed how site effects, such as elevation and aspect, help explain BAI variation for individual trees in the temperate forests of the study area. With this aim, this work helps understand how ecosystems such as this one can profit from including random effects in predicting BAI.

\subsection{Materials and Methods}

\subsubsection{Study Area}

For testing the random effects on BAI models, a study area located across two Mexican states, at the southeast of Hidalgo and at the northwest of Puebla, was chosen. The extreme coordinates are $\min [$ Long $=-98.49796$, Lat $=19.68858$ ] and $\max [$ Long $=-98.06963$, Lat $=19.94516$ ], (Figure 5.1). The physiography is related to the "Eje Neovolcánico" geographical province (INEGI, 2001), and includes a wide heterogeneity of altitudes, with extensive variability of climates and vegetation types, predominantly coniferous and oak forests. The weather is mostly temperate sub-humid $\left[12-18^{\circ} \mathrm{C}\right]$ with rains in the summer season (INEGI, 2008).

Areas with higher humidity are dominated by coniferous species such as Pinus patula Schltdl. \& Cham., which is abundant in the north of Puebla. P. patula grows in elevations between 1,500 and 3,100 m, with an annual precipitation 


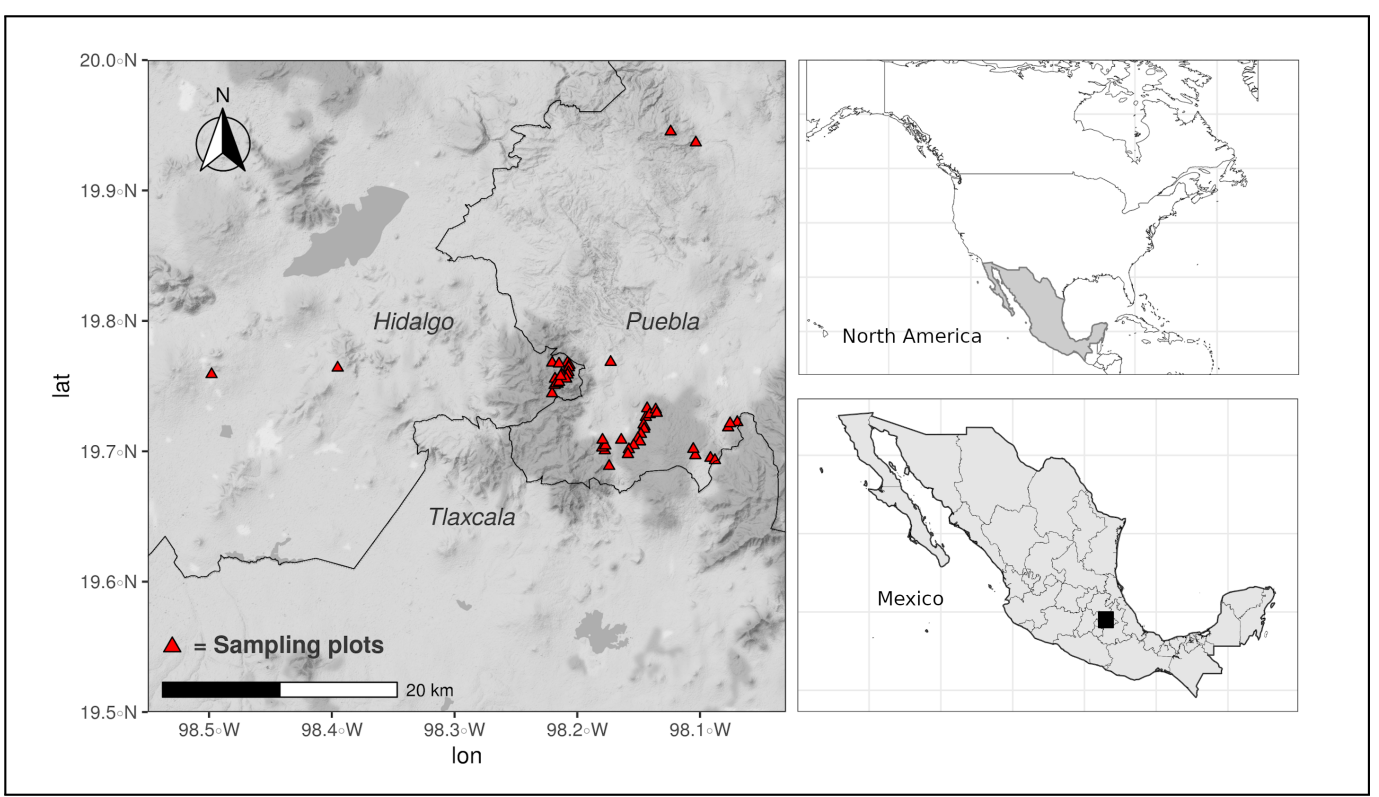

Figure 2.1: Study area localization in central Mexico.

of 1000-1500 mm (Dvorak and Donahue, 1992). P. patula is also valuable for its growth rate and wood quality (Gillespie, 1992; Dvorak et al., 2000; Velázquez et al., 2004) because it can grow more than 1 meter in height per year (Monroy, 1995; Vela-Gálvez, 1980). It is a medium to large tree, which can reach heights of up to $40 \mathrm{~m}$ and diameters of up to $120 \mathrm{~cm}$ (Vela-Gálvez, 1980).

\subsubsection{Data collection}

Individual-tree growth measurements were obtained from $49(30 \times 30 \mathrm{~m})$ plots of pure and mixed stands dominated by Pinus patula. The plots were established in 2008 and remeasured in 2012 by the National Forest Commission (CONAFOR) in the forest management unit UMAFOR2108 located in the northwest of Puebla. The UMAFOR2108 is divided into different age classes where the main objective is timber production, but the plots used in this study had been left without silvicultural interventions five years before the first inventory in 2008 and remained without management during the study.

The database species composition, with respect to density, is $81 \%$ for Pinus genera (P. ayacahuite Ehrenb., P. montezumae Lamb., P. patula, P. pseudostrobus, and P. teocote), 7\% for Quercus (Q. rugosa Née and Q. laurina), and $11 \%$ for Abies 
religiosa.

The plots were arranged according to a stratified random sampling design, the species composition and the age of the stands: a) 10-35, b) 36-61, c) 62-87 years. The plots were located along an elevation gradient of $600 \mathrm{~m}$, where the minimum elevation plot was established at $2500 \mathrm{~m}$ and the maximum at about $3100 \mathrm{~m}$ above sea level in different aspects: North, South, East, and West.

Forest inventory data were taken, such as diameter at breast height $(d, c m)$, tree height $(h, m)$, species names, age, and diameter increment with increment-cores of every Pinus and Abies trees with $d>=7.5 \mathrm{~cm}$ from the 2012 measurement. The increment-cores were processed in the field by counting and measuring the rings from the bark to the core. The basal area increment in $\mathrm{cm}^{2}$ has been estimated through the diameter increment for Pinus and Abies from the 2012 database, while for the Quercus group BAI has been estimated by tracking the same trees in the 2008 database. Tracking all the trees and species was not possible due to inconsistencies in the 2008 database.

\subsubsection{Data compilation}

In order to develop BAI models for the study area, the data analysis was carried out by dividing the database into species and genus groups. P. patula with $\mathrm{n}=1622$ was the only species used to develop a species-specific BAI model while other important but less abundant species were grouped into genera. The resulting groups were: Abies $(\mathrm{n}=327)$, Quercus $(\mathrm{n}=177)$ and Pinus $(\mathrm{n}=645)$, covering the rest of the Pinus species other than P. patula.

\section{Tree size and stand variables}

The tree size variables were tree diameter $(d, c m)$ and tree height $(h, m)$ while stand variables, considered as independent, were: tree mean diameter $(\mathrm{dm}, \mathrm{cm})$, tree mean height $(h m, m)$, basal area per hectare $G h a^{-1}, m^{2}$, dominant tree height $\left(H_{0}, m\right)$, and number of trees per hectare $\left(N h a^{-1}\right)$. Descriptive statistics for the studied groups show that $P$. patula is the species with the highest mean in all the statistics and indices. For instance, P. patula is the taller species on average 
and with larger mean values in tree diameter, followed by the Abies group. The principal difference among species and groups are the stand values where the dominance of P. patula is evident (Table 2.1).

In terms of stand characteristics, the basal area per hectare is dominated by $P$. patula, followed by the Abies, and Pinus groups, while the Quercus group has the lowest values. A similar case is that of tree density $\left(\mathrm{Nha}^{-1}\right)$, where P. patula is the most abundant species, followed by the Pinus group, while Abies and Quercus have similar values of $N \mathrm{ha}^{-1}$. The other variables show similar trends among groups (Table 2.1).

Table 2.1: Summary statistics by group in the study area. Where $d=$ tree diameter $(\mathrm{cm}), h$ $=$ tree height $(m), g=$ basal area $\left(m^{2}\right), B A L=$ basal area larger index, $B A L M O D=$ modified BAL index, $G h a^{-1}=$ basal area per hectare, $N h a^{-1}=$ number of tree per hectare, and $H_{O}$ = dominant tree height.

\begin{tabular}{|c|c|c|c|c|c|c|c|c|c|}
\hline Group & Variable & $d$ & $h$ & $g$ & $G h a^{-1}$ & $B A L$ & $B A L M O D$ & $N h a^{-1}$ & $H_{0}$ \\
\hline \multicolumn{10}{|c|}{ Pinus patula } \\
\hline & mean & 26.9 & 20.0 & 0.072 & 44.9 & 29.7 & 4.6 & 882.4 & 24.9 \\
\hline & sd & 13.9 & 6.9 & 0.083 & 14.8 & 17.3 & 2.2 & 441.4 & 5.5 \\
\hline & $\min$ & 7.5 & 4.0 & 0.004 & 10.9 & 0.0 & 0.0 & 200.0 & 11.4 \\
\hline & $\max$ & 83.6 & 40.2 & 0.549 & 84.3 & 84.2 & 9.3 & 1755.6 & 38.3 \\
\hline \multicolumn{10}{|c|}{ Pinus group } \\
\hline & mean & 18.2 & 12.1 & 0.033 & 40.1 & 28.5 & 4.3 & 1475.0 & 18.1 \\
\hline & sd & 9.2 & 5.9 & 0.041 & 12.7 & 16.6 & 2.3 & 705.5 & 8.4 \\
\hline & $\min$ & 7.5 & 4.6 & 0.004 & 10.9 & 0.0 & 0.0 & 200.0 & 8.2 \\
\hline & $\max$ & 67.6 & 38.0 & 0.359 & 84.3 & 84.2 & 9.3 & 2311.1 & 38.3 \\
\hline \multicolumn{10}{|c|}{ Abies group } \\
\hline & mean & 24.8 & 19.4 & 0.065 & 46.7 & 34.9 & 5.8 & 734.4 & 29.6 \\
\hline & $\mathrm{sd}$ & 14.6 & 6.9 & 0.082 & 9.8 & 14.6 & 2.2 & 280.8 & 4.0 \\
\hline & $\min$ & 7.5 & 4.8 & 0.004 & 26.4 & 0.0 & 0.0 & 311.1 & 19.6 \\
\hline & $\max$ & 81.6 & 40.2 & 0.523 & 66.0 & 65.7 & 9.0 & 1466.7 & 38.3 \\
\hline \multicolumn{10}{|c|}{ Quercus group } \\
\hline & mean & 16.7 & 11.0 & 0.026 & 43.6 & 40.9 & 7.4 & 471.6 & 35.0 \\
\hline & sd & 7.1 & 4.5 & 0.031 & 9.6 & 9.8 & 1.2 & 127.3 & 2.7 \\
\hline & $\min$ & 8.2 & 4.0 & 0.005 & 17.6 & 17.1 & 3.1 & 244.4 & 22.9 \\
\hline & $\max$ & 59.0 & 35.0 & 0.273 & 61.1 & 61.0 & 9.4 & 1088.9 & 38.3 \\
\hline
\end{tabular}

\section{Site effects}

The site variables taken into account were elevation, aspect, and the plot itself. Elevation and aspect were nested as factor, that for the sake of simplicity we called 'Geo,' resulting in 18 classes (Table 2.2), while plot was used as the only 
factor with 49 classes in total. The purpose was to have the basic elements (size, competition, and site characteristics) to fit BAI models for all the groups in the study area.

Table 2.2: Classification of the environmental variables used as factor in the models, showing the number of trees and plots per class. Where Geo is the nested class including elevation and aspect. The first part of the class indicates the aspect $(\mathrm{N}=$ north, $\mathrm{S}=$ south, $\mathrm{E}=$ east, $\mathrm{W}=$ west), and the second part is the elevation classes of 100 meters, from 2500 to $3100 \mathrm{~m}$ above sea level

\begin{tabular}{|c|c|c|c|c|c|c|c|c|}
\hline \multirow[b]{2}{*}{ Geo } & \multicolumn{2}{|c|}{ Pinus patula } & \multicolumn{2}{|c|}{ Pinus } & \multicolumn{2}{|c|}{ Abies } & \multicolumn{2}{|c|}{ Quercus } \\
\hline & Plots & Trees & Plots & Trees & Plots & Trees & Plots & Trees \\
\hline E:2500 & 1 & 71 & - & - & - & - & - & - \\
\hline E:2600 & 1 & 9 & 1 & 8 & - & - & - & - \\
\hline E:2700 & 3 & 153 & 3 & 150 & 2 & 3 & 1 & 3 \\
\hline E:2800 & 3 & 68 & 2 & 43 & - & - & 2 & 4 \\
\hline E:2900 & 5 & 201 & 4 & 70 & 3 & 6 & 2 & 2 \\
\hline E:3000 & 3 & 85 & 2 & 30 & 3 & 34 & - & - \\
\hline E:3100 & 1 & 1 & 1 & 48 & 1 & 4 & - & - \\
\hline $\mathrm{N}: 2600$ & 1 & 87 & 1 & 27 & - & - & - & - \\
\hline $\mathrm{N}: 2700$ & 3 & 89 & 1 & 4 & 1 & 1 & 1 & 31 \\
\hline $\mathrm{N}: 2800$ & 4 & 91 & 4 & 24 & 2 & 14 & 2 & 33 \\
\hline $\mathrm{N}: 2900$ & 1 & 24 & 1 & 2 & - & - & 1 & 1 \\
\hline $\mathrm{N}: 3000$ & 2 & 85 & 1 & 2 & 3 & 41 & 2 & 4 \\
\hline S:2600 & 2 & 84 & 1 & 3 & 1 & 20 & - & - \\
\hline S:2800 & - & - & 1 & 208 & - & - & - & - \\
\hline S:2900 & 4 & 266 & 4 & 15 & 1 & 62 & - & - \\
\hline S:3000 & - & - & 1 & 1 & 1 & 88 & 1 & 1 \\
\hline W:2600 & 1 & 24 & - & - & 1 & 3 & - & - \\
\hline W:2700 & 4 & 165 & - & - & 2 & 3 & 3 & 39 \\
\hline W:2800 & 5 & 112 & 1 & 1 & 5 & 47 & 4 & 37 \\
\hline W:2900 & 2 & 7 & 1 & 9 & 1 & 1 & 2 & 22 \\
\hline Total & 46 & 1622 & 30 & 645 & 27 & 327 & 21 & 177 \\
\hline
\end{tabular}

\section{Competition indices}

Competition has an impact on the growth, survival, or reproduction of trees, and it is regularly described with mathematical functions (Burkhart and Tomé, 2012). Tree competition indices can be spatially and non-spatially dependent: the former is less common because distances and coordinates are not always available in forest inventory databases. Therefore, only non-spatial indices are tested in this research, such as the basal area larger (BAL, $m^{2} h a-{ }^{1}$ ) index and the BALMOD-index (Schröder and von Gadow, 1999). The BALMOD is a modified 
version of the BAL index and is computed as follows:

$$
\mathrm{BALMOD}_{i j}=\frac{1-p_{j}}{R S_{i}}
$$

with:

$$
R S_{i}=\frac{\sqrt{\frac{10,000}{N h a_{i}^{-1}}}}{H_{0 i}} \quad \text { and } p_{j}=1-\frac{B A L_{i j}}{B A_{i}}
$$

where $p_{j}$ is the basal area percentile of a representative tree $j, B A L_{i j}$ is the sum of the basal area of the trees larger than the subject tree $j$ in the stand $i, B A_{i}$ is the basal area of the stand, $N h a_{i}^{-1}$ is the number of stems per hectare, and $H_{0 i}$ is the dominant height of the stand $i$ (Schröder and von Gadow, 1999).

\subsubsection{Regression models}

Multiple linear regression models were fitted to estimate the basal area increment $(\log (\mathrm{BAI}))$. Three different models for each species group were tested: first, the classical linear fixed effects model; second, the linear mixed effects model using the plot as random effect; and third, the mixed effects model using site factors such as elevation and aspect, as random effects. Such models have a matrix notation form:

The classical linear fixed effects model

$$
\begin{gathered}
y=X \beta+e \\
\text { with } \quad e \sim N\left(0, \sigma^{2} I\right)
\end{gathered}
$$

where $y$ is the $n \times 1$ vector of responses, $\beta$ is the $p \times 1$ vector of parameters, $X$ is the $n \times p$ design matrix, $e$ is the $n \times 1$ vector of error terms, and $I$ is an $n \times n$ identity matrix (Fahrmeir et al., 2013).

The linear mixed effects model The following formula is a general matrix notation form that is applicable to the two mixed models, the random Plot model 
and the random Geo model.

$$
\begin{gathered}
y_{i}=X_{i} \beta+Z_{i} b_{i}+e_{i} \\
\text { with } e_{i} \sim N\left(0, \sigma^{2} I_{n i}\right) \text { and } b_{i} \sim N(0, Q)
\end{gathered}
$$

where $y_{i}$ is the $n_{i}$-dimensional vector of responses, $\beta$ is the $p$-dimensional vector of fixed parameters, $X_{i}$ and $Z_{i}$ are the $n_{i} \times p$ and $n_{i} \times(q+1)$-dimensional design matrices from unknown variables, $b_{i}$ is the $(q+1)$-dimensional vector of random effects, $e_{i}$ is the $n_{i}$-dimensional vector of error terms, and $Q$ is the $(q+1) \times(q+1)$-covariance matrix (Fahrmeir et al., 2013).

\section{Model fitting and evaluation}

In all models, we used the natural logarithmic transformation of BAI $(\log (B A I+1)$ to approximate the data to linearity and normal distribution of the residuals (Dolph, 1988; Wykoff et al., 1982). To develop the BAI models, we performed a preliminary analysis to choose the most suitable competition index and tree size variables. BALMOD was chosen as the competition index for P. patula, Pinus and Abies groups, while for Quercus the most suitable competition variable was the BAL index. For all groups, $\log (d)$ was selected as tree size indicator.

In the fitting of BAI models, tree age as predictor was excluded intentionally in order to make these models easier to apply. In Mexico, not all forest inventories provide tree age, including the National Forest Inventory that only requires a sub-sample to estimate tree age because it is a variable that implies more time and effort to obtain. Therefore, if tree age were included in BAI models, those models only be useful to forest inventories with tree age in all trees.

$\log (B A I+1)$ fixed effects model. We fitted the fixed effects models to the groups (P. patula, Pinus, Abies, and Quercus), using R (R Core Team, 2019) based on the generalized least squares method with the function gls from the nlme package (Pinheiro and Bates, 2000).

The specific linear fixed effects model for predicting BAI based on Equation 2.3 can be written in scalar notation as follows:

$$
\log \left(B A I_{i}+1\right)=\beta_{0}+\beta_{1} \cdot B A L M O D_{i}+\beta_{2} \cdot \log \left(d_{i}\right)+e_{i}
$$


where $\log \left(B A I_{i}+1\right)$ is the response variable as the logarithmic transformation of the basal area increment in $c m^{2}+1, \beta_{0}$ is the intercept parameter, $\beta_{1}$ is the slope parameter, $B A L M O D_{i}$ is the competition index, $\log \left(d_{i}\right)$ is the logarithmic transformation of the tree $i^{\text {th }}$ diameter observation and $e_{i}$ is the model error.

$\log (B A I+1)$ mixed effects models. Parameters of the mixed effects models were estimated via restricted maximum likelihood (REML) with nlme package using the function lme (Pinheiro et al., 2019). The general procedure to choose the random effects was first tp keep the fixed parameters from the linear fixed effects model (Equation 2.5) and second to systematically add random effects (plot, elevation, and aspect) to test for significance until reach the best model or convergence would be reached. Elevation and aspect (Geo classes) were tested as interaction model based on the classification of Table 2.2.

Then the specific linear mixed effects model for predicting BAI for both random Plot and random Geo can be written in scalar notation as follows:

$$
\log \left(B A I_{i j}+1\right)=\left(\beta_{0}+u_{i}\right)+\beta_{1} \cdot B A L M O D_{i j}+\left(\beta_{2}+v_{i}\right) \cdot \log \left(d_{i j}\right)+e_{i j}
$$

where $\log \left(B A I_{i j}+1\right)$ is the $j^{\text {th }}$ observation of the response variable from plot $i^{\text {th }}$, as the logarithmic transformation of the basal area increment in $\mathrm{cm}^{2}+1, \beta_{0}$ is the fixed population intercept, $u_{i}$ is the random deviation from the population intercept; $\beta_{0}+u_{i}=$ is the random intercept for group $i$ (either Plot or Geo); $\beta_{1}$ is the fixed population slope, $B A L M O D_{i j}$ is the competition index of the $j^{\text {th }}$ tree on the $i^{\text {th }}$ plot, $\log \left(d_{i j}\right)$ is the logarithmic transformation of the $j^{\text {th }}$ tree diameter observation from the $i^{\text {th }}$ plot, $v_{i}$ is the random deviation from the population slope, $\beta_{1}+v_{i}=$ is the random slope for group $i$ and $e_{i j}$ is the model error.

The model ranking for P. patula and for all groups an individual BAI model was made based on the Akaike Information Criterion (AIC) (Fahrmeir et al., 2013; Pinheiro and Bates, 2000). Additionally, the coefficient of determination $R^{2}$ was estimated for original data, and the root mean squared error (RMSE) was used. The RMSE and the $R^{2}$ are described in Equations (2.7) and (2.8) respectively.

$$
R M S E=\sqrt{\frac{\sum_{i=1}^{n}\left(y_{i}-\hat{y}_{i}\right)^{2}}{n-p}},
$$




$$
R^{2}=1-\frac{(n-1) \sum_{i=1}^{n}\left(y_{i}-\hat{y}_{i}\right)^{2}}{(n-p) \sum_{i=1}^{n}\left(y_{i}-\bar{y}_{i}\right)^{2}}
$$

where $i$ is the tree level observation, $y_{i}, \hat{y}_{i}$ and $\bar{y}_{i}$ are the observed, predicted, and average values respectively, $p$ is the number of parameters, and $n$ is the number of observations.

\section{Heteroscedasticity}

For heteroscedastic data, i.e. when residuals are not equally distributed, it is possible to model the variance structure through variance functions (Pinheiro and Bates, 2000). Although the log transformation applied to BAI could be helpful to deal with heterogeneity, in a preliminary analysis we detected heteroscedasticity. In all models, the residuals variation tended to change with the increasing size of diameters. The nlme package contains several functions for modeling heteroscedasticity (Pinheiro et al., 2019). For the models in this study, the power-type function was the most suitable in all cases, and can be expressed as follows:

$$
\operatorname{Var}\left(\epsilon_{i j}\right)=\sigma^{2}\left|v_{i j}\right|^{2 \delta}
$$

where $\delta$ is the model parameter, and $v_{i j}$ could be assigned to the variance given by the covariates or by the fitted values (Pinheiro and Bates, 2000).

This power-type function is applicable for both, the fixed and the mixed effects models. The 'gls' function used for fitting the fixed effects models and 'lme' for the linear mixed effects allow both for correlated errors and/or for unequal variances by including the variance power-type function as weight in the fitting process (Pinheiro et al., 2019).

\subsubsection{Random effects localization and model validation}

In general, linear mixed effects models are used for prediction in three ways: first, the conditional mode (using both the random and fixed effects); second, marginal predictions (only fixed effects); and third, predictions through localization techniques. This latter option was used for new plots with the best linear unbiased 
predictor (BLUP), (Fang and Bailey, 2001; Calama and Montero, 2004; Mehtätalo, 2013), where a few trees are taken to localize the random effects, allowing the use of a conditional prediction to the new plot. This process is usually known as calibration or localization of the random effects, and we also implemented it as well for model validation.

In the validation process, BLUP was used to localize random effects on new plots (Mehtätalo, 2013), with an adaptation of the so called leave-one-out crossvalidation technique. For this purpose, a for loop was coded to iterate along the plots, in each iteration, the model was fitted estimating the fixed effects and leaving one plot out at a time. In the same iteration, we extracted few trees from the plot left out to localize the random effects using Equation 2.10. Once the fixed and random effects were known, the last step was to estimate BAI to each tree in the plot left out. Then the process was repeated iteratively until the random effects were localized in all plots and BAI was estimated to all trees via cross-validation. In its simplified version, the localization of random effects can be described as:

$$
\hat{\alpha_{1 i}}=\frac{\sigma_{\alpha}^{2}}{\frac{1}{n} \sigma^{2}+\sigma_{\alpha}^{2}}\left(\bar{y}_{1 i}-\mu_{1 i}\right)
$$

where $\hat{\alpha_{1 i}}$ is the random effect of the new plot, $\sigma_{\alpha}^{2}$ is the variance of the random effect, $\sigma^{2}$ is the residual variance of the model, $\bar{y}_{1 i}$ is the mean of the observed values (of the sub-sample), and $\mu_{1 i}$ is the mean of the predicted values (of the subsample, using only the fixed part of the model). For more details and examples see Mehtätalo (2013) and de Souza-Vismara et al. (2016).

Implementing the procedure described above allowed us to evaluate the localized prediction for new observations by combining the BLUP and the crossvalidation approximations. Generally, it is recommended to use the localization technique in order to get better predictions on new plots (Fang and Bailey, 2001; Calama and Montero, 2004). It is also important to take into account the number of localization elements (trees), as it may have a greater influence on the accuracy of the predictions (de Souza-Vismara et al., 2016; Sharma et al., 2016). Therefore, we assessed the number of localization trees in BAI models and analyzed the number of trees needed to localize the BAI models in this study. 


\subsection{Results}

In general, the results of testing out mixed and fixed effects BAI models support the hypothesis that including random effects provide more precise outcomes. The evaluation in all groups shows that the inclusion of random effects results in better models compared to the linear fixed effect ones, and these outcomes are confirmed by the validation procedure. Regarding the localization, results show that, in general, the more trees used in the localization the better the prediction of random effects is.

In subsection 2.3.1, the results are developed systematically, and the findings in the fitting process are provided in a table for each group (P. patula, Pinus, Abies, and Quercus) as well as in corresponding residual plots for visual evaluation. The subsection 2.3.2 describes the localization outcomes and analyzes the number of trees necessary to predict random effects on new plots.

\subsubsection{Model fitting}

P. patula. Regarding tree size and competition, the parameter $\beta_{2}$, associated to the logarithm transformation of tree diameter, has a significant positive influence over $\log (B A I+1)$. In contrast, the parameter $\beta_{1}$, associated to the competition index BALMOD, shows a statistically significant negative effect on the three models (Table 2.3). Regarding the site characteristics, the fitting results generally indicate that random effects are relevant for predicting BAI in the study area because in the comparative analysis (fixed effects model vs. random Plot model), significant differences were found, based on the likelihood ratio test $\left(\chi^{2}=2330.07, p<\right.$ 0.001). Likewise, significant differences were found when comparing the fixed effects model vs. the random Geo model $\left(\chi^{2}=975.82, p<0.001\right)$.

With regard to the ranking and evaluation, for P. patula the model with better goodness-of-fit statistics is the random Plot (Table 2.3). The validation and localization procedure showed that both mixed models (random Plot and random Geo) had better predictive performance than the fixed effects ones. Results of the variance modeling with the power function are shown in Table 2.3, while Figure 2.2 shows that no heteroscedasticity can be detected once the variance function is included. 
Table 2.3: Pinus patula $\log (B A I+1)$ models parameters and goodness-of-fit statistic values, including the classical linear fixed effects (FE) and the mixed effects models. The mixed models are divided into random Plot and random Geo variables. Where RMSE.val is the root mean squared error obtained through the cross-validation/calibration.

\begin{tabular}{lrrr}
\hline & \multicolumn{3}{c}{ Pinus patula } \\
\cline { 2 - 4 } Indicator & Fixed effects model & Random Plot & Random Geo \\
\cline { 2 - 4 }$\beta_{0}$ & 1.435 & -0.615 & 0.451 \\
$\beta_{1}$ & -0.092 & -0.041 & -0.078 \\
$\beta_{2}$ & 0.342 & 0.852 & 0.598 \\
$s d\left(u_{i}\right)$ & - & 0.660 & 0.786 \\
$s d\left(v_{i}\right)$ & - & 0.177 & 0.184 \\
$\sigma$ & 0.847 & 0.227 & 0.201 \\
$\delta$ & -0.587 & -0.107 & 0.720 \\
AIC & $2.165 K$ & -159.243 & $1.195 K$ \\
$R^{2}$ & 0.353 & 0.877 & 0.659 \\
RMSE & 0.472 & 0.206 & 0.342 \\
RMSE.val & 0.503 & 0.290 & 0.307 \\
\hline
\end{tabular}
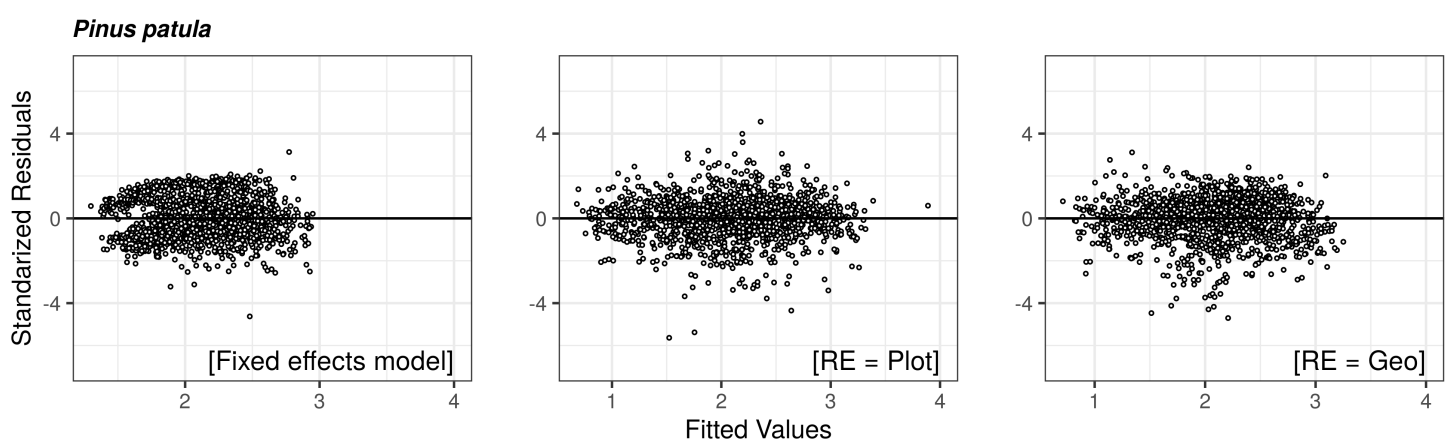

Figure 2.2: Residual plots for P. patula group. Where RE are the random effects.

The most appropriate model for P. patula was the mixed effects including the plot as random effect and it is described as follows:

$$
\begin{aligned}
\log \left(B A I_{i j}+1\right)=\left(-0.615+u_{i}\right)+(-0.041) \cdot & B A L M O D_{i j} \\
& +\left(0.852+v_{i}\right) \cdot \log \left(d_{i j}\right)+e_{i j}
\end{aligned}
$$

where $\log \left(B A I_{i j}+1\right)$ is the logarithm of the basal area increment of the $j^{\text {th }}$ tree in the $i^{\text {th }}$ plot, $u_{i}$ and $v_{i}$ are the random effects on intercept and slope respectively, $B A L M O D_{i j}$ is the competition index of the $j^{\text {th }}$ tree in the $i^{\text {th }}$ plot, and $\log \left(d_{i j}\right)$ is the logarithm of the tree diameter of the $j^{\text {th }}$ tree in the $i^{\text {th }}$ plot.

Pinus group. For the Pinus group, the findings are similar to P. patula in the fitting and comparative analyses. The parameter $\beta_{2}$ of tree size indicator 
$(\log (d))$ shows a positive effect, while the parameter $\beta_{1}$ associated to BALMOD has a negative influence over $\log (B A I+1)$ (Table 2.4). When comparing the models, significant differences can be found in the fixed effects model vs random Plot model $\left(x^{2}=838.86, p<0.0001\right)$ and fixed effects model vs the random Geo model $\left(\chi^{2}=747.23, p<0.0001\right)$ against the linear model.

The best fitted model was the random plot, followed by the random Geo model (Table 2.4). The results of the validation confirm that the models with better performance are the models with mixed effects (Table 2.4, RMSE.val). Regarding the homoscedasticity assumption, once the variance function has been applied, the models show no sign of heteroscedasticity in the distribution of the residuals (Figure 2.3).

Table 2.4: Pinus group $\log (B A I+1)$ models parameters and goodness-of-fit statistic values, including the classical linear fixed effects (FE) and the mixed effects models. The mixed models are divided into random Plot and random Geo. Where RMSE.val is the root mean squared error obtained through the cross-validation/calibration.

\begin{tabular}{lrrr}
\hline & \multicolumn{3}{c}{ Pinus group } \\
\cline { 2 - 4 } Indicator & Fixed effects model & Random Plot & Random Geo \\
\cline { 2 - 4 }$\beta_{0}$ & 0.423 & -0.009 & -0.171 \\
$\beta_{1}$ & -0.059 & -0.049 & -0.031 \\
$\beta_{2}$ & 0.573 & 0.686 & 0.714 \\
$s d\left(u_{i}\right)$ & - & 0.745 & 0.717 \\
$s d\left(v_{i}\right)$ & - & 0.246 & 0.213 \\
$\sigma$ & 0.783 & 0.238 & 0.199 \\
$\delta$ & -0.067 & -0.599 & -0.083 \\
AIC & 548.331 & -284.525 & -192.904 \\
$R^{2}$ & 0.424 & 0.872 & 0.847 \\
RMSE & 0.363 & 0.171 & 0.187 \\
RMSE.val & 0.539 & 0.291 & 0.283 \\
\hline
\end{tabular}
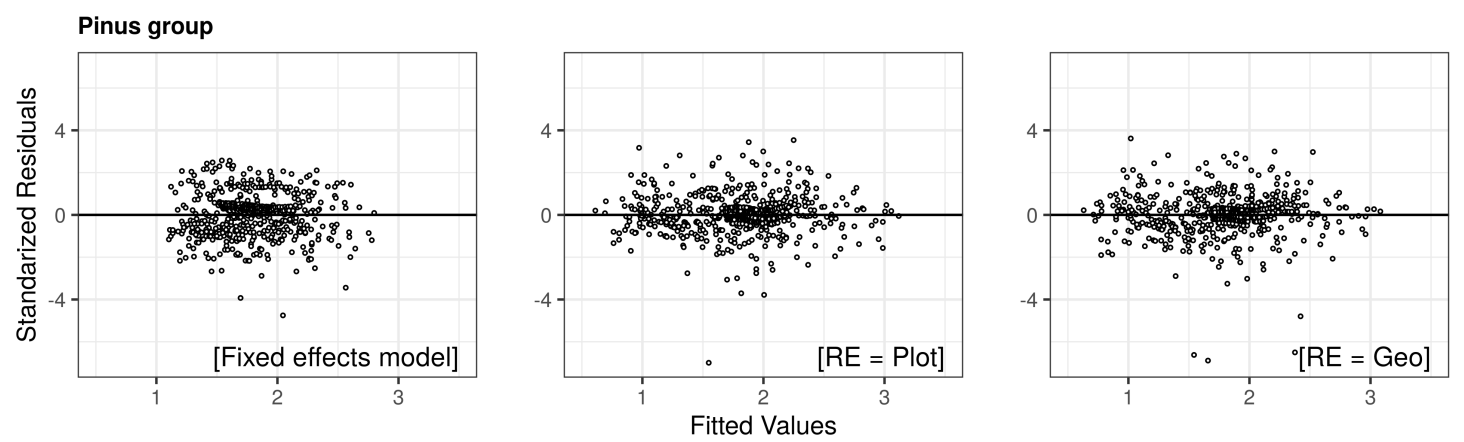

Figure 2.3: Residual plots for Pinus group. Where RE are the random effects.

For the Pinus group the most appropriate model is the mixed effects with the 
plot as random effects:

$$
\begin{aligned}
\log \left(B A I_{i j}+1\right)=\left(-0.009+u_{i}\right)+(-0.049) \cdot & B A L M O D_{i j} \\
& +\left(0.686+v_{i}\right) \cdot \log \left(d_{i j}\right)+\epsilon_{i j}
\end{aligned}
$$

where $\log \left(B A I_{i j}+1\right)$ is the logarithm of the basal area increment of the $j^{\text {th }}$ tree in the $i^{\text {th }}$ plot, $u_{i}$ and $v_{i}$ are the random effects on intercept and slope respectively, $B A L M O D_{i j}$ is the competition index of the $j^{\text {th }}$ tree in the $i^{\text {th }}$ plot, and $\log \left(d_{i j}\right)$ is the logarithm of the tree diameter of the $j^{\text {th }}$ tree in the $i^{\text {th }}$ plot.

Abies group. For this group, the size indicator parameter $\left(\beta_{2}\right)$ has a positive effect on BAI similar to the previous groups. Nonetheless, regarding BALMOD, the fixed effects model show a positive effect while in both (random Geo and random Plot) mixed models the influence is negative. With regard to the comparative analysis fixed effects model vs random Plot model results are: $\chi^{2}=355.80$, $p<0.0001$, and the fixed effects model vs the random Geo model are: $\chi^{2}=324.24$, $p<0.0001)$.

In the ranking, the best fitted models are the random Plot and random Geo models (Table 2.5). These results are consistent with the validation procedure, where the localized models have demonstrated better performance (Table 2.5). With regard to the homoscedasticity assumption, the distribution of the residuals is also improved in all models (Figure 2.4).

Table 2.5: Abies group $\log (B A I+1)$ models parameters and goodness-of-fit statistic values, including the classical linear fixed effects (FE) and the mixed effects models. The mixed models are divided into random Plot and random Geo. Where RMSE.val is the root mean squared error obtained through the cross-validation/calibration.

\begin{tabular}{lrrr}
\hline & \multicolumn{3}{c}{ Abies group } \\
\cline { 2 - 4 } Indicator & Fixed effects model & Random Plot & Random Geo \\
\cline { 2 - 4 }$\beta_{0}$ & -1.769 & -0.447 & -0.128 \\
$\beta_{1}$ & 0.047 & -0.049 & -0.065 \\
$\beta_{2}$ & 1.087 & 0.823 & 0.745 \\
$s d\left(u_{i}\right)$ & - & 0.337 & 0.384 \\
$s d\left(v_{i}\right)$ & - & 0.004 & 0.021 \\
$\sigma$ & 0.761 & 0.213 & 0.251 \\
$\delta$ & 0.546 & 0.202 & 0.079 \\
AIC & 437.352 & 85.678 & 119.109 \\
$R^{2}$ & 0.542 & 0.889 & 0.861 \\
RMSE & 0.466 & 0.230 & 0.257 \\
RMSE.val & 0.467 & 0.280 & 0.261 \\
\hline
\end{tabular}



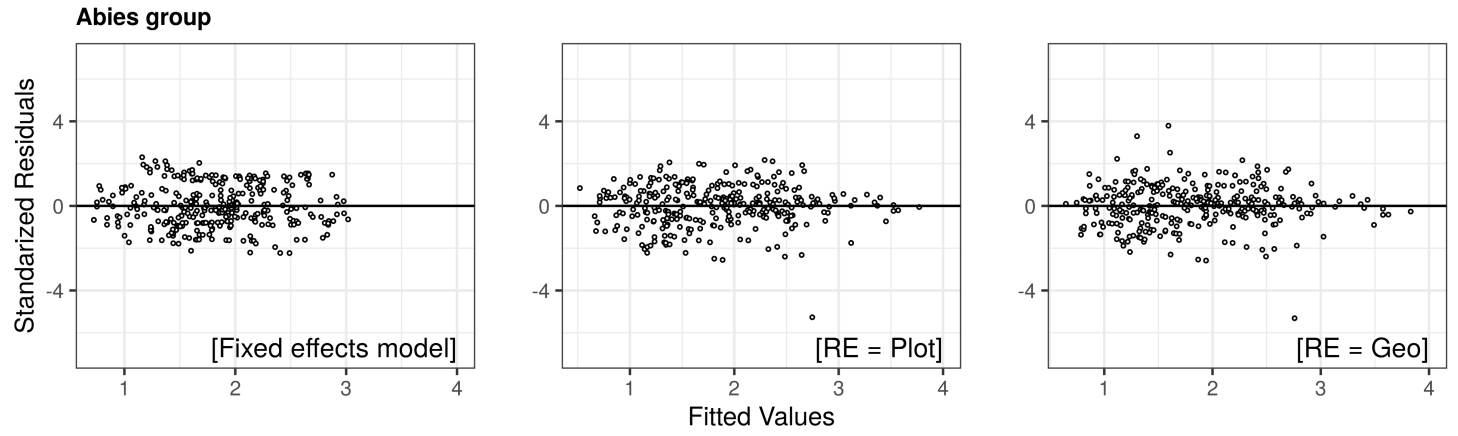

Figure 2.4: Residual plots for Abies group. Where RE are the random effects.

The most useful model for Abies group is the mixed effects with the plot as random effects. This can be written as follows:

$$
\begin{aligned}
\log \left(B A I_{i j}+1\right)=\left(-0.447+u_{i}\right)+(-0.049) \cdot & B A L M O D_{i j} \\
& +\left(0.823+v_{i}\right) \cdot \log \left(d_{i j}\right)+\epsilon_{i j}
\end{aligned}
$$

where $\log \left(B A I_{i j}+1\right)$ is the logarithm of the basal area increment of the $j^{\text {th }}$ tree in the $i^{\text {th }}$ plot, $u_{i}$ and $v_{i}$ are the random effects on intercept and slope respectively, $B A L M O D_{i j}$ is the competition index of the $j^{\text {th }}$ tree in the $i^{\text {th }}$ plot, and $\log \left(d_{i j}\right)$ is the logarithm of the tree diameter of the $j^{\text {th }}$ tree in the $i^{\text {th }}$ plot.

Quercus group. With regard to the tree size and competition, the parameter $\beta_{2}$, associated to the logarithm transformation of tree diameter has a significant positive influence over $\log (B A I+1)$; in contrast, the parameter $\beta_{1}$, associated to the competition index BALMOD, has a statistically significant negative effect on BAI models (Table 2.6). The comparative analysis of the fixed effects model vs random Plot model, shows significant differences $\left(\chi^{2}=27.33, p<0.0001\right)$. Likewise, differences were also apparent in our comparison of the fixed effects model and the random Geo model $\left(\chi^{2}=15.50, p<0.005\right)$.

For the Quercus group, the better fit is given by the random Plot and the random Geo models. These results were validated by improving the performance in comparison to the fixed effect model (Table 2.6). With regard to the residuals distribution, no signs of heteroscedasticity can be observed after the variance function has been applied (Figure 2.5).

The most appropriate model for Quercus group is also the mixed effects with 
Table 2.6: Quercus group $\log (B A I+1)$ models parameters and goodness-of-fit statistic values, including the classical linear fixed effects (FE) and the mixed effects models. The mixed models are divided into random Plot and random Geo variables. Where RMSE.val is the root mean squared error obtained through the cross-validation/calibration.

\begin{tabular}{lrrr}
\hline & \multicolumn{3}{c}{ Quercus group } \\
\cline { 2 - 4 } Indicator & Fixed effects model & Random Plot & Random Geo \\
\cline { 2 - 4 }$\beta_{0}$ & -0.770 & -0.668 & -0.746 \\
$\beta_{1}$ & -0.017 & -0.018 & -0.015 \\
$\beta_{2}$ & 1.095 & 1.084 & 1.061 \\
$s d\left(u_{i}\right)$ & - & 1.301 & 0.714 \\
$s d\left(v_{i}\right)$ & - & 0.464 & 0.294 \\
$\sigma$ & 0.610 & 0.124 & 0.188 \\
$\delta$ & 1.284 & 1.249 & 0.898 \\
AIC & 281.188 & 259.857 & 271.679 \\
$R^{2}$ & 0.381 & 0.583 & 0.515 \\
RMSE & 0.518 & 0.425 & 0.458 \\
RMSE.val & 0.588 & 0.520 & 0.553 \\
\hline
\end{tabular}
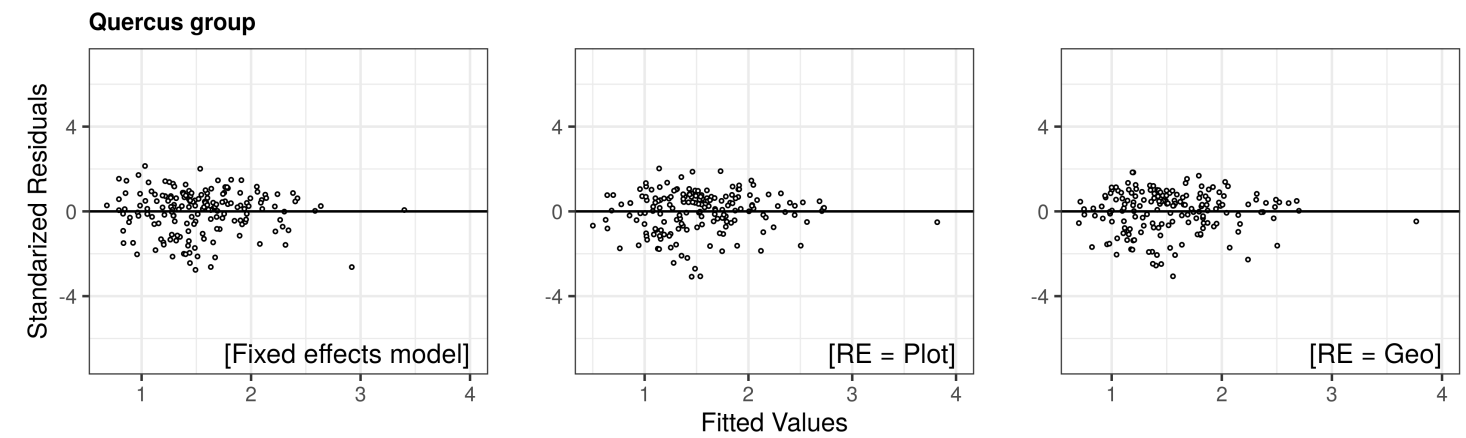

Figure 2.5: Residual plots for Quecus group. Where RE are the random effects.

the plot as random effect:

$$
\begin{aligned}
\log \left(B A I_{i j}+1\right)=\left(-0.668+u_{i}\right)+(-0.018) \cdot & B A L_{i j} \\
& +\left(1.084+v_{i}\right) \cdot \log \left(d_{i j}\right)+\epsilon_{i j}
\end{aligned}
$$

where $\log \left(B A I_{i j}+1\right)$ is the logarithm of the basal area increment of the $j^{\text {th }}$ tree in the $i^{\text {th }}$ plot, $u_{i}$ and $v_{i}$ are the random effects on intercept and slope respectively, $B A L_{i j}$ is the competition index of the $j^{\text {th }}$ tree in the $i^{\text {th }}$ plot, and $\log \left(d_{i j}\right)$ is the logarithm of the tree diameter of the $j^{\text {th }}$ tree in the $i^{\text {th }}$ plot. 


\section{Individual Random Effects on Geo models}

The mixed modeling approach allows for an analysis of the individual random effects of any level used to fit the models. In this study, we describe the random effects variation on the intercept and slope among classes of the Geo models. Figure 2.6 shows the results of the individual random effects for all groups.

The analysis has not revealed any strong trend of the random effects on the Geo classes. We were expecting that the tree growth would be lower at higher elevations. However, the intercept and slope of the models analyzed show different results depending on the group. For P. patula, the larger negative values are shown by the E:2500 and E:2600 classes, while the N:2700 and W:2700 show the larger positive effects on the model intercept. In the case of the Pinus group, the W:2700 and N:2600 classes show larger positive effects on the intercept. In this case, the negative effects are related to the East aspect class, where the larger negative values are given by the E:3100 and E:2800 classes.

For the Abies and Quercus groups the number of classes is lower because they have fewer trees. In the case of the Abies group, the S:2900 and W:2600 classes show the larger positive values, and the N:300 has the larger negative effect on the intercept. For the Quercus group, the larger positive effects are shown by the $\mathrm{W}: 2700$ and $\mathrm{W}: 2800$ classes, and the N:2800 class has the larger negative value.

\subsubsection{Random effects localization}

Figure 2.7 shows the advantage of using a few trees in the localization of random effects at plot level. In general, while the number of trees increases, the value of RMSE decreases. For $P$. patula, using even just one tree results in lower RMSE than the fixed effects model (RMSE.val) in Table 2.3, but including two or more trees improved the localization. In the case of the Pinus group, the RMSE reduction by the localization starts at a lower value compared to the other groups, although the RMSE is similar to the Abies and P. patula groups from seven trees onwards. For the Abies group, the RMSE shows a decreasing tendency with an increasing number of trees, similar to the P. patula. The Quercus is the model with the lower performance in the localization process: it shows an unexpected increasing 

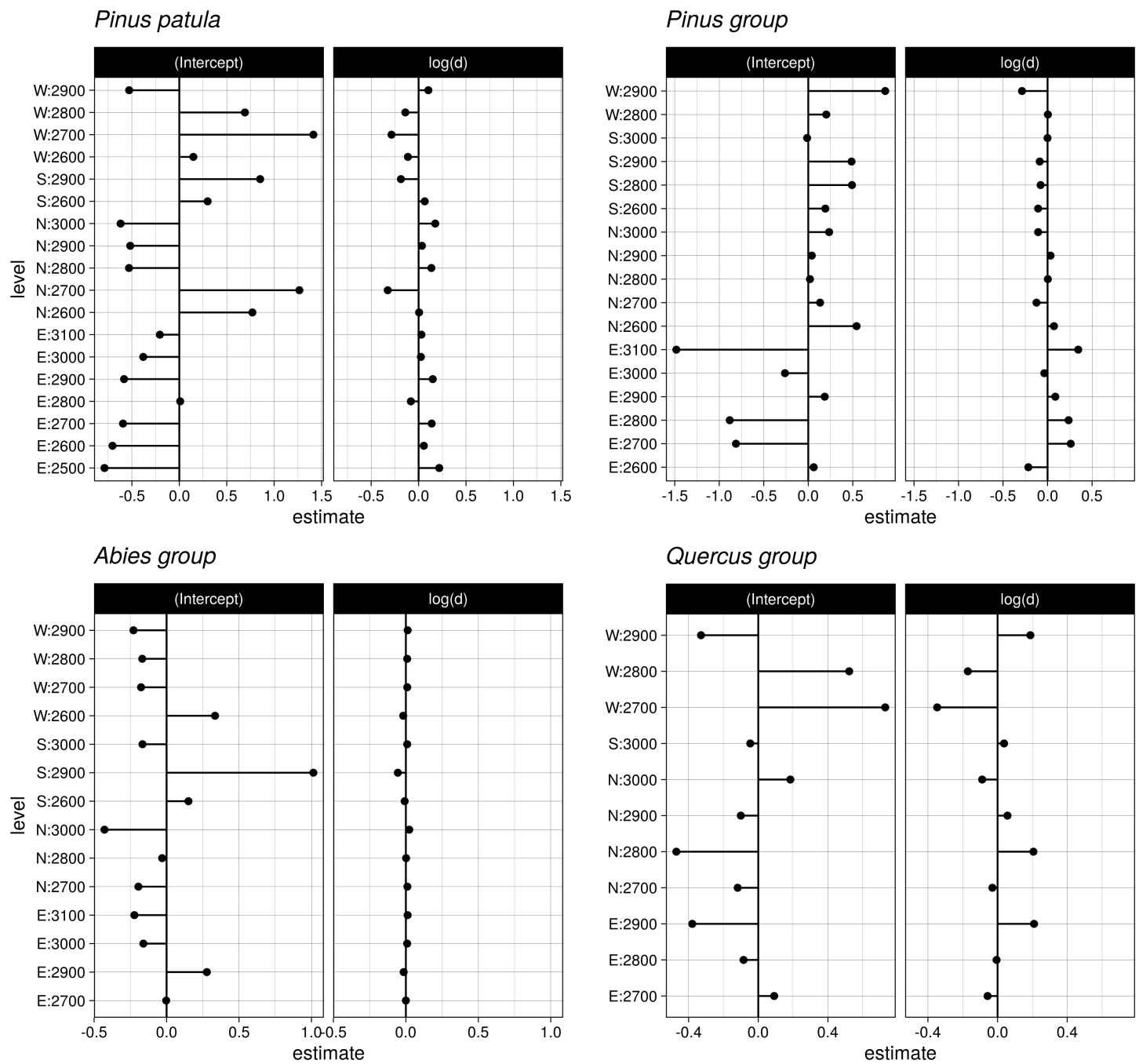

Figure 2.6: Random effects from Geo models for Pinus patula, Pinus, Abies, and Quercus group.

tendency of RMSE with an increasing number of trees. Using just one tree is better than using ten for the localization.

\subsection{Discussion}

The overall aim of this research was to test out random effects models for BAI prediction. In general, indicators of tree size, site effects, and tree competition are essential variables to estimate BAI. Here our results resemble the contributions of similar recent studies. Including site effects as random provided an interesting 

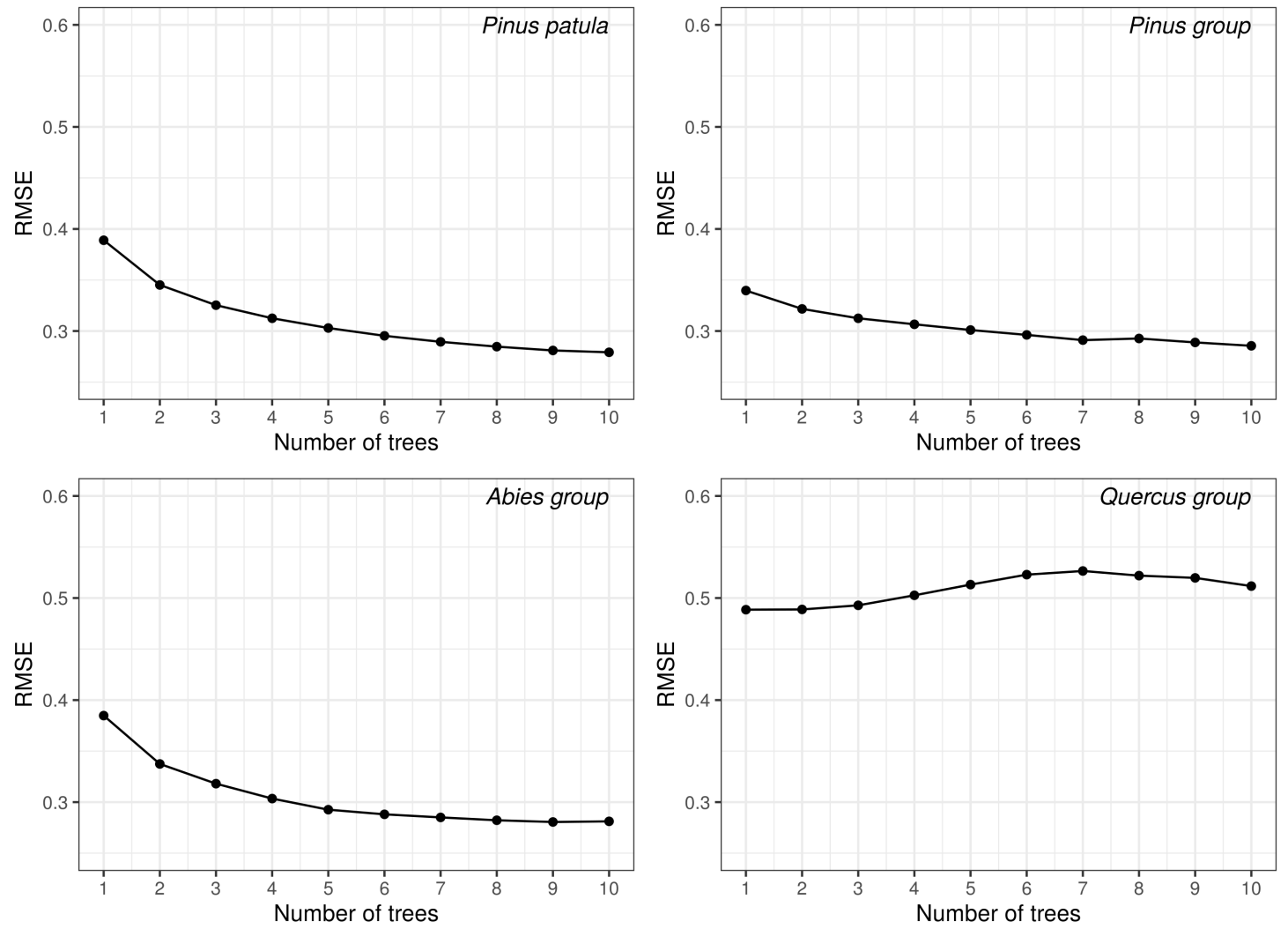

Figure 2.7: Number of trees for localization of random effects on new plots. Relationship between RMSE and the number of trees used for the localization of BAI models, generated through the leave one plot out cross-validation. Only includes the random Plot.

alternative to the traditional way of including them as fixed. Another noteworthy contribution is the localization/validation tested since we adapted the crossvalidation technique and combined the localization of random effects. We used the BLUP approximation, thus adding robustness to the overall model evaluation. The principal specific findings are discussed in the following subsections.

\subsubsection{Tree size}

For all the groups, the final model was fitted with only one tree size indicator as fixed parameter, $\log (d)$. Here we agree with Uzoh et al. (2008) who found that $\log (d)$ was one of the most important variables to include in tree diameter increment models of ponderosa pine. In similar research, a diameter increment model for uneven-aged hardwood forests of Hyrcania was fitted with $\log (d)$ as fixed parameter (Bayat et al., 2013). In addition to statistical convenience, 
having the diameter as a single size indicator offers several advantages, since tree diameter is a standard measurement in forest inventories. It is easy to measure and it is usually less prone to measurement errors than tree height.

\subsubsection{Site effects}

Regarding the principal research question on the inclusion of random effects, our results support the assumption that site effects help explain BAI variation. In this study, we evaluated the random effects in two ways: first, by including them at sampling plot level (random Plot) and, second, using the random effects at a level that combines elevation and aspect (random Geo). In both cases, the results were quite similar, i.e. significantly better than the fixed effects model.

The model with environmental characteristics (random Geo) showed consistency with other studies, such as that of Uzoh et al. (2008), where a diameter increment model for ponderosa pine in the United States was developed, including slope and aspect as fixed effects with significant results. However, in their study, elevation was avoided in the final model due to a lack of significance, underlining the importance of having plots at several elevations to improve the models. This might explain our findings because we have several plots located at a $600 \mathrm{~m}$ range (2500-3100 $\mathrm{m}$ above sea level). We tested the combination of elevation and aspect as random effects, which resulted in significant results, using the Likelihood Ratio Test.

All in all, the plot as random intercept showed better performance for all the groups studied. This could be explained by the number of random elements used: for the random Plot model, 49 elements were tested, while for the Geo model, only 18 elements were used as random. In this context, we could assume that the plots capture additional information related to site-specific features, such as soil, and that such characteristics could possibly be omitted by the Geo model. Soil type has an influence on tree growth and is an important element to be considered in model growth functions (Vanclay, 1994). However, the influence of soil and other factors could be indirectly added to the models by taking into account the site index or, as in this study, by including the plot as random effect. 


\subsubsection{Competition index}

As expected, the inclusion of $B A L M O D$ has a negative effect on tree growth. This is in complete agreement with the study of Corral-Rivas et al. (2005) whose research shows a negative correlation $(r=-0.77)$ between BALMOD and basal area increment for Pinus cooperi in Mexico. In a similar study carried out in Spain, BALMOD improved the growth model of Pinus radiata (Álvarez Taboada et al., 2003). However, a study on diameter growth of silver birch in Estonia highlighted the importance of including spatial metrics in competition indices (Maleki et al., 2015), similar to the study of Quiñonez-Barraza et al. (2018) of several species of pines and oaks in the state of Durango, Mexico. Nonetheless, in Mexico not all forest inventories include tree coordinates. Besides, BALMOD is one of the easiest indices to estimate and only requires the number of trees per hectare $\left(N h a^{-1}\right)$, basal area $(g)$, and dominant tree height $\left(H_{0}\right)$ (Schröder and von Gadow, 1999). Therefore, we preferred BALMOD instead of spatially dependent tree competition indices.

\subsubsection{Random effects localization and model validation}

In all cases the cross-validation was a good approximation in the absence of external validation data for testing mixed models. Besides, leaving one plot out at each iteration gave us the possibility to test the number of trees for the localization of mixed models. In this regard, our results confirm that, in general, the higher the number of elements used in the localization is, the smaller the error in prediction of random effects gets (Figure 2.7). This corresponds to the findings of Sharma et al. (2016) and de Souza-Vismara et al. (2016).

An important aspect, when working with mixed effects models, is the model localization and the number of trees used for such a purpose. A similar study by de Souza-Vismara et al. (2016) found that the higher the number of elements is, the better the final model becomes. On the one hand, it is important to localize the random effects in order to take advantage of the random effects models, because the localization can be done even by including only one tree. In the study of Vargas-Larreta et al. (2009), only one tree was randomly selected to localize the random effects. They concluded that including one random tree height per 
diameter category was even better. On the other hand, Sharma et al. (2016) recommend using the total number of trees available to have better predictions of missing trees, while in our research, using nine trees showed reliable results in the localization procedure (Tables 2.3-2.6).

\subsubsection{Future applications}

The data used in this research comes from a wide range of conditions, representing many forest growth scenarios in the north of Puebla. Therefore, in this region, the mixed effects models selected could be employed for conditional predictions on the same plots and for new sites using localization techniques. Excluding the random effects for making predictions is not recommended because it has been shown that using only the fixed part of the mixed models resulted in biased predictions. In such a case, it is better to use the classical fixed effects model (Monleon, 2003; Temesgen et al., 2008). If localization is pursued, we recommend the same number of trees required to estimate dominant tree height since this is a standard measure in Mexican forest inventories. However, in this study, the number of trees is not recommended for the Quercus group because using just one tree was better than using nine.

The localization of random effects on the Quercus group showed an unexpected result. We were expecting an improvement of RMSE with an increasing number of localization trees, but the opposite was the case. This might be the result of the number of trees used in the fitting, being the smaller group, or might be due to the specific trees used to localize the random effects, i.e. the nine tallest trees. Therefore, we recommend, in future studies, to use a different combination of localization trees, such as the closest to the mean, median, or range (min and max), to capture more variation.

In this study, mixed BAI models increased the variance explained compared to the traditional fixed effects linear regression. In Mexico, other studies have shown that BAI is difficult to predict using only fixed effects (Vargas-Larreta et al., 2010). We demonstrated that including site characteristics as random effects in BAI models, in addition to competition and tree size, can better explain the variance in BAI. For future research, we therefore recommend the use of random 
effects for other species and to extend the number of plots for P. patula to other areas.

After having presented the models of the study, further research is needed on how to integrate these models into forest simulators (Hansen and Nagel, 2014; Nagel, 2003). Depending on the software structure, mixed effects can be used under certain circumstances. For example, when the simulation is based on real data, random effects could be localized in advance, or it would be necessary to modify the simulator to make the predictions of the random effects before the simulation starts.

\subsection{Conclusions}

As expected, including random effects leads to more accurate and reliable forest growth models by adding an error component to specific levels. In our study, we concluded that it is better to use the plot as source of variability (random effect) because it showed consistency and is more specific regarding levels. Due to its flexibility, the inclusion of random effects is useful in various scales of forest inventories as well, such as the Mexican National Forest Inventory, which uses different levels of clustering and collects variables from each tree. Using the mixed effects models could be an option to reduce time and effort in repeated measurements and for data imputation when data bases are considerably large. We recommend to implement this approximation not only in forest inventories, but also in forest research projects because it provides more biologically realistic predictions. We hope to contribute to the knowledge of forest ecosystems by introducing these functions as well as by providing tools to those forest managers, policy makers, students, and researchers striving for sustainable forest management. 


\section{Literature}

Álvarez Taboada, M.F., Barrio Anta, M., Gorgoso Varela, J., Álvarez-González, J.G., 2003. Influencia de la competencia en el crecimiento en sección en Pinus radiata D. Don. Invest. Agrar.: Sist. Recur. For. 12, 25-35. URL: https://recyt. fecyt.es/index.php/IA/article/view/2493.

Bayat, M., Pukkala, T., Namiranian, M., Zobeiri, M., 2013. Productivity and optimal management of the uneven-aged hardwood forests of Hyrcania. European Journal of Forest Research 132, 851-864. doi:10.1007/s10342-013-0714-1.

Bowman, D.M.J.S., Brienen, R.J.W., Gloor, E., Phillips, O.L., Prior, L.D., 2013. Detecting trends in tree growth: Not so simple. doi:10.1016/j.tplants.2012.08. 005.

Burkhart, H.E., Tomé, M., 2012. Modeling Forest Trees and Stands. Springer Netherlands, Dordrecht. doi:10.1007/978-90-481-3170-9.

Calama, R., Montero, G., 2004. Interregional nonlinear heightdiameter model with random coefficients for stone pine in Spain. Canadian Journal of Forest Research 34, 150-163. URL: http://www.nrcresearchpress.com/doi/10.1139/x03-199, doi:10.1139/x03-199.

Corral-Rivas, J.J., Álvarez-González, J.G., Aguirre-Calderón, O.A., Hernández, F.J., 2005. The effect of competition on individual tree basal area growth in mature stands of Pinus cooperi Blanco in Durango (Mexico). European Journal of Forest Research 124, 133-142. URL: http://link.springer.com/10.1007/ s10342-005-0061-y, doi:10.1007/s10342-005-0061-y.

Corral-Rivas, S., Álvarez-González, J., Crecente-Campo, F., Corral-Rivas, J., 2014. Local and generalized height-diameter models with random parameters for mixed, uneven-aged forests in Northwestern Durango, Mexico. Forest Ecosystems 1, 6. URL: http://forestecosyst.springeropen.com/articles/10.1186/ 2197-5620-1-6, doi:10.1186/2197-5620-1-6.

Corral-Rivas, S., Silva-Antuna, A.M., Quiñonez Barraza, G., 2019. A generalized nonlinear heightdiameter model with mixed-effects for seven Pinus species in Durango, Mexico. Revista Mexicana de Ciencias Forestales 10, 86-117. URL: https://doi.org/10.29298/rmcf.v10i53.500\{\%\}0A, doi:https://doi.org/10.29298/rmcf. v10i53.500.

Dolph, L.K., 1988. Prediction of periodic basal area increment for young-growth mixed conifers in sierra Nevada. Technical Report. URL: https://www.fs.usda. gov/treesearch/pubs/29196, doi:10.2737/PSW-RP-190.

Dvorak, W.S., Hodge, G.R., Kietzka, J.E., Malan, F., Osorio, L.F., Stanger, T.K., 2000. Pinus patula, in: Conservation \& Testing of Subtropical \& Subtropical Forest 
Tree Species by the CAMCORE Cooperative College of Natural Resources, NCSU.. NC STATE UNIVERSITY, Raleigh. chapter Pinus patu, pp. 149-173.

Fahrmeir, L., Kneib, T., Lang, S., Marx, B., 2013. Regression: models, methods and applications. Springer, Berlin, Germany. doi:10.1007/978-3-642-34333-9.

Fang, Z., Bailey, R.L., 2001. Nonlinear Mixed Effects Modeling for Slash Pine Dominant Height Growth Following Intensive Silvicultural Treatments. Forest Science 47, 287-300. URL: https://academic.oup.com/forestscience/article/47/3/287/ 4617175, doi:10.1093/forestscience/47.3.287.

FAO, 2017. Global Forest Products, facts and figures. Technical Report. Food and Agriculture Organization of the United Nations. URL: http://www.fao.org/3/ I7034EN/i7034en.pdf.

Fox, J.C., Ades, P.K., Bi, H., 2001. Stochastic structure and individual-tree growth models. Forest Ecology and Management 154, 261-276. doi:10.1016/ S0378-1127(00)00632-0.

Gillespie, A.J.R., 1992. Pinus patula Schiede and Deppe. Patula pine. Pinaceae. Pine family. USDA Forest Service, Southern Forest Experiment Station, Institute of Tropical Forestry; . 5 p. (SO-ITF-SM; 54). .

Gregorie, T.G., 1987. Generalized Error Structure for Forestry Yield Models. Forest Science 33, 423-444. doi:10.1093/forestscience/33.2.423.

Hall, D.B., Bailey, R.L., 2001. Modeling and Prediction of Forest Growth Variables Based on Multilevel Nonlinear Mixed Models. Forest Science 47, 311-321. doi:10.1093/forestscience/47.3.311.

Hansen, J., Nagel, J., 2014. Waldwachstumskundliche Softwaresysteme auf Basis von TreeGrOSS - Anwendung und theoretische Grundlagen. Universitätsverlag Göttingen, Gottingen, Germany. URL: https://www.univerlag.uni-goettingen.de/ handle/3/isbn-978-3-86395-149-8.

INEGI, 2001. Conjunto de datos vectoriales Fisiográficos. Continuo Nacional serie I. Provincias fisiográficas. Technical Report. Instituto Nacional de Estadística y Geografía (INEGI). URL: https://www.inegi.org. $m x / a p p / b i b l i o t e c a / f i c h a . h t m l$ upc= 702825267568 .

INEGI, 2008. Conjunto de datos vectoriales escala 1:1 000 000. Unidades climáticas. Technical Report. Instituto Nacional de Estadística y Geografía (INEGI). Aguascalientes. URL: https://www.inegi.org. $m x /$ app/biblioteca/ficha.html? upc= 702825267568 .

ITTO, 2017. Biennial review statistics | ITTO | The International Tropical Timber Organization. URL: https://www.itto.int/biennal__lreview/. 
Maleki, K., Kiviste, A., Korjus, H., 2015. Analysis of Individual Tree Competition on Diameter Growth of Silver Birch in Estonia. Forest Systems 24, e023. URL: http://revistas.inia.es/index.php/fs/article/view/5742, doi:10.5424/fs/ 2015242-05742.

MEA, 2005. Millennium Ecosystem Assessment, 2005. Ecosystems and Human Well-being: Synthesis. Island Press, Washington, DC. doi:10.1196/annals.1439. 003.

Mehtätalo, L., 2013. Forest Biometrics with Examples in R. University of Eastern Finland, Joensuu.

Mehtätalo, L., De-Miguel, S., Gregoire, T.G., 2015. Modeling height-diameter curves for prediction. Canadian Journal of Forest Research 45, 826-837. URL: http://www.nrcresearchpress.com/doi/10.1139/cjfr-2015-0054, doi:10.1139/ cjfr-2015-0054.

Monleon, M., 2003. A hierarchical linear model for tree height prediction, in: Joint Statistical Meetings - Section on Statistics \& the Environment, pp. 2865-2869. URL: https://www.fs.usda.gov/treesearch/pubs/20148.

Monroy, R.C., 1995. Pinus patula Schl. et Cham., en México. Folleto técnico No.29. Technical Report. SAGAR/CIRGOC-INIFAP. Mexico.

Nagel, J., 2003. TreeGrOSS: Tree Growth Open Source Software. URL: http: //treegross.sourceforge.net/.

Pinheiro, J., Bates, D., DebRoy, S., Sarkar, D., R Core Team, 2019. Linear and Nonlinear Mixed Effects Models [R package nlme version 3.1-137]. URL: https://cran.r-project.org/web/packages/nlme/index.html.

Pinheiro, J.C., Bates, D.M., 2000. Mixed-effects models in S and S-PLUS. SpringerVerlag, New York.

Pokharel, B., Dech, J.P., 2012. Mixed-effects basal area increment models for tree species in the boreal forest of Ontario, Canada using an ecological land classification approach to incorporate site effects. Forestry 85, 255-270. URL: https://academic.oup.com/forestry/article-lookup/doi/10.1093/forestry/cpr070, doi:10.1093/forestry/cpr070.

Pretzsch, H., 2009. Forest Dynamics, Growth and Yield: From Measurement to Model. Springer-Verlag, Berlin, Germany. doi:10.1007/978-3-540-88307-4.

Pretzsch, H., Grote, R., Reineking, B., Rötzer, T., Seifert, S., 2008. Models for forest ecosystem management: a European perspective. Annals of botany 101, 1065-87. URL: http://www.ncbi.nlm.nih.gov/pubmed/17954471http: //www.pubmedcentral.nih.gov/articlerender.fcgi?artid=PMC2710278, doi:10.1093/ $a o b / \mathrm{mcm} 246$. 
Quiñonez-Barraza, G., Zhao, D., De Los Santos Posadas, H.M., Corral-Rivas, J.J., 2018. Considering neighborhood effects improves individual dbh growth models for natural mixed-species forests in Mexico. Annals of Forest Science 75, 1-11. doi:10.1007/s13595-018-0762-2.

R Core Team, 2019. R: A language and environment for statistical computing. R Foundation for Statistical Computing. URL: http://www.r-project.orghttps: //www.r-project.org/.

Salas, C., Gregoire, T.G., Craven, D.J., Gilabert, H., 2016. Modelación del crecimiento de bosques: estado del arte. Bosque (Valdivia) 37, 03-12. URL: http://www.scielo.cl/scielo.php?script= sci\{_\}arttext $\{\mathcal{E}\}$ pid $=$ S0717-92002016000100001 $\{\mathcal{E}\} \operatorname{lng}=e n\{\mathcal{E}\}$ nrm $=i s o\{\mathcal{E}\} t \operatorname{lng}=e n$, doi:10.4067/S0717-92002016000100001.

Schröder, J., von Gadow, K., 1999. Testing a new competition index for Maritime pine in northwestern Spain. Canadian Journal of Forest Research 29, 280-283. URL: http://www.nrcresearchpress.com/doi/10.1139/x98-199, doi:10.1139/x98-199.

Sharma, R., Vacek, Z., Vacek, S., 2016. Nonlinear mixed effect height-diameter model for mixed species forests in the central part of the Czech Republic. Journal of Forest Science 62, 470-484. URL: http://www.agriculturejournals.cz/ web/jfs.htm? volume $=62\{\mathcal{E}\}$ firstPage $=470\{\mathcal{E}\}$ type $=$ published Article, doi:10.17221/ 41/2016-JFS.

Shifley, S.R., He, H.S., Lischke, H., Wang, W.J., Jin, W., Gustafson, E.J., Thompson, J.R., Thompson, F.R., Dijak, W.D., Yang, J., 2017. The past and future of modeling forest dynamics: from growth and yield curves to forest landscape models. Landscape Ecology 32, 1307-1325. URL: http://link.springer.com/10. 1007/s10980-017-0540-9, doi:10.1007/s10980-017-0540-9.

de Souza-Vismara, E., Mehtätalo, L., Batista, J.L.F., 2016. Linear mixedeffects models and calibration applied to volume models in two rotations of Eucalyptus grandis plantations. Canadian Journal of Forest Research 46, 132-141. URL: http://www.nrcresearchpress.com/doi/10.1139/cjfr-2014-0435, doi:10.1139/cjfr-2014-0435.

Temesgen, H., Monleon, V.J., Hann, D.W., 2008. Analysis and comparison of nonlinear tree height prediction strategies for Douglas-fir forests. Canadian Journal of Forest Research 38, 553-565. doi:10.1139/X07-104.

Torres-Rojo, J.M., Moreno-Sánchez, R., Mendoza-Briseño, M.A., 2016. Sustainable Forest Management in Mexico. Current Forestry Reports 2, 93-105. URL: http: //link.springer.com/10.1007/s40725-016-0033-0, doi:10.1007/s40725-016-0033-0.

Uzoh, F.C., Oliver, W.W., 2008. Individual tree diameter increment model for managed even-aged stands of ponderosa pine throughout the western United 
States using a multilevel linear mixed effects model. Forest Ecology and Management 256, 438-445. doi:10.1016/j.foreco.2008.04.046.

Vanclay, J.K., 1994. Modelling Forest Growth and Yield: Applications to Mixed Tropical Forests. 1 ed., CABI, Wallingford, U.K.

Vargas-Larreta, B., Castedo-Dorado, F., Alvarez-Gonzalez, J.G., Barrio-Anta, M., Cruz-Cobos, F., 2009. A generalized height-diameter model with random coefficients for uneven-aged stands in El Salto, Durango (Mexico). Forestry 82, 445-462. URL: https://academic.oup.com/forestry/article-lookup/doi/10.1093/ forestry/cpp016, doi:10.1093/forestry/cpp016.

Vargas-Larreta, B., Corral-Rivas, J., Aguirre-Calderón, Ó., Nagel, J., 2010. Modelos de crecimiento de árbol individual: Aplicación del Simulador BWINPro7. Madera y bosques 16,81-104. URL: http://www.scielo.org. $m x /$ scielo.php?script= sci\{_\}arttext $\{\mathcal{E}\}$ pid=S1405-04712010000400006.

Vargas-Larreta, B., Corral-Rivas, J.J., Aguirre-Calderon, O.A., Lopez-Martinez, J.O., De los Santos-Posadas, H.M., Zamudio-Sanchez, F.J., Trevino-Garza, E.J., Martinez-Salvador, M., Aguirre-Calderon, C.G., 2017. SiBiFor: Forest Biometric System for forest management in Mexico. Revista Chapingo Serie Ciencias Forestales y del Ambiente 23, 437-455. doi:10.5154/r.rchscfa.2017.06.040.

Vela-Gálvez, L., 1980. Pinus patula, una importante especie Mexicana de pino. Ciencia Forestal, Revista del instituto nacional de investigaciones forestales 1 , 12-20. URL: www.inifap.gob.mx/Documents/revistas/rmcf/CF01.pdf.

Velázquez, M.A., Ángeles, P., Llanderal, O., Román, J., Reyes, H., 2004. Monografía de Pinus patula. Technical Report. CONAFOR/Colegio de Postgraduados. Mexico.

Weiskittel, A.R., Hann, D.W., Kershaw, J.A., Vanclay, J.K., 2011. Forest Growth and Yield Modeling. John Wiley and Sons, Chichester, UK. URL: http://doi. wiley.com/10.1002/9781119998518, doi:10.1002/9781119998518.

Wykoff, W.R., Crookston, N.L., Stage, A.R., 1982. User's Guide to the Stand Prognosis Model. Technical Report. URL: https://www.fs.usda.gov/treesearch/ pubs/7510, doi:10.2737/INT-GTR-133. 


\section{Chapter 3}

\section{Generalized Height-Diameter Models with Random Effects for Natural Forests of Central Mexico}

Ernesto Alonso Rubio-Camacho ${ }^{1,4}$, Sacramento Corral-Rivas ${ }^{2}$, Juan Antonio López-Hernández ${ }^{3}$, and Jürgen Nagel $^{1}$

\section{Author details}

${ }^{1}$ Department Ecoinformatics, Biometrics \& Forest Growth, Georg-August University of Göttingen. Busgenweg 4, 37077 Gottingen, Germany.

${ }^{2}$ Instituto Tecnológico de El Salto. Calle Tecnológico 101, Col. La Forestal, C.P. 34946. El Salto, P.N., Durango, México.

${ }^{3}$ Facultad de Ciencias Forestales, Universidad Autónoma de Nuevo León. Carretera Nacional 85, Km. 145, 67700 Linares, Mexico.

${ }^{4}$ INIFAP-CIRPAC C.E. Centro Altos: Av. Biodiversidad núm. 2470, Col. Las Cruces, Tepatitlán, Jalisco, México. CP. 47600.

\section{Authors contributions}

EARC designed the study, conducted the data analysis and wrote the manuscript; SCR reviewed and partially wrote the manuscript, reviewed and approved the data analysis; JALH coordinated the field data collection and prepared the database; JN supervised the project and approved the final version.

\section{Status}

The manuscript is being prepared for submission to a scientific journal. 


\title{
Generalized Height-Diameter Models with Random Effects for Natural Forests of Central Mexico
}

\begin{abstract}
Tree height is an important variable in forestry, it is commonly used to estimate volume, biomass, and to evaluate site productivity. In this study, we developed four generalized equations to model the tree height-diameter $(h-d)$ relationships for coniferous and broadleaf species. For this purpose, we used information from 49 permanent sampling plots located in natural forests of northwestern Puebla, Mexico. Non-linear fixed and mixed-effects modeling approach were used to fit generalized versions of the Gompertz function to Pinus patula and Pinus group; Näslund function to Abies religiosa; and Curtis function to Quercus group. Results showed a $R^{2}=0.91$ and RMSE $=2.04$ for $P$. patula and $R^{2}=0.91$, RMSE $=1.63$ for Pinus group. The $R^{2}$ and a RMSE for Abies religiosa were 0.88 and 2.21, while for Quercus group these values were 0.72 and 1.9 respectively. From the mixed-effects models calibration, it was concluded that only a sub-sample of three trees is required to make accurate predictions. The accuracy of the mixed-effects models was evaluated by estimating the RMSE through cross-validation. The proposed models represent a tool for sustainable forest management of natural forests in the study area.
\end{abstract}

\subsection{Introduction}

The tree height $(h)$ is an important element in forestry and it is used to characterize forest structure, to estimate volume, biomass, and to assess site quality (Burkhart and Tomé, 2012; van Laar and Akça, 2007). However, tree height measurement often requires more time and effort with respect to tree diameter. In addition, tree height is prone to measurement errors as it requires to observe the top of the tree to make precise estimates of total height (Prodan et al., 1997), which is often complicated in closed canopy conditions, with broken trees, and in complex topographic positions (Vanclay, 1994). Nonetheless, there are tools, such as the allometric tree $h$ - $d$ models that can be used to estimate tree height instead of direct measurements (Calama and Montero, 2004; Mehtätalo et al., 2015).

Several functions, both linear and nonlinear, have been used to fit allometric tree $h$ - $d$ relationships, a compilation of which can be found in Mehtätalo et al. 
(2015) and Ogana et al. (2020). Functions that only include tree diameter as predictor variable are known as local models, and can be applied to accurately predict tree height, but they are not inherently useful in all forest conditions (Corral-Rivas et al., 2019; van Laar and Akça, 2007). Therefore, a possible solution is to generalize local models by including stand variables that account for tree density or site quality (López et al., 2012; Hernández-Ramos et al., 2015). In addition, generalized models are often necessary in forest growth simulators (Hansen and Nagel, 2014) and for imputation of missing tree heights in large databases (Mehtätalo et al., 2015).

In general, tree height is collected in sample plots, which generate hierarchically structured data. This structure, often leads to a lack of independence among observations, thus violating the assumptions of ordinary least squares (OLS) traditionally used in forestry (Fox et al., 2001; Gillespie, 1992). Mixed-effects modeling approximation accounts for hierarchical structures (López et al., 2012) by modeling the variability between plots (Caballero-Deloya, 1998; Castedo Dorado et al., 2006). In addition, mixed-effects models can be calibrated (also known as localized) for tree height prediction on new plots when at least one additional tree height measurement is available, which simplifies their use and application in forestry (Corral-Rivas et al., 2019).

In Mexico, mixed-effects models for predicting tree height have been scarcely applied, some studies have been developed in the state of Durango (VargasLarreta et al., 2009; Corral-Rivas et al., 2019). However, for central Mexico, most research studies do not include random effects (Guerra-De la Cruz et al., 2019). Therefore, deploying tree $h-d$ models that account for hierarchical data structure, i.e. random effects, would contribute to the Mexican forest science by providing a new management tool for economically and ecologically important species in central Mexico.

The aim of this study was to develop four generalized tree $h$ - $d$ mixed-effects models for Pinus patula Schiede ex Schltdl. \& Cham. and other major species of pure and mixed stands in northwestern Puebla, Mexico. The specific objectives were: (i) to test several local models from the literature and select the best fitted per species or genera (four in total); (ii) to generalize the best local models by including stand-level predictor variables; (iii) to test different combinations of 
parameters to expand with random effects at plot level; (iv) to calibrate and validate the generalized mixed-effects models; and (vi) to evaluate the number of trees used in the calibration.

The developed models can be used for: i) imputation of missing heights in forest inventory databases; ii) tree height prediction in the same plots used in the fitting process, particularly useful in remeasurement forest inventory data; and iii) tree height prediction on new plots using calibration methods.

\subsection{Materials and Methods}

\subsubsection{Study area}

This study was carried out in natural forests of northwestern Puebla, Mexico, located in the "Eje Neovolcanico Transversal" geographical province. The selected forests stands are part of the Forest Management Unit 2108 (UMF2108) "Zacatlán" located at the extreme coordinates of longitude $\left[-98.06963^{\circ} ;-98.49796^{\circ}\right]$ and latitude $\left[19.68858^{\circ} ; 19.94516^{\circ}\right.$. In this section of Puebla, the climate is mostly temperate sub-humid $\left[12-18^{\circ} \mathrm{C}\right]$ with rains in summer (INEGI, 2008). The natural forests are mainly represented by associations of Pinus patula, Pinus teocote Schltdl. \& Cham, Pinus ayacahuite, P. pseudostrobus Lindl., Abies religiosa (Kunth) Schltdl. \& Cham., and Quercus laurina Humb et Bonpl.

\subsubsection{Data}

The database used in this study comes from 49 permanent sampling plots (30x30 $\mathrm{m})$, established in 2008 under a stratified random sampling design and remeasured in 2012. In these plots, each tree with diameter at breast height $(1.3 \mathrm{~m})$ equal to or greater than $7.5 \mathrm{~cm}$ was measured and collected data on species, diameter at $1.3 \mathrm{~m}(d, \mathrm{~cm})$, and total tree height $(h, \mathrm{~m})$. With these data, we estimated the number of trees per hectare $\left(N h a^{-1}\right)$, the basal area per hectare $\left(G h a^{-1}\right)$, the mean square diameter $(d g ; \mathrm{cm})$, the dominant tree height, as the average of the 100 highest trees per hectare $\left(H_{0}, \mathrm{~m}\right)$, and its corresponding dominant tree diameter $\left(D_{0}, \mathrm{~cm}\right)$ (Assmann, 1970). 
The species composition in the database is $81 \%$ for Pinus (P. ayacahuite Ehrenb., P. montezumae Lamb., P. patula, P. pseudostrobus, and P. teocote), 7\% for Quercus (Q. rugosa Née and Q. laurina) and 11\% for Abies religiosa. Table 3.1 summarizes the descriptive statistics of the database. As some species have few observations, the $h$ - $d$ models were grouped and fitted as follows; (i) P. patula, (ii) Pinus group ( $P$. ayacahuite, P. montezumae, P. pseudostrobus, and P. teocote), (iii) Abies religiosa and, (iv) Quercus group (Q. rugosa and Q. laurina).

Table 3.1: Descriptive statistics of the database by group and stand. Where $d=$ mean tree diameter in $\mathrm{cm}, h=$ mean tree height in $\mathrm{m}, N=$ number of trees per hectare (Nha $\left.{ }^{-} 1\right), G=$ basal area per hectare in $\mathrm{m}^{2}, d g=$ quadratic mean diameter in $\mathrm{cm}, H_{o}=$ dominant tree height in $\mathrm{m}, D_{o}=$ dominant tree diameter in $\mathrm{cm}$.

\begin{tabular}{lrrrrr}
\hline & Obs. & min & max & mean & standard deviation \\
\hline Pinus patula & & & & & \\
\hline$d(\mathrm{~cm})$ & \multirow{2}{*}{1594} & 7.5 & 78.5 & 26.6 & 13.6 \\
$h(\mathrm{~m})$ & 5.44 & 39 & 19.9 & 6.7 \\
\hline Pinus & & & & & 8.3 \\
\hline$d(\mathrm{~cm})$ & \multirow{2}{*}{625} & 7.5 & 67.6 & 17.6 & 5.5 \\
$h(\mathrm{~m})$ & 4.75 & 33.5 & 11.8 & \\
\hline Abies religiosa & & & & & 13.4 \\
\hline$d(\mathrm{~cm})$ & \multirow{2}{*}{302} & 7.5 & 81.6 & 23.6 & 6.3 \\
$h(\mathrm{~m})$ & 5.25 & 40.25 & 18.9 & 4.8 \\
\hline Quercus & & & & & 3.6 \\
\hline$d(\mathrm{~cm})$ & \multirow{2}{*}{204} & 7.5 & 33.4 & 15.0 & 571 \\
$h(\mathrm{~m})$ & 2.9 & 22.5 & 9.9 & 7.6 \\
\hline Stand & & & & & 7.5 \\
\hline N & & 200 & 2311 & 981 & 13.3 \\
G & 10.9 & 84.3 & 43.7 & \\
$d g$ & 2725 & 13.7 & 52.4 & 26.3 & \\
$H_{0}$ & & 8.2 & 38.3 & 24.4 & \\
$D_{0}$ & & 16.9 & 66.7 & 36.5 & \\
\hline
\end{tabular}

\subsubsection{Model development}

The tree $h-d$ modeling process was divided into three steps: the first step was the fixed-effects generalized model development, where we fitted the six local models from Table 3.2 and selected the best model per group (Figure 3.1). Then, we generalized the best local models by testing different combinations of stand variables on Table 3.1 with different transformations (logarithm and square root), 
in order to improve the model fit.

The second step was the mixed-effects generalized models fitting. Once we had the seven generalized models per group, six from the literature (Table 3.2, generalized models) and the generalized model per group developed in the first step, in the second step we tested different combinations of parameters to expand with random effects on each of the seven generalized models per group, i.e. fit the mixed-effects model. At the end we ranked the mixed effects generalized models in order to select the one that better describes the $h$ - $d$ relationship per group.

The third step comprised the mixed-effects generalized models calibration and validation. On the one hand, mixed-effects models calibration (known as well as localization) involved the prediction of random effects on new plots. For this purpose, it is necessary to take a subsample from the new plot to properly calibrate the model. In this study, we used the cross-validation technique to calibrate and validate the models simultaneously. These three processes are further in detail described.

\section{Tree height-diameter functions}

To select the models that better explain the $h-d$ relationship per group (P. patula, $A$. religiosa, Pinus, and Quercus groups) we tested 12 non-linear functions frequently used in forestry (López et al., 2012; Corral-Rivas et al., 2014; Hernández-Ramos et al., 2015; Ogana et al., 2020)(Table 3.2). While the 6 local models were fitted using the ordinary nonlinear least squares (ONLS) method with the function 'nls' of R (R Core Team, 2019), the other 6 generalized models were fitted using only the mixed-effects modeling approximation.

\section{Mixed-effects modeling approach}

Mixed-effects models can incorporate variables as fixed and random. In tree $h-d$ modeling, while fixed effects are common to all trees and plots, random effects are specific to each plot, or to any other predefined grouping factor (Pinheiro and Bates, 2000; Mehtätalo et al., 2015). In this study, we used the mixed-effects modeling approach to account for tree height variation within and between plots, incorporating the random effect at plot level. We also used this approach 

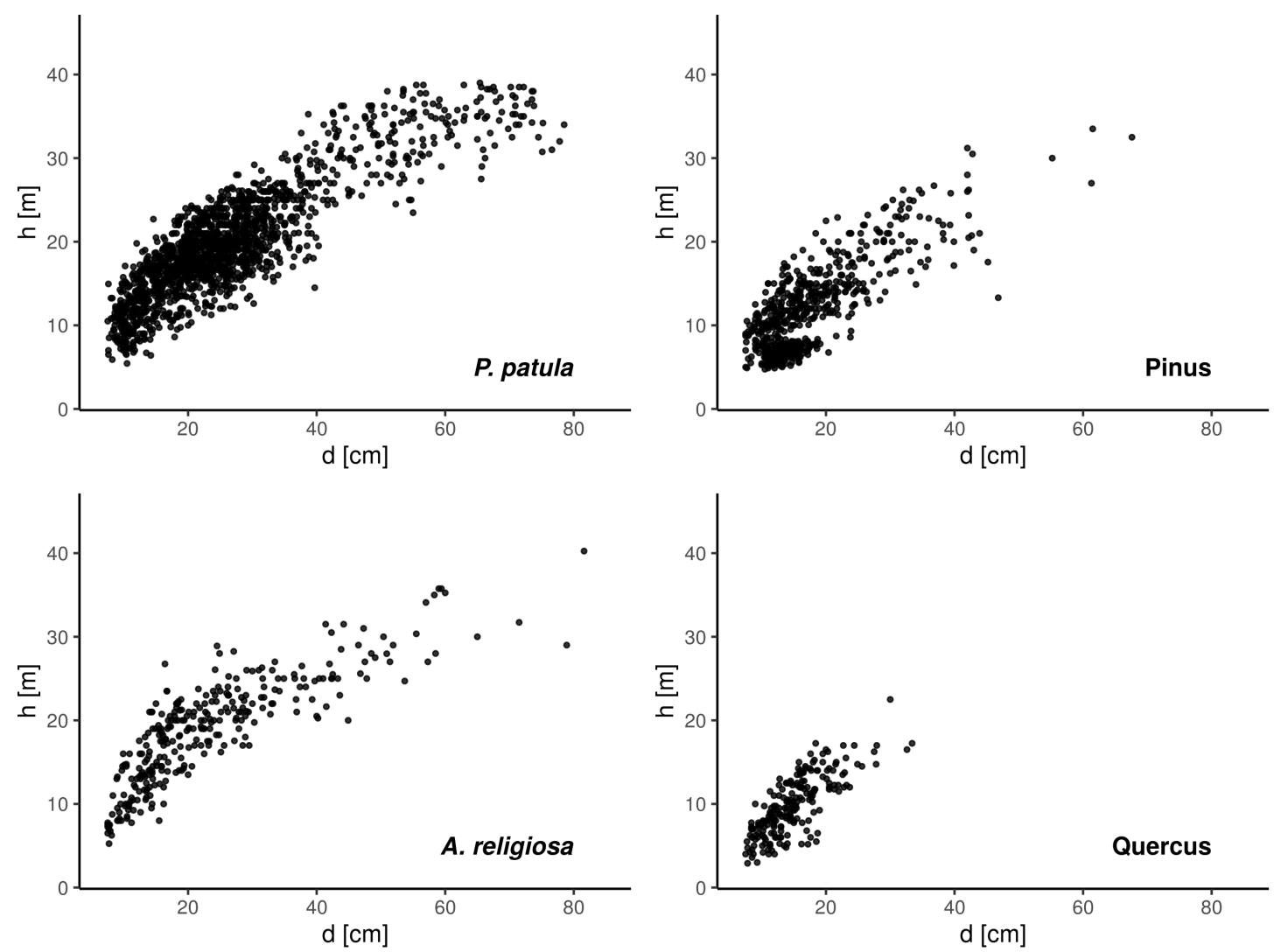

Figure 3.1: Tree height-diameter data used to fit the non-linear fixed and mixed-effects models.

to overcome the lack of independence between observations (Castedo Dorado et al., 2006; Corral-Rivas et al., 2019). According to Pinheiro and Bates (2000) a mixed-effects model can be defined as follows:

$$
y_{i j}=f\left(\beta_{i}, x_{i j}\right)+e_{i j}
$$

Where: $y_{i j}=$ the $j$-th height (tree) taken at the $i$-th plot, $x_{i j}=$ the $j$-th measurement of the predictor variable taken from the $i$-th plot, $\beta_{i}=$ parameter vector $r \times 1(r$ is the total number of parameters in the model) specific for each plot, $f=$ nonlinear function, $e_{i j}=$ error term.

The parameter vector $\beta_{i}$ can be divided into a fixed part, common to whole the population, and random components, specific to each sampling plot with the form: $\beta_{i}=\mathbf{A}_{i} \lambda+\mathbf{B}_{i} \mathbf{b}_{i}+\mathbf{e}_{i}$, where $\lambda$ is the vector $p \times 1$ of the fixed parameters, $(p$ is the number of fixed parameters); $\mathbf{b}_{i}$ is the vector $q \times 1$ of the random parameters 
Table 3.2: Tree $h-d$ equations analyzed in this study. Where $h=$ total height $(\mathrm{m}) ; d=$ tree diameter $(\mathrm{cm}) ; H_{0}=$ dominant tree height $(\mathrm{m}) ; D_{0}=$ dominant tree diameter $(\mathrm{cm}) ; N=$ number of trees per hectare; $G=$ basal area per hectare $\left(m^{2} h a^{-1}\right) ; d_{g}=$ quadratic mean diameter $(\mathrm{cm}) ; h_{g}=$ height corresponding quadratic mean diameter $(\mathrm{m}) ; \beta_{i}=$ model parameters.

\begin{tabular}{|c|c|c|}
\hline Local equations & Expression & No. \\
\hline Curtis (Curtis, 1967) & $h=1.3+\frac{\beta_{0} \cdot d}{(1+d)^{\beta_{1}}}$ & (1) \\
\hline $\begin{array}{l}\text { Schumacher (Mehtätalo et al., } \\
\text { 2015) }\end{array}$ & $h=1.3+\beta_{0} \cdot \exp \left(-\beta_{1} \cdot d^{-1}\right)$ & (2) \\
\hline Näslund (Näslund, 1936) & $h=1.3+\frac{d^{2}}{\left(\beta_{0}+\beta_{1} \cdot d\right)^{2}}$ & (3) \\
\hline $\begin{array}{l}\text { Chapman-Richards (Richards, } \\
\text { 1959) }\end{array}$ & $h=1.3+\beta_{0} \cdot\left(1-\exp \left(-\beta_{1} \cdot d\right)\right)^{\beta_{2}}$ & (4) \\
\hline Gompertz (Gompertz, 1825) & $h=1.3+\beta_{0} \cdot \exp \left(-\beta_{1} \cdot \exp \left(-\beta_{2} \cdot d\right)\right)$ & (5) \\
\hline Weibull (Weibull, 1951) & $h=1.3+\beta_{0} \cdot\left(1-\exp \left(-\beta_{1} \cdot d^{\beta_{2}}\right)\right)$ & (6) \\
\hline \multicolumn{3}{|l|}{ Generalized equations } \\
\hline Nagel (Nagel, 1999) & $h=1.3+(h g-1.3) \cdot \exp \left(\beta_{0} \cdot\left(1.0-\left(\frac{\mathrm{dg}}{d}\right)\right)\right) \cdot \exp \left(\beta_{1} \cdot\left(\left(\frac{1}{\mathrm{dg}}\right)-\left(\frac{1}{d}\right)\right)\right)$ & (7) \\
\hline Schröder and Álvarez (2001) & $h=1.3+\left(\beta_{0}+\beta_{1} \cdot H_{0}-\beta_{2} \cdot d g\right) \cdot \exp \left(\frac{-\beta_{3}}{\sqrt{d}}\right)$ & (8) \\
\hline Schröder and Álvarez (2001) & $h=1.3+\left(\beta_{0}+\beta_{1} \cdot H_{0}-\beta_{2} \cdot d g+\beta_{3} \cdot G\right) \cdot \exp \left(\frac{-\beta_{4}}{\sqrt{d}}\right)$ & (9) \\
\hline Ogana et al. (2020) & $h=1.3+\left(\frac{\frac{d^{\beta_{2}}}{\exp \left(-\beta_{4}\right)}}{\log \left(H_{0}\right)} \cdot \frac{\beta_{1}+d^{3}}{\beta_{2}}\right) \cdot \exp \left(\frac{-\beta_{3}}{\sqrt{\left(\frac{N}{\mathrm{dg}}\right)}}\right)$ & $(10)$ \\
\hline Corral-Rivas et al. (2019) & $h=1.3+\beta_{0} \cdot \log \left(H_{0}\right)^{\beta_{1}} \cdot\left(1-\exp \left(-\beta_{2} \cdot d\right)\right)^{\beta_{3}} \cdot\left(\frac{N}{G}\right)^{\beta_{4}}$ & (11) \\
\hline Sharma et al. (2016) & $h=1.3+\beta_{0} \cdot H_{0}^{\beta_{1}} \cdot\left(1-\exp \left(-\beta_{2} \cdot \mathrm{dg}^{\beta_{3}} \cdot d\right)\right)^{\beta_{4}}$ & (12) \\
\hline
\end{tabular}

associated with the $i$-th plot ( $q$ is the number of random parameters), A and $\mathbf{B}$ are design matrices of size $r \times p$ and $r \times q$ for the fixed and random effects specific to the $i$-th plot, respectively. The basic theoretical assumptions of nonlinear mixed-effects models assume that the vector of residuals $\left(\mathbf{e}_{i}\right)$ and the vector of the random effect $\left(\mathbf{b}_{i}\right)$ have a normal distribution with mean equal to zero and a variance-covariance matrix $\left(R_{i}\right.$ and $\left.D\right)$ representing the variability among the different sampling plots (Lindstrom and Bates, 1990; Littell et al., 2006). 
To carry out the parameter estimation, the nonlinear models were linearized using the first-order Taylor expansion around the random effects (Pinheiro and Bates, 2000). The first-order conditional expectation (FOCE) approximation was used as the expansion method based on Lindstrom and Bates (1990). In the fitting process we chose the restricted maximum likelihood method (REML) to obtain the model parameters with the nlme package of $R$ (R Core Team, 2019).

\section{Calibration of the mixed-effects model}

In forestry, the application of an already fitted mixed-effects model to a new plot is usually done by a method called calibration or localization (Hall and Bailey, 2001). In this study, the calibration involved the use of at least one tree height measurement from the new plot to predict the random effects. We used the FOCE method in the calibration procedure, where the value of the vector of random parameters $b_{j}$, associated with the sampling plot, can be estimated through the following equation (Vonesh and Chinchilli, 1997):

$$
\hat{\boldsymbol{b}} \approx \hat{\mathbf{D}} \hat{\mathbf{Z}}_{i}^{T}\left(\hat{\mathbf{R}}_{i}+\hat{\mathbf{Z}}_{i} \hat{\mathbf{D}} \hat{\mathbf{Z}}_{i}^{T}\right)^{-1} \hat{\boldsymbol{e}}_{\boldsymbol{i}}
$$

Where: $\hat{\mathbf{D}}=$ variance-covariance matrix $q \times q$ associated with the random parameters, ( $q$ is the number of random parameters included in the model) common to all plots. $\hat{\mathbf{R}}_{i}=$ variance-covariance matrix $m_{j} \times m_{j}$ of the model error term, $\hat{\boldsymbol{e}}_{i}$ = vector of residuals $m \times 1$, whose components are obtained by the difference between the observed height of each tree and the predicted value using the model with only the fixed parameters. $\mathbf{Z}_{i}=$ matrix $m \times q$ of the partial derivatives of the random parameters evaluated in $\hat{\boldsymbol{b}}_{i}=0$.

\section{Model assessment}

The best models were selected based on model accuracy and parsimony. While the former was evaluated using the root mean squared error (RMSE) and the coefficient of determination $R_{a d j}^{2}$, parsimony was evaluated through the Akaike and Schwarz Bayesian information criteria, AIC and BIC respectively (Schwarz, 1978), which are expressed as follows: 


$$
\begin{gathered}
\mathrm{RMSE}=\sqrt{\frac{\sum_{i=1}^{n}\left(y_{i}-\hat{y}_{i}\right)^{2}}{n-p}} \\
R^{2}=1-\frac{(n-1) \sum_{i=1}^{n}\left(y_{i}-\hat{y}_{i}\right)^{2}}{(n-p) \sum_{i=1}^{n}\left(y_{i}-\bar{y}\right)^{2}} \\
\mathrm{AIC}=n \ln \left(\frac{\mathrm{SSR}}{n}\right)+2 p \\
\mathrm{BIC}=n \ln \left(\frac{\mathrm{SSR}}{n}\right)+p \ln (n)
\end{gathered}
$$

Where: $y_{i}=$ observed values, $y_{i}=$ predicted values, $y_{i}=$ average, $n=$ total number of observations, $p=$ number of parameters of the equation, $S S R=$ sum of the squares of the residuals, $\ln =$ natural logarithm.

\section{Number of trees for calibration}

In order to evaluate the number of trees in the calibration process we followed a similar approach to Ogana et al. (2020) and Corral-Rivas et al. (2019), i.e. we tested different subsample combinations based on the diameter distribution. In this regard, we selected different sample trees per plot under the following combinations: three sample trees $\mathbf{Q}_{[1 ; 2 ; 3]}=$ taking a subsample of the three nearest trees to the $0.25,0.50$, and 0.75 quantiles of the diameter distribution. The remaining subsample categories include the $\mathbf{Q}_{[1 ; 2]}$, $\mathbf{Q}_{[1 ; 3]}, \mathbf{Q}_{[2 ; 3]}, \mathbf{Q}_{[2]}$, and the three trees nearest to the $d_{g}$, the smallest ${ }_{[\min ]}$, and largest ${ }_{[\max ]}$ diameter respectively.

The calibration was evaluated by estimating the amount of RMSE and $R_{a d j}^{2}$ reduction given by the different calibration options. Then, we compared the calibration options with the ONLS models (no random effects) and the NLME when all trees in the sampling plot are considered to estimate the random parameters. Using this approach, we will be able to evaluate the number of trees using different calibration options, this process could also be combined with the model validation step.

\section{Validation of the mixed-effects model}

Validation is an important step in forest modeling and consists of making predictions on new data other than those used in the fitting process. In mixed-effects modeling approach, validation and calibration can be performed in separate steps, i.e. estimating random effects on the new plot using the FOCE method and predicting tree heights of 
the new trees not used in the calibration. The ideal case is to use large databases and divide them into two parts, then use one part to build the model and the other part to validate it. However, when the bases are relatively small, the cross-validation technique is often used (Hastie et al., 2009).

In this study we used the leave-one-out cross-validation to evaluate the models. For this purpose, we used a for loop in R that follows the next steps: step 1) take out the plot number one and fit the mixed-effects model using the remaining plots, step 2) take a subsample from plot one and estimate the random effects using the equation (13), step 3) use the predicted random effects along with the fixed effects from step 1 and make tree height predictions on the remaining trees, step 5) repeat the process with the plot number two and continue with the remaining plots until the whole database has all tree heights predicted, and step 6) with the observed and predicted tree heights calculate the RMSE.

Overall, it would be possible to use the results to rank the model based on the RMSE cross-validated. In the end, by using the cross-validation approximation we expect to confirm that the outputs of our models are acceptable.

\subsection{Results}

Overall, the results showed that the proposed generalized models have better prediction capabilities than those from the literature. With respect to the local functions, in general, while the models with three parameters showed a better fit for P. patula and Pinus group, the opposite was the case for A. religiosa and Quercus group where the 2-parameter models showed better fit. Regarding the generalization process, a noteworthy result was that the stand variables selected do not require additional measurements but tree diameter, which makes this models easier to apply. Concerning the random effects calibration, the number of sub-sample trees recommended in this study are three in different combinations. Further details on results are given in the next sections.

\subsubsection{Local fixed-effects models}

Comparison of all six fixed-effects models (models 1 to 6 from Table 3.2) showed different degrees of accuracy depending on the group and the number of parameters in the model. In general, for the P. patula and Pinus group, 3-parameter models (4 to 6) showed lower RMSE and AIC compared to the 2-parameter models (1 to 3). On the contrary, 
for A. religiosa and Quercus group, the 2-parameter models were best fitted to the data (Table 3.3).

Based on the results of Table 3.3, different models were selected for further analysis. In the specific case, while the Gomperz model (5) was selected for P. patula and Pinus group, for A. religiosa and Quercus group the best models were Näslund (3) and Curtis (1) respectively. The decision was based purely on the results of the goodness-of-fit statistics (Table 3.3).

Table 3.3: Root mean square error (RMSE) and Akaike information criterion (AIC) for ONLS fixed-effects $h$ - $d$ local models.

\begin{tabular}{|c|c|c|c|c|c|c|c|c|}
\hline \multirow[b]{2}{*}{ No. } & \multicolumn{2}{|c|}{ Pinus patula } & \multicolumn{2}{|c|}{ Pinus group } & \multicolumn{2}{|c|}{ Abies religiosa } & \multicolumn{2}{|c|}{ Quercus group } \\
\hline & RMSE & AIC & RMSE & AIC & RMSE & AIC & RMSE & AIC \\
\hline (1) & 3.572 & 8585.93 & 3.325 & 3279.45 & 3.039 & 1532.36 & 2.265 & 916.43 \\
\hline (2) & 3.601 & 8611.77 & 3.338 & 3284.56 & 3.044 & 1533.45 & 2.266 & 916.75 \\
\hline (3) & 3.376 & 8406.33 & 3.244 & 3248.74 & 3.030 & 1530.57 & 2.266 & 916.73 \\
\hline (4) & 3.216 & 8252.83 & 3.233 & 3245.46 & 3.076 & 1540.78 & 2.268 & 918.07 \\
\hline (5) & 3.212 & 8248.83 & 3.212 & 3237.46 & 3.151 & 1555.29 & 2.270 & 918.35 \\
\hline (6) & 3.217 & 8253.48 & 3.231 & 3244.83 & 3.075 & 1540.60 & 2.269 & 918.22 \\
\hline
\end{tabular}

\subsubsection{Generalized mixed-effects models}

\section{Pinus patula}

For P. patula, the Gompertz model (5) was generalized by including quadratic mean diameter $\left(\log \left(d_{g}\right)\right)$, basal area per hectare $(G)$, and number of trees per hectare $(N)$. The $\log \left(d_{g}\right)$ was incorporated to $\beta_{0}$ and the $\log (G / N)$ ratio to $\beta_{1}$ parameter. Although other stand-level variables were also tested, such as mean tree height, dominant tree height $\left(H_{0}\right)$, and its corresponding dominant tree diameter $\left(D_{0}\right)$, they did not improve the model fit. With regard to random effects, even though we tried different combinations, only two parameters could be expanded with random effects $\beta_{0}$ and $\beta_{1}$. Therefore, the generalized mixed-effects model for $P$. patula was fitted through the following expression:

$$
\begin{aligned}
& h_{i j}=1.3+\left(\beta_{0}+u_{i}+\beta_{3} \cdot \log \left(d g_{i}\right)\right) \\
& \cdot \exp \left(-\left(\beta_{1}+v_{i}+\beta_{4} \cdot \log \left(\frac{G_{i}}{N_{i}}\right)\right) \cdot \exp \left(-\beta_{2} \cdot d_{i j}\right)\right)+e_{i j}
\end{aligned}
$$

Where $h_{i j}$ is the height of tree $j$ in the $i$ sample plot, $d_{i j}$ is the diameter of tree $j$ in the $i$ sample plot, $d g_{i}$ is the quadratic mean diameter for plot $i, G_{i}$ and $N_{i}$ are the basal area 
per hectare and the number of trees per hectare for plot $i, \beta_{0} \ldots \beta_{4}$ are the fixed-effects parameters, $u_{i}$ and $v_{i}$ are random effects and $e_{i j}$ is the model error.

The proposed generalized mixed-effects model (19) was compared to the generalized from the literature (models 7 to 12 from Table 3.3) and the results are shown in Table 3.4. In most cases, in the fitting process the models converged expanding two parameters with random effects, only two models (11 and 7) converged expanding just one parameter. In general, although the generalized models have only marginal differences, we selected the model (19) as the final model because it has the lowest values of RMSE, AIC, and BIC. In addition, the model (19) does not include stand-level predictors associated to tree height, i.e. in practice it does not need additional tree height measurements other than those used in the calibration procedure. Figure 3.2 shows no systematic trend in the distribution of the residuals.

Table 3.4: Parameter estimates of the generalized mixed-effects models for Pinus patula. Where $\beta_{0} \ldots \beta_{4}$ are the fixed-effects parameters, RE denotes the parameters expanded with random effects, $u_{i}$ and $v_{i}$ are random effects and GOF are the goodness-of-fit statistics.

\begin{tabular}{|c|c|c|c|c|c|c|c|}
\hline \multicolumn{8}{|c|}{$\begin{array}{c}\text { Pinus patula } \\
\text { Generalized Mixed Models }\end{array}$} \\
\hline No. & (19) & (10) & (12) & (8) & (9) & (11) & (7) \\
\hline \multicolumn{8}{|c|}{ Fixed effects } \\
\hline$\beta_{0}$ & -35.41 & -67835.57 & 0.84 & 15.95 & 17.52 & 1.93 & 0.68 \\
\hline$\beta_{1}$ & 4.68 & -1609162.04 & 1.05 & 1.65 & -0.05 & 2.25 & -4.69 \\
\hline$\beta_{2}$ & 0.06 & 0.6 & 1.32 & 0.24 & 0.21 & 0.02 & - \\
\hline$\beta_{3}$ & 18.87 & 0.62 & -0.9 & 5.11 & 1.64 & 0.74 & - \\
\hline$\beta_{4}$ & 1.01 & -6.24 & 1.36 & - & 5.12 & 0.09 & - \\
\hline \multicolumn{8}{|c|}{ Random effects } \\
\hline RE & $\beta_{0}, \beta_{1}$ & $\beta_{2}, \beta_{3}$ & $\beta_{1}, \beta_{3}$ & $\beta_{1}, \beta_{3}$ & $\beta_{4}, \beta_{3}$ & $\beta_{4}$ & $\beta_{1}$ \\
\hline$u_{i}$ & 3.724 & 0.145 & 0.018 & 0.433 & 1.542 & 0.021 & 5.51 \\
\hline$v_{i}$ & 0.471 & 2.215 & 0.068 & 1.53 & 0.429 & - & - \\
\hline \multicolumn{8}{|l|}{ GOF } \\
\hline RMSE & 2.04 & 2.06 & 2.06 & 2.06 & 2.07 & 2.29 & 2.88 \\
\hline$R_{a d j}^{2}$ & 0.91 & 0.91 & 0.91 & 0.91 & 0.91 & 0.88 & 0.82 \\
\hline AIC & 6800.74 & 6832.88 & 6836.19 & 6841.05 & 6844.42 & 7171.15 & 7896.93 \\
\hline BIC & 6832.99 & 6865.13 & 6868.44 & 6867.92 & 6876.67 & 7203.39 & 7913.06 \\
\hline
\end{tabular}

\section{Pinus group}

The generalized model for Pinus group, based on Gompertz (5), includes the quadratic mean diameter $\left(d_{g}\right)$ and the number of trees per hectare $(\log (N))$ incorporated to $\beta_{0}$ and to $\beta_{1}$ respectively. In relation to random effects, as well as for P. patula, only two 


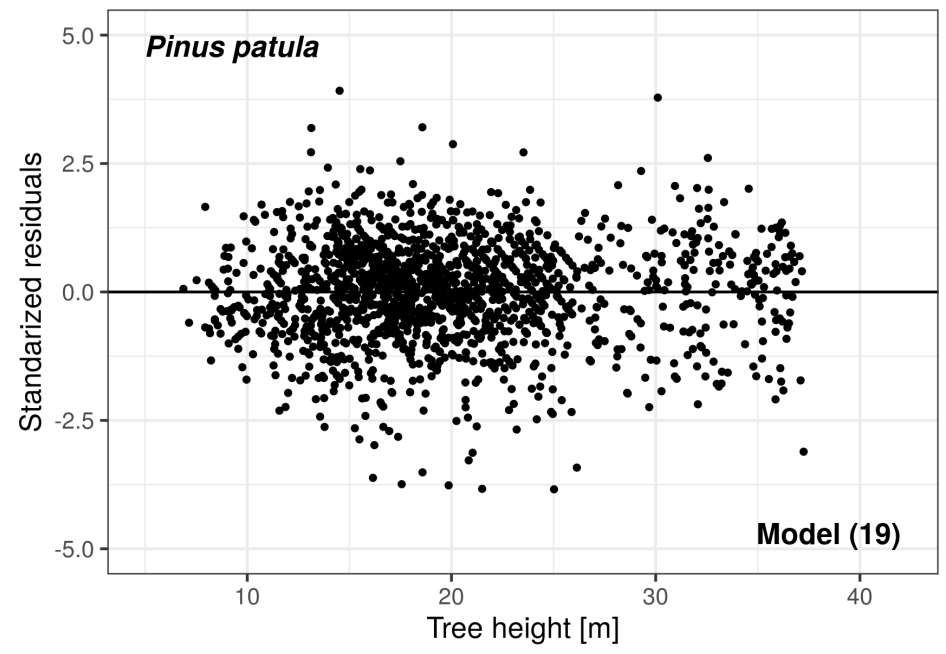

Figure 3.2: Residual plot for Pinus patula generalized mixed-effects model.

parameters could be expanded with random effects, $\beta_{0}$ and $\beta_{1}$. Thus, the generalized mixed-effects model for Pinus group was fitted through the following expression:

$$
h_{i j}=1.3+\left(\beta_{0}+u_{i}+\beta_{3} \cdot d g_{i} \cdot \exp \left(-\left(\beta_{1}+v_{i}+\beta_{4} \cdot \log \left(N_{i}\right)\right) \cdot \exp \left(-\beta_{2} \cdot d_{i j}\right)\right)+e_{i j}\right.
$$

The generalized mixed-effects model for Pinus group (20) showed the best goodness-of-fit statistics compared to the generalized models from the literature (Table 3.5). In this case, only the model (20) converged expanding two parameters with random effects, the rest of the models converged expanding just one parameter. Although the generalized models have only marginal differences with models (8) to (12), we selected the model (20) as the final model because it has the lowest values of RMSE, AIC, and BIC and does not include stand-level predictors associated to tree height. As in the case of P. patula, the regression line for Pinus group shows no evidence of heteroscedasticity in the distribution of the residuals (Figure 3.3).

\section{Abies religiosa}

The generalized model for Abies religiosa was based on the Näslund model (3). The stand-level predictors included the $\log (G / N)$ ratio associated to $\beta_{0}$ and the quadratic mean diameter $\left(d_{g}\right)$ to $\beta_{1}$. With respect to random effects, similar to the previous groups, only two parameters could be expanded with random effects, $\beta_{0}$ and $\beta_{1}$. Therefore, the generalized mixed-effects model for $A$. religiosa was fitted through the following 
Table 3.5: Parameter estimates of the generalized mixed-effects models for Pinus group. Where $\beta_{0} \ldots \beta_{4}$ are the fixed-effects parameters, RE denotes the parameters expanded with random effects, $u_{i}$ and $v_{i}$ are random effects and GOF are the goodness-of-fit statistics.

\begin{tabular}{|c|c|c|c|c|c|c|c|}
\hline \multicolumn{8}{|c|}{$\begin{array}{c}\text { Pinus group } \\
\text { Generalized Mixed Models }\end{array}$} \\
\hline No. & (20) & (9) & (12) & (10) & (8) & (11) & (7) \\
\hline \multicolumn{8}{|c|}{ Fixed effects } \\
\hline$\beta_{0}$ & -18.96 & 9.75 & 0.8 & 0.06 & 26.7 & 3.72 & 0.53 \\
\hline$\beta_{1}$ & 4.41 & -0.3 & 1.03 & -104.37 & 0.93 & 1.66 & 0.6 \\
\hline$\beta_{2}$ & 0.08 & -0.27 & 2.44 & -2.49 & 0.25 & 0.02 & - \\
\hline$\beta_{3}$ & 12.77 & 1.75 & -1.11 & 1.5 & 5.16 & 0.72 & - \\
\hline$\beta_{4}$ & 0.73 & 5.8 & 1.32 & -4.64 & - & 0.1 & - \\
\hline \multicolumn{8}{|c|}{ Random effects } \\
\hline RE & $\beta_{0}, \beta_{1}$ & $\beta_{4}$ & $\beta_{1}$ & $\beta_{2}$ & $\beta_{0}$ & $\beta_{4}$ & $\beta_{1}$ \\
\hline$u_{i}$ & 4.908 & 1.12 & 0.04 & 0.054 & 7.335 & 0.046 & 0.002 \\
\hline$v_{i}$ & 0.679 & - & - & - & - & - & - \\
\hline \multicolumn{8}{|l|}{ GOF } \\
\hline RMSE & 1.63 & 1.74 & 1.75 & 1.77 & 1.81 & 1.81 & 4.45 \\
\hline$R_{a d j}^{2}$ & 0.91 & 0.9 & 0.9 & 0.9 & 0.89 & 0.89 & 0.34 \\
\hline AIC & 2391.09 & 2475.49 & 2480.09 & 2490.97 & 2519.16 & 2524.22 & 3643.72 \\
\hline BIC & 2417.72 & 2502.12 & 2506.72 & 2517.59 & 2541.35 & 2550.84 & 3657.03 \\
\hline
\end{tabular}

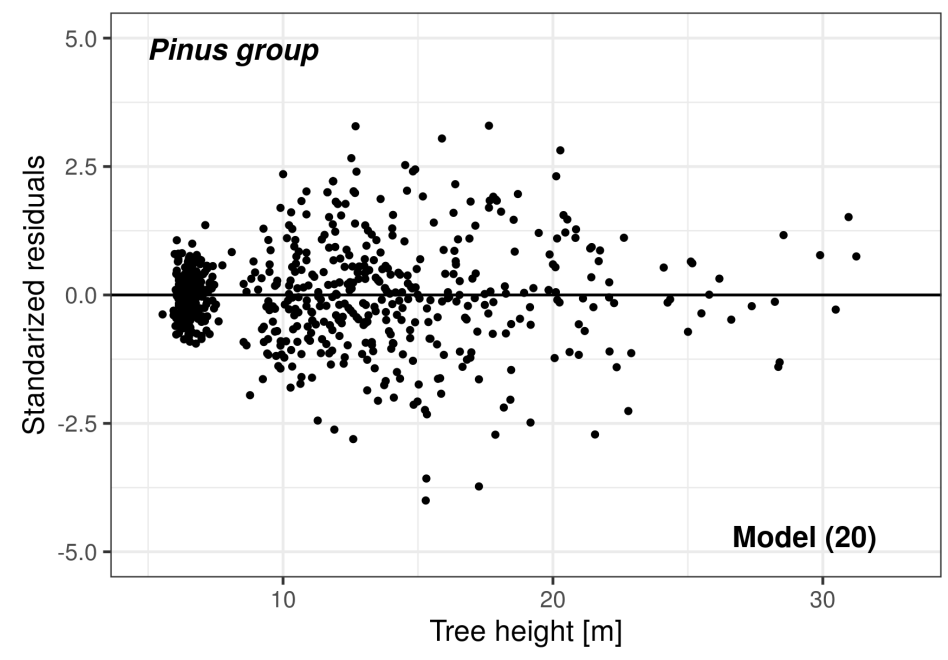

Figure 3.3: Residual plot for Pinus group generalized mixed-effects model.

expression:

$$
h_{i j}=1.3+\frac{d_{i j}^{2}}{\left(\left(\beta_{0}+u_{i}+\log \left(\frac{G_{i}}{N_{i}}\right) \cdot \beta_{2}\right)+\left(\beta_{1}+v_{i}+\log \left(d g_{i}\right) \cdot \beta_{3}\right) \cdot d_{i j}\right)^{2}}+e_{i j}
$$


In the case of $A$. religiosa, all models, but the proposed one (21), converged only expanding one parameter with random effects. Regarding the goodness-of-fit statistics the nearest model was the number (9), thus we selected the model (21) as the final model based on the results of RMSE, AIC, BIC, and the stand-level predictors. Besides, the regression line for $A$. religiosa shows no systematic trend in the distribution of the residuals (Figure 3.4).

Table 3.6: Parameter estimates of the generalized mixed-effects models for Abies religiosa. Where $\beta_{0} \ldots \beta_{4}$ are the fixed-effects parameters, RE denotes the parameters expanded with random effects, $u_{i}$ and $v_{i}$ are random effects, and GOF are the goodness-of-fit statistics.

\begin{tabular}{lrrrrrrr}
\hline \multicolumn{7}{c}{ Abies religiosa } \\
\multicolumn{7}{c}{ Generalized Mixed Models } \\
\hline No. & $\mathbf{( 2 1 )}$ & $\mathbf{( 9 )}$ & $\mathbf{( 1 0 )}$ & $\mathbf{( 8 )}$ & $\mathbf{( 1 2 )}$ & $\mathbf{( 1 1 )}$ & $\mathbf{( 7 )}$ \\
\hline Fixed effects & & & & & & & \\
\hline$\beta_{0}$ & 3.58 & 11.36 & 0.03 & 56.01 & 3.51 & 6.08 & 0.59 \\
$\beta_{1}$ & 0.32 & -0.59 & -210.22 & 0.7 & 0.62 & 1.2 & -4.53 \\
$\beta_{2}$ & 0.65 & -1.21 & -2.52 & 0.5 & 1.08 & 0.02 & - \\
$\beta_{3}$ & -0.05 & 1.29 & 2.18 & 5.79 & -0.85 & 0.82 & - \\
$\beta_{4}$ & - & 6.04 & -5.38 & - & 1.44 & 0.14 & - \\
\hline Random effects & & & & & & & \\
\hline RE & $\beta_{0}, \beta_{1}$ & $\beta_{4}$ & $\beta_{2}$ & $\beta_{0}$ & $\beta_{4}$ & $\beta_{4}$ & $\beta_{1}$ \\
$u_{i}$ & 0.438 & 1.048 & 0.032 & 3.402 & 0 & 0.019 & 2.306 \\
$v_{i}$ & 0.015 & - & - & - & - & - & - \\
\hline GOF & & & & & & & \\
\hline RMSE & 2.21 & 2.31 & 2.55 & 2.73 & 2.75 & 2.78 & 3.02 \\
$R_{a d j}^{2}$ & 0.88 & 0.87 & 0.84 & 0.82 & 0.81 & 0.81 & 0.77 \\
AIC & 1342.84 & 1369.02 & 1429.33 & 1469 & 1474.01 & 1481.36 & 1528.78 \\
BIC & 1361.4 & 1391.28 & 1451.59 & 1487.56 & 1496.27 & 1503.63 & 1539.92 \\
\hline
\end{tabular}

\section{Quercus group}

The proposed generalized model for Quercus group was based on the Curtis model (1) and only included the ratio $\sqrt{\frac{N_{i}}{G_{i}}}$ as stand-level predictor on $\beta_{0}$. In relation to random effects, only two parameters could be expanded with random effects, $\beta_{0}$ and $\beta_{1}$. Therefore, the generalized mixed-effects model for Quercus group was fitted through the following expression:

$$
h_{i j}=1.3+\frac{\left(\beta_{0}+u_{i}+\sqrt{\frac{N_{i}}{G_{i}}} \cdot \beta_{2}\right) \cdot d_{i j}}{\left(1+d_{i j}\right)^{\beta_{1}+v_{i}}}+e_{i j}
$$




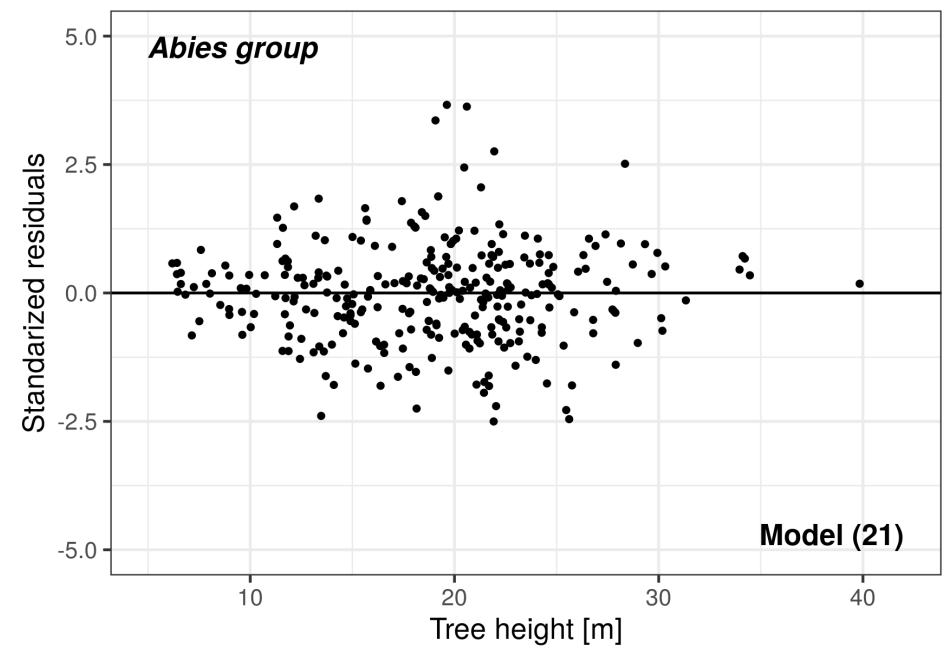

Figure 3.4: Residual plot for Abies religiosa generalized mixed-effects model.

The generalized mixed-effects model for Quercus group (22) showed the best goodnessof-fit statistics compared to the generalized models from the literature (Table 3.7). In the case of Quercus group, tree models $(22,9,10)$ converged expanding two parameters with random effects, the rest of the models converged expanding just one parameter. For Quercus group in Figure 3.5 there is no evidence of heteroscedasticity in the distribution of the residuals.

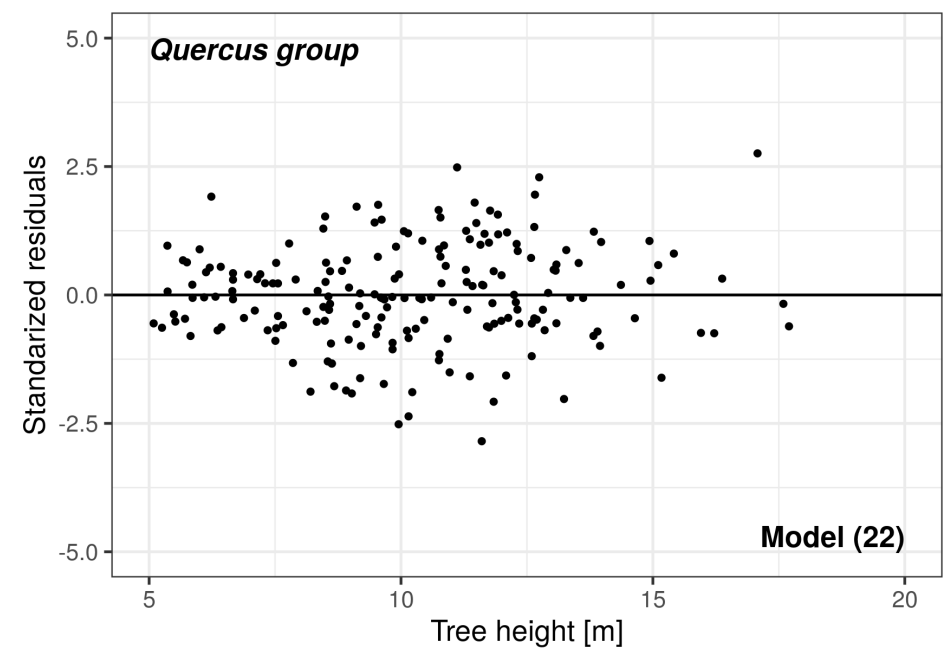

Figure 3.5: Residual plot for Quercus group generalized mixed-effects model. 
Table 3.7: Parameter estimates of the generalized mixed-effects models for Quercus group. Where $\beta_{0} \ldots \beta_{4}$ are the fixed-effects parameters, RE denotes the parameters expanded with random effects, $u_{i}$ and $v_{i}$ are random effects, and GOF are the goodness-of-fit statistics.

\begin{tabular}{lrrrrrrr}
\hline \multicolumn{7}{c}{ Quercus group } \\
\multicolumn{7}{c}{ Generalized Mixed Models } \\
\hline No. & $\mathbf{( 2 2 )}$ & $\mathbf{( 9 )}$ & $\mathbf{( 8 )}$ & $\mathbf{( 1 1 )}$ & $\mathbf{( 1 0 )}$ & $\mathbf{( 1 2 )}$ & $\mathbf{( 7 )}$ \\
\hline Fixed effects & & & & & & & \\
\hline$\beta_{0}$ & 31.53 & 24.45 & 24.32 & 0.94 & 0.11 & 1.7 & -0.21 \\
$\beta_{1}$ & 15.08 & 0.37 & 1.24 & 2.15 & -166.21 & 0.7 & 35.21 \\
$\beta_{2}$ & -2.48 & 0.83 & 0.31 & 0.07 & -2.22 & 0.17 & - \\
$\beta_{3}$ & - & 1.31 & 7.12 & 1.89 & 1.08 & -0.26 & - \\
$\beta_{4}$ & - & 7.11 & - & 0.13 & -6.13 & 1.8 & - \\
\hline Random effects & & & & & & & \\
\hline RE & $\beta_{0}, \beta_{1}$ & $\beta_{3}, \beta_{1}$ & $\beta_{0}$ & $\beta_{4}$ & $\beta_{3}, \beta_{4}$ & $\beta_{4}$ & $\beta_{1}$ \\
$u_{i}$ & 3.02030 & 0.50053 & 4.77625 & 0.02550 & 0.15165 & 0.00246 & 4.16486 \\
$v_{i}$ & 0.00017 & 0.45081 & - & - & 0.00003 & - & - \\
\hline GOF & & & & & & & \\
\hline RMSE & 1.9 & 1.91 & 1.95 & 1.98 & 1.99 & 2.08 & 2.68 \\
$R_{a d j}^{2}$ & 0.72 & 0.72 & 0.71 & 0.7 & 0.69 & 0.67 & 0.45 \\
AIC & 846.68 & 849.92 & 857.82 & 863.94 & 867.42 & 884.09 & 985.16 \\
BIC & 859.96 & 869.83 & 874.41 & 883.85 & 887.32 & 904 & 995.12 \\
\hline
\end{tabular}

\subsubsection{Calibration and validation}

Overall, the results of the evaluation of the calibration approach showed that in all cases it is better to use three trees to predict random effects. For P. patula and the Pinus group, the best option was achieved by measuring the total tree height of the three trees, 1) the tree with diameter closer the $d g, 2$ ) the smaller ( $\min d$ ), and 3) the larger tree (max d), reducing the RMSE by 25.4 and $43.6 \%$, respectively (Table 3.8). The best calibration strategy for Abies religiosa and Quercus group was achieved by measuring the total height of three trees with diameter close to the first three quantiles of the diameter distribution, the RMSE value was reduced by $14.4 \%$ and $4.2 \%$ respectively (Table 3.8 ).

\subsection{Discussion}

In this research we developed four tree $h-d$ generalized mixed-effects models for Pinus patula, Abies religiosa, Pinus and Quercus groups for pure and mixed forest stands in northwestern Puebla, Mexico. First, we tested several local fixed-effects models to select the best one per group, second, we generalized the best local model by including stand- 
Table 3.8: Comparison of the calibration alternatives applied to the selected generalized mixed-effects models. The table shows the RMSE, estimated via cross-validation, reduction using different combinations of sub-sample tree heights.

\begin{tabular}{|c|c|c|c|c|c|c|c|c|}
\hline \multirow[t]{2}{*}{ Calibration } & \multicolumn{2}{|c|}{$\begin{array}{c}\text { Pinus patula } \\
\text { Model (19) }\end{array}$} & \multicolumn{2}{|c|}{$\begin{array}{l}\text { Pinus group } \\
\text { Model (20) }\end{array}$} & \multicolumn{2}{|c|}{$\begin{array}{c}\text { Abies religiosa } \\
\text { Model (21) }\end{array}$} & \multicolumn{2}{|c|}{$\begin{array}{l}\text { Quercus group } \\
\text { Model (22) }\end{array}$} \\
\hline & RMSE & Reduction & RMSE & Reduction & RMSE & Reduction & RMSE & Reduction \\
\hline NLME & 2.038 & -36.9 & 1.632 & -57.4 & 2.213 & -34.4 & 1.904 & -13.2 \\
\hline ONLS & 3.230 & - & 3.829 & - & 3.375 & - & 2.193 & . \\
\hline$Q[1 ; 2 ; 3]$ & 2.543 & -21.3 & 2.164 & -43.5 & 2.891 & -14.4 & 2.100 & -4.2 \\
\hline $\mathrm{Q}[1 ; 2]$ & 2.643 & -18.2 & 2.525 & -34.1 & 2.895 & -14.2 & 2.239 & 2.1 \\
\hline$Q[1 ; 3]$ & 2.785 & -13.8 & 2.180 & -43.1 & 2.911 & -13.8 & 2.134 & -2.7 \\
\hline $\mathrm{Q}[2 ; 3]$ & 2.467 & -23.6 & 2.394 & -37.5 & 3.354 & -0.6 & 2.126 & -3.1 \\
\hline $\mathrm{Q}[2]$ & 2.576 & -20.3 & 2.874 & -24.9 & 3.260 & -3.4 & 2.284 & 4.1 \\
\hline$d g, d_{\min }, d_{\max }$ & 2.408 & -25.5 & 2.158 & -43.6 & 3.222 & -4.6 & 2.148 & -2.0 \\
\hline
\end{tabular}

level variables, to finally expand the generalized model parameter with random effects and compared them to generalized models from the literature. The final models were evaluated then using random effects calibration along with cross-validation.

\subsubsection{Local fixed-effects $h$ - $d$ models}

Among the six local functions evaluated (Table 3.2), the Gompertz function (Gompertz, 1825) was the most accurate for P. patula and Pinus group. The Gompertz function has a wide range of application in forest growth modeling (Burkhart and Tomé, 2012; Pödör et al., 2014). It also has been previously applied to describe the tree $h$ - $d$ relationships on natural forests in Nigeria (Ogana, 2019), for conifer species in the inland Northwest of the United States (Zhang, 1997) and to analyze how the tree $h-d$ allometry is related to climate in the United States (Hulshof et al., 2015). In our study, considering the results on goodness-of-fit and model parsimony, the Gompertz function (5) was chosen for further analysis for P. patula and Pinus group.

Näslund (Näslund, 1936) (3) and Curtis (Curtis, 1967) (1) functions were the most suitable for A. religiosa and Quercus group respectively. On the one hand, the Näslund function has been widely applied to describe tree $h$ - $d$ relationships, for example in the studies of Mehtätalo et al. (2015) and Sharma et al. (2016) it was one of the most appropriate functions for modeling the tree $h-d$ relationship on several datasets. On the other hand, the Curtis function has been tested in several studies (Mehtätalo et al., 2015; Sharma et al., 2016; Ogana, 2019). However, contrary to our case, the Curtis function usually tended to show lower goodness-of-fit compared to other tree $h$ - $d$ functions 
(Sharma et al., 2016; Ogana, 2019), particularly when compared to 3-parameter models ( $\mathrm{Ng}^{\prime}$ andwe et al., 2019). In this study, we generalized the Näslund and Curtis functions using stand-level variables for $A$. religiosa and Quercus group respectively.

\subsubsection{Tree $h-d$ model generalization}

Generalization of tree $h-d$ models is necessary to account for stand density, competition and site quality (Corral-Rivas et al., 2019; Bronisz and Mehtätalo, 2020; Prodan et al., 1997). For this purpose, it is requited to include stand-level variables such as quadratic mean diameter $(d g)$ or dominant tree height $\left(H_{0}\right)$ to $h$ - $d$ models. In the study of Nagel (1999) it was developed a generalized model using $d g$ and $h g$ as stand predictors. CorralRivas et al. (2019) included $H_{0}, G$, and $N$, while Ogana et al. (2020), Sharma et al. (2016) and Schröder and Álvarez (2001) used $H_{0}$ and $d g$ as predictor variables. On the contrary, in our study we did not include stand-level variables related to tree height, such as $H_{0}$ or $h g$, because they did not improve the model. Besides, the integration of such stand-level predictors would imply additional field work to estimate tree heights (Mehtätalo et al., 2015; Bronisz and Mehtätalo, 2020).

In this study, the stand-level predictors included in all final generalized models can be estimated through tree diameters and number of trees. A common variable in all four generalized models was the number of trees per hectare $(N)$, while $d g$ was added to $P$. patula, A. religiosa, and Pinus models, and $G$ was included in P. patula, A. religiosa, and Quercus models. Comparable studies included $d g$ and $G$ as stand-level predictor variables as these did not require additional measurements but tree diameter (Mehtätalo et al., 2015; Bronisz and Mehtätalo, 2020).

\subsubsection{Parameter expansion with random effects}

The parameter expansion procedure included the exploration of different parameter combinations. As recommended by Sharma and Parton (2007) and Mehtätalo et al. (2015) the first step was try to fit the mixed-effects model using the three parameters expanded with random effects, however, convergence was not achieved in any case, so it was decided to reduce the number and systematically combine the parameters until convergence was achieved. Other studies have pointed out convergence problems, specially in models with more than two parameters to expand (Corral-Rivas et al., 2019; Ogana et al., 2020; Mehtätalo et al., 2015). In our study, in all the proposed generalized 
models the convergence was achieved with two parameters.

\subsubsection{Random effects calibration}

In this research, we used the calibration through cross-validation to evaluate the prediction of random effects on new plots. For this purpose, it was necessary to take a sub-sample of tree heights from the new plot using an iterative approach to evaluate different calibration options (from one to three trees). In this context, some studies examined different calibration alternatives and although the results share some similarities, they also have some differences.

In the study of Corral-Rivas et al. (2019) different sub-sample options were analyzed, from one to three trees, the best calibration option was to randomly select the three closest trees to the second quantile of the diameter distribution. In the study of Ogana et al. (2020), the best strategy was to randomly select just one tree. Calama and Montero (2004) used a sub-sample of four trees. In the study of Bronisz and Mehtätalo (2020) they tested several combinations and the best strategy was to select the thinnest and thickest trees to predict random effects. Similar to our study, where the best strategy was to use the thinnest, the thickest, and the closest to the quadratic mean diameter for P. patula and Pinus group. Although, many studies have shown that only a small sub-sample of trees is necessary to make accurate predictions, the number and size of trees in the calibration is not consistent and may vary depending on the final mixed-effects model. Nonetheless, most research works agreed that the use of mixed-effects models is justified when at least one additional tree height measurement is available.

\subsection{Conclusions}

In this work we have developed four generalized mixed-effects models that describe the tree height-diameter relationship for Pinus patula, Abies religiosa, Pinus and Quercus groups. In general, the proposed models showed appropriate goodness-of-fit statistics and with no evident violations of the statistical assumptions. These generalized models do not use tree height related stand-level variables as predictors, i.e. except for the calibration trees, no extra height measurements of the new plot are needed to make accurate predictions.

Regarding the model calibration, the best option is to estimate the random effects 
by only measuring the total height of three trees in the new plot. We recommend these models for total height prediction of trees growing in natural forests of northwestern Puebla, Mexico, specifically in the Forest Management Unit (UMAFOR) 2108, Zacatlán. Nevertheless, their use can be extended to other regions where Pinus patula is naturally distributed, in which case we encourage users to first test the models by calibrating them.

We are confident that our research will serve as a base for futures studies on another species and other regions. We suggest that further research should be undertaken at national forest inventory level, because with the use of mixed-effects models for predicting tree heights or another variables (e.g. crown width, crown base height, and crown length), will reduce cost and effort by estimating heights instead of direct measurements. In addition, it will be possible to use these models for imputation of missing tree heights in large databases, such as those from the national forest inventory of Mexico. Finally, the generalized mixed-effects models developed in this study contribute to Mexican forest science by providing new tools that support sustainable forest management, specifically by reducing the cost and effort in forest inventories. 


\section{Literature}

Assmann, E., 1970. The principles of forest yield study: studies in the organic production, structure, increment and yield of forest stands. Pergamon Press, New York, NY, USA.

Bronisz, K., Mehtätalo, L., 2020. Mixed-effects generalized heightdiameter model for young silver birch stands on post-agricultural lands. Forest Ecology and Management 460, 117901. doi:10.1016/j.foreco.2020.117901.

Burkhart, H.E., Tomé, M., 2012. Modeling Forest Trees and Stands. Springer Netherlands, Dordrecht. doi:10.1007/978-90-481-3170-9.

Caballero-Deloya, M., 1998. EI Inventario Forestal de Mexico: Evolución y Perspectivas, USDA-FOREST SERVICE, Guadalajara, Jalisco, Mexico. pp. 186-189. URL: http://www.fs.fed.us/rm/pubs/rmrsi_\}p012/rmrsi_\}p012\{_\}1861_\}189.pdf.

Calama, R., Montero, G., 2004. Interregional nonlinear heightdiameter model with random coefficients for stone pine in Spain. Canadian Journal of Forest Research 34, 150-163. URL: http://www.nrcresearchpress.com/doi/10.1139/x03-199, doi:10.1139/x03-199.

Castedo Dorado, F., Diéguez-Aranda, U., Barrio Anta, M., Sánchez Rodríguez, M., von Gadow, K., 2006. A generalized height-diameter model including random components for radiata pine plantations in northwestern Spain. Forest Ecology and Management 229, 202-213. doi:10.1016/j.foreco.2006.04.028.

Corral-Rivas, S., Álvarez-González, J., Crecente-Campo, F., Corral-Rivas, J., 2014. Local and generalized height-diameter models with random parameters for mixed, uneven-aged forests in Northwestern Durango, Mexico. Forest Ecosystems 1, 6. URL: http://forestecosyst.springeropen.com/articles/10.1186/ 2197-5620-1-6, doi:10.1186/2197-5620-1-6.

Corral-Rivas, S., Silva-Antuna, A.M., Quiñonez Barraza, G., 2019. A generalized nonlinear heightdiameter model with mixed-effects for seven Pinus species in Durango, Mexico. Revista Mexicana de Ciencias Forestales 10, 86-117. URL: https://doi.org/10.29298/rmcf.v10i53.500\{\%\}0A, doi:https://doi.org/10.29298/rmcf. v10i53.500.

Curtis, R.O., 1967. Height-Diameter and Height-Diameter-Age Equations For Second-Growth Douglas-Fir. Forest Science 13, 365-375. doi:10.1093/ forestscience/13.4.365.

Fox, J.C., Ades, P.K., Bi, H., 2001. Stochastic structure and individual-tree growth models. Forest Ecology and Management 154, 261-276. doi:10.1016/ S0378-1127(00)00632-0. 
Gillespie, A.J.R., 1992. Pinus patula Schiede and Deppe. Patula pine. Pinaceae. Pine family. USDA Forest Service, Southern Forest Experiment Station, Institute of Tropical Forestry; . 5 p. (SO-ITF-SM; 54). .

Gompertz, B., 1825. On the Nature of the Function Expressive of the Law of Human Mortality, and on a New Mode of Determining the Value of Life Contingencies. Philosophical Transactions of the Royal Society of London 115, 513-583.

Guerra-De la Cruz, V., Islas-Gutiérrez, F., Flores-Ayala, E., Acosta-Mireles, M., Buendía-Rodríguez, E., Carrillo-Anzures, F., Tamarit-Urías, J.C., Pineda-Ojeda, T., 2019. Modelos locales altura-diámetro para Pinus montezumae Lamb. y Pinus teocote Schiede ex Schltdl. en Nanacamilpa, Tlaxcala. Revista Mexicana de Ciencias Forestales 10, 133-156. URL: https://doi.org/10.29298/rmcf.v10i51. 407, doi:10.29298/rmcf.v10i51.407.

Hall, D.B., Bailey, R.L., 2001. Modeling and Prediction of Forest Growth Variables Based on Multilevel Nonlinear Mixed Models. Forest Science 47, 311-321. doi:10.1093/forestscience/47.3.311.

Hansen, J., Nagel, J., 2014. Waldwachstumskundliche Softwaresysteme auf Basis von TreeGrOSS - Anwendung und theoretische Grundlagen. Universitätsverlag Göttingen, Gottingen, Germany. URL: https://www.univerlag.uni-goettingen.de/ handle/3/isbn-978-3-86395-149-8.

Hastie, T., Tibshirani, R., Friedman, J., 2009. The Elements of Statistical Learning. Springer Series in Statistics. second ed., Springer New York, New York, NY. doi:10.1007/978-0-387-84858-7.

Hernández-Ramos, J., García-Cuevas, X., Hernández-Ramos, A., García-Magaña, J.J., Muñoz-Flores, Hipólito Jesús Flores-López, C., García-Espinoza, G.G., 2015. Ecuaciones altura-diámetro generalizadas para Pinus teocote Schlecht. \& Cham. en el estado Hidalgo. Rev. Mex. Cienc. Forestales 6, 8-21. doi:doi: 10.29298/rmcf.v6i31.192.

Hulshof, C.M., Swenson, N.G., Weiser, M.D., $2015 . \quad$ Tree heightdiameter allometry across the United States. Ecology and Evolution 5, 1193-1204. URL:/pmc/articles/PMC4377263//pmc/articles/PMC4377263/?report= abstracthttps://www.ncbi.nlm.nih.gov/pmc/articles/PMC4377263/, doi:10.1002/ ece3.1328.

INEGI, 2008. Conjunto de datos vectoriales escala 1:1 000 000. Unidades climáticas. Technical Report. Instituto Nacional de Estadística y Geografía (INEGI). Aguascalientes. URL: https://www.inegi.org.mx/app/biblioteca/ficha.html? upc= 702825267568 . 
van Laar, A., Akça, A., 2007. Forest Mensuration. volume 13 of Managing Forest Ecosystems. Springer Netherlands, Dordrecht. URL: http://link.springer.com/10. 1007/978-1-4020-5991-9, doi:10.1007/978-1-4020-5991-9.

Lindstrom, M.J., Bates, D.M., 1990. Nonlinear Mixed Effects Models for Repeated Measures Data. Biometrics 46, 673. doi:10.2307/2532087.

Littell, R.C., Milliken, G.A., Stroup, W.W., Wolfinger, D.D., Schabenberger, O., 2006. SAS for mixed models. 2nd ed.: SAS Institute. SAS Institute, Cary, NC, USA.

López, S.C.A., Rodríguez, R.S., Álvarez-González, J.G., 2012. Relación alturadiámetro con parámetros aleatorios para rodales regulares de Pseudotsuga menziesii en el norte de España. Cuadernos de la Sociedad Española de Ciencias Forestales , 135-140.

Mehtätalo, L., De-Miguel, S., Gregoire, T.G., 2015. Modeling height-diameter curves for prediction. Canadian Journal of Forest Research 45, 826-837. URL: http://www.nrcresearchpress.com/doi/10.1139/cjfr-2015-0054, doi:10.1139/ cjfr-2015-0054.

Nagel, J., 1999. Konzeptionelle Uberlegungen zum schrittweisen Aufbau eines waldwachstumskundlichen Simulationssystems fur Nordwestdeutschland. Sauerlander, Göttingen.

Näslund, M., 1936. Skogsförsöksanstaltens gallringsförsök i tallskog. Technical Report. Statens skogsförsöksanstalt. Stockholm.

Ng'andwe, P., Chungu, D., Yambayamba, A.M., Chilambwe, A., 2019. Modeling the height-diameter relationship of planted Pinus kesiya in Zambia. Forest Ecology and Management 447, 1-11. doi:10.1016/j.foreco.2019.05.051.

Ogana, F.N., 2019. Tree height prediction models for two forest reserves in Nigeria using mixed-effects approach. Tropical Plant Research 6, 119-128. doi:10.22271/tpr.2019.v6.i1.017.

Ogana, F.N., Corral-Rivas, S., jose javier Gorgoso-Varela, 2020. Nonlinear mixed-effect height-diameter model for Pinus pinaster ait. and Pinus radiata d. Don. CERNE 26, 150-161. URL: https://www.scielo.br/ j/cerne/a/ySDvwBTbCnpPngdZvV7sdTR/?lang=en, doi:https://doi.org/10.1590/ 01047760202026012695.

Pinheiro, J.C., Bates, D.M., 2000. Mixed-effects models in S and S-PLUS. SpringerVerlag, New York.

Pödör, Z., Manninger, M., Jereb, L., 2014. Application of sigmoid models for growth investigations of forest trees. Advances in Intelligent Systems and Computing 282, 353-364. URL: https://link.springer.com/chapter/10.1007/ 978-3-319-06569-4\{_326, doi:10.1007/978-3-319-06569-4_26. 
Prodan, M., Peters, R., Cox, F., Real, P., 1997. Mensura forestal. Serie de investigación y educación en desarrollo sostenible, GTZ/IICA-Agroamerica, San José, Costa Rica.

R Core Team, 2019. R: A language and environment for statistical computing. R Foundation for Statistical Computing. URL: http://www.r-project.orghttps: //www.r-project.org/.

Richards, F.J., 1959. A flexible growth function for empirical use. Journal of Experimental Botany 10, 290-301. URL: https://academic.oup.com/jxb/article/10/ 2/290/528209, doi:10.1093/jxb/10.2.290.

Schröder, J., Álvarez, J.G., 2001. Comparing the performance of generalized diameter-height equations for Maritime pine in Northwestern Spain. Forstwissenschaftliches Centralblatt 120, 18-23. URL: https://link.springer.com/ article/10.1007/BF02796077, doi:10.1007/BF02796077.

Schwarz, G., 1978. Estimating the dimension of a model. The Annals of Statistics 5, 461-464. doi:https://doi.org/10.1214/aos/1176344136.

Sharma, M., Parton, J., 2007. Heightdiameter equations for boreal tree species in Ontario using a mixed-effects modeling approach. Forest Ecology and Management 249, 187-198.

Sharma, R., Vacek, Z., Vacek, S., 2016. Nonlinear mixed effect height-diameter model for mixed species forests in the central part of the Czech Republic. Journal of Forest Science 62, 470-484. URL: http://www.agriculturejournals.cz/ web/jfs.htm? volume $=62\{\mathcal{E}\}$ firstPage $=470\{\mathcal{E}\}$ type $=$ publishedArticle, doi:10.17221/ 41/2016-JFS.

Vanclay, J.K., 1994. Modelling Forest Growth and Yield: Applications to Mixed Tropical Forests. 1 ed., CABI, Wallingford, U.K.

Vargas-Larreta, B., Castedo-Dorado, F., Alvarez-Gonzalez, J.G., Barrio-Anta, M., Cruz-Cobos, F., 2009. A generalized height-diameter model with random coefficients for uneven-aged stands in El Salto, Durango (Mexico). Forestry 82, 445-462. URL: https://academic.oup.com/forestry/article-lookup/doi/10.1093/ forestry/cpp016, doi:10.1093/forestry/cpp016.

Vonesh, E.F., Chinchilli, V.M., 1997. Linear and Nonlinear Models for the Analysis of Repeated Measurements. Marcel Dekker Inc., NY, USA.

Weibull, W., 1951. A Statistical Distribution Function of Wide Applicability. Journal of Applied Mechanics 19, 293-297.

Zhang, L., 1997. Cross-validation of non-linear growth functions for modelling tree height-diameter relationships. Annals of Botany 79, 251-257. doi:10.1006/ anbo.1996.0334. 


\section{Chapter 4}

\section{ForestSimulator Mexico: Models and Software Settings for Temperate}

\section{Forests}

Ernesto Alonso Rubio-Camacho ${ }^{1,2}$ and Jürgen Nagel ${ }^{1}$

Author details

${ }^{1}$ Department Ecoinformatics, Biometrics \& Forest Growth, Georg-August University of Göttingen. Busgenweg 4, 37077 Gottingen, Germany.

${ }^{2}$ INIFAP-CIRPAC C.E. Centro Altos: Av. Biodiversidad núm. 2470, Col. Las Cruces, Tepatitlán, Jalisco, México. CP. 47600.

Authors contributions

EARC selected and added the models, wrote Java plugins, and wrote the manuscript; JN supervised the project, wrote and review Java plugins, and approved the final version.

\section{Status}

The manuscript is being prepared for submission to a technical journal. 


\section{ForestSimulator Mexico: Models and Software Set- tings for Temperate Forests}

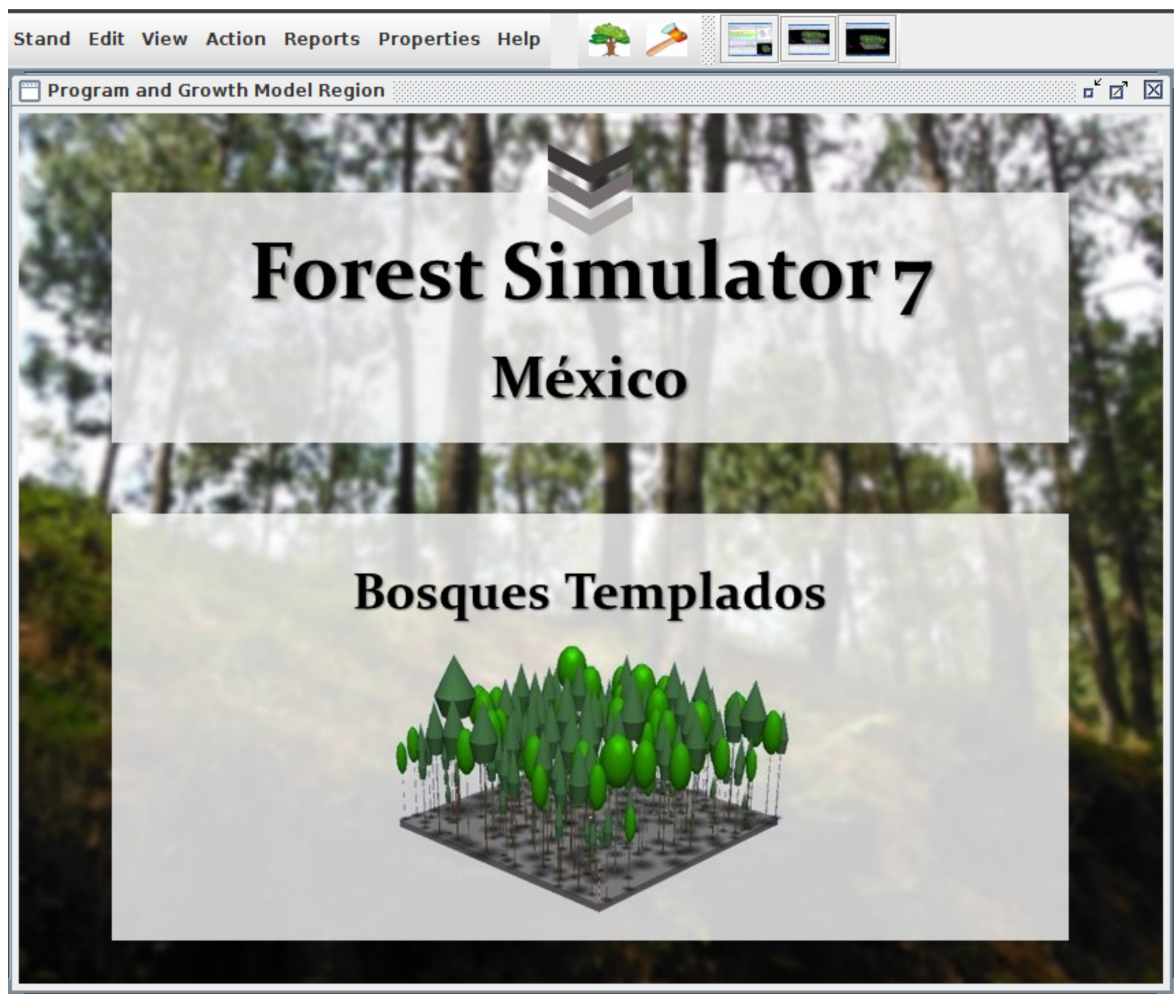

\subsection{Background}

Sustainable forest management often relies in growth models that are usually integrated in complex decision support systems (Moreno-Sánchez and TorresRojo, 2010). In Mexico, such systems have been applied in a few regions and for different purposes. SICODESI (1986), SIMBAT (1991) (Moreno-Sánchez and Torres-Rojo, 2010), and SiPlaFor (2013) (Corral-Rivas et al., 2016) are examples of such systems, designed to assist in developing forest management plans. SIPIMIF (1987) and ForestSimulator (BwinPro7 [2006]) are forest growth simulators adapted to the specific conditions of el Salto, Durango (Vargas-Larreta, 2006; VargasLarreta et al., 2010). However, although forest growth simulators are intended to be an aid for sustainable forest management, their use in Mexico is still limited, 
either because they are difficult to use or because they were designed to be applicable to specific regions.

ForestSimulator is a well-known forest growth simulator used mainly in northwestern Germany. It was developed with the intention to assist foresters in managing mixed forests (Nagel, 2003; Hansen and Nagel, 2014). Lately, ForestSimulator has been adapted to other regions, languages and species. For example, a version for some Mexican species was developed to be applicable in 'El Salto', Durango, located in northwest Mexico (Vargas-Larreta et al., 2010). However, not all conditions can be included in a single version, therefore this chapter describes the adaptation process of a new Mexican version for temperate forests.

Generally ForestSimulator is used to simulate growth in pure, mixed, even aged, and uneven forest stands. In addition, it is free and open source software. It is written in Java 8 and interacts with XML and HTML (Hansen and Nagel, 2014). This are important features because it can be freely adapted to other tree species and forest regions.

The most important task in the ForestSimulator adaptation process is to complete the parameters of the species manager. This is an XML file containing general information and instructions for the ForestSimulator. For instance, it contains aspects about the range of application, i.e., the area where this particular settings are applicable. However, when users have Java programming skills, they can also modify the internal code, thus gaining more flexibility.

The adaptation of ForestSimulator to Mexican temperate forests was carried out in three stages. First, it was necessary to select a specific region to serve as a model and gather information about forest biometric models from the literature. In this case, the Forest Management Unit 2108 was used as a case study, because it is one of the most important regions for forest production, and there was information available to complete the growth equations. The following is a list of models that ForestSimulator requires to properly run: 1) tree height-diameter uniform or generalized model; 2) diameter distribution model; 3) volume function; 4) stem volume function; 5) crown width; 6) crown base height; 7) site index; 8) index height; 9) potential height increment; 10) height increment; 11) diameter increment; 12) density; and 13) biomass functions.

The second stage was to develop the missing models required by ForestSim- 
ulator. Although there were many equations in the literature, some important ones were still missing. Therefore, a set of models were developed that included: 1) tree height-diameter generalized models; 2) diameter distribution; 5) crown width; 6) crown base height; and 11) Diameter increment models. Some of these were developed in previous chapters, and others such as Diameter distributions, Crown width and Crown base height are presented in this one.

The third stage involved the integration of the forest models into ForestSimulator. First, simpler models were included in the XML file directly, but when models had more complex structures the internal code was modified by writing plugins in Java 8. All plugins and models have to be recognized by the species manager for the simulator to work.

This section is concerned with the methodology used for adapting the ForestSimulator software to the Mexican standards. First, the study area is described; second, the ForestSimulator settings and programming steps are depicted; and third, all the biometric models are defined.

\subsubsection{Region and Tree Species}

The Forest Management Unit 2108 (UMF2108) is located at northwestern Puebla, Mexico, in the "Eje Neovolcanico Transversal" geographical province between coordinates of longitude $\left[\mathrm{min}=-98.3150^{\circ} ; \max =-97.64358^{\circ}\right]$ and latitude [min $=19.4645^{\circ} ; \max =20.10739^{\circ}$ ] (Figure 4.1$)$. This forest management unit is mainly characterized by temperate forests, including species mixtures of Pinus, Abies, and Quercus (see chapters two and three for more information).

After the study area was chosen, the most important tree species were selected to be included in ForestSimulator. These species were those that were already available in SIBIFOR for the UMF2108. SIBIFOR is the Spanish abbreviation for "Forest Biometric System for forest management in Mexico" and it contains about 6000 biometic equations, including volume, taper, and site index models (Vargas-Larreta et al., 2017). In the case of UMF2108 there are models available for the tree species listed in Table 4.1.

In this work, only volume, taper, and site index functions were taken from SIBIFOR and are applicable to all species. The rest of the models required by 


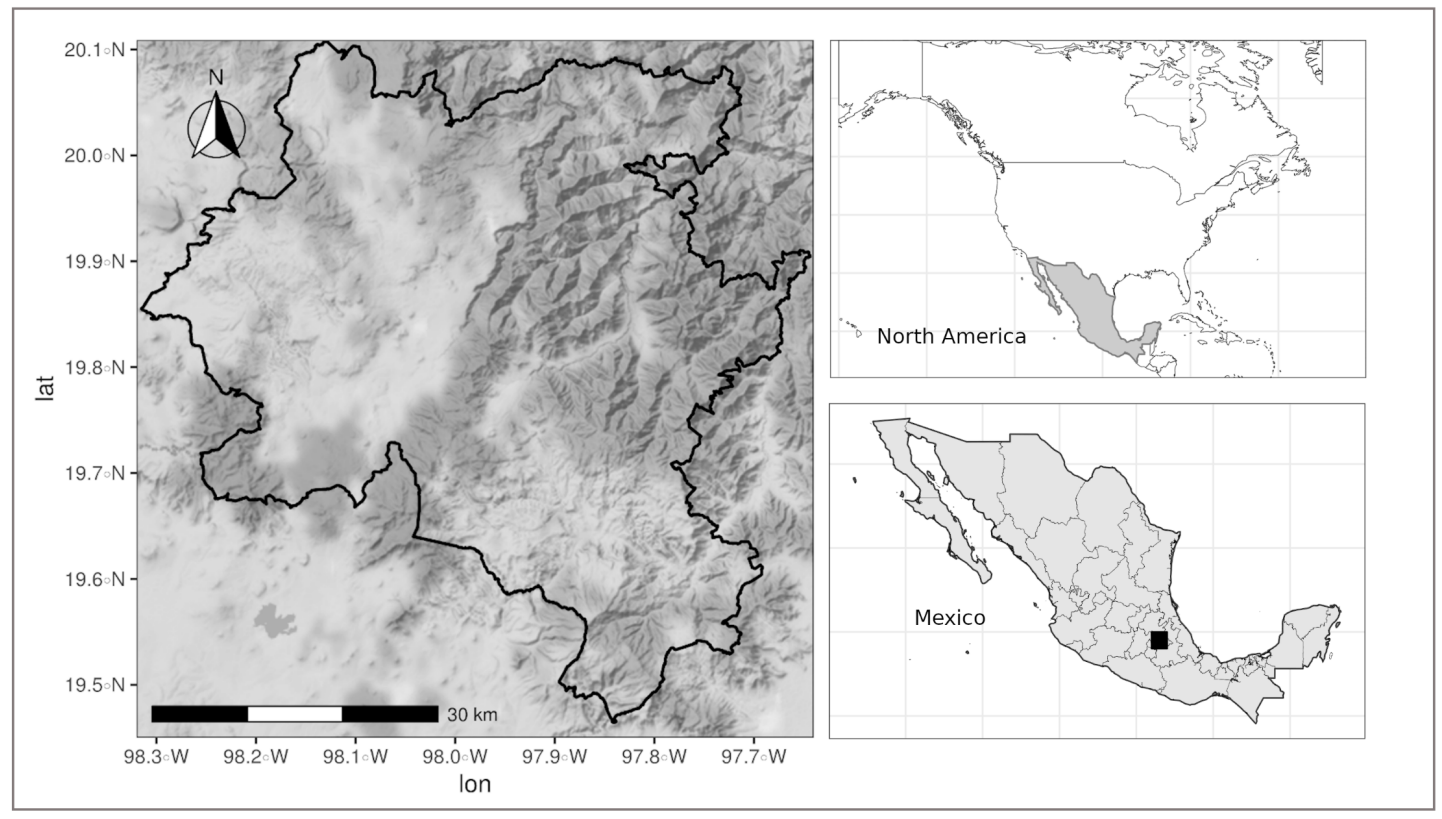

Figure 4.1: Localization of the UMF2108.

Table 4.1: Species included in ForestSimulator Mexico: Bosques templados [UMF2108]. For consistency, species codes were taken from SIBIFOR.

\begin{tabular}{lcc}
\hline Scientific name & Species ID & Internal code \\
\hline Pinus ayacahuite Ehren. & PIAYA & 1846 \\
Pinus hartwegii Lindl. & PIHAR & 1873 \\
Pinus leiophylla Schl. \& Cham. & PILEI & 1861 \\
Pinus montezumae Lamb. & PIMON & 1857 \\
Pinus patula Schl. et Cham. & PIPAT & 3588 \\
Pinus pseudostrobus Lindl. & PIPSE & 1871 \\
Pinus teocote Schiede ex Schltdl. & PITEO & 1876 \\
Abies religiosa (Kunth Schltdl. et Cham.) & ABREL & 2 \\
Quercus sp. & QUERCUS & 808 \\
\hline
\end{tabular}

ForestSimulator were developed for this specific software version by making groups. Therefore, while models from SIBIFOR and biomass equations are recognized at species level (Table 4.1) the rest of the models are applied by group as follows: Pinus patula, Pinus group, Abies group, and Quercus group. 


\subsubsection{ForestSimulator Mexico}

Given the information mentioned above, ForestSimulator was adapted to UMF2108 conditions, including the models for the species listed. Although the Mexican version of ForestSimulator only includes equations for UMF2108, settings to other forest management units (using the SIBIFOR equations) would be faster to implement, since it would only be necessary to include the model parameters.

In order to adapt the ForestSimulator software to SIBIFOR it was necessary to code and rewrite plugins in Java 8. The purpose was to include functions that share parameters for several tree species in a single file. Besides, some of the models included have complex structures (e.g. mixed effects, see chapters two and three) that would make them difficult to fit into the species manager (Figure 4.2). Table 4.2 shows an example of the XML file with the settings for P. patula. From the volume to the quadratic diameter increment model table 4.2 shows the name of the plugins written for this particular version of ForestSimulator.

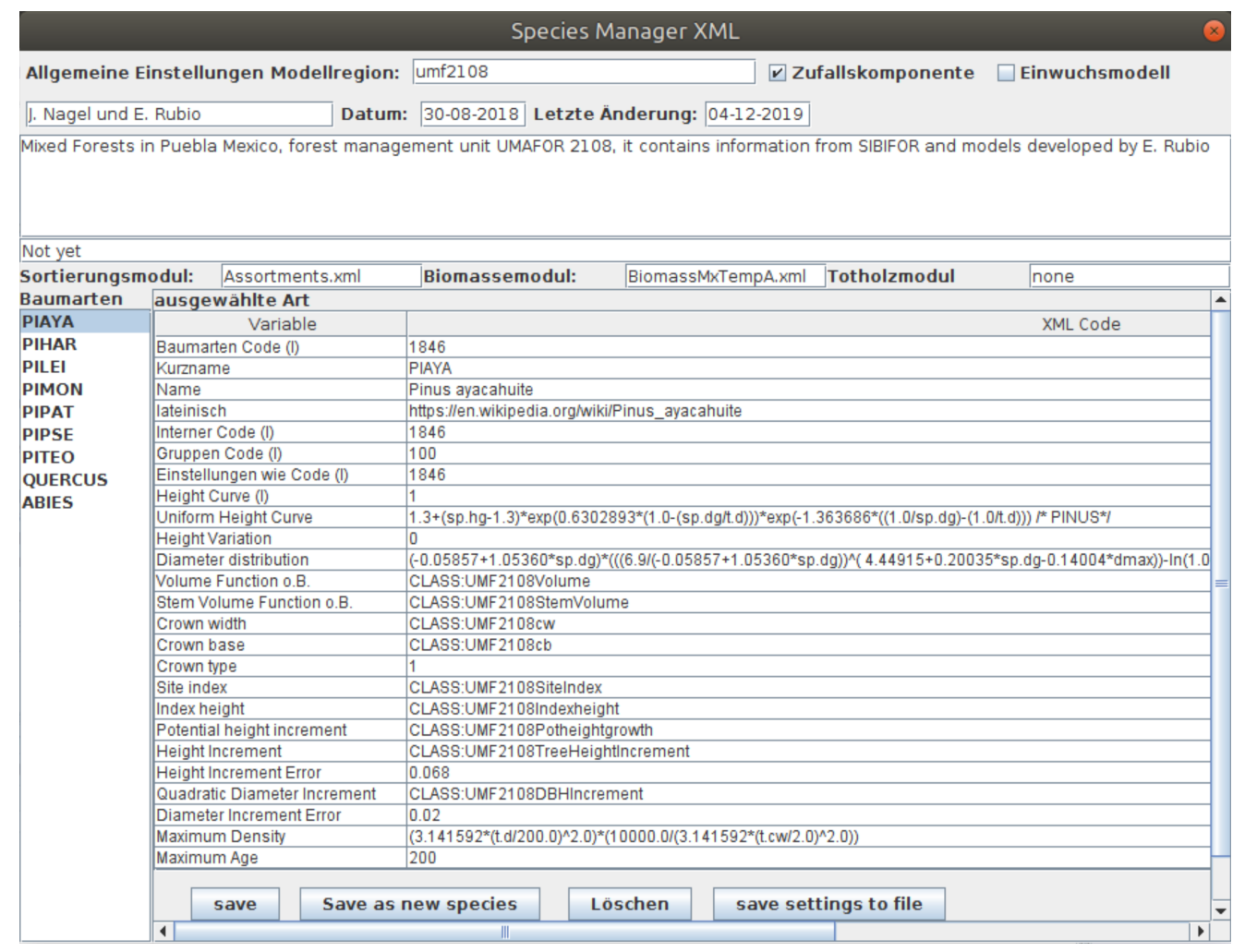

Figure 4.2: Species manager. 
Table 4.2: Example of the XML file input with the species parameters to include in ForestSimulator.

\begin{tabular}{|c|c|}
\hline Parameter & Parameter value \\
\hline Species Code & 3588 \\
\hline Short name & PIPAT \\
\hline Latin name & Pinus patula \\
\hline Source & https://de.wikipedia.org/wiki/Pinus_patula \\
\hline Intern Code & 3588 \\
\hline Group Code & 100 \\
\hline Settings like Code & 3588 \\
\hline Height Curve (I) & 4 \\
\hline Uniform Height Curve & $\begin{array}{l}\text { 1.3+(sp.hg-1.3)*exp }\left(0.68^{*}(1.0-(\mathrm{sp} . \mathrm{dg} / \mathrm{t} . \mathrm{d}))\right)^{*} \\
\exp \left(-4.69^{*}((1.0 / \mathrm{sp} \cdot \mathrm{dg})-(1.0 / \mathrm{t} . \mathrm{d}))\right) /^{*} \mathrm{PIT}{ }^{*} /\end{array}$ \\
\hline Height Variation & $\begin{array}{l}2.9 \\
\left(-0.05857+1.05360^{*} \mathrm{sp} . \mathrm{dg}\right)^{*}\left(\left(\left(6.9 /\left(-0.05857+1.05360^{*} \mathrm{sp} . \mathrm{dg}\right)\right)\right.\right.\end{array}$ \\
\hline Diameter distribution & $\begin{array}{l}\left.\left.\left.\hat{(} 4.44915+0.20035^{*} \mathrm{sp} \cdot \mathrm{dg}-0.14004^{*} \mathrm{dmax}\right)\right)-\ln (1.0 \text {-random })\right) \\
\hat{(}\left(1.0 /\left(4.44915+0.20035^{*} \mathrm{sp} \cdot \mathrm{dg}-0.14004^{*} \mathrm{dmax}\right)\right) /^{*} \text { PIPAT }^{*} /\end{array}$ \\
\hline Volume Function & CLASS:UMF2108Volume \\
\hline Stem Volume Function & CLASS:UMF2108StemVolume \\
\hline Crown width & CLASS:UMF2108cw \\
\hline Crown base & CLASS:UMF2108cb \\
\hline Crown type & 1 \\
\hline Site index & CLASS:UMF2108SiteIndex \\
\hline Index height & CLASS:UMF2108Indexheight \\
\hline Potential height increment & CLASS:UMF2108Potheightgrowth \\
\hline Height Increment & CLASS:UMF2108TreeHeightIncrement \\
\hline Height Increment Error & 0.068 \\
\hline Quadratic Diameter Increment & CLASS:UMF2108DBHIncrement \\
\hline Diameter Increment Error & 0.02 \\
\hline Maximum Density & $\begin{array}{l}\text { if(t.h>=8.0,47.0250-184.8930*exp(-exp }(-1.4110)^{*} \\
\text { t.hî.0000),20.80) } /{ }^{*} \text { Kiefer Nordwest (Woerdehoff 2013)* }\end{array}$ \\
\hline Maximum Age & 200 \\
\hline Plugin Ingrowth & none \\
\hline Decay & 1.0-((sp.year-t.out-5.0)/50.0) \\
\hline Target Diameter & 40 \\
\hline Height of first Thinning & 12 \\
\hline Moderate Thinning Factor & $12.0 ; 0.60 ; 18.0 ; 18.0 ; 0.65 ; 22.0 ; 22.0 ; 0.70 ; 100.0$ \\
\hline Color & $102 ; 255 ; 102$ \\
\hline Plugin Competition & treegross.base.Competition \\
\hline Plugin Mortality & treegross.base.Mortality \\
\hline Plugin Taper Fuction & treegross.base.TaperFunctionByRubio \\
\hline
\end{tabular}

\subsection{Forest models}

This section describes the models integrated in ForestSimulator Mexico. These models are used in different ways in the simulation process. Some are required to simulate stands from the beginning with no previous data, i.e., simulating new 
stands with specific settings, for instance, it can generate a new stand with certain age, dominant tree height, and with a specific diameter distribution. Other are used to simulate growth and to impute missing values in external databases. These models have to be integrated in the species manager (XML file), either by directly capturing them or by making plugins. However, in the last case users need basic knowledge of Java programming.

\subsubsection{Uniform height curve - [chapter two]}

The first model required by the species manager is the tree height-diameter generalized or uniform curve. These kind of models include stand variables such as quadratic mean diameter or dominant tree height as predictors. Chapter two describes the model fitting and evaluation process that is commonly used to develop tree $h-d$ models. In this section, generalized models fitted to the species in UMF2108 (see chapter two) were taken and integrated in ForestSimulator. For this software version, the model used is that based on the Nagel (1999) generalized equation.

$$
h=1.3+(h g-1.3) \cdot \exp \left(\beta_{0} \cdot\left(1.0-\left(\frac{\mathrm{dg}}{d}\right)\right)\right) \cdot \exp \left(\beta_{1} \cdot\left(\left(\frac{1}{\mathrm{dg}}\right)-\left(\frac{1}{d}\right)\right)\right)
$$

For each species the same model is used but different parameters (Table 4.3).

Table 4.3: Model parameters by group for Equation 4.1.

\begin{tabular}{rrrrr}
\hline & P. Patula & Pinus & Abies & Quercus \\
\hline$\beta_{0}$ & 0.68 & 0.53 & 0.59 & -0.21 \\
$\beta_{1}$ & -4.69 & 0.6 & -4.53 & 35.21 \\
\hline
\end{tabular}

\subsubsection{Diameter distribution - [this section]}

Tree diameter distributions are commonly used to describe the forest structure (Prodan et al., 1997) and are important components in forest simulators (Hansen 
and Nagel, 2014). These diameter distributions can be modeled through probability density functions $(p d f)$. A popular distribution in forestry is the Weibull function, it can be used to describe the actual diameter distribution, and to model future stand structures (Bailey and Dell, 1973; Von Gadow and Hui, 1999; Prodan et al., 1997). The Weibull distribution can have two or three parameters (scale = $\beta$, shape $=\alpha$ and location). The two-parameter Weibull distribution has a $p d f$ :

$$
f(x)=\frac{\alpha}{\beta}\left(\left(\frac{x}{\beta}\right)\right)^{\alpha-1} \exp \left[-\left(\frac{x}{\beta}\right)^{\alpha}\right]
$$

where $\alpha, \beta>0$.

And a cumulative distribution function $c d f$ :

$$
f(x)=1-\exp \left[-\left(\frac{x}{\beta}\right)^{\alpha}\right]
$$

\subsubsection{Weibull parameter prediction models}

In forestry a common use of the Weibull distribution is to model future stand structures by estimating the model parameters. This process is usually done by two main methods, parameter recovery and parameter prediction. The later takes stand characteristics, such as mean diameter, as independent variables to predict the Weibull parameters using regression techniques (Bailey and Dell, 1973; Von Gadow and Hui, 1999; Prodan et al., 1997).

In the case of P. patula the Weibull distribution was fitted to all plots described in chapter one through the "fitdistrplus" package (Delignette-Muller et al., 2014) with R (R Core Team, 2019). Then, using the plots where the fitting was significantly different to zero, ordinary least squares were used to fit regression models for parameter prediction. In this case, stand characteristics such as mean- and max tree-diameter were tested as predictor variables using the equations 4.4 and 4.5 for the scale and shape parameters respectively.

Regression model for the scale parameter

$$
\text { scale }=\beta_{0}+\beta_{1} \cdot d_{\text {mean }}+\beta_{2} \cdot d_{\max }
$$




\section{Regression results for the scale parameter}

Table 4.4: Regression statistics for the Weibull scale parameter.

\begin{tabular}{rrrrr}
\hline & Estimate & Std. Error & $\mathrm{t}$ value & $\operatorname{Pr}(>|\mathrm{t}|)$ \\
\hline (Intercept) & 0.0895 & 0.3040 & 0.29 & 0.7713 \\
$d_{\text {mean }}$ & 1.0062 & 0.0154 & 65.25 & 0.0000 \\
$d_{\max }$ & 0.0587 & 0.0119 & 4.92 & 0.0001 \\
\hline
\end{tabular}

Residual standard error: 0.4831 on 22 degrees of freedom. Multiple Rsquared: 0.999, Adjusted R-squared: 0.9989. F-statistic: $1.14 \mathrm{e}+04$ on 2 and 22 DF, p-value: $<2.2 \mathrm{e}-16$.

\section{Regression model for the shape parameter}

$$
\text { shape }=\beta_{0}+\beta_{1} \cdot d_{\text {mean }}+\beta_{2} \cdot d_{\text {max }}
$$

\section{Regression results for the shape parameter}

Table 4.5: Regression statistics for the Weibull shape parameter.

\begin{tabular}{rrrrr}
\hline & Estimate & Std. Error & $\mathrm{t}$ value & $\operatorname{Pr}(>|\mathrm{t}|)$ \\
\hline (Intercept) & 4.3608 & 0.4573 & 9.54 & 0.0000 \\
$d_{\text {mean }}$ & 0.1869 & 0.0232 & 8.06 & 0.0000 \\
$d_{\max }$ & -0.1238 & 0.0179 & -6.90 & 0.0000 \\
\hline
\end{tabular}

Residual standard error: 0.7267 on 22 degrees of freedom. Multiple Rsquared: 0.7478, Adjusted R-squared: 0.7249. F-statistic: 32.62 on 2 and 22 DF, p-value: 2.623e-07.

In both cases, the results show a statistical significance in parameter prediction. Thus, the regression models were included in the ForestSimulator species manager as shown in Table 4.2 .

\subsubsection{Crown width and crown base height models - [this sec- tion]}

Crown width and crown base height are basic elements in forest growth simulators, and are a standard measurement in Mexico's national forest inventory. On the one hand, $c w$ could serve as an indicator of tree vigor and is a determinant 
element in tree crown competition indices (Nagel, 1999; Hansen and Nagel, 2014). On the other hand, $c b$ is used to estimate forest products and, like $c w$, is key in estimating crown competition indices. Generally, these models involve few covariates such as tree diameter or height, in this study, we developed models for the estimation of $c w$ and $c b$ including the plot as random effect.

The $c w$ and $c b$ models were fitted following the steps described in chapter one for BAI mixed-effects models, using the same plots and trees. In both cases, only the plot was used as random effect (intercept). In order to avoid illogical predictions in the forest growth simulations (e.g. crown width after removal trees), only tree diameter was used as a predictor for $c w$ models. In the case of $c b$ regression, the tree diameter, tree height, and crown width were also tested as predictors.

The crown width model is:

$$
c w=\left(\beta_{0}+v_{0}\right)+d \cdot \beta_{1}
$$

and the crown base height model:

$$
c b=\left(\beta_{0}+v_{0}\right)+h \cdot \beta_{1}+c w \cdot \beta_{2}
$$

where $d=$ tree diameter, $h=$ tree height, $\beta=$ model parameters, and $v_{0}=$ random effect.

For the integration in ForestSimulator (Table 4.2) it was necessary to write two plugins [UMF2108cw and UMF2108cb] containing the equations described above and the parameters shown in the following paragraphs.

\section{Results - crown width}

Crown width models were fitted using mixed effects approach, including the plot as random intercept. Tree diameter was the only predictor variable tested in the fitting process, and it was statistically significant for all models $(p<0.05)$. The goodness-of-fit statistics are shown in Table 4.6.

\section{Results - crown base height}

In the case of crown base height models, findings of the fitting procedure are shown in Table 4.7. In all models, both (fixed effects) predictor variables ( $h$ and 
Table 4.6: Regression parameters and goodness-of-fit statistics of crown width models by group.

\begin{tabular}{lrrrr}
\hline Parameters & Pinus patula & \multicolumn{1}{c}{ Pinus } & Abies & Quercus \\
\hline$\beta_{0}$ & 1.08 & 1.91 & 2.82 & 1.10 \\
$\beta_{1}$ & 0.14 & 0.12 & 0.10 & 0.18 \\
$\operatorname{var}\left(u_{0}\right)$ & 0.65 & 0.47 & 0.40 & 0.09 \\
$\operatorname{var}(\epsilon)$ & 1.02 & 0.88 & 0.94 & 0.83 \\
AIC & 4542.96 & 3200.15 & 872.96 & 538.70 \\
cAIC & 4443.45 & 3125.50 & 843.52 & 524.69 \\
RMSE & 1.00 & 0.92 & 0.94 & 0.89 \\
$R_{a d j}^{2}$ & 0.80 & 0.74 & 0.68 & 0.51 \\
\hline
\end{tabular}

$c w)$ were statistically significant $(p<0.05)$.

Table 4.7: Regression parameters and goodness-of-fit statistics of crown base height models by group.

\begin{tabular}{lrrrr}
\hline Parameters & Pinus patula & \multicolumn{1}{c}{ Pinus } & Abies & Quercus \\
\hline$\beta_{0}$ & 0.83 & 0.67 & 1.85 & 1.45 \\
$\beta_{1}$ & 0.58 & 0.54 & 0.52 & 0.38 \\
$\beta_{2}$ & -0.22 & -0.47 & -0.57 & -0.23 \\
$\operatorname{var}\left(u_{0}\right)$ & 5.85 & 8.36 & 8.16 & 0.03 \\
$\operatorname{var}(\epsilon)$ & 4.98 & 2.14 & 5.21 & 1.28 \\
AIC & 7384.98 & 2434.20 & 1548.59 & 515.74 \\
cAIC & 7258.37 & 2352.22 & 1499.32 & 505.04 \\
RMSE & 2.20 & 1.43 & 2.20 & 1.13 \\
$R_{\text {adj }}^{2}$ & 0.85 & 0.86 & 0.87 & 0.58 \\
\hline
\end{tabular}

\subsubsection{Volume model - [SIBIFOR]}

Volume and Stem volume models were taken from the SIBIFOR system (VargasLarreta et al., 2017). For each of them, a plugin was coded [UMF2108Volume and UMF2108StemVolume] and included in ForestSimulator. These two equations share the model parameters shown in Table 4.8. The total volume function is written as follows:

$$
\text { Vol }=\beta_{0} \cdot d^{\beta_{1}} \cdot h^{\beta_{2}}+\beta_{3} \cdot d^{2}
$$

and the stem volume model

$$
\text { Vstem }=\beta_{3} \cdot d^{2}
$$

where $d=$ tree diameter, $h=$ tree height, and $\beta=$ model parameters. 
Table 4.8: Total volume and stem volume parameters by species. Values retrieved from SIBIFOR

\begin{tabular}{lcccc}
\hline \multirow{2}{*}{ Species } & \multicolumn{4}{c}{ Parameters } \\
\cline { 2 - 5 } & $\beta_{0}$ & $\beta_{1}$ & $\beta_{2}$ & $\beta_{3}$ \\
\hline P. ayacahuite & 0.0000495 & 1.6253924 & 1.3117874 & 0.0000400 \\
P. hartwegii & 0.0001144 & 1.7587469 & 0.9555884 & 0.0000847 \\
P. leiophylla & 0.0000671 & 1.9695400 & 0.8705182 & 0.0000752 \\
P. montezumae & 0.0000599 & 1.8358140 & 1.0727690 & 0.0000294 \\
P. patula & 0.0000800 & 1.6899978 & 1.1105510 & 0.0000239 \\
P. pseudostrobus & 0.0000606 & 1.7979294 & 1.1075763 & 0.0000342 \\
P. teocote & 0.0000781 & 1.8482361 & 0.9547915 & 0.0000217 \\
Abies religiosa & 0.0000455 & 1.4905970 & 1.5049423 & 0.0000105 \\
Quercus & 0.0001023 & 1.7326541 & 0.9572415 & 0.0001485 \\
\hline
\end{tabular}

\subsubsection{Taper function - [SIBIFOR]}

Taper function was also taken from the SIBIFOR system. The model is based on Fang et al. (2000) equation, and for the integration to the ForestSimulator software it was necessary to overwrite an additional plugin [TaperFunctionByRubio]. The model parameters of all species in SIBIFOR and UMF2108 are shown in Table 4.9. Thus, the taper equation is described as follows:

$$
\begin{gathered}
v_{i}=c_{1}^{2} \cdot h^{\left(k / b_{1}\right)} \cdot\left(b_{1} \cdot \Gamma_{0}+\left(I_{1}+I_{2}\right) \cdot\left(b_{2}-b_{1}\right) \cdot \Gamma_{1}+I_{2} \cdot\left(b_{3}-b_{2}\right) \cdot \alpha_{1}\right. \\
\left.\cdot \Gamma_{2}-\beta \cdot(1-q)^{(k / \beta)} \cdot \alpha_{1}^{\left(I_{1}+I_{2}\right)} \cdot \alpha_{2}^{I_{2}}\right) \cdot g_{2} \\
c_{1}=\sqrt{\frac{\left(a_{0} \cdot\left(d^{a_{1}}\right) \cdot\left(h^{\left(a_{2}-\left(k / b_{1}\right)\right)}\right)\right)}{\left(b_{1} \cdot\left(\Gamma_{0}-\Gamma_{1}\right)+b_{2} \cdot\left(\Gamma_{1}-\alpha_{1} \cdot \Gamma_{2}\right)+b_{3} \cdot \alpha_{1} \cdot \Gamma_{2}\right)}}
\end{gathered}
$$

with

$$
\begin{gathered}
\beta=b_{1}^{\left(1-\left(I_{1}+I_{2}\right)\right)} \cdot b_{2}^{I_{1}} \cdot b_{3}^{I_{2}} \\
\alpha_{1}=\left(1-p_{1}\right)^{\left(\left(\left(b_{2}-b_{1}\right) \cdot k\right) /\left(b_{1} \cdot b_{2}\right)\right)} \\
\alpha_{2}=\left(1-p_{2}\right)^{\left(\left(\left(b_{3}-b_{2}\right) \cdot k\right) /\left(b_{2} \cdot b_{3}\right)\right)} \\
\Gamma_{0}=\left(1-h_{s t} / h\right)^{\left(k / b_{1}\right)} \\
\Gamma_{1}=\left(1-p_{1}\right)^{\left(k / b_{1}\right)} \\
\Gamma_{2}=\left(1-p 3^{\left(k / b_{2}\right)}\right.
\end{gathered}
$$


where $p_{1}$ and $p_{2}$ are the proportions (relative to tree height) of the two heights $h_{1} / h$ and $h_{2} / h$ where two inflections points occur.

$$
\begin{gathered}
q=h_{i} / h \\
k=\pi / 40000 \\
I_{1}=1 \text { if } p_{1}<=q<=p_{2} ; 0 \text { otherwise } \\
I_{2}=1 \text { if } p_{2}<=q<=1 ; 0 \text { otherwise }
\end{gathered}
$$

Table 4.9: Taper volume parameters by species. Values retrieved from SIBIFOR

\begin{tabular}{lccccccccc}
\hline \multirow{2}{*}{ Species } & \multicolumn{10}{c}{ Parameters } \\
\cline { 2 - 10 } & $\boldsymbol{a}_{\boldsymbol{0}}$ & $\boldsymbol{a}_{1}$ & $\boldsymbol{a}_{2}$ & $\boldsymbol{b}_{1}$ & $\boldsymbol{b}_{2}$ & $\boldsymbol{b}_{3}$ & $\boldsymbol{p}_{1}$ & $\boldsymbol{p}_{2}$ & $\boldsymbol{g}_{2}$ \\
\hline P. ayacahuite & 0.000050 & 1.625392 & 1.311787 & 0.000004 & 0.000033 & 0.000029 & 0.047067 & 0.639508 & 0.929494 \\
P. hartwegii & 0.000114 & 1.758747 & 0.955588 & 0.000006 & 0.000041 & 0.000029 & 0.053928 & 0.690138 & 0.931135 \\
$\boldsymbol{P}$. leiophylla & 0.000067 & 1.969540 & 0.870518 & 0.000006 & 0.000038 & 0.000029 & 0.037655 & 0.640630 & 0.890290 \\
P. montezumae & 0.000060 & 1.835814 & 1.072769 & 0.000007 & 0.000041 & 0.000031 & 0.048521 & 0.705259 & 0.899679 \\
P. patula & 0.000080 & 1.689998 & 1.110551 & 0.000006 & 0.000040 & 0.000028 & 0.063097 & 0.765384 & 0.892833 \\
P. pseudostrobus & 0.000061 & 1.797929 & 1.107576 & 0.000006 & 0.000041 & 0.000030 & 0.051174 & 0.705703 & 0.900501 \\
P. teocote & 0.000078 & 1.848236 & 0.954792 & 0.000006 & 0.000039 & 0.000030 & 0.048704 & 0.758079 & 0.896311 \\
Abies religiosa & 0.000046 & 1.490597 & 1.504942 & 0.000003 & 0.000008 & 0.000036 & 0.025494 & 0.055232 & 0.899872 \\
Quercus & 0.000102 & 1.732654 & 0.957242 & 0.000007 & 0.000031 & 0.000026 & 0.074076 & 0.660035 & 0.890639 \\
\hline
\end{tabular}

\subsubsection{Site index - [SIBIFOR]}

In SIBIFOR two main equations are used to describe site index curves, Korf (Equation 4.22) and Bertalanffy-Richards (Equation 4.23). The former is used for P. ayacahuite, P. patula, and P. teocote, and the Bertalanffy-Richards model for P. hartwegii, P. leiophylla, P. montezumae, P. pseudostrobus, and A. religiosa. In this study the plugin UMF2108Indexheight was written including both equations and parameters shown in Table 4.10.

Korf site index model:

$$
s i=\exp \left(X_{0}\right) \cdot \exp \left[-\left[\frac{\left(\beta_{0}+\beta_{1}\right)}{X_{0}}\right] \cdot t^{\beta_{2}}\right]
$$


where

$$
X_{0}=\frac{1}{2} \cdot t_{0}^{\left(-\beta_{2}\right)}\left[\beta_{0}+t_{0}^{\left(-\beta_{2}\right)} \cdot \log \left(H_{0}\right)+\sqrt{4 \cdot \beta_{1} \cdot t_{0}^{\left(-\beta_{2}\right)}+\left[-\beta_{0}-t_{0}^{\left(-\beta_{2}\right)} \cdot \log \left(H_{0}\right)\right]^{2}}\right]
$$

$H_{0}=$ Dominant tree height, $t_{i}=$ reference age, $t_{0}=$ initial age, and $\beta=$ model parameters.

\section{Bertalanffy-Richards site index model:}

$$
s i=H_{0} \cdot\left[\frac{1-\exp \left(-\beta_{0} \cdot t\right)}{1-\exp \left(-\beta_{0} \cdot t_{0}\right)}\right]^{\left(\beta_{1}+\beta_{2} / X_{0}\right)}
$$

where

$$
X_{0}=\frac{1}{2} \cdot\left[\log \left(H_{0}\right)-\beta_{1} \cdot L_{0}+\sqrt{\left(\log \left(H_{0}-\beta_{1} \cdot L_{0}\right)^{2}-4 \cdot \beta_{2} \cdot L_{0}\right)}\right]
$$

and

$$
L_{0}=\log \left[1-\exp \left(-\beta_{0} \cdot t_{0}\right)\right]
$$

\begin{tabular}{|c|c|c|c|c|}
\hline \multirow{2}{*}{ Species } & \multirow{2}{*}{ Model } & \multicolumn{3}{|c|}{ Parameters } \\
\hline & & $\beta_{0}$ & $\beta_{1}$ & $\beta_{2}$ \\
\hline P. ayacahuite & & 0.209923 & 65.52556 & 0.198572 \\
\hline P. patula & $\mathbf{K}$ & -1.41157 & 38.11761 & 0.435403 \\
\hline P. teocote & & -2.77689 & 43.88105 & 0.323189 \\
\hline P. hartwegii & & 0.025919 & -0.84243 & 6.471769 \\
\hline P. leiophylla & & 0.015561 & -0.35301 & 4.802089 \\
\hline P. montezumae & BR & 0.032814 & -1.2301 & 8.756195 \\
\hline P. pseudostrobus & & 0.035029 & -1.11309 & 9.022212 \\
\hline Abies religiosa & & 0.018649 & -8.79579 & 39.23149 \\
\hline
\end{tabular}

Table 4.10: Site index model parameters by species. Where $K=$ Korf model and BR $=$ Bertalanffy-Richards model. Values retrieved from SIBIFOR

\subsubsection{Index height - [adapted from SIBIFOR]}

In order to fit the ForestSimulator requirements both original site index equations were modified. Then, the index height equations included in the plugin UMF2108Indexheight (Table 4.2) are described as follows: 
Korf Index height model

$$
i h=\exp \left(X_{0}\right) \cdot \exp \left[-\left[\frac{\left(\beta_{0}+\beta_{1}\right)}{X_{0}}\right] \cdot t_{0}^{\beta_{2}}\right]
$$

where

$$
X_{0}=\frac{1}{2} \cdot t_{0}^{\left(-\beta_{2}\right)}\left[\beta_{0}+t_{0}^{\left(-\beta_{2}\right)} \cdot \log (s i)+\sqrt{4 \cdot \beta_{1} \cdot t_{0}^{\left(-\beta_{2}\right)}+\left[-\beta_{0}-t_{0}^{\left(-\beta_{2}\right)} \cdot \log (s i)\right]^{2}}\right]
$$

Bertalanffy-Richards Index height model

$$
i h=s i \cdot\left[\frac{1-\exp \left(-\beta_{0} \cdot t_{0}\right)}{1-\exp \left(-\beta_{0} \cdot t\right)}\right]^{\left(\beta_{1}+\beta_{2} / X_{0}\right)}
$$

where

$$
X_{0}=\frac{1}{2} \cdot\left[\log \left(H_{0}\right)-\beta_{1} \cdot L_{0}+\sqrt{\left(\log \left(H_{0}-\beta_{1} \cdot L_{0}\right)^{2}-4 \cdot \beta_{2} \cdot L_{0}\right)}\right]
$$

and

$$
L_{0}=\log \left[1-\exp \left(-\beta_{0} \cdot t_{0}\right)\right]
$$

\subsubsection{Potential height increment - [adapted from SIBIFOR]}

Similar to index height models, the potential height increment model was adapted by modifying the original site index equations as follows:

\section{Korf Potential height increment model}

$$
p h=\left[\exp \left(X_{0}\right) \cdot \exp \left[-\left[\frac{\left(\beta_{0}+\beta_{1}\right)}{X_{0}}\right] \cdot\left(t_{0}+5\right)^{\beta_{2}}\right]\right]-\left[\exp \left(X_{0}\right) \cdot \exp \left[-\left[\frac{\left(\beta_{0}+\beta_{1}\right)}{X_{0}}\right] \cdot t_{0}^{\beta_{2}}\right]\right]
$$

Bertalanffy-Richards Potential height increment model

$$
p h=\left[s i \cdot\left[\frac{1-\exp \left(-\beta_{0} \cdot\left(t_{0}+5\right)\right)}{1-\exp \left(-\beta_{0} \cdot t\right)}\right]^{\left(\beta_{1}+\frac{\beta_{2}}{X_{0}}\right)}\right]-\left[s i \cdot\left[\frac{1-\exp \left(-\beta_{0} \cdot t_{0}\right)}{1-\exp \left(-\beta_{0} \cdot t\right)}\right]^{\left(\beta_{1}+\beta_{2} / X_{0}\right)}\right]
$$




\subsubsection{Height increment - [adapted from SIBIFOR]}

Finally, height increment was also adapted by modifying the original site index equations as follows:

\section{Korf Height increment model}

$$
h i=h \cdot \frac{\left[\exp \left(X_{0}\right) \cdot \exp \left[-\left[\frac{\left(\beta_{0}+\beta_{1}\right)}{X_{0}}\right] \cdot\left(t_{0}+5\right)^{\beta_{2}}\right]\right]-\left[\exp \left(X_{0}\right) \cdot \exp \left[-\left[\frac{\left(\beta_{0}+\beta_{1}\right)}{X_{0}}\right] \cdot t_{0}^{\beta_{2}}\right]\right]}{H_{0}}
$$

\section{Bertalanffy-Richards height increment model}

$$
h i=h \cdot \frac{\left[s i \cdot\left[\frac{1-\exp \left(-\beta_{0} \cdot\left(t_{0}+5\right)\right)}{1-\exp \left(-\beta_{0} \cdot t\right)}\right]^{\left(\beta_{1}+\beta_{2} / X_{0}\right)}\right]-\left[s i \cdot\left[\frac{1-\exp \left(-\beta_{0} \cdot t_{0}\right)}{1-\exp \left(-\beta_{0} \cdot t\right)}\right]^{\left(\beta_{1}+\beta_{2} / X_{0}\right)}\right]}{H_{0}}
$$

\section{Quercus group height increment model}

For Quercus no site index model was found in the literature, with which ForestSimulator could predict tree height increment. One reason for this is that age in Quercus is difficult to estimate. However, Vargas-Larreta et al. (2010) modified classical growth models (Lundqvist-Korf and McDill-Amateis) to include tree diameter instead of tree age. Based on this, the same approach was tested to fit the Lundqvist-Korf model with ordinary non-linear least squares method in R. For this purpose data from the two measurements available (2008 and 2012) in the database described in chapter two were used. The customized version of the Lundqvist-Korf model is described as follows:

$$
h i=\beta_{0} \cdot\left(\frac{h_{1}}{\beta_{0}}\right)^{\left(\frac{d_{1}}{d_{2}}\right)^{\beta_{1}}}
$$

where $h i=$ tree height increment, $h_{1}=$ tree height in the first measurement (2008), $d_{1}=$ tree diameter in the first measurement, $d_{2}=$ tree diameter in the second measurement, $\beta=$ model parameters.

\section{Results - Quercus height increment}

The goodness-of-fit statistics showed an $R_{a d j}^{2}=0.86, \mathrm{RMSE}=1.77$, and AIC $=679.6$. Both parameters are statistically significant (Table 4.11), therefore they were included in ForestSimulator. 
Table 4.11: Height increment model parameter estimation results (Lundqvist-Korf).

\begin{tabular}{lllll}
\hline Parameter & Estimate & Std. Error & $\mathbf{t}-\mathbf{v a l u e}$ & $\operatorname{Pr}(>|\mathbf{t}|)$ \\
\hline$\beta_{0}$ & 23.4473 & 5.4736 & 4.284 & $3.09 \mathrm{e}-05^{* * *}$ \\
$\beta_{1}$ & 1.1337 & 0.3206 & 3.536 & $0.000526^{* * *}$ \\
\hline
\end{tabular}

\subsubsection{Diameter increment - [chapter two]}

One of the most important single-tree elements required by ForestSimulator is the diameter increment model. The plugin UMF2108DBHIncrement has the back-transformed basal area increment model developed in chapter two. This transformation is made through the following equation:

$$
d I n c_{i j}=\frac{\exp \left[\left[\left(\beta_{0}+u_{i}\right)+\beta_{1} \cdot B A L M O D_{i j}+\left(\beta_{2}+v_{i}\right) * \log (d) \cdot \log \left(d_{i}\right)\right]-1\right]}{10000}
$$

whose parameters are obtained from Table 4.12.

Table 4.12: Diameter increment model parameter by group. Values retrieved from chapter two of this thesis.

\begin{tabular}{lrrrr}
\hline Parameter & Pinus patula & Pinus & Abies & Quercus \\
\hline$\beta_{0}$ & -0.615 & -0.009 & -0.447 & -0.668 \\
$\beta_{1}$ & -0.041 & -0.049 & -0.049 & -0.018 \\
$\beta_{2}$ & 0.852 & 0.686 & 0.823 & 1.084 \\
$s d\left(u_{i}\right)$ & 0.660 & 0.745 & 0.337 & 1.301 \\
$s d\left(v_{i}\right)$ & 0.177 & 0.246 & 0.004 & 0.464 \\
$\sigma$ & 0.227 & 0.238 & 0.213 & 0.124 \\
\hline
\end{tabular}

where $d I n c_{i j}=$ diameter increment of the $j^{\text {th }}$ tree in the $i^{\text {th }}$ plot, $u_{i}$ and $v_{i}$ $=$ random effects on intercept and slope respectively, $B A L M O D_{i j}=$ competition index of the $j^{\text {th }}$ tree in the $i^{\text {th }}$ plot, and $\log \left(d_{i j}\right)=$ logarithm of the tree diameter of the $j^{\text {th }}$ tree in the $i^{\text {th }}$ plot.

\subsubsection{Maximum density and tree mortality}

ForestSimulator estimates density-dependent tree mortality based on tree density. Therefore, the species manager requires the element called Maximum density, which refers to the maximum possible basal area (in $\mathrm{m}^{2}$ ) of a stand. In this 
study it was used the Equation 4.28 developed by Wördehoff (2016) for several tree species in Germany. This function is the cumulative Weibull distribution parameterized for maximum density estimation.

$$
\max D=\beta_{0}-\beta_{1} \cdot \exp \left(-\exp \left(-\beta_{2}\right) \cdot H_{o}^{\beta_{3}}\right)
$$

In this case, the parameters for Pinus were used, where $\beta_{0}=47.0250, \beta_{1}=$ 184.8930, $\beta_{2}=-1.4110$, and $\beta_{3}=1.000$.

ForestSimulator measures tree mortality by means of PlugInMortality. It calculates the density-dependent tree mortality through the maximum crown closure under a influence zone, using a spatially-dependent competition index. In this case, the crown closure degree is derived from the maximum density for the respective species through Equation 4.28, and the critical crown closure ratio is calculated through the maximum density and the crown width of the reference tree (for more details see Hansen and Nagel (2014)).

\subsubsection{Competition - [this section]}

In addition to predict mortality, tree competition is used by ForestSimulator to estimate diameter increment. Generally, tree diameter or basal area increment models include three main elements: tree size, site characteristics, and competition. In chapter two several models were developed to estimate basal area increment including tree diameter $d$ as size indicator, the plot (random effect) as site characteristics, and BALMOD (Schröder and von Gadow, 1999) as competition index (Equation 4.29).

In ForestSimulator Mexico the Java plugin Competition was modified to use BALMOD instead of the crown competition index c66. Therefore, the user must be aware that in ForestSimulator Mexico the competition index should be interpreted as BALMOD and not as c66. However, for tree mortality, ForestSimulator Mexico still uses c66xy to estimate maximum crown closure.

$$
B_{A L M O D}=\frac{1-p_{j}}{R S_{i}}
$$


with:

$$
R S_{i}=\frac{\sqrt{\frac{10,000}{N h a_{i}^{-1}}}}{H_{0_{i}}} \text { and } p_{j}=1-\frac{B A L_{i j}}{B A_{i}}
$$

where $p_{j}$ is the basal area percentile of a representative tree $j, B A L_{i j}$ is the sum of the basal area of the trees larger than the subject tree $j$ in the stand $i, B A_{i}$ is the basal area of the stand, $N h a_{i}^{-1}$ is the number of stems per hectare, and $H_{0_{i}}$ is the dominant height of the stand $i$ (Schröder and von Gadow, 1999).

\subsubsection{Biomass models - [from literature]}

ForestSimulator has a module to estimate biomass and other wood properties. This process is carried out using both taper and biomass functions. For this purpose, the user must select an XML file called BiomassEnna.xml, in the Mexican version this file is called BiomassMx.xml and contains the functions listed in Table 4.13. In the specific case of Pinus patula the biomass equation is given by component (Soriano-Luna et al., 2015) as follows:

$$
\begin{gathered}
\text { stem }=\exp (-4.682959) \cdot\left(d^{2} \cdot h\right)^{1.033543} \\
\text { branch }=\exp (-5.510841) \cdot\left(d^{2} \cdot h\right)^{0.951067} \\
\text { bark }=\exp (-7.441298) \cdot\left(d^{2} \cdot h\right)^{1.103910} \\
\text { leaf }=\exp (-4.750974) \cdot\left(d^{2} \cdot h\right)^{0.709796}
\end{gathered}
$$

Table 4.13: Biomass models parameters by species included in the ForestSimulator Mexico: Temperate forests. Where $B=$ above-ground biomass and $d=$ tree diameter.

\begin{tabular}{lll}
\hline Especies & Biomass Equation & Source \\
\hline P. ayacahuite & $B=\left(\exp (-3.066) \cdot\left(d^{2.646}\right)\right)$ & Navar-Chaidez (2010) \\
P. hartwegii & $B=(0.0635) \cdot\left(d^{2.4725}\right)$ & Carrillo-Anzures et al. (2016) \\
P. leiophylla & $B=(0.1751) \cdot\left(d^{2.2629}\right)$ & Navar-Chaidez (2008) \\
P. montezumae & $B=(0.013) \cdot\left(d^{3.046}\right)$ & Carrillo-Anzúres et al. (2014) \\
P. pseudostrobus & $B=(0.35179) \cdot\left(d^{2}\right)$ & Aguirre-Calderón and Jimenez-Perez (2011) \\
P. teocote & $B=(0.032495) \cdot\left(d^{2.76658}\right)$ & Rodríguez-Laguna et al. (2009) \\
Abies religiosa & $B=(0.0713) \cdot\left(d^{2.5104}\right)$ & Avendaño-Hernandez et al. (2009) \\
Quercus & $B=(0.0342) \cdot\left(d^{2.7590}\right)$ & Aguilar et al. (2012) \\
\hline
\end{tabular}




\subsection{Concluding remarks and future work}

In this chapter it is described how ForestSimulator was adapted for Mexican temperate forests. For this purpose, a database was used to develop several tree biometric models to include them in the software. Besides, models from SIBIFOR and other sources were also incorporated. This Mexican version is set to the temperate forest conditions of the Forest Management Unit 2108, located in Puebla, Mexico. Several tree species of Pinus, Quercus, and Abies from this region were added to the simulator. Although the software is customized for UMF2108, it can be easily adapted to other regions, particularly those included in SIBIFOR. However, other models must be developed and integrated into ForestSimulator.

A natural progression of this current project is to develop models not included in SIBIFOR for other species and regions. Here a list of models to complement those from SIBIFOR: Tree mortality, Maximum density, Diameter increment [tree size, competition, and site characteristics], Crown width, Crown base height, Biomass, and other wood properties. The inclusion of these functions would make predictions more precise.

The results of this work have a number of important implications for future practice. ForestSimulator Mexico can be used by foresters, policy makers, researchers and students to make model-based stand projections. This new version provides a new tool for forest management, and represents a humble contribution to Mexican forest management and forestry science. 


\section{Literature}

Aguilar, R., Ghilardi, A., Vega, E., Skutsch, M., Oyama, K., 2012. Sprouting productivity and allometric relationships of two oak species managed for traditional charcoal making in central Mexico. Biomass and Bioenergy 36, 192-207. doi:10.1016/j.biombioe.2011.10.029.

Aguirre-Calderón, Ó.A., Jimenez-Perez, J., 2011. Evaluación del contenido de carbono en bosques del sur de Nuevo León. Revista mexicana de ciencias forestales 2, 73-84. URL: http://www.scielo.org.mx/scielo.php?script=sci\{_\}arttext\{E\}pid= S2007-11322011000400007.

Avendaño-Hernandez, D.M., Acosta-Mireles, M., Carrillo-Anzures, F., Etchevers Barra, J.D., 2009. Estimación de biomasa y carbono en un bosque de Abies religiosa. Rev. Fitotec. Mex. 32, 233-238. URL: http://www.scielo.org.mx/scielo. php?script=sci\{_\}arttext $\{\mathcal{E}\}$ pid=S0187-73802009000300011.

Bailey, R.L., Dell, T.R., 1973. Quantifying Diameter Distributions with the Weibull Function. Forest Science 19, 97-104.

Carrillo-Anzúres, F., Acosta-Mireles, M., Flores-Ayala, E., Juárez-Bravo, J.E., Bonilla-Padilla, E., 2014. Estimación de biomasa y carbono en dos especies arboreas en La Sierra Nevada, México. Rev. Mex. Cienc. Agríc 5, 779-793. URL: http://www.scielo.org.mx/scielo.php?script=sci\{_\}arttext $\{\mathcal{E}\}$ pid= S2007-09342014000500005.

Carrillo-Anzures, F., Acosta-Mireles, M., Jiménez-Cruz, C.d.R., González Molina, L., Etchevers Barra, J.D., 2016. Ecuaciones alométricas para estimar la biomasa y el carbono de la parte aérea de Pinus hartwegii en el Parque Nacional Ixta-Popo, México. Rev. Mex. Cienc. Agríc 7, 681-691. URL: http://www.scielo.org.mx/scielo.

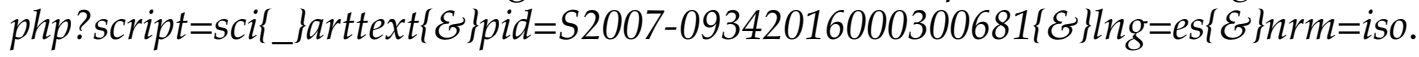

Corral-Rivas, J.J., Briseño-Reyes, C., López-Sánchez, C.A., Diéguez-Aranda, U., González-González, J.M., 2016. Sistema de Planeación Forestal para Bosque Templado. (SiPlaFor). MONTE , 24-26URL: https://asmadera.com/wp-content/ uploads/2014/11/TRESEME40web.pdf.

Delignette-Muller, M.L., Dutang, C., Pouillot, R., Denis, J.B., 2014 fitdistrplus: Help to fit of a parametric distribution to non-censored or censored data. URL: http://cran.r-project.org/web/packages/fitdistrplus/index.html.

Fang, Z., Borders, B.E., Bailey, R.L., 2000. Compatible volume-taper models for loblolly and slash pine based on a system with segmented-stem form factors. Forest Science 46, 1-12. URL: https://academic.oup.com/forestscience/article/46/1/ 1/4617337, doi:10.1093/forestscience/46.1.1.

Hansen, J., Nagel, J., 2014. Waldwachstumskundliche Softwaresysteme auf Basis von TreeGrOSS - Anwendung und theoretische Grundlagen. Universitätsverlag Göttingen, Gottingen, Germany. URL: https://www.univerlag.uni-goettingen.de/ handle/3/isbn-978-3-86395-149-8. 
Moreno-Sánchez, R., Torres-Rojo, J.M., 2010. Decision Support Systems For Forest Management In Mexico, in: Decision Support Systems in Agriculture, Food and the Environment: Trends, Applications and Advances. IGI Global, pp. 74-100. URL: http://services.igi-global.com/resolvedoi/resolve.aspx?doi=10.4018/ 978-1-61520-881-4.ch004, doi:10.4018/978-1-61520-881-4.ch004.

Nagel, J., 1999. Konzeptionelle Uberlegungen zum schrittweisen Aufbau eines waldwachstumskundlichen Simulationssystems fur Nordwestdeutschland. Sauerlander, Göttingen.

Nagel, J., 2003. TreeGrOSS: Tree Growth Open Source Software. URL: http: //treegross.sourceforge.net/.

Navar-Chaidez, J., 2008. Allometric equations and expansion factors for tropical dry forest trees of eastern Sinaloa, Mexico. Tropical and Subtropical Agroecosystems 10, 45-52. URL: https://www.revista.ccba.uady.mx/ojs/index.php/TSA/ article/view/5.

Navar-Chaidez, J., 2010. Biomass allometry for tree species of northwestern Mexico. Tropical and Subtropical Agroecosystems 12, 507-519. URL: https: //www.revista.ccba.uady.mx/ojs/index.php/TSA/article/view/391.

Prodan, M., Peters, R., Cox, F., Real, P., 1997. Mensura forestal. Serie de investigación y educación en desarrollo sostenible, GTZ/IICA-Agroamerica, San José, Costa Rica.

R Core Team, 2019. R: A language and environment for statistical computing. R Foundation for Statistical Computing. URL: http://www.r-project.orghttps: //www.r-project.org/.

Rodríguez-Laguna, R., Jiménez-Pérez, J., Aguirre-Calderón, Ó.A., Treviño-Garza, E.J., Razo-Zárate, R., 2009. Estimación de carbono almacenado en el bosque de pino-encino en la reserva de la biosfera el cielo, Tamaulipas, México. Ra Ximhai 5, 317-327. URL: http://www.revistas.unam.mx/index.php/rxm/article/view/15164.

Schröder, J., von Gadow, K., 1999. Testing a new competition index for Maritime pine in northwestern Spain. Canadian Journal of Forest Research 29, 280-283. URL: http://www.nrcresearchpress.com/doi/10.1139/x98-199, doi:10.1139/x98-199.

Soriano-Luna, M.d.l.Á., Ángeles-Pérez, G., Martínez-Trinidad, T., PlascenciaEscalante, F.O., Razo-Zárate, R., 2015. Estimación de biomasa aérea por componente estructural en Zacualtipán, Hidalgo, México. Agrociencia 49, 423-438. URL: http://www.scielo.org.mx/pdf/agro/v49n4/v49n4a6.pdf.

Vargas-Larreta, B., 2006. Analyse und Prognose des Einzelbaumwachstums in strukturreichen Mischbestanden in Durango, Mexiko. Cuvillier.

Vargas-Larreta, B., Corral-Rivas, J., Aguirre-Calderón, Ó., Nagel, J., 2010. Modelos de crecimiento de árbol individual: Aplicación del Simulador BWINPro7. 
Madera y bosques 16,81-104. URL: http://www.scielo.org.mx/scielo.php?script= sci\{_\}arttext\{E\}pid=S1405-04712010000400006.

Vargas-Larreta, B., Corral-Rivas, J.J., Aguirre-Calderon, O.A., Lopez-Martinez, J.O., De los Santos-Posadas, H.M., Zamudio-Sanchez, F.J., Trevino-Garza, E.J., Martinez-Salvador, M., Aguirre-Calderon, C.G., 2017. SiBiFor: Forest Biometric System for forest management in Mexico. Revista Chapingo Serie Ciencias Forestales y del Ambiente 23, 437-455. doi:10.5154/r.rchscfa.2017.06.040.

Von Gadow, K., Hui, G., 1999. Size-class Models, in: Modelling Forest Development, pp. 61-128. doi:10.1007/978-94-011-4816-0_4.

Wördehoff, R., 2016. Kohlenstoffspeicherung als Teilziel der strategischen Waldbauplanung erläutert an Reinbeständen verschiedener Baumarten in Niedersachsen. Ph.D. thesis. Georg-August Universität Göttingen. URL: https://ediss.uni-goettingen.de/handle/11858/00-1735-0000-0028-87F3-1. 


\title{
Chapter 5
}

\section{Spatial Patterns of Tree Mortality in a Montane Forest of Central Mexico}

Ernesto Alonso Rubio-Camacho ${ }^{1,2}$, José Germán Flores-Garnica ${ }^{2}$, Miguel AcostaMireles $^{3}$, and Maximilian H.K. Hesselbarth ${ }^{4}$

\begin{abstract}
Author details
${ }^{1}$ Department Ecoinformatics, Biometrics \& Forest Growth, Georg-August University of Goettingen. Busgenweg 4, 37077 Goettingen, Germany.

${ }^{2}$ INIFAP-CIRPAC C.E. Centro Altos: Av. Biodiversidad núm. 2470, Col. Las Cruces, Tepatitlán, Jalisco, México. CP. 47600.

${ }^{3}$ INIFAP C.E. Valle de México, Texcoco, Estado de México, México.

${ }^{4}$ Department of Ecosystem Modelling. University of Goettingen, Buesgenweg 4, Room 0.126, D-37077 Göttingen, Germany.
\end{abstract}

\section{Authors contributions}

EARC designed the study, conducted the data analysis, and wrote the manuscript; JGFG prepared the database and review the document; MCM collected field information and generated the original database; $\mathrm{MHKH}$ collaborated in data analysis, read, and corrected the final version.

\section{Status}

The manuscript is being prepared for submission to a scientific journal. 


\title{
Spatial Patterns of Tree Mortality in a Montane Forest of Central Mexico
}

\begin{abstract}
Tree mortality is an important process of forest dynamics and its knowledge is fundamental to implement adequate management strategies. Subject to several factors, tree mortality can cause different spatial patterns on the remaining live and dead trees. While spatially clustered tree mortality in young forests is often driven by density-dependent competition, in old-growth forests spatially clustered tree mortality is often caused by disturbance agents. To get a better insight into possible underlying processes, the aim of this study was to spatially characterize the tree mortality in a mature temperate forest of central Mexico. We took information from a forest dynamics permanent plot $(300 \times 300, m)$ in which all trees with a diameter at breast height $>=7.5 \mathrm{~cm}$ labeled and measured during three censuses in a 20 year period. The results from applying point pattern analysis showed that tree mortality was significantly clustered at short to medium scales $(0-18 \mathrm{~m})$, but showed no clear deviation from complete spatial randomness at all other scales. Similar results were found in the specific analysis of the two most important species, Pinus montezumae (clustered at 0-12 m) and Alnus firmifolia (clustered on almost all studied scales apart from 18-21 m). However, density-dependent mortality could not been shown for the overall population of trees at any scale. The remaining live trees maintained a clustered distribution and size heterogeneity at different scales during the whole measurement period. These results lead to the following remarks: i) tree mortality in the study area is not a random process, ii) in general, no density-dependent tree mortality was detected through the spatial point patterns analysis and iii) spatial irregularity and size heterogeneity were maintained the whole measurement period on the remaining live trees. The information generated by this study can contribute to implement management strategies based on the principles of continuous cover forestry and provides novel information regarding tree mortality in Mexican montane forests.
\end{abstract}

\subsection{Introduction}

Tree mortality is an essential process in forest ecosystems and its knowledge is fundamental for sustainable forest management. It has multiple effects on the forest structure and ecosystem functions. For example, dead trees lead to open spaces that promote regeneration, incorporate nutrients into the soil and 
provide habitat for wildlife (Franklin et al., 1987). Although many efforts have been made to comprehend its role on forest ecosystems, yet less attention has been focused on the spatial aspects of tree mortality using point patterns analysis (Larson et al., 2015). However, understanding the drivers of mortality and their effects on spatial patterns, could be one of the key aspects for the adequate use, conservation, and restoration of forest ecosystems (Franklin et al., 1987, 2002; Larson et al., 2015; Stephens et al., 2008).

In temperate forests, tree mortality is primarily influenced by competition, age, disease and disturbance agents. Competition takes place especially in the early stages of forest development, when young trees intensively compete for sunlight, nutrients and water (Peet and Christensen, 1987). Age related tree mortality is generally connected to the successional stage and how it changes over time (Franklin et al., 1987). Finally, depending on the regime (Pickett and White, 1985), disturbances can dramatically induce tree mortality and reshape the spatial patterns in forest ecosystems. Examples can be forest forest fires, hurricanes, insect attacks, and severe droughts (Agee, 1993; Choat et al., 2018; Franklin et al., 1987; Rodríguez-Trejo, 2014).

Regardless of the ecosystem and causes, spatial patterns of tree mortality tend to be clustered (Kenkel, 1988; Larson et al., 2015). However, the causes of this patterning differs between young and old growth forests. Since mortality in young forest is more likely attributed to a competitive-based mortality (Kenkel et al., 1997; Wiegand and Moloney, 2014) e.g. self-thinning (Kenkel, 1988), tree mortality in older forests is often related disturbance agents, like fires (Franklin et al., 2002; Stephens et al., 2008). Therefore, although the spatial patterns of death trees sometimes do not differ from young to old, a shift form competitive mortality in young to a non-competitive tree mortality in old growth forests is expected (Franklin and Van Pelt, 2004; Getzin et al., 2006; Larson et al., 2015).

Generaly, the spatial relationship between living and dead trees can be described as spatial attraction or segregation. Attraction is when live and dead trees are spatially clustered, which is usually attributed to a density-dependent competitive mortality (Kenkel, 1988; Kenkel et al., 1997; Wiegand and Moloney, 2014). Spatial segregation could be present when dead and live trees are spatially separated from each other. This might be explained by the agent-based tree mortality 
(Franklin et al., 2002). In addition, spatial segregation is often related to the scramble competition, resulting in spatial patterns of clumped dead trees of the same species with more isolated surviving trees (Wiegand and Moloney, 2014).

The spatial patterns of the remaining living trees are related to the processes described above. On the one hand, there is the hypothesis that the outcome of competitive-based mortality tends towards a regular distribution (Kenkel et al., 1997) and this is specially found in young forests (Larson et al., 2015). On the other hand, in old-growth forests, agent-based mortality leads to spatial clustering in the remaining trees (Franklin and Van Pelt, 2004), which, together with size heterogeneity, has been correlated with more resilient forests, especially to forest fires (Stephens et al., 2008). This provides important insights about the forest dynamics, that could be implemented into management strategies, grounded in the expectations of global change to come (Choat et al., 2018).

As most ecological processes and resulting patterns, also mortality is most likely scale-dependent. Point pattern analysis are one powerful tool to infer underlying processes from resulting scale-dependent patterns (Brown et al., 2011). Thereby, the main assumption is that the patterns contain information about the processes that shaped them. By describing, analyzing, and modelling the point patterns, i.e. the spatially explicit location of all individuals in the study area, point pattern analysis allows to explore and confirm ecological hypotheses of the acting processes (Brown et al., 2011; Law et al., 2009; Wiegand and Moloney, 2014).

The aim of this study was to deepen current knowledge of tree mortality in mature temperate forests. For this purpose, we used data from a permanent forest dynamics plot (9 hectares) located in central Mexico. The point pattern of all individual trees were repeatedly measured over 20 years. To the best of our knowledge, in this region there is no study on spatial patterns of tree mortality, conducted at these scales, both spatially and temporally. Regarding the study area, our research questions were: i) Are dead trees randomly distributed? ii) Is tree mortality density-dependent due to competition? iii) Does tree mortality lead to spatial regular distribution? iv) Does tree mortality lead to spatial size homogeneity? The answer to these questions could help to understand how this type of forest develops, and to utilize this information to implement the 
most appropriate methods for the use, conservation, and restoration of temperate forest ecosystems.

\subsection{Materials and Methods}

\subsubsection{Study Area}

This study was carried out in the "San Juan Tetla" old research station (SJTRS), Chiautzingo, Puebla, Mexico (Figure 5.1). The SJTRS used to be located besides the western part of the Ixta-Popo National Park, between the geographic coordinates of longitude $\left[\min =98.55^{\circ}, \max =98.58^{\circ}\right]$ and latitude $\left[\min =19.17^{\circ}, \max =\right.$ $19.22^{\circ}$ ]. The soils are classified as Ando, or Humic Allophane with a mean slope between $30 \%$ and $40 \%$, mainly facing the East exposition. The mean temperature is $9^{\circ} \mathrm{C}$ with a minimum of $-5^{\circ} \mathrm{C}$ and the precipitation is mainly concentrated from May to October, with $849.6 \mathrm{~mm}$, which means $84.2 \%$ of the total, and from November to April $159.4 \mathrm{~mm}$. The maximum monthly rainfall is in June, with $215.7 \mathrm{~mm}$ and the minimum in December, with $11.9 \mathrm{~mm}$ (Zepeda-Bautista and Acosta-Mireles, 2000; Acosta-Mireles et al., 1997).

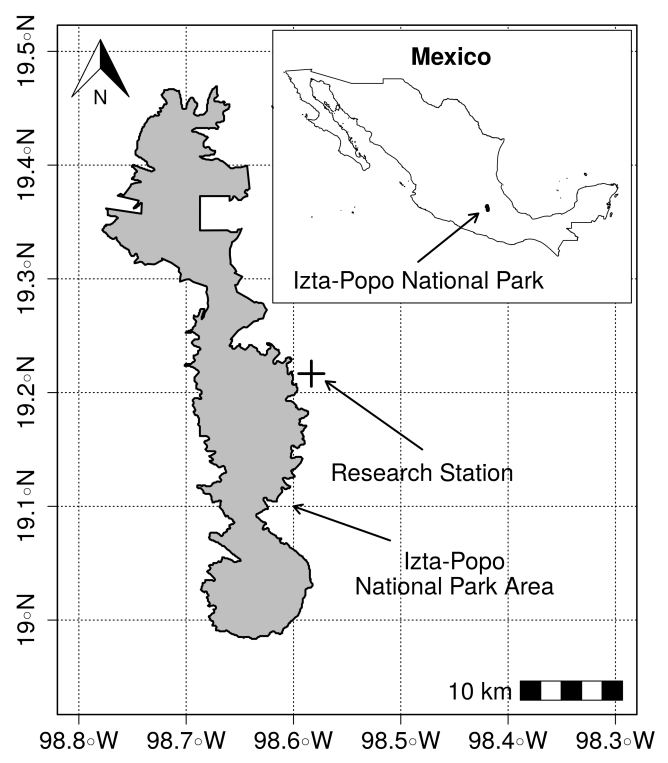

Figure 5.1: Study area localization, showing the location of the research station, outside the national park area. Where the inset map shows the total area of Mexico and the location of the national park as reference. 
The vegetation type is classified as temperate forest with predominance of Pinus montezumae Lamb. This species is distributed in an elevation range from 2,700 to 3,450 meters over the sea level and it is commonly found in association with Pinus teocote Schltdl. \& Cham., Pinus ayacahuite C. Ehrenb. ex Schltdl., Pinus leiophylla Schiede ex Schltdl. \& Cham., Abies religiosa (Kunth) Schltdl. \& Cham. and broad-leaved trees like Alnus firmifolia Fernald and Quercus sp. (ZepedaBautista and Acosta-Mireles, 2000). This ecosystem has a fire regime of low severity frequent fires (Rodríguez-Trejo, 2008; Jardel-Peláez et al., 2009) and $P$. montezumae is highly adapted to them (Rodríguez-Trejo and Fulé, 2003). Besides, it has been reported that in similar areas fires on synergy with plagues can increase the risk of tree mortality (Fonseca-González et al., 2016).

\subsubsection{Data collection}

The data were taken from a forest dynamics permanent plot $300 \times 300 \mathrm{~m}, 9$ ha in total), with three censuses over 20 years in a mature forest. The average tree-age was 70.5 years by the beginning of the measurement period (Zepeda-Bautista and Acosta-Mireles, 2000). The plot was established and the first census was carried out by the National Institute of Forestry, Agriculture and Livestock Research (INIFAP, Spanish abbr.) in 1974. The second and third census were carried out in 1989-90 and 1995-96. The original plot consisted of 16 ha, however, we excluded a border to maintain data consistency between 1974, 1989 and 1995. For more details about the data collection, see Zepeda-Bautista and Acosta-Mireles (2000). The censuses included all trees with a diameter at breast height $(d) \geq 7.5 \mathrm{~cm}$. All trees were tagged, the $x$ and $y$ coordinates recorded and the following inventory variables were taken: tree diameter $(d, c m)$, total height $(h, m)$, crown width $(c w, m)$, crown base height $(c b, m)$. In addition, qualitative data, such as damage and condition (living or dead), as well as the scientific name were included.

\subsubsection{Data Analysis: Spatial Patterns}

\section{Spatial distribution of dead trees}

Pair-correlation function $g(r)$

Spatial point pattern analysis makes use of the spatial location of all individuals 
within the study area. To characterize spatial tree mortality patterns we used several so-called summary functions. First, we included the pair-correlation function $g(r)$ (Stoyan and Stoyan, 1994). The $g(r)$ function is the derivative of the Ripley's K-function (Ripley, 1977) and it is described as $g(r)=K^{\prime}(\mathrm{r}) /(2 \pi r)$, where $K(r)$ is the expected number of points within a disk of radius $r$ of an arbitrary point, divided by the intensity $\lambda$ of the pattern (5.1). In general, while $K(r)$ is based on disks and is cumulative within distance $r, g(r)$ is based on rings and following non-cumulative at distance $r$. This makes $g(r)$ more intuitive to interpret: while $g(r)=1$ indicates complete spatial randomness (CSR) at distance r, $g(r)>1$ means that the points are clustered at distance r, whereas $g(r)<1$ indicates regularity at distance $r$, respectively (Stoyan and Stoyan, 1994; Wiegand and Moloney, 2014).

$$
K(r)=\frac{A}{n(n-1)} \sum_{i=1}^{n} \sum_{j \neq 1}^{n} l_{i j}(r) e_{i j}(r)
$$

Where $A$ is the area, $l_{i j}$ is the count function at the specific distance $(r)$ from the reference point and $e_{i j}(r)$ is the edge correction factor. For all summary statistics used in this study we applied the isotropic edge correction (Ripley, 1977; Stoyan and Stoyan, 1994).

\section{Relationship among dead and live trees}

Mark-connection function $p_{i, j}(r)$

Furthermore, we used the bivariate mark-connection function $p_{i, j}(r)$ as summary function to describe the relationship between dead and live trees. For two marked points (dead or live trees) separated by a distance $r$ the $p_{i, j}(r)$ is described as the probability that the first point is type $i$ and the second type $j$ (Illian et al., 2008; Wiegand and Moloney, 2014). Thus the mark connection is denoted as follows:

$$
p_{i, j}(r)=p_{i} p_{j} \frac{g_{i j}(r)}{g(r)}
$$

In this case, the observed pattern $p_{i, j}(r)$ above $\left(p_{i, j}(r)>p_{i} p_{j}\right)$ and below $\left(p_{i, j}(r)<\right.$ $p_{i} p_{j}$ ) the theoretical value indicates association or segregation respectively. In the equation $5.2 g_{i j}$ is the bivariate pair correlation function where $g_{i j}(r)=$ $K_{12}^{\prime}(r) /(2 \pi r)$ and $K_{12}(r)$ is the expected number of points belonging to type 2 
within a disk of radius $r$ of an arbitrary point of type 1 , divided by the intensity $\lambda_{2}$ of the pattern 2 (Stoyan and Stoyan, 1994; Wiegand and Moloney, 2014; Illian et al., 2008).

\section{Spatial and size analysis among live trees}

Mark-correlation function $k_{m m}(r)$

Finally, to test the spatial correlation between live tree sizes, we used the mark correlation function $k_{m m}(r)$. This is a measure of dependence based on marks (e.g. tree diameter) attached to the points (e.g. trees), related to the distance between them. The value of similarity or dissimilarity is analyzed as follows: $\left(m_{1,2}\right)=$ $m_{1} \cdot m_{2}$, where $\mathrm{m}$ are the marks. Then, $k_{m m}(r)$ is described as the normalized mean squared division of the marks $f\left(m_{1}, m_{2}\right)$ (Stoyan and Stoyan, 1994; Illian et al., 2008; Baddeley et al., 2015; Wälder and Wälder, 2008) and can be obtained through the next equation.

$$
k_{m m}(r)=\frac{E[u v][m(u) \cdot m(v)]}{E\left(M, M^{\prime}\right)}
$$

Where $E[u v]$ is the conditional expected value of two points separated by the distance $r ; m(u) \cdot m(v)$ are the marks assigned to the coordinates and $E$ corresponds to the expected value of independent random marks $\left(M, M^{\prime}\right)$ generated through the marginal distribution and serve as a normalization factor. In this case we used the tree diameter as size mark due to, generally, diameter is well correlated with tree height or tree crown, besides $d$ is easier to measure with less errors.

The interpretation of the $k_{m m}(r)$ is not the same as the classic statistical correlation. As $k_{m m}(r)$ compares the mean of the two marks with the mean of two randomly chosen points, then values $k_{m m}(r)=1$ indicate an absence of correlation, values $k_{m m}(r)>1$ indicate a positive correlation and values $k_{m m}(r)<1$ indicate a negative correlation at a distance $r$ (Stoyan and Stoyan, 1994; Wälder and Wälder, 2008).

\section{Null models and simulation envelopes}

In spatial point pattern analysis, null models act as standard statistical null hypothesis test and can be used in a exploratory or confirmatory purposes (Wiegand 
and Moloney, 2014). In this context, null models normally use point process models to generate random patterns based on certain ecological hypotheses. Selection of an appropriate null model is one of the most challenging tasks (Wiegand and Moloney, 2004) and depends on the specific question.

In this study we used three null models. First, the simplest used null model was complete spatial randomness (CSR) for univariate patterns. Here, we used a homogeneous Poisson process to create random null model data. The homogeneous Poisson process is characterized by a constant point density throughout the study plot and no interaction between individual points. Second, we used a Thomas cluster process to simulated a clustered pattern. The Thomas cluster process simulates cluster centers following using a Poisson process. Following, at the cluster centers daughter-points are placed and the number of points per cluster and the size of the cluster follow a two-dimensional Gaussian distribution (Illian et al., 2008). In the case of the pair correlation the formula is described as follows:

$$
g\left(r, \lambda_{p}, \sigma\right)=1+\frac{1}{4 \pi \lambda_{p} \sigma^{2}} \exp \left(-\frac{r^{2}}{4 \sigma^{2}}\right)
$$

Where $\lambda_{p}$ is the intensity of cluster centers or parents and $\sigma$ is the standard deviation of displacement of daughter-points from the parents. The fitting process was carried out through the "kppm" function from the SPATSTAT package (Baddeley et al., 2015). Last, we used random labeling, where the null model randomizes the marks of a bivariate pattern while keeping the point locations constant (Wiegand and Moloney, 2014). Random labeling is the appropriate null model to evaluate a posteriori effects of a given process. This means, that the labeling process rather than the pattern itself is of interest, for example, to test the random mortality hypothesis (Goreaud and Pélissier, 2003)

In order to approximate a statistical significance of $\alpha=0.05$, we used Monte Carlo envelopes built from 199 replicates of the null models. From these simulations, the $5^{\text {th }}$ largest and lowest values, respectively, were used to construct the simulation envelopes. Thus, the interpretation is intuitive, for scales $r$ at which the observed summary function is located within the simulation envelope the null hypothesis is accepted (e.g. no significant departure from the CSR); if the observed summary function is located above the simulation envelope clustering/positive correlation is indicated and correspondingly if the summary function is located 
below the simulation envelope regularity/negative correlation.

Due to simulation envelopes test the null hypothesis at several scales $r$ simultaneously, are susceptible to a Type one error inflation. To account for this, we additionally used the Diggle-Cressie-Loosmore-Ford test (DCLF) to asses the Goodness-of-Fit (GoF) (Loosmore and Ford, 2006; Baddeley et al., 2015). Since the maximum crown radius is $8.7 \mathrm{~m}$, we applied the DCLF test at the scale of 0-18 $\mathrm{m}$ and defined it as maximum distance for interaction or competition among trees. All the analysis in this research were processed through R 3.6.0 (R Core Team, 2019) using the SPATSTAT package (Baddeley and Turner, 2005; Baddeley et al., 2015). For specific questions, methods and models see Table 5.1.

Table 5.1: Summary table for the hypothesis tested and null models applied

\begin{tabular}{|c|c|c|c|}
\hline Research questions & Main background theories & Spatial point patterns & Null models \\
\hline $\begin{array}{l}\text { Are dead trees ran- } \\
\text { domly distributed? }\end{array}$ & $\begin{array}{l}\text { Dead trees show a clumped } \\
\text { distribution in young and old } \\
\text { growth forests. }\end{array}$ & $\begin{array}{l}\text { Spatial distribution of dead trees. } \\
\text { Univariate pair correlation func- } \\
\text { tion } g(r) \text {. }\end{array}$ & CSR null model. \\
\hline $\begin{array}{l}\text { Is tree mortality } \\
\text { density-dependent } \\
\text { due to competition? }\end{array}$ & $\begin{array}{l}\text { Density-dependent tree competi- } \\
\text { tive mortality is usually found in } \\
\text { young forests while agent based } \\
\text { mortality in old growth. }\end{array}$ & $\begin{array}{l}\text { Spatial distribution of dead and } \\
\text { alive trees. Bivariate mark con- } \\
\text { nection function } p_{i j}(r) \text {. }\end{array}$ & Random labeling null model. \\
\hline $\begin{array}{l}\text { Does the tree mortal- } \\
\text { ity lead to spatial reg- } \\
\text { ular distribution of } \\
\text { the remaining alive } \\
\text { trees? }\end{array}$ & $\begin{array}{l}\text { Tree mortality leads to spatial } \\
\text { regular distribution in young } \\
\text { forests and clustered distribution } \\
\text { in old growth. }\end{array}$ & $\begin{array}{l}\text { Spatial distribution of alive trees } \\
\text { before and after the tree mortal- } \\
\text { ity period. Univariate pair corre- } \\
\text { lation function } g(r) \text {. }\end{array}$ & CSR null model. \\
\hline $\begin{array}{l}\text { Does the tree mortal- } \\
\text { ity lead to spatial size } \\
\text { homogeneity of the } \\
\text { remaining alive trees? }\end{array}$ & $\begin{array}{l}\text { Spatially tree size heterogeneity } \\
\text { is found in old growth forests } \\
\text { and related to natural perturba- } \\
\text { tion regimes. }\end{array}$ & $\begin{array}{l}\text { Spatial and size related distribu- } \\
\text { tion of alive trees before and after } \\
\text { the tree mortality period. Mark- } \\
\text { Correlation function } k_{m m}(r) \text {. }\end{array}$ & Random labeling null model. \\
\hline
\end{tabular}

\subsection{Results}

\subsubsection{Dead and live trees tracking}

The density of dead and live trees was dominated mainly by two species, namely P. montezumae and A. firmifolia. During 1974 - 1989, the mean annual death was 17.5 trees, only $7 \%$ of $P$. montezumae trees died, while for A. firmifolia $21 \%$. However, by 1995 these numbers changed, mean annual death was 33 trees from 1989 to 1995, reducing the proportion of dead A. firmifolia, while for P. montezumae 
it increased (Table 5.2). It should be noted that this period was shorter (6 years), indicating that the rate of dead trees was higher in the case of P. montezumae.

Table 5.2: Monitoring of the absolute number of live and dead trees by species throughout the plot $(300 \times 300 \mathrm{~m})$ per measurement year. Tracking the same tagged trees for 20 years.

\begin{tabular}{|c|c|c|c|c|c|c|}
\hline & \multicolumn{3}{|c|}{ Alive } & \multicolumn{3}{|c|}{ Dead } \\
\hline Species & 1974 & 1989 & 1995 & 1989 & 1995 & Total dead \\
\hline P. montezumae & 1610 & 1495 & 1378 & 115 & 117 & 232 \\
\hline A. firmifolia & 699 & 553 & 472 & 146 & 81 & 227 \\
\hline Q. laurina & 52 & 51 & 51 & 1 & 0 & 1 \\
\hline P. ayacahuite & 2 & 2 & 2 & 0 & 0 & $\mathbf{0}$ \\
\hline Other & 1 & 1 & 1 & 0 & 0 & $\mathbf{0}$ \\
\hline Total & 2364 & 2102 & 1904 & 262 & 198 & 460 \\
\hline
\end{tabular}

Most of the trees that died, regardless the species and period, had a rather small $d$ (Figure 5.2). However, while P. montezumae dead trees were found in all diametric categories in both measurements (1989 and 1995), for A. firmifolia, most of dead trees were given by the smaller categories. Besides, most of $A$. firmifolia larger dead trees were found by 1989 (Figure 5.2).
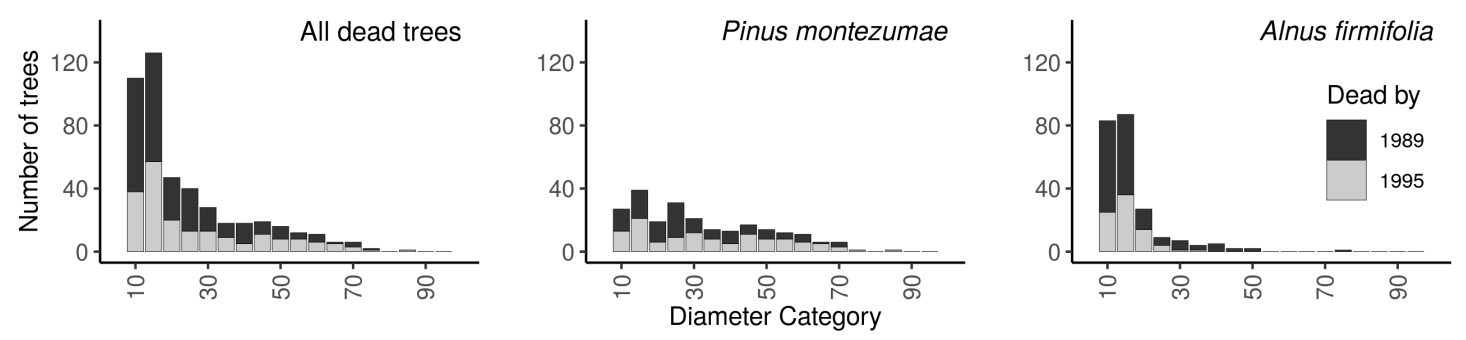

Figure 5.2: Diametric distributions of dead trees in all measurement period. The bar colors are given by the year, gray $=1989$ and black $=1995$.

The sizes of the live trees by 1974 and 1995 showed a bimodal diametric distribution (Figure 5.3). In both cases the smaller diameters were given by $A$. firmifolia trees and the larger by P. montezmae, meaning that the pines were the dominant trees in the study area. The shape of the diameter distributions had not changed remarkably in 15 years of measurements and only shifted from one category to another (Figure 5.3).

\subsubsection{Spatial patterns of dead trees}

The mapped data of all dead trees during the entire 20-year period are illustrated in Figure 5.4. The overall pair-correlation function showed that tree mortality 

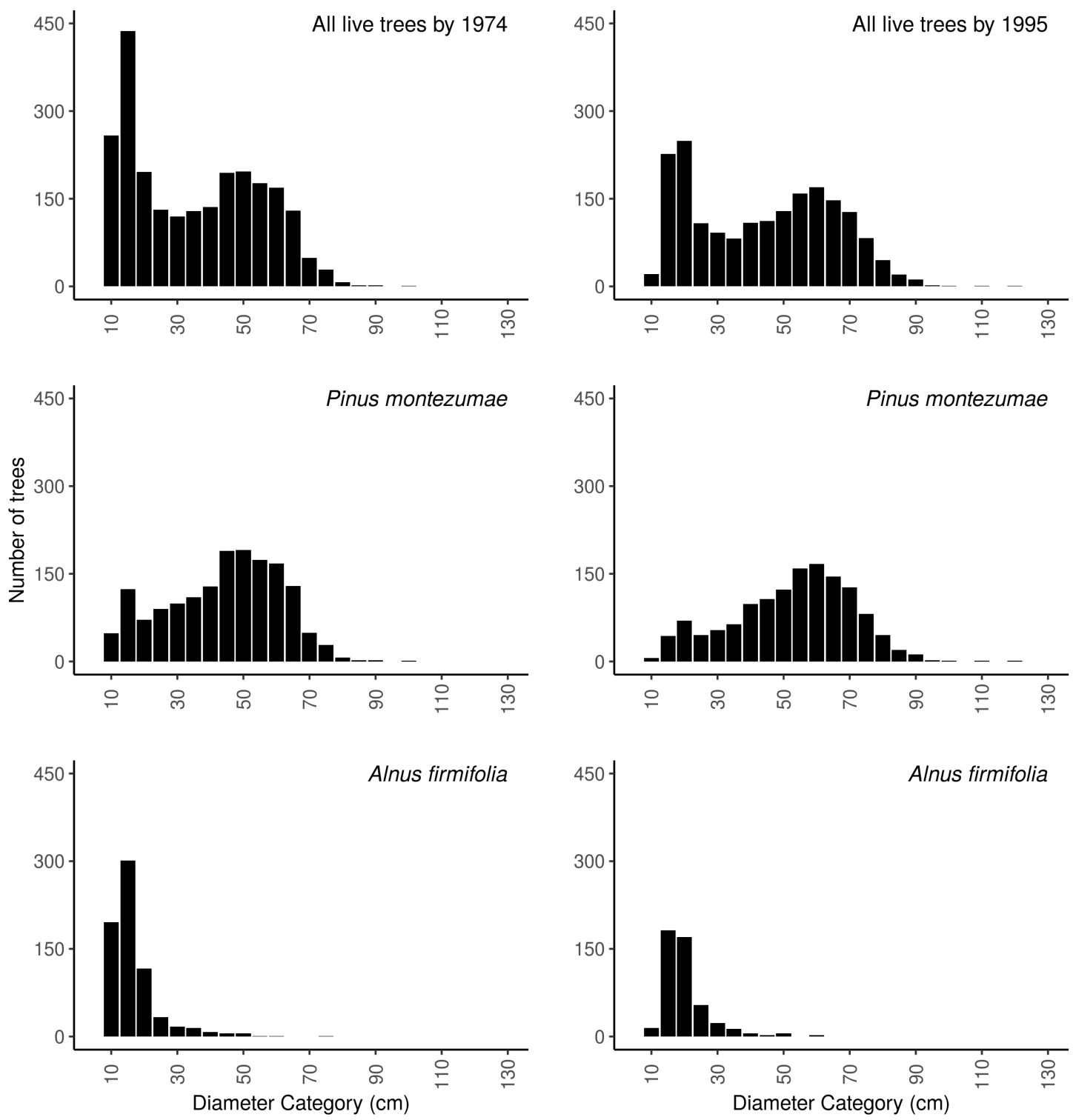

Figure 5.3: Diametric distributions of live trees by 1974 and 1995

significantly differed from CSR at various scales after 20 years. All dead trees were aggregated at short to medium scales (0.0-18.0 m). At lager scales, no clear deviation from the null model could be observed (Figure 5.5). The analysis by species showed some differences: the aggregation was significant at shorter distances for P. montezumae ( $<12 \mathrm{~m})$, while A. firmifolia was aggregated at almost all scales (Figure 5.5).

Since the pair correlation function $g(r)$ revealed significant clustering of tree mortality, we fitted the Thomas process to all dead trees. The Thomas process 
could model the observed pattern quite well and the observed pattern was within the simulation envelopes at almost all scales $r$. The parameters of the final Thomas process model for the all dead trees group resulted in a density of 443 clusters in the whole area $\left(49 \mathrm{ha}^{-1}\right)$, with a mean of 1.02 points around the parents or daughters. P. montezumae showed a density of 240 clusters $\left(26 \mathrm{ha}^{-1}\right)$ and a mean of 0.97 daughters, while A. firmifolia showed 130 clusters $\left(15 \mathrm{ha}^{-1}\right)$ with a mean of 1.72 daughters (Figure 5.6).

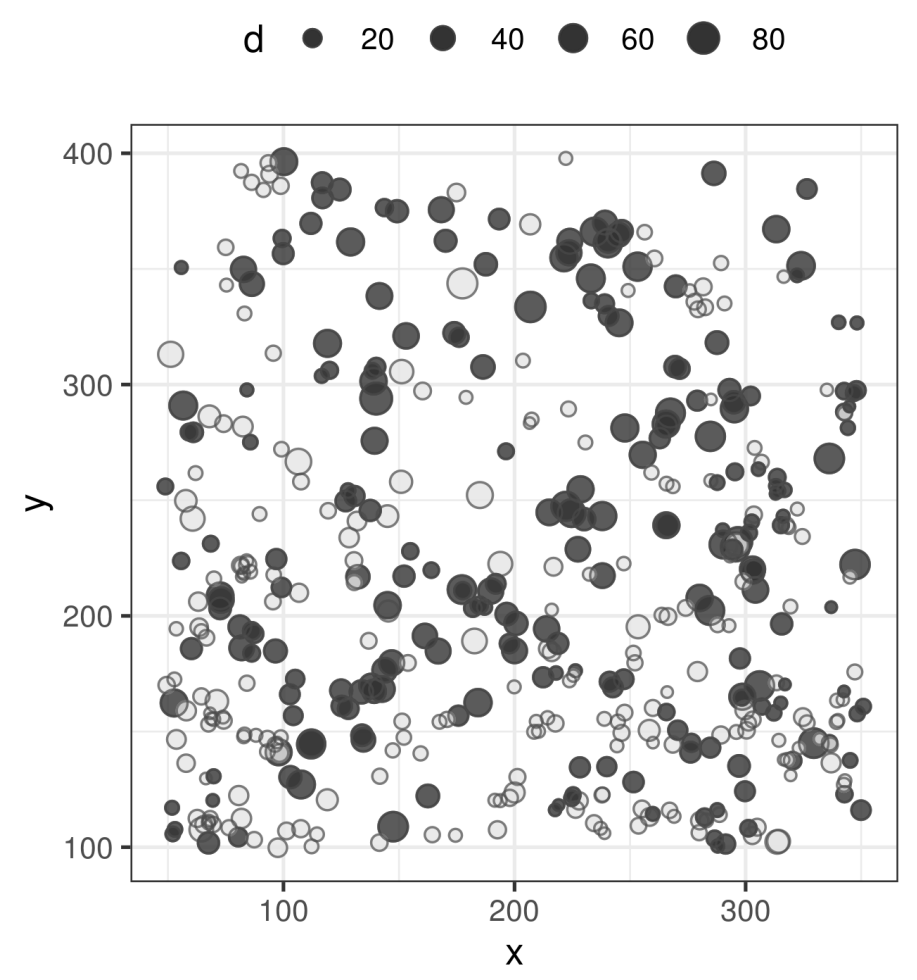

Figure 5.4: Study plot $(300 \times 300 \mathrm{~m})$ showing the spatial distribution of all dead trees. The darker points represent $P$. montezumae and the lighter $A$. firmifolia trees; the size of the circles is scaled to tree diameter measured at the beginning in 1974; the $\mathrm{x}$ and $\mathrm{y}$ axes are the distance in meters.

\subsubsection{Spatial relationship between dead and live trees}

\section{Dead vs Live trees after 20 years}

The testing for density dependencies between dead and live trees $\mathrm{p}_{i j}(\mathrm{r})$, showed no difference for most scales in the overall analysis (Figure 5.7, left). However, 

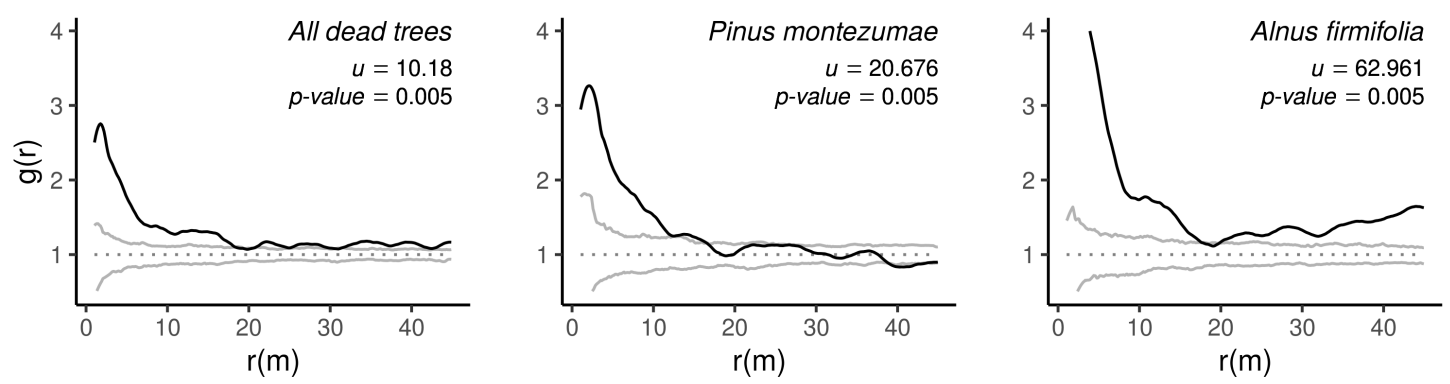

Figure 5.5: Homogeneous pair-correlation function $g(r)$ applied to all dead trees [left], P. montezumae [center] and A. firmifolia [right], by the end of the measurement period. Where the black solid line describes the observed $g(r)$; the gray solid lines are the $95 \%$ upper and lower confidence limits constructed using 199 Monte Carlo randomizations of the CSR null model. The plots show the statistic test $u$ and $p-v a l u e s$ obtained through DCLF test at the maximum interaction [competition] scale [0-18 m.].
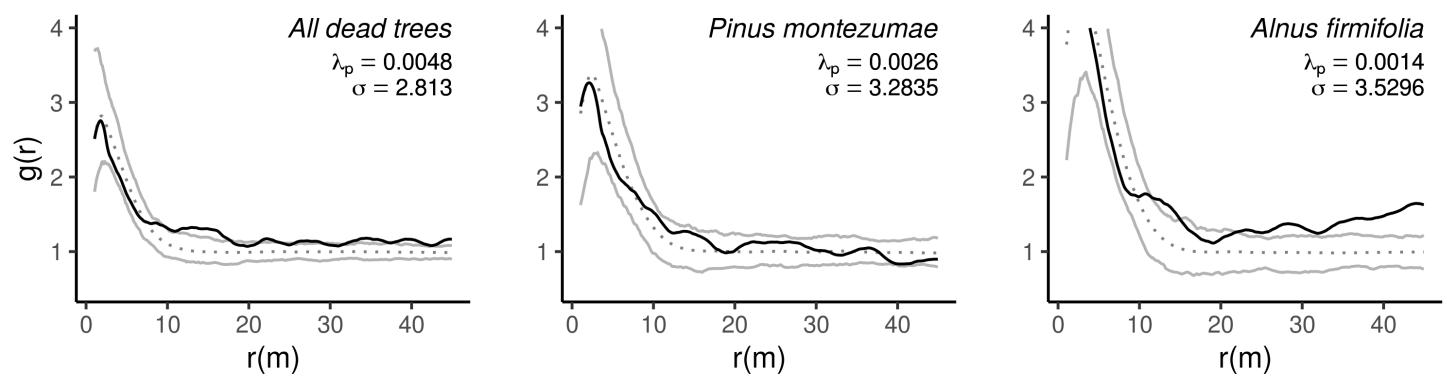

Figure 5.6: Thomas cluster process applied to the pair-correlation function $g(r)$ of dead trees. Where the black solid line describes the observed $g(r)$; the gray solid lines are the 95\% upper and lower confidence limits constructed using 199 Monte Carlo randomizations of the Thomas cluster process; $\lambda_{p}$ and $\sigma$ are the intensity and standard deviation from the fitted cluster parameters.

at specific distances this relationship showed a tendency toward segregation at short scales. The analysis by species indicated that the relationship of $P$. montezumae dead trees and all live trees have a tendency towards segregation at certain short scales, being the most pronounced around $12 \mathrm{~m}$ (Figure 5.7, middle). Nevertheless, for $A$. firmifolia it was different, the dead trees spatial distribution showed segregation from the live ones at short scales and a tendency towards attraction at medium/larger ones (Figure 5.7, right), only significant around 15 m. 

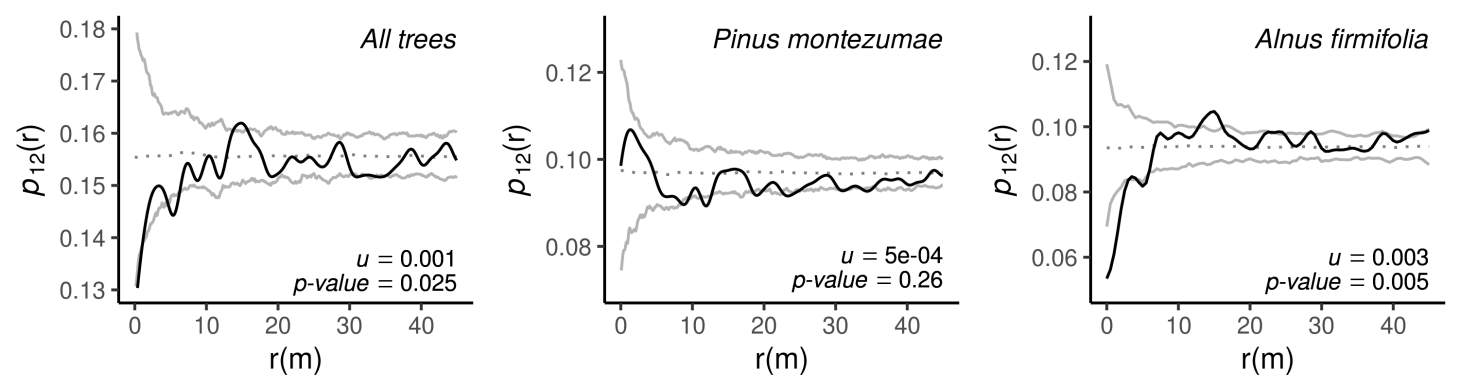

Figure 5.7: Bivariate mark-connection function $p_{12}(\mathrm{r})$ for testing spatial relationships between dead and live trees at various scales $\mathrm{r}(\mathrm{m})$. The black solid line describes the observed $p_{12}(\mathrm{r})$; the gray solid lines are the $95 \%$ upper and lower confidence limits constructed using 199 Monte Carlo simulations of the random labeling null model. The plots show the statistic test $u$ and $p$-values obtained through DCLF test at the maximum interaction [competition] scale [0-18 m.].

\subsubsection{Spatial patterns of live trees}

\section{Pair correlation function}

In order to asses the changes in the spatial distribution of the remaining live trees, we made size classes based on percentiles (small $=\left[d<=33^{\text {rd }}\right]$, medium $=\left[>33^{r d} d<=66^{\text {th }}\right]$, and large $=\left[d>66^{\text {th }}\right]$ ). This provides consistency by using a standardized hierarchical structures to each measurement period and allows to have enough individuals to perform the spatial analysis. For the first measurement period the small class included trees with $d<=19 \mathrm{~cm}$, the medium class trees with $>19 \mathrm{~cm} d<=46.7 \mathrm{~cm}$, and the larger class trees with $d>46.7 \mathrm{~cm}$. For last measurement period (1995) the small class included trees with $d<=28.7 \mathrm{~cm}$, the medium class trees with $>28.7 \mathrm{~cm} d<=56.6 \mathrm{~cm}$, and the larger class trees with $d>56.6 \mathrm{~cm}$.

Spatial patterns for all live trees were different among size classes, but remain almost the same through time. By 1974 the small live trees were more aggregated than expected in almost all scales, while the medium size class trees were aggregated at short scales and the larger trees were aggregated only in very short ones (Figure 5.8, upper plots). After 20 years, in 1995 the remaining live trees showed almost no difference in spatial distributions related to size classes; however, small differences are shown in the medium size class (Figure 5.8, middle plots), by 1995 showed a weaker clumping at short scales compared to the 1974 distribution. 

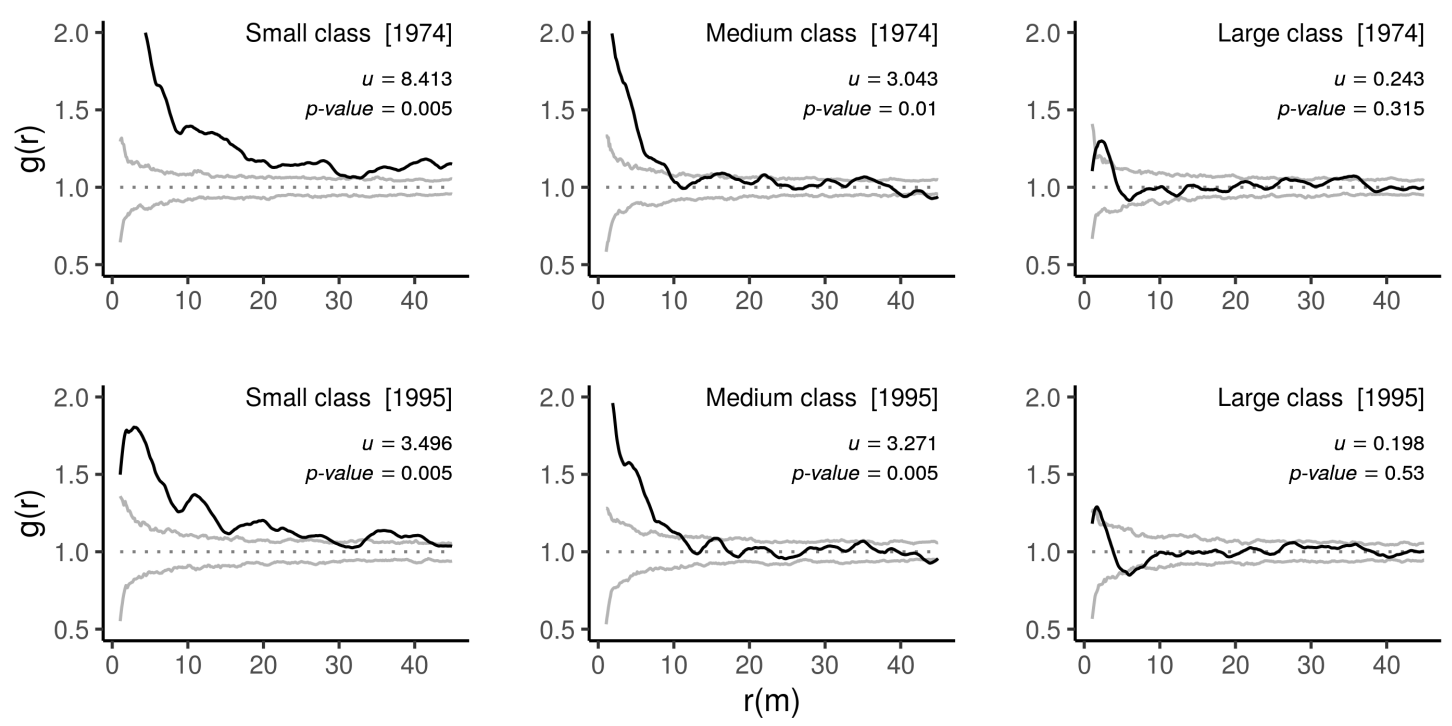

Figure 5.8: Homogeneous pair-correlation function $g(r)$ applied to all live trees from 1974 and the remaining ones from 1995 by diameter classes; from smaller [left] to larger [right]. Where the black solid line describes the observed $g(r)$; the gray solid lines are the $95 \%$ upper and lower confidence limits constructed using 199 Monte Carlo randomizations of the CSR null model. The plots show the statistic test $u$ and $p-$ values obtained through DCLF test at the maximum interaction [competition] scale [0-18 m.].

Thomas cluster process was fitted only to the small and medium size classes for the live trees both in 1974 and 1995. The parameters of the final Thomas process model for the small class [1974] group resulted in a density of 203 clusters in the whole area $\left(22 \mathrm{ha}^{-1}\right)$, with a mean of 3.9 daughters. The medium class [1974] showed a density of 1123 clusters $\left(123 \mathrm{ha}^{-1}\right)$ and a mean of 0.7 daughters. Finally the small class [1995] has a density of 252 clusters $\left(28 \mathrm{ha}^{-1}\right)$ with a mean of 2.52 daughters and the medium class [1995] with a density of 891 clusters $\left(97 \mathrm{ha}^{-1}\right)$ and a mean of cluster size of 0.71 (Figure 5.8).

\section{Mark correlation function}

The results of the Mark Correlation Function $\left(\mathrm{k}_{m m}(\mathrm{r})\right)$ showed that the tree mortality did not affect the spatial-size original distribution. Live trees at the beginning had a negative correlation at different scales (size heterogeneity), which remained at the end of the measurement period. The negative correlation at the beginning was significant on several scales (6.0-18.5, 37.5-42.5) (Figure 5.10). In general this tendency was retained by 1995 , only few small differences at very specific scales 

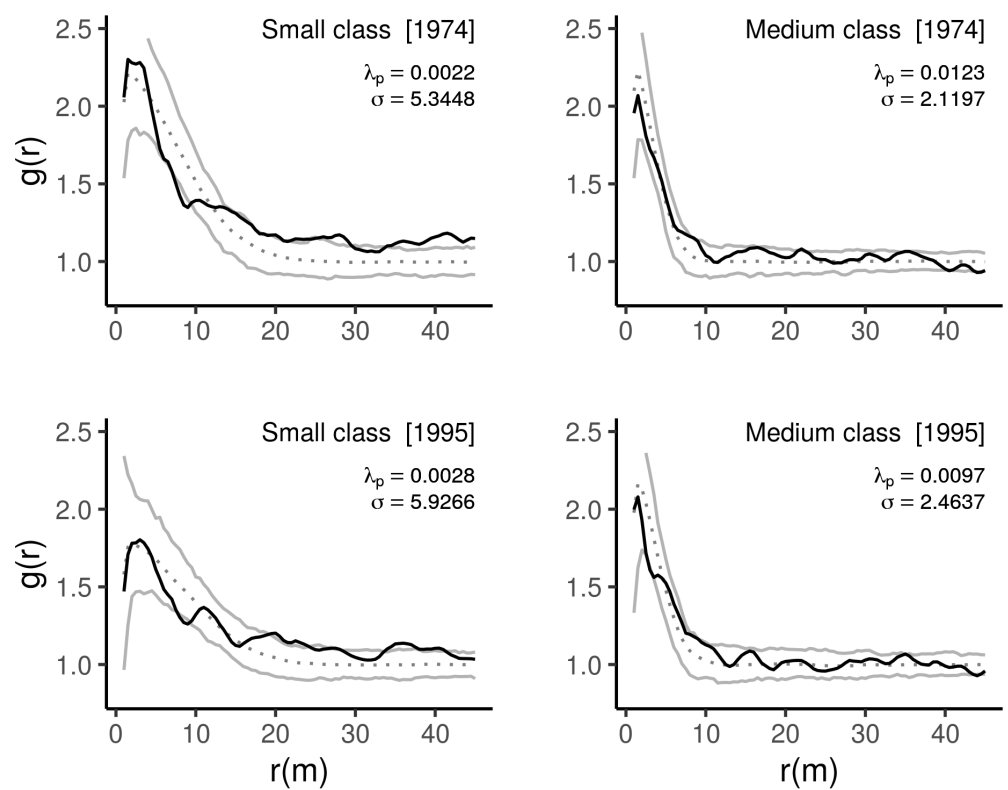

Figure 5.9: Thomas cluster process applied to the pair-correlation function $g(r)$ of live trees by class. Where the black solid line describes the observed $g(r)$; the gray solid lines are the $95 \%$ upper and lower confidence limits constructed using 199 Monte Carlo randomizations of the Thomas cluster process; $\lambda_{p}$ and $\sigma$ are the intensity and standard deviation from the fitted cluster parameters.

were detected (Figure 5.10).
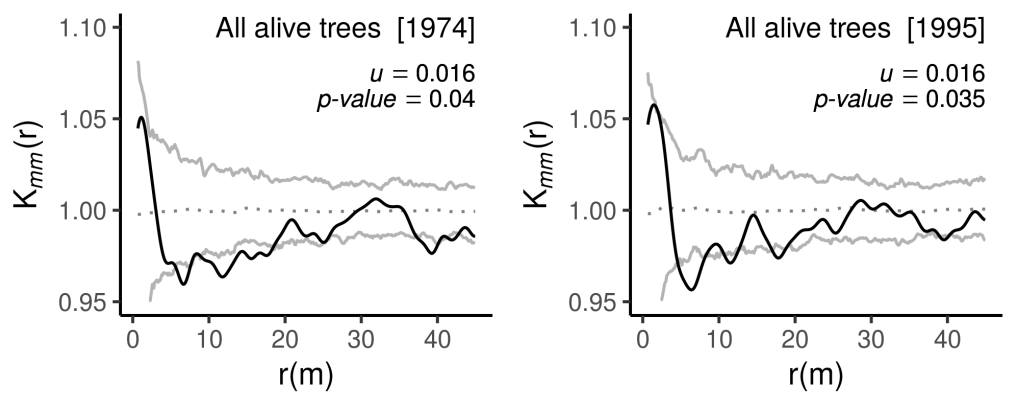

Figure 5.10: Mark correlation function $\mathrm{k}_{m m}(\mathrm{r})$ applied to live trees at the beginning [left] and the end [right] of measurement period using diameter as mark. The black solid line is observed $\mathrm{k}_{m m}(\mathrm{r})$; the gray solid lines are the $95 \%$ upper and lower confidence limits constructed using 199 Monte Carlo randomizations of the random labeling null model. The plots show the statistic test $u$ and $p-v a l u e s$ obtained through DCLF test at the maximum interaction [competition] scale [0-18 m.]. 


\subsection{Discussion}

The main focus of this research was to deepen current knowledge of tree mortality in mature temperate forests. According to our major findings, the spatial distribution of tree mortality i) occurs in clusters at different scales; ii) in general, did not show strong evidence of competition mortality by suppression, iii) the spatial distribution of the live trees did not show strong changes, and iv) spatial size heterogeneity, of the live trees, was maintained the entire time period. These results are consistent with other studies carried out in mature and old-growth forests (Larson et al., 2015; Getzin et al., 2006).

\subsubsection{Spatial patterns of dead trees}

Trees that died in the study area and during the sampling term were spatially clustered at various scales. In general, this clumped arrangement of dead trees is driven by density-dependent competitive mortality, often related to the selfthinning process in young forests (Kenkel, 1988; Kenkel et al., 1997; Wiegand and Moloney, 2014) and by non-competitive or agent-based tree mortality, where mortality is caused by a variety of disturbance agents (Franklin et al., 2002; Pickett and White, 1985). In the study region, the most common disturbance agents are fire, plagues, and anthropogenic interventions (Rodríguez-Trejo, 2008; FonsecaGonzález et al., 2016). However, by the time of this study, only a small fire was detected in the southern part of the plot that was contained before it caused a mayor damage to the trees.

In general, other causes of agent-based tree mortality are related to environmental factors, such as high temperatures and droughts (Franklin et al., 1987). Throughout the region there were severe droughts seasons in 1983 and 1988 [-3/4 values of the Palmer Drought Severity Index (PDSI)] (Stahle et al., 2016) before the first re-measurement in 1989, overlapping with El Niño/Southern Oscillation events (Wolter and Timlin, 2011). Severe droughts cause stress on trees and can increase their probabilities to die at various scales (Choat et al., 2018; Franklin et al., 1987). This provides another perspective that might help explain the spatial patterns of dead trees in Figure 5.5 and mortality rates shown in Table 5.2 and Figure 5.2, similarly to the study of van Mantgem and Stephenson (2007) in a 
temperate forest. However, more research is needed in order to understand what is the effect of droughts on the species studied, are they tolerant or intolerant species to drought?, to what kind of drought are they adapted better?

\subsubsection{Spatial relationship between dead and live trees}

Competitive tree mortality by suppression, was not supported by the data. However, dead individuals of $A$. firmifolia showed a tendency to aggregation with live trees, although only significant at scales around $15 \mathrm{~m}$, thus it would not be appropriate to assume density competition due to the mean crown radius for this species is around $2 \mathrm{~m}$ and for P. montezumae is around $3.5 \mathrm{~m}$. Some processes could be the possible explanation for this: i) age, as this species is a pioneer species (Gutiérrez-Guzmán et al., 2005) and whereas as the forest succession develops other species take its place, ii) disturbance agents, the severe droughts seasons in 1983 and 88, see the number of $A$. firmifolia death in Table 5.2. Especially in the second case, severe droughts would exacerbate competition for water as a limited resource, resulting in clusters of dead trees, a situation that would be explained more by scramble competition (Wiegand and Moloney, 2014).

\subsubsection{Spatial patterns of live trees}

The uniform distribution theory was not fully supported by the study. However, processes that usually lead to uniform distribution of the remaining trees are specially found in young forests (Kenkel et al., 1997; Larson et al., 2015). In other cases, old growth forests showed no significant changes towards uniformity (Larson et al., 2015). Nevertheless, it is expected in old growth forests, that tree mortality by non-competitive agents leads to a heterogeneous outcome of live trees (Franklin et al., 2002) and forests that have spatial and size heterogeneity become more resilient to disturbances (Stephens et al., 2008).

In this research, the rates of tree mortality maintained the size spatial heterogeneity through time (Figure 5.10). This is, to certain extent, similar to those fire-resilient forests of Jeffery pine in California (Stephens et al., 2008). This has important management implications, due to, historically in Mexico some common 
silvicultural treatments have been focused to produce uniform stands (Bray and Merino-Pérez, 2005), contrasting with the natural structure of resilient forests. Furthermore, this information can be used as basis for designing forest restoration plans and programs, based on spatial and size heterogeneity to promote stands close to natural structures similar to those found in this study.

\subsubsection{Concluding remarks}

To the best of our knowledge, especially for the Mexican forests, there is a lack of long-term information taken from medium-large plots to provide the insights mentioned above. This study has both, a relatively large plot and standardized repeated measurements during 20 years; however, for this work no spatial data of recruitment were taken. In addition, the minimal size of the trees to be included was $7.5 \mathrm{~cm}$ of diameter at $1.30 \mathrm{~m}$ from the ground. Therefore, we recommend that further research would include more information regarding seedlings and a standardized protocol for recording the disturbances. Finally, although the measurement period was about 20 years, it is still a short period given the time needed for the forest to grow, thus we believe that longer period of time is needed to have a better understanding of general forest processes.

Finally, this study provides relevant information on tree mortality and shows that it is a dynamic process that changes over time, space and is species dependent. Understating tree mortality dynamics and the process that generate specific spatial patterns in forests is fundamental to the sustainable forest management (Franklin et al., 2002, 2007; Stephens et al., 2008). In accordance to the principles of the continuous cover forestry or close to nature forestry (von Gadow et al., 2002), it is necessary to understand how natural forests, as dynamic systems, develop through time and space in order to emulate these natural energy inputs and outputs throughout silvicultural treatments. 


\section{Literature}

Acosta-Mireles, M., Torres-Rojo, J.M., Rodríguez-Franco, C., 1997. Predicción del rendimiento en Pinus montezumae lamb. usando modelos de distribuciones diamétricas. Ciencia forestal en México 22, 71-89.

Agee, J.K., 1993. Fire ecology of pacific northwest forests. Island Press, Washington D.C.

Baddeley, A., Rubak, E., Turner, R., 2015. Spatial Point Patterns: Methodology and Applications with R. Chapman and Hall/CRC. URL: https://www.amazon. es/Spatial-Point-Patterns-Applications-Interdisciplinary/dp/1482210207.

Baddeley, A., Turner, R., 2005. Spatstat: An R package for analyzing spatial point patterns. Journal of Statistical Software 12, 1-42. URL: https://www.jstatsoft.org/ article/view/v012i06, doi:10.18637/jss.v012.i06.

Bray, B., Merino-Pérez, L., 2005. La experiencia de las comunidades forestales en México. Instituto Nacional de Ecología (INE-SEMARNAT), Mexico, DF.

Brown, C., Law, R., Illian, J.B., Burslem, D.F.R.P., 2011. Linking ecological processes with spatial and non-spatial patterns in plant communities. Journal of Ecology 99, 1402-1414. URL: http://doi.wiley.com/10.1111/j.1365-2745.2011. 01877.x, doi:10.1111/j.1365-2745.2011.01877.x.

Choat, B., Brodribb, T.J., Brodersen, C.R., Duursma, R.A., López, R., Medlyn, B.E., 2018. Triggers of tree mortality under drought. Nature 558, 531-539. URL: http: //www.nature.com/articles/s41586-018-0240-x, doi:10.1038/s41586-018-0240- $x$.

Fonseca-González, J., De Los Santos-Posadas, H.M., Llanderal-Cázares, C., Cibrián-Tovar, D., Rodríguez-Trejo, D.A., Vargas-Hernández, J., 2016. Ips e insectos barrenadores en árboles de Pinus montezumae dañados por incendios forestales. Madera y Bosques 14, 69-80. URL: http://myb.ojs.inecol.mx/ index.php/myb/article/view/1220, doi:10.21829/myb.2008.1411220.

Franklin, J.F., Mitchell, R.J., Palik, B.J., 2007. Natural disturbance and stand development principles for ecological forestry. Technical Report. Department of Agriculture, Forest Service, Northern Research Station. Newtown Square, PA: U.S. URL: http://www.nrs.fs.fed.us/pubs/3293.

Franklin, J.F., Shugart, H.H., Harmon, M.E., 1987. Tree Death as an Ecological Process. BioScience 37, 550-556. URL: https://academic.oup.com/bioscience/ article-lookup/doi/10.2307/1310665, doi:10.2307/1310665.

Franklin, J.F., Spies, T.A., Pelt, R.V., Carey, A.B., Thornburgh, D.A., Berg, D.R., Lindenmayer, D.B., Harmon, M.E., Keeton, W.S., Shaw, D.C., Bible, K., Chen, J.., 2002. Disturbances and structural development of natural forest ecosystems 
with silvicultural implications, using Douglas-fir forests as an example. Forest Ecology and Management 155, 399-423. URL: http://www.treesearch.fs.fed.us/ pubs/6026.

Franklin, J.F., Van Pelt, R., 2004. Spatial aspects of structural complexity in oldgrowth forests. Journal of Forestry 102, 22-28. URL: https://academic.oup.com/ jof/article/102/3/22/4613153, doi:https://doi.org/10.1093/jof/102.3.22.

von Gadow, K., Nagel, J., Saborowski, J. (Eds.), 2002. Continuous Cover Forestry. volume 4. Kluwer Academic Plublishers, Dordrecht. doi:10.1007/ 978-94-015-9886-6.

Getzin, S., Dean, C., He, F., A. Trofymow, J., Wiegand, K., Wiegand, T., 2006. Spatial patterns and competition of tree species in a Douglas-fir chronosequence on Vancouver Island. Ecography 29,671-682. URL: http://onlinelibrary.wiley. com/doi/10.1111/j.2006.0906-7590.04675.x/abstract, doi:10.1111/j.2006.0906-7590. 04675.x.

Goreaud, F., Pélissier, R., 2003. Avoiding misinterpretation of biotic interactions with the intertype K12 function: population independence vs. random labelling hypotheses. Journal of Vegetation Science 14, 681-692. URL: https://onlinelibrary. wiley.com/doi/abs/10.1111/j.1654-1103.2003.tb02200.x, doi:10.1111/j.1654-1103. 2003.tb02200.x.

Gutiérrez-Guzmán, B., Etchevers-Barra, Jorge D. Velázquez-Martínez, A., Almaraz-Suárez, J., 2005. Influencia del aile (Alnus firmifolia) en el crecimiento de plantas de Pinus patula. Terra Latinoamericana 1, 88-96. URL: http://www.redalyc.org/articulo.oa? id $=57323112$.

Illian, D.J., Penttinen, P.A., Stoyan, D.H., Stoyan, D., 2008. Statistical Analysis and Modelling of Spatial Point Patterns. 1 edition ed., Wiley-Interscience, Chichester, England ; Hoboken, NJ.

Jardel-Peláez, E., Alvarado-Celestino, E., Morfín-Rios, J., Castillo-Navarro, F., Flores-Garnica, J., 2009. Regímenes de fuego en ecosistemas forestales de México, in: Flores-Garnica, J. (Ed.), Impacto ambiental de incendios forestales. 1 ed.. Mundi-Prensa, México, pp. 73-100.

Kenkel, N., Hendrie, M., Bella, I., 1997. A long-term study of Pinus banksiana population dynamics. Journal of Vegetation Science 8, 241-254. URL: http: //doi.wiley.com/10.2307/3237353, doi:10.2307/3237353.

Kenkel, N.C., 1988. Pattern of Self-Thinning in Jack Pine: Testing the Random Mortality Hypothesis. Ecology 69, 1017-1024. URL: http://doi.wiley.com/10. 2307/1941257, doi:10.2307/1941257.

Larson, A.J., Lutz, J.A., Donato, D.C., Freund, J.A., Swanson, M.E., HilleRisLambers, J., Sprugel, D.G., Franklin, J.F., 2015. Spatial aspects of tree mortality 
strongly differ between young and old-growth forests. Ecology 96, 2855-2861. URL: http://doi.wiley.com/10.1890/15-0628.1, doi:10.1890/15-0628.1.

Law, R., Illian, J., Burslem, D.F.R.P., Gratzer, G., Gunatilleke, C.V.S., Gunatilleke, I.A.U.N., 2009. Ecological information from spatial patterns of plants: insights from point process theory. Journal of Ecology 97, 616-628. URL: http://doi.wiley. com/10.1111/j.1365-2745.2009.01510.x, doi:10.1111/j.1365-2745.2009.01510.x.

Loosmore, N.B., Ford, E.D., 2006. Statistical inference using the g or k point pattern spatial statistics. Ecology 87, 1925-1931. doi:10.1890/0012-9658(2006) 87[1925:SIUTGO]2.0.CO;2.

van Mantgem, P.J., Stephenson, N.L., 2007. Apparent climatically induced increase of tree mortality rates in a temperate forest. Ecology Letters 10, 909-916. URL: http://doi.wiley.com/10.1111/j.1461-0248.2007.01080.x, doi:10. 1111/j.1461-0248.2007.01080.x.

Peet, R.K., Christensen, N.L., 1987. Competition and Tree Death. BioScience 37, 586-595. URL: https://academic.oup.com/bioscience/article-lookup/doi/10.2307/ 1310669, doi:10.2307/1310669.

Pickett, S.T., White, P.S., 1985. The ecology of natural disturbance and patch dynamics. Academic Press.

R Core Team, 2019. R: A language and environment for statistical computing. R Foundation for Statistical Computing. URL: http://www.r-project.orghttps: //www.r-project.org/.

Ripley, B.D., 1977. Modelling spatial patterns: with discussion 39, 172-212.

Rodríguez-Trejo, D., 2008. Fire Regimes, Fire Ecology, and Fire Management in Mexico. AMBIO: A Journal of the Human Environment 37, 548-556. URL: http: //www.bioone.org/doi/abs/10.1579/0044-7447-37.7.548, doi:10.1579/0044-7447-37. 7.548 .

Rodríguez-Trejo, D., 2014. Incendios de Vegetación su Ecología Manejo e Historia. volume 1. 1 ed., Biblioteca Básica de Agricultura, México. URL: https://www. gandhi.com.mx/incendios-de-vegetacion-su-ecologia-manejo-e-historia.

Rodríguez-Trejo, D., Fulé, P., 2003. Fire ecology of Mexican pines and a fire management proposal. International Journal of Wildland Fire 12, 23-37. URL: http://www.publish.csiro.au/paper/WF02040.

Stahle, D.W., Cook, E.R., Burnette, D.J., Villanueva, J., Cerano, J., Burns, J.N., Griffin, D., Cook, B.I., Acuña, R., Torbenson, M.C., Szejner, P., Howard, I.M., 2016. The Mexican Drought Atlas: Tree-ring reconstructions of the soil moisture balance during the late pre-Hispanic, colonial, and modern eras. Quaternary Science Reviews 149, 34-60. URL: https://www.sciencedirect.com/science/article/ abs/pii/S0277379116302244, doi:10.1016/J.QUASCIREV.2016.06.018. 
Stephens, S.L., Fry, D.L., Franco-Vizcaíno, E., 2008. Wildfire and Spatial Patterns in Forests in Northwestern Mexico: The United States Wishes It Had Similar Fire Problems. Ecology and Society 13,1-13. URL: http://www.ecologyandsociety. org/vol13/iss2/art10/, doi:10.5751/ES-02380-130210.

Stoyan, D., Stoyan, S., 1994. Fractals, random shapes and point fields. Methods of geometrical statistics. John Wiley \& Sons, Chichester, England ; Hoboken, NJ. URL: https://www.wiley.com/en-us/Fractals $\{\%\} 2 C+$ Random +Shapes+and +Point+ Fields\{\%\}3A+Methods+of+Geometrical+Statistics-p-9780471937579.

Wälder, K., Wälder, O., 2008. Analysing interaction effects in forests using the mark correlation function. iForest - Biogeosciences and Forestry 1, 34-38. doi:10.3832/ifor0449-0010034.

Wiegand, T., Moloney, K., 2004. Rings, circles, and null-models for point pattern analysis in ecology. Oikos 104, 209-229. URL: http://doi.wiley.com/10.1111/j. 0030-1299.2004.12497.x, doi:10.1111/j.0030-1299.2004.12497.x.

Wiegand, T., Moloney, K., 2014. Handbook of Spatial Point-Pattern Analysis in Ecology. CRC Press is an imprint of Taylor \& Francis Group, an Informa business, Boca Raton, FL. URL: https: //www.crcpress.com/Handbook-of-Spatial-Point-Pattern-Analysis-in-Ecology/ Wiegand-Moloney/p/book/9781420082548.

Wolter, K., Timlin, M.S., 2011. El Niño/Southern Oscillation behaviour since 1871 as diagnosed in an extended multivariate ENSO index (MEI.ext). International Journal of Climatology 31, 1074-1087. URL: http://doi.wiley.com/10.1002/joc.2336, doi:10.1002/joc.2336.

Zepeda-Bautista, E., Acosta-Mireles, M., 2000. Incremento y rendimiento maderable de Pinus montezumae Lamb., en San Juan Tetla, Puebla. Madera y Bosques 6, 15-27. URL: https://www.redalyc.org/html/617/61760102/. 


\section{Chapter 6}

\section{Above-Ground Carbon Dynamics in a Mexican Temperate Forest: A Simulation Study}

Ernesto Alonso Rubio-Camacho ${ }^{1,3}$, Juan Antonio López-Hernández ${ }^{2}$, and Jürgen Nagel $^{1}$

\section{Author details}

${ }^{1}$ Department Ecoinformatics, Biometrics \& Forest Growth, Georg-August University of Göttingen. Busgenweg 4, 37077 Gottingen, Germany.

${ }^{2}$ Facultad de Ciencias Forestales, Universidad Autónoma de Nuevo León. Carretera Nacional 85, Km. 145, 67700 Linares, Mexico.

${ }^{3}$ INIFAP-CIRPAC C.E. Centro Altos: Av. Biodiversidad núm. 2470, Col. Las Cruces, Tepatitlán, Jalisco, México. CP. 47600.

Authors contributions

EARC designed the simulation study, conducted the data analysis and wrote the manuscript; JALH coordinated the field data collection and prepared the database; JN supervised the project and approved the final version.

\section{Status}

The manuscript is being prepared for submission to a scientific journal. 


\title{
Above-Ground Carbon Dynamics in a Mexican Tem- perate Forest: A Simulation Study
}

\begin{abstract}
Lately, there has been a debate on forest management for carbon and climate change benefits. However, many studies focus solely on maximizing the carbon balance, but accumulating carbon in situ might not be the best option in all forests, especially in fire-adapted ecosystems. In this study we simulated the carbon balance in a 120-year span in three different scenarios: 1) Protected; 2) Gaps; and 3) Harvest scenarios, the latter with different target diameters $(40$ and $60 \mathrm{~cm}$ ). The study was conducted in a Mexican temperate forest located in northern Puebla, using four pure stands of Pinus patula as initial stands. Results showed that, after 120 years, the largest amount of carbon was stored in situ by the Protected scenario, followed by the Gaps and Harvest scenarios. Although the Protected scenario seemed to be the best option for carbon sequestration, necromass accumulation in fire-adapted ecosystems increases the risk for more extensive and severe fires, which could release more carbon into the atmosphere, while having a negative effect on forest resilience. Instead, a more convenient approach would be the Gaps scenario since it emulated the effect of mixed-severity disturbances, it reduced the amount of carbon from tree mortality, increased the carbon storage in live trees, and enhanced productivity. Nonetheless, the Harvest scenarios seemed to be a better option for carbon sequestration and storage. The main factor was the substitution effect of using wood products instead of carbon-intensive materials. Besides, the economic impact of harvests could larger than the other alternatives. Forest management is an important component in carbon sequestration and storage, consequently, it plays a key role in climate adaptation. However, to maximize the climate benefits, forests must be managed to take into consideration the natural carbon-balance drivers such as fire and drought regimes, specific to each ecosystem.
\end{abstract}

\subsection{Introduction}

Recently, there has been growing interest in the role of forest management for carbon and climate change adaptation (Bellassen and Luyssaert, 2014; FAO, 2016; Ontl et al., 2020; Pukkala, 2018). For this purpose, two main approaches have been investigated with contradictory findings. First, some authors argue that forest management is the best option for carbon sequestration, as it maintains 
and enhances productivity, while wood from harvesting could be used as a substitute for carbon-intensive materials (Pingoud et al., 2010; Leskinen et al., 2018; Wördehoff et al., 2017). Second, recent studies have found that in the longterm the best climate benefits can be achieved by allowing the forest to grow rather than timber harvesting (Pukkala, 2018). However, the carbon management strategy should be adapted to each ecosystem, since many of them have evolved along with specific disturbance regimes (Pickett and White, 1985). Therefore, retaining carbon in situ may affect forest resilience to such disturbances (Stephens et al., 2008, 2018), which are expected to shift with climate change (Choat et al., 2018).

The carbon balance is a dynamic process that changes over time and is driven by carbon sequestration and storage rates. In general, when stands are young they tend to grow faster, but as they become older the growth rate decreases. Certainly, due to tree mortality and disturbances, forests could release more carbon than they absorb (Mitchard, 2018). However, the carbon balance can be manipulated through silviculture treatments, maintaining or enhancing the growth rate (Crow et al., 2006; Moore et al., 2012), thus capturing more carbon faster and sustained over time, while storing it in timber products (Pukkala, 2017; Wördehoff et al., 2017).

Wood products can store carbon in different ways, which could generate climate benefits (Bergman et al., 2014; FAO, 2016; Leskinen et al., 2018). Approximately half of the biomass in trees is carbon, and when it is converted into wood products the carbon will be stored in them. However, wood products store carbon up to a certain point, and depending on the use and decay rate, can be classified into long, medium, and short-lasting wood products. Construction timber is an example of a long-lasting product, where the decay rate is lower compared to other usages, such as paper, which is an illustration of the short-lasting product. Furniture and veneers would fall into the category of medium-lasting products (Wördehoff, 2016).

Another relevant contribution of wood products is the cascade of use. It refers to the reuse of wood products over time until they are transformed into energy wood, from which no contribution can be derived because it releases carbon rather than storing it (Ciccarese et al., 2014; Wördehoff, 2016; Wördehoff et al., 
2017). For example, after the main use of construction timber, it can be reused in other wood-based materials such as furniture and then converted into firewood (Bergman et al., 2014).

The substitution effect is an important component in carbon forestry and plays a key role in climate change mitigation. Forest wood products can be used as a substitute for carbon intensive-materials or energy, such as concrete and fossil fuels respectively (Gustavsson et al., 2006; Leskinen et al., 2018; UNECE/FAO, 2010). The substitution effect can be estimated through displacement factors, which measure the carbon emissions avoided when a wood-based product is used instead of carbon-intensive materials. Displacement factors may vary depending on wood product types, materials substituted and geographical regions (Sathre and $\mathrm{O}^{\prime}$ Connor, 2010).

Analyses such as that conducted by Leskinen et al. (2018) have shown a mean displacement factor of $1.2 \mathrm{kgC} / \mathrm{kgC}$, based in 51 reviewed studies. With a similar approach, the meta-analysis by Sathre and O'Connor (2010) has found an average displacement factor of $2.1 \mathrm{tC} / \mathrm{tC}$. In a simulation study Wördehoff et al. (2017) used a displacement factor of $1.5 \mathrm{tC} / \mathrm{tC}$ for long- and medium-lasting wood products, meaning that for every $\mathrm{t} C$ stored in substitute wood products, there is a reduction in emissions from carbon-intensive materials of approximately $1.5 \mathrm{tC}$.

Although there has been a debate about the accuracy of displacement factors (Harmon, 2019; Leturcq, 2020), we believe that substitution effects, used with caution, help understand the climate benefits of harvesting. Furthermore, in a general context, the forest management strategy could be based on maximizing both carbon stocks and timber harvesting, taking into consideration the ecosystem-specific carbon balance drivers (Bellassen and Luyssaert, 2014).

In forest ecosystems, carbon dynamics is driven by both natural and anthropogenic factors. The former includes disturbance regimes such as fire, plagues, droughts, and wind storms (Pickett and White, 1985; Heinselman, 1981). For instance, many temperate coniferous forests have evolved alongside specific fire regimes (Jardel-Peláez et al., 2009; Rodríguez-Trejo, 2008), where the dominant species are fire-adapted or even fire-dependent, which is the case of several Mexican pine species (Rodríguez-Trejo and Fulé, 2003). The anthropogenic factor includes human-caused disturbances such as land-use change, deforestation, and 
forest management. These disturbance agents induce changes in the stand carbon balance (Bellassen and Luyssaert, 2014), and at least basic knowledge of these processes should be included in forest management plans. However, this is a process that often requires forest growth simulators to help foresters make better decisions.

In this study, we used ForestSimulator (Nagel, 2003; Hansen and Nagel, 2014) to analyze different silvicultural treatments and their effects on the above-ground carbon dynamics in a Mexican temperate forest. The specific objectives were to estimate and compare the carbon stored in live and dead trees, and substitution effects over a 120-year period. Three alternatives were explored: i) no management actions other than forest protection; ii) emulation of natural disturbances by silvicultural treatments; and iii) implementing traditional silvicultural treatments, such as thinning and harvesting. Besides, it is also discussed if carbon stored on live and dead trees retained in situ is an appropriate forest management strategy for Mexican temperate forests.

\subsection{Materials and Methods}

In order to analyze the effects of silvicultural treatments we selected four pure stands of Pinus patua Schl. et Cham. located in Puebla, Mexico. P. patula is one of the most important species in central Mexico. It is naturally distributed across several Mexican states (Veracruz, Tlaxcala, Hidalgo, Oaxaca and Puebla, among others) and it is well known for its fast growth and wood quality, hence P. patula seemed to be the ideal species to test different growth scenarios. In the following subsections we describe the ForestSimulator settings and the modules used, as well as the specific details of each simulation scenario.

\subsubsection{ForestSimulator settings}

For this purpose, ForestSimulator was adapted for the specific conditions of the Forest Management Unit 2108 (UMF2108). In previous chapters we used information from 49 forest stands to develop different biometric models, which were integrated into ForestSimulator, i.e. Basal Area Increment, Crown width, 
Crown base height, and Tree height diameter models. For this specific simulation we integrated Site Index, Volume, and Taper models from the Forest Biometric System called SIBIFOR (Vargas-Larreta et al., 2017). Besides, we included the above-ground biomass equations from Soriano-Luna et al. (2015) and MartínezDomínguez et al. (2020) respectively. The wood density of P. patula was taken from Castellanos-Sotomayor (2005) to estimate biomass and carbon content.

In this chapter we selected 4 of the 49 plots as initial stands (2012) in the simulations (Table 6.1).

Table 6.1: Initial state, measured in 2012, of the stands used in the simulation. Where $d_{g}=$ quadratic mean diameter, $h_{g}=$ corresponding tree height of the quadratic mean diameter, $H_{o}=$ dominant tree height, $D_{o}=$ corresponding diameter of the dominant tree height, $G=$ basal area, and $V=$ volume.

\begin{tabular}{lcccccccc}
\hline Stand ID & Age & $\begin{array}{c}d_{g} \\
(\mathbf{c m})\end{array}$ & $\begin{array}{c}h_{g} \\
(\mathbf{m})\end{array}$ & $\begin{array}{c}D_{o} \\
(\mathbf{c m})\end{array}$ & $\begin{array}{c}H_{o} \\
(\mathbf{m})\end{array}$ & $\begin{array}{c}\mathbf{N} \\
\left(\mathrm{Nha}^{-1}\right)\end{array}$ & $\begin{array}{c}\mathrm{G} \\
\left(\mathrm{m}^{2} h a^{-1}\right)\end{array}$ & $\begin{array}{c}\mathbf{V} \\
\left(\mathrm{m}^{3} h a^{-1}\right)\end{array}$ \\
\hline UMF2108P007 & 30 & 21.5 & 16.4 & 34.9 & 18.9 & 1244.4 & 45.4 & 433.0 \\
UMF2108P010 & 22 & 25.7 & 19.9 & 33.6 & 21.7 & 711.1 & 36.9 & 418.5 \\
UMF2108P041 & 26 & 21.5 & 13.3 & 30.2 & 15.9 & 633.3 & 23.0 & 188.1 \\
UMF2108P048 & 27 & 27.7 & 15.3 & 36.4 & 17.3 & 422.2 & 25.4 & 217.8 \\
\hline
\end{tabular}

To carry out the simulations we have used the silviculture and carbon modules of ForestSimulator. The silviculture module is useful to carry out silvicultural prescriptions, either by programming them using algorithmic rules or by applying treatments manually. The carbon module, on the other hand, is helpful for estimating carbon content in live and dead trees. The following paragraphs describe the silvicultural and carbon modules in more detail.

\section{Silviculture module}

ForestSimulator has a module designed to apply silvicultural treatments based on a chain of rules derived from the work of Duda (2006). The chain is divided into phases, intervals, and treatment elements (each phase comprises different intervals with their treatment elements). The intervals are designed to restrict the individual treatment elements to certain height ranges, e.g. it can be specified in which height interval thinnings should start and end (Hansen and Nagel, 2014). 
There are different treatment elements available in ForestSimulator. For instance: tree protection, which defines habitat trees; crop-tree selection, that selects the largest tree of the stand and further trees so that a minimum distance between the crop-trees is ensured; the Thinning group is also available including different algorithms for thinning, and can be used to release crop-trees or to perform other thinning alternatives such as thinnings from above and below. There is also a group for timber harvest that includes clear cut, harvest by target diameter, and shelter among other. Finally, it can be specified, different tree planting alternatives in the treatment element called Plant (Hansen and Nagel, 2014).

\section{Carbon module}

The carbon module of ForestSimulator was specially coded to estimate the carbon content in different products and substitution effects. The product classes are defined based on different main wood-based products, as well as by their specific decay rates. Four product main classes are used in ForestSimulator: Long-lasting, medium-lasting, short-lasting, and energy wood products.

Wood products can substitute fossil fuel or carbon-intensive materials. The resulting so-called substitution effects represent an avoidance of fossil-based carbon emissions. Since a fossil fuel carbon emission once avoided is irreversible, substitution effects add up over time. To depict the effect of wood use, a substitution contribution is assigned to the respective wood product classes (Table 6.2). Carbon emissions from the provision of wood (harvesting, transport) are already taken into account in the factors (Wördehoff et al., 2017).

Table 6.2: List of product classes with the corresponding decomposition constants (modified from Wördehoff (2016)).

\begin{tabular}{|c|c|c|c|c|c|}
\hline Category & Product class & & $\begin{array}{l}\text { Decay } \\
\text { rate constant }\end{array}$ & Main products & Substitution \\
\hline 4 & \multirow{3}{*}{ Product with } & Long-lasting & 0.020 & Building, construction timber & \multirow{2}{*}{$\begin{array}{c}\text { Material } \\
(1.5 \mathrm{t} \mathrm{C} / \mathrm{t} \mathrm{C})\end{array}$} \\
\hline 3 & & Medium-lasting & 0.039 & $\begin{array}{l}\text { Wood-based materials, } \\
\text { veneers, furniture }\end{array}$ & \\
\hline 2 & & Short-lasting & 0.320 & Paper, cardboard, cartons & \multirow{2}{*}{$\begin{array}{c}\text { Energy } \\
(0.67 \mathrm{t} \mathrm{C} / \mathrm{t} \mathrm{C})\end{array}$} \\
\hline 1 & Energy wood & & 0.700 & Firewood, pellets & \\
\hline
\end{tabular}




\subsubsection{Simulation scenarios}

Three different scenarios were designed to evaluate the carbon dynamics under different management alternatives. The simulation period was established at 120 years because we wanted to investigate the carbon dynamics in a full rotation. First, a control-type scenario called Protected scenario was designed under protection from disturbances to compare the effects of silvicultural treatments. Second, as the representative ecosystems of the study area have a potential fire regime of frequent, low-severity fires (Jardel-Peláez et al., 2009; Rodríguez-Trejo, 2008), and the tree mortality driven by droughts is given in spatial clusters (see chapter five), we designed the Gaps scenario. For this purpose, we followed a similar approach to Palik and D'Amato (2019) of small patch openings, to emulate the spatial distribution of tree mortality induced by mixed-severity disturbances. Finally, the Harvested scenario, including silvicultural thinnings and crop-tree harvests programmed in a 5-year regime. In this particular case, the scenario was divided into two sub-scenarios with different target diameter: the Harvested $d 40$ scenario and the Harvested d60 scenario with target diameter of 40 and $60 \mathrm{~cm}$ respectively.

To illustrate the treatment variants and their effects on the carbon stocks under consideration, the four pure stands from Table 6.1 served as the initial stands. Rules and assumptions of the simulation scenarios were developed as follows:

(1) Protection scenario $=$ Stand grows with human protection from natural and anthropogenic disturbances.

Scenario phases and assumptions:

- Planting phase. Tree planting is applied to emulate natural regeneration $(3 \times 3 \mathrm{~m})$, it will start when the crown coverage is at minimum of 20 percent no matter the stand height, and the plant success rate is set at $80 \%$.

- Tree planting and mortality are applied at 5-year intervals.

- The stand will be protected throughout the simulation period.

- We assume the absence of major disturbances.

(2) Gaps scenario = Trees are thinned in clusters or gaps to emulate the effects of natural or anthropogenic disturbances.

Scenario phases and assumptions:

- Planting phase. Tree planting is applied to emulate natural regeneration $(3 \times 3 \mathrm{~m})$, it will start when the crown coverage is at minimum of 
20 percent no matter the stand height and the plant success rate is set at $80 \%$.

- Thinning phase. Silvicultural thinnings are applied in 30-year intervals. The first intervention is carried out in the year 2012, by taking out around $120 \mathrm{~m}^{3} \mathrm{ha}^{-1}$ in clusters of trees no matter the tree size or age.

- Tree planting and mortality are applied at 5-year intervals.

- We assume the absence of major disturbances.

(3) Harvest scenario = Thinning and harvest of crop trees are programmed in a 5-year regime of silvicultural interventions.

Scenario phases and assumptions:

- Planting phase. Tree planting will be applied to emulate natural regeneration $(3 \times 3 \mathrm{~m})$, it will start when the crown coverage is at minimum of 20 percent no matter the stand height and the plant success rate is set at $80 \%$.

- Crop selection phase. Crop-tree selection is programmed to start at the height of $12 \mathrm{~m}$. Setting the max number of trees at 100 per hectare.

- Thinning phase. This phase is programmed to start at the height of 14 $m$ and includes two treatments, Crop-tree release and Thinning from above. In both cases the max volume per intervention is set to $50 \mathrm{~m}^{3} \mathrm{ha}$.

- Harvest phase. The harvest phase has only one treatment, Harvest by target diameter. Trees are harvested as soon as they reach the target diameter of 40 and $60 \mathrm{~cm}$ (sub-scenarios "Harvest (d40)" and "Harvest (d60)" respectively) with a max volume of $150 \mathrm{~m}^{3} \mathrm{ha}^{-1}$ per intervention.

- All four phases are programmed to be applied at 5-year intervals.

- We assume the absence of major disturbances.

\subsection{Results}

Overall, the effects of silvicultural treatments on the above-ground carbon stock were different between scenarios. The Protected scenario shows the largest amount of carbon stored in live and dead trees, while the Harvested scenario has the lowest amount of carbon stored in both live and dead trees. However, the Protected scenario has no carbon stored in wood products, and certainly does not have the substitution effects provided by the Gaps and Harvested scenarios. 


\subsubsection{Stand structure}

Figure 6.1 shows an example of the output provided by ForestSimulator. This visualization tool is an aid for the initial evaluation. In the particular case of the stand UMF2108P010, it is possible to infer about the stand structure generated by each scenario. The Protected scenario generated a final stand with bigger trees, while the Gaps scenario seems less homogeneous, and Harvested scenarios denote even more complex structures.

Related to the stand structure, Figure 6.2 shows the diameter distributions generated by the simulation scenarios including all four plots. The initial diameter distribution (beginning, measured in 2012) resembles a normal curve, where the $25 \mathrm{~cm}$ class has the larger number of trees. The diameter distribution generated by the Protected scenario (final output in 2132) approximates a bimodal curve, where the smaller trees are more abundant as a result of the planting strategy, and the larger trees are less abundant as a result of protection. Comparable results were given by the Gaps scenario (2132), but with less trees in the larger classes. While these two scenarios show old trees from the initial state, and new ones from the planting strategy, the Harvest scenarios only show trees from the renewed stand.

Both Harvested scenarios (2132) generated stands similar the to initial stand, i.e. resembling a normal distribution, as a result of the silvicultural treatments. The diameter class of $15 \mathrm{~cm}$ shows the larger number of trees in both Harvest scenarios, but with more trees per hectare in the Harvest (d40) scenario. However, there are more larger trees $d>40 \mathrm{~cm}$ in the Harvest (d60) scenario because the crop-trees selected should reach a diameter of $60 \mathrm{~cm}$.

\subsubsection{Mean annual increment}

Figure 6.3 shows the volume mean annual increment $\left(\mathrm{m}^{3} \mathrm{ha} \mathrm{a}^{-1}\right)$ of the Protected scenario. The stand UMF2108P010 showed the largest volume increment, at the initial age of 22 years it had an increment of $19 \mathrm{~m}^{3} \mathrm{ha}-1$, followed by the stand UMF2108P007 with $14.4 \mathrm{~m}^{3} \mathrm{ha}^{-1}$ at the beginning. In general, the mean annual increment reaches the growth limit at around 60 years in all stands, and then the 
Protected

[2132]

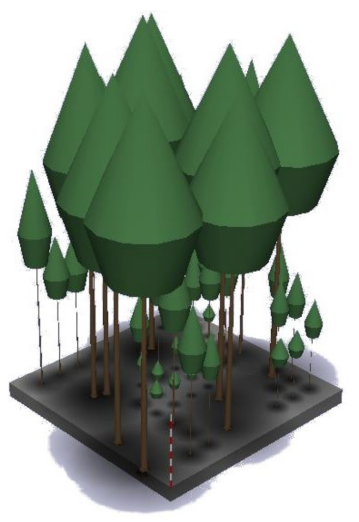

Harvested d40

[2132]

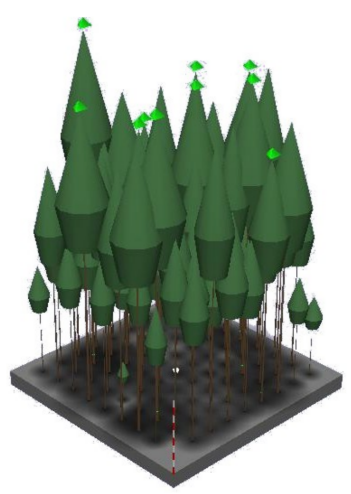

Gaps

[2132]

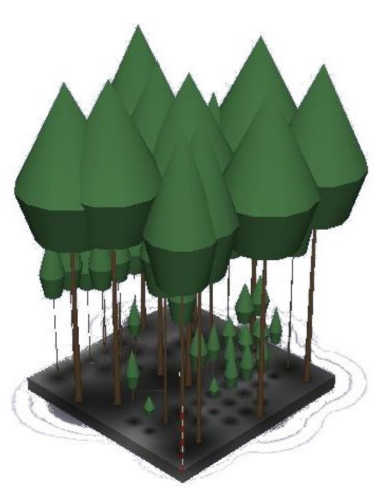

Harvested d60

[2132]

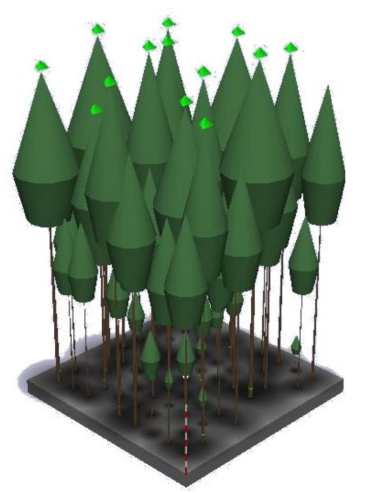

Figure 6.1: Output of ForestSimulator, only one stand is shown as an example. The stand UMF2108P010 is presented as the initial state in 2012 and the simulation scenarios at the end of the simulation period in 2132. In both Harvested scenarios crop trees are marked with a pyramid shape on top. 


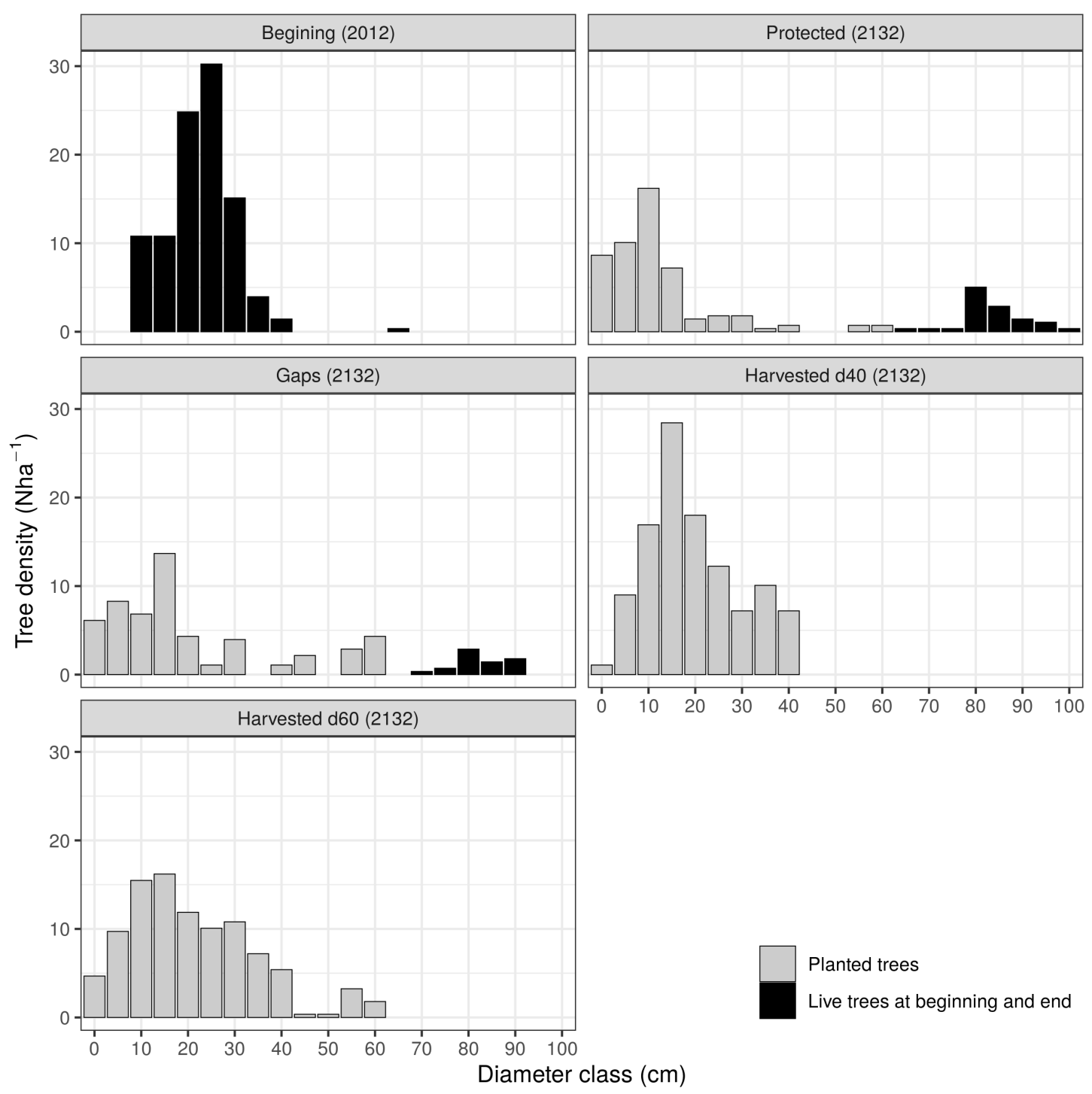

Figure 6.2: Diameter distributions of live trees in all scenarios. 
growth rate gradually decreases until the end of the simulation period.

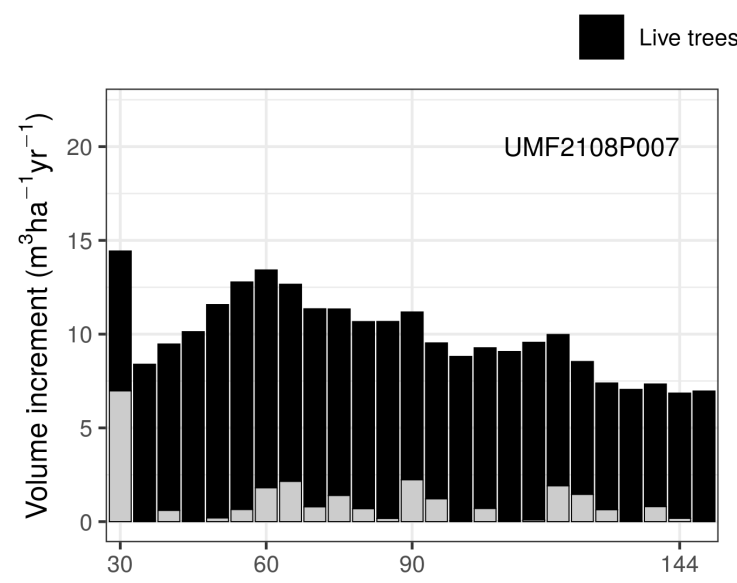

$\square$ Mortality
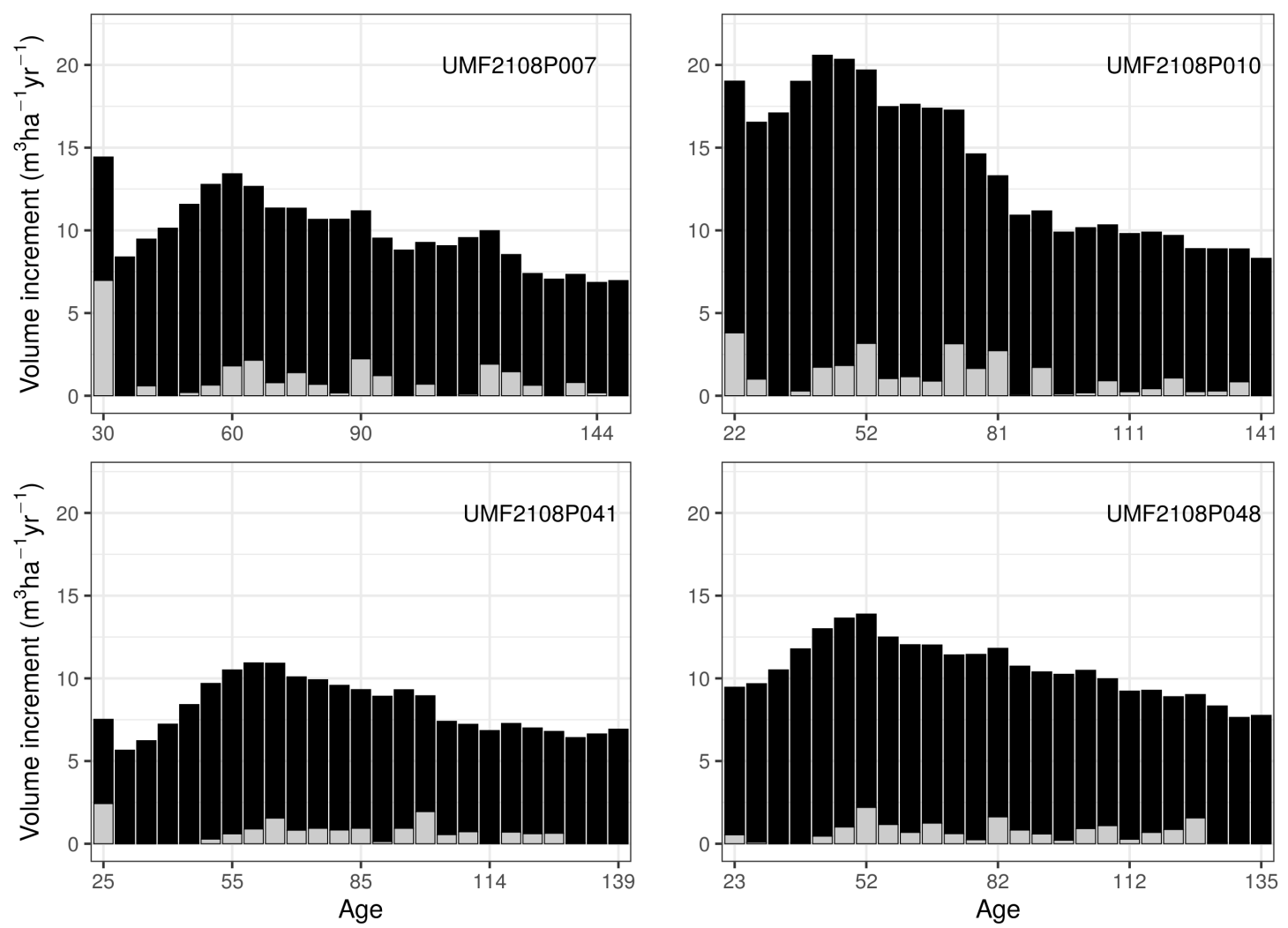

Figure 6.3: Volume mean annual increment (MAI) by stand.

\subsubsection{Stand volume}

The stand volume exhibited an ascending trend in live trees for all scenarios. However, this trend was less pronounced in the Harvested scenarios (Figure 6.4). The mean starting volume in 2012 was $314 \pm 129 \mathrm{~m}^{3} \mathrm{ha}^{-1}$, while the final stand mean volume of live trees was $1055 \pm 87 \mathrm{~m}^{3} \mathrm{ha}^{-1}$ for the Protected scenario, followed by the Gaps scenario with $933 \pm 262 \mathrm{~m}^{3} \mathrm{ha}^{-1}$, the Harvested d60 scenario with $659 \pm 231$ $\mathrm{m}^{3} \mathrm{ha}^{-1}$, and the Harvested $d 40$ scenario with $515 \pm 101 \mathrm{~m}^{3} \mathrm{ha}^{-1}$. In all cases the stand volume was higher than the beginning, even the Harvested $d 40$ scenario that almost doubles the initial volume.

Figure 6.5 shows the effect of treatments (thinning and harvesting) on stand volume trend in live trees. On the one hand, the Gaps scenario had only four 


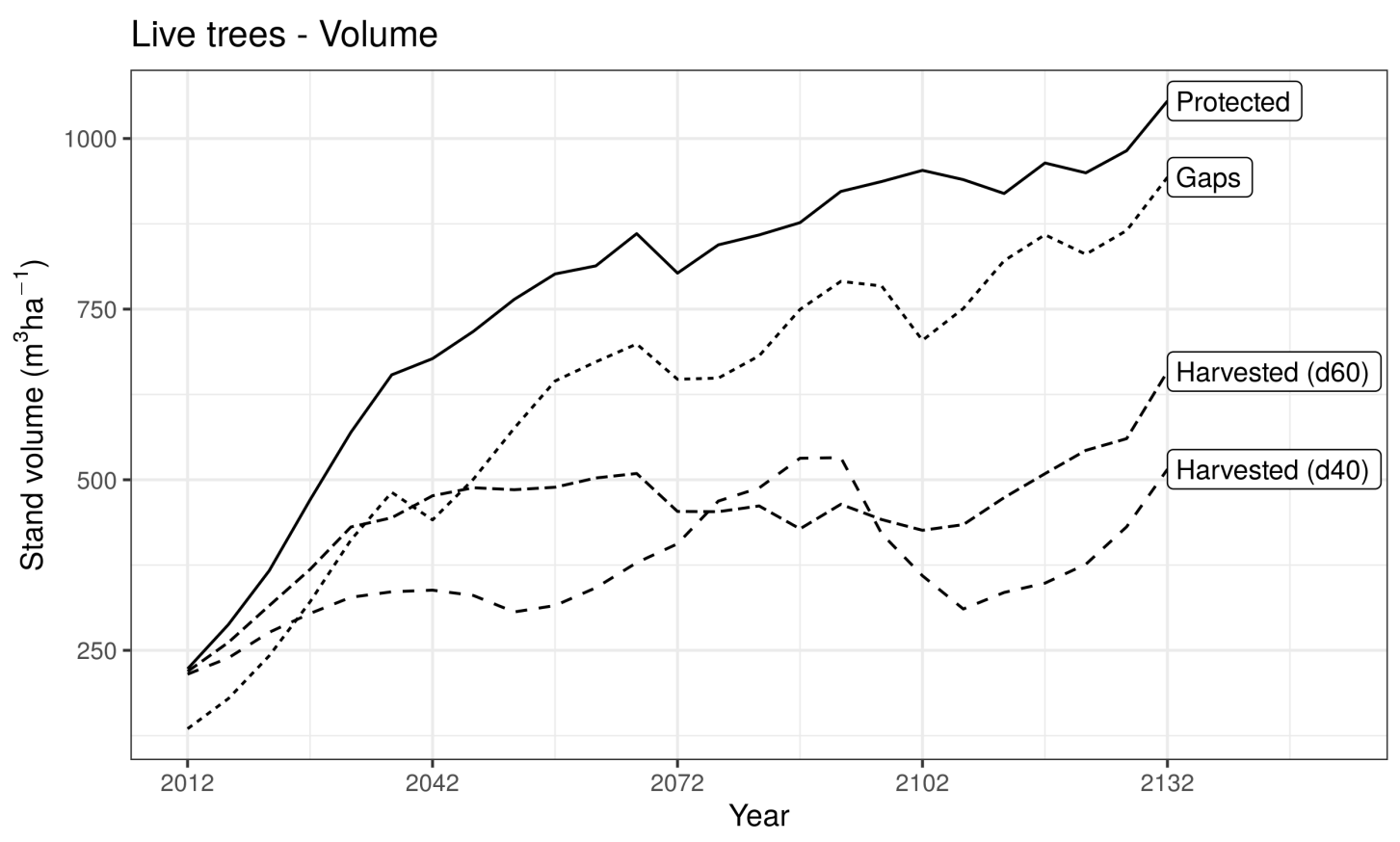

Figure 6.4: Volume trend of live trees by simulation scenario.

silvicultural interventions, the first one in 2012 that modified the starting volume, and the last one in 2102 after 90 years. On the other hand, the Harvested scenarios show that the silvicultural interventions were constant throughout the simulation period. Only small differences can be depicted among the Harvested scenarios, for example, the Harvested (d40) shows a volume increment around 2050, which decreases steeply after 2080. For the Harvested (d60) scenario, this volume increment occurred from the beginning of the simulation period, then stabilized around 500 $\mathrm{m}^{3} h \mathrm{a}^{-1}$. Although the Harvest scenarios had interventions every 5 years, these left enough stand volume to continue to increase over time.

\subsubsection{Carbon stored in live trees}

As a consequence of their intrinsic relationship, carbon stored in live trees has a similar trend to that of volume, i.e., an increasing trend in all scenarios (Figure 6.6). The average initial carbon stored in 2012 was $79.0 \pm 32.5 \mathrm{tCha}^{-1}$, while the final stand carbon stored in live tress was $265 \pm 21.7 \mathrm{tCha}^{-1}$ for the Protected scenario, followed by the Gaps scenario with $237 \pm 26.4 \mathrm{tCha}^{-1}$, the Harvested d60 with $165 \pm 58$ $\mathrm{tCha}^{-1}$, and the Harvested 440 scenario with $130 \pm 25.3 \mathrm{tCha}^{-1}$. 

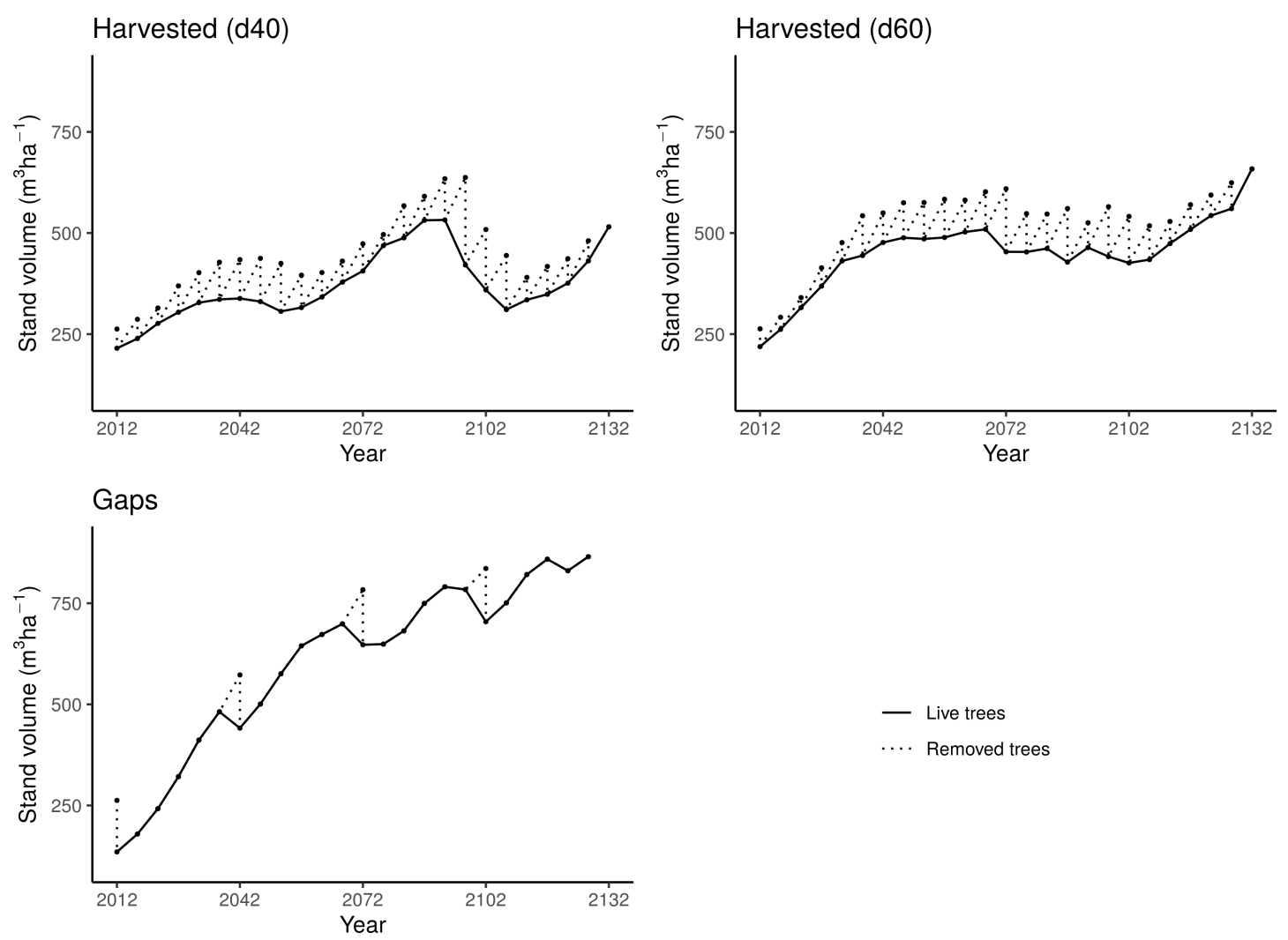

Figure 6.5: Volume extracted in Gaps and Harvested scenarios.

Live trees - Carbon

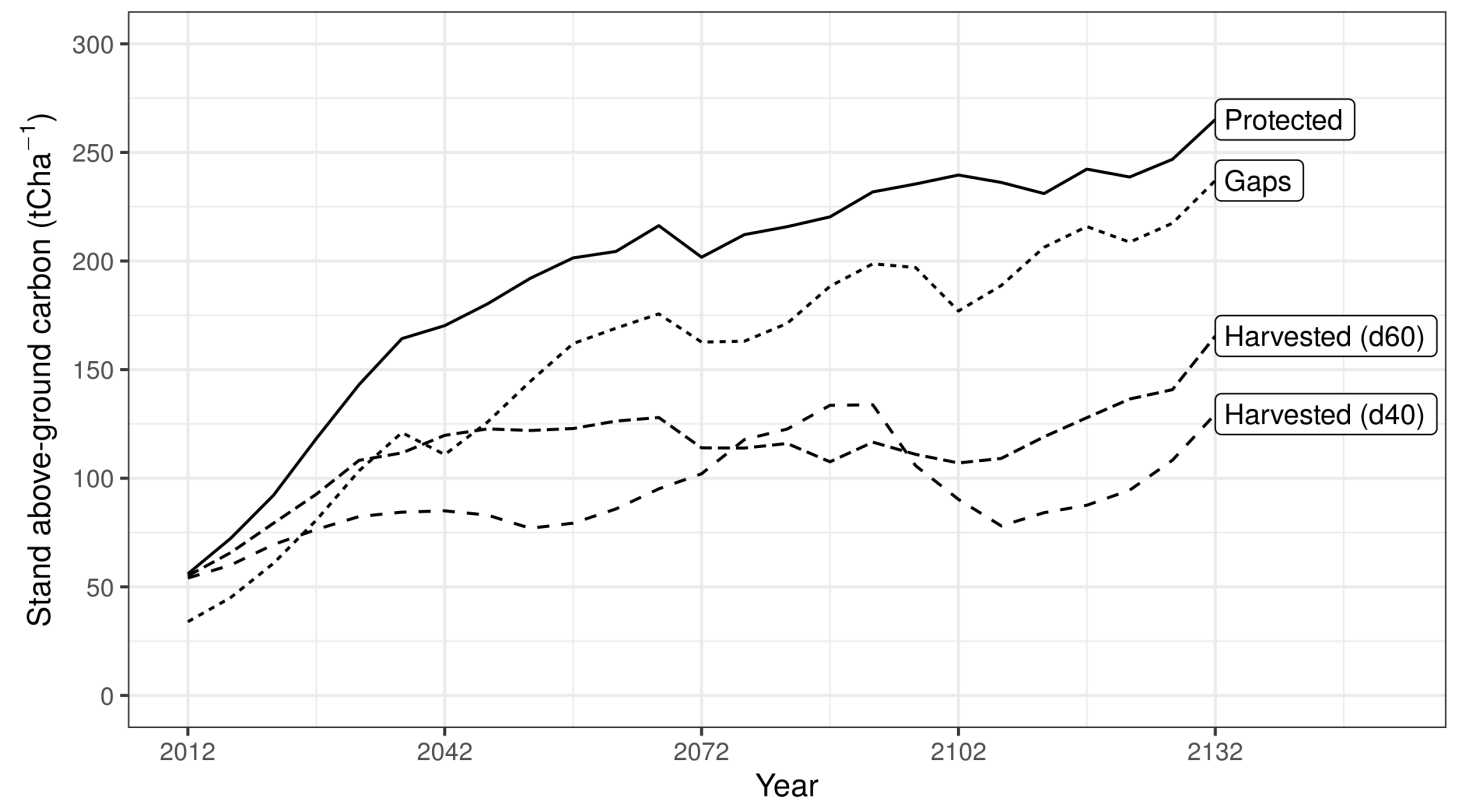

Figure 6.6: Carbon trends of live trees by stand and simulation scenario. 


\subsubsection{Carbon storage in dead and removed trees}

As expected, the carbon outputs show that the Protected scenario has the highest amount of carbon from tree mortality, and the Harvest scenarios has the highest amount of carbon from removed trees. The Protected scenario started in 2012 with an average of $23 \pm 21.1 \mathrm{tCha}^{-1}$ from dead trees, and at the end of the simulation period (2132) ended with $393 \pm 81.4 \mathrm{tCha}^{-1}$. The Gaps scenario started with $13 \pm 13.9$ $\mathrm{tCha}^{-1}$ and ended with $269 \pm 75.3 \mathrm{tCha}^{-1}$. The Harvested (d40) and Harvested (d60) scenarios started with $13 \pm 14.9 \mathrm{tCha}^{-1}$ and $12.9 \pm 14.6 \mathrm{tCha}^{-1}$, and ended with $20 \pm 17.9 \mathrm{tCha}^{-1}$ and $40.8 \pm 35.6 \mathrm{tCha}^{-1}$ respectively.

With respect to carbon from removed trees, the two Harvest scenarios show comparable results. At the beginning of the simulation period, the Gaps scenario exhibited the highest amount of carbon from removed trees with $32 \pm 0.6 \mathrm{tCha}^{-1}$, then the Harvest (d40) scenario with $11.9 \pm 6.2 \mathrm{tCha}^{-1}$, and the Harvest (d60) scenario with $11.1 \pm 7.8 \mathrm{tCha}^{-1}$. However, at the end of the simulation period, the Harvest (d40) scenario produced the highest amount of carbon from removed trees with $490 \pm 103 \mathrm{tCha}^{-1}$, followed by the Harvest (d60) scenario with $474 \pm 81 \mathrm{tCha}^{-1}$, and the Gaps scenario with $132 \pm 2.30 \mathrm{tCha}^{-1}$.

Figure 6.7 shows the accumulated carbon from removed trees and mortality. This figure illustrates the amount of carbon from mortality and removed trees at a given time, and also depicts the effects of management alternatives. In this context, it can be seen how silvicultural interventions influence the trend in carbon from tree mortality. In both Harvested scenarios, tree mortality is minimized compared to the Gaps and Protected scenarios.

Figure 6.8 shows the carbon stored in dead and removed trees for each 5-year class. In the Protected scenario, the most critical period is around 2070, with an average carbon from tree mortality of $39.8 \pm 16.2 \mathrm{tCha}^{-1}$ in 2072 . For this scenario, the 5-year classes of 2017, 2022, and 2027 had the lowest values of carbon from tree mortality with $1.9 \pm 3.31,1.5 \pm 3.0$, and $0.9 \pm 1.2 \mathrm{tCha}^{-1}$ respectively. The Gaps scenario had the largest values of carbon from tree mortality at 2122 with $28.5 \pm 26.5$ $\mathrm{tCha}^{-1}$, while the 2017 and 2022 classes showed no mortality at all.

In the case of the Harvest scenarios, 2012 had the largest values of carbon from tree mortality, with $13.0 \pm 14.9$ and $12.95 \pm 14.6 \mathrm{tCha}^{-1}$ for the Harvest (d40) and 


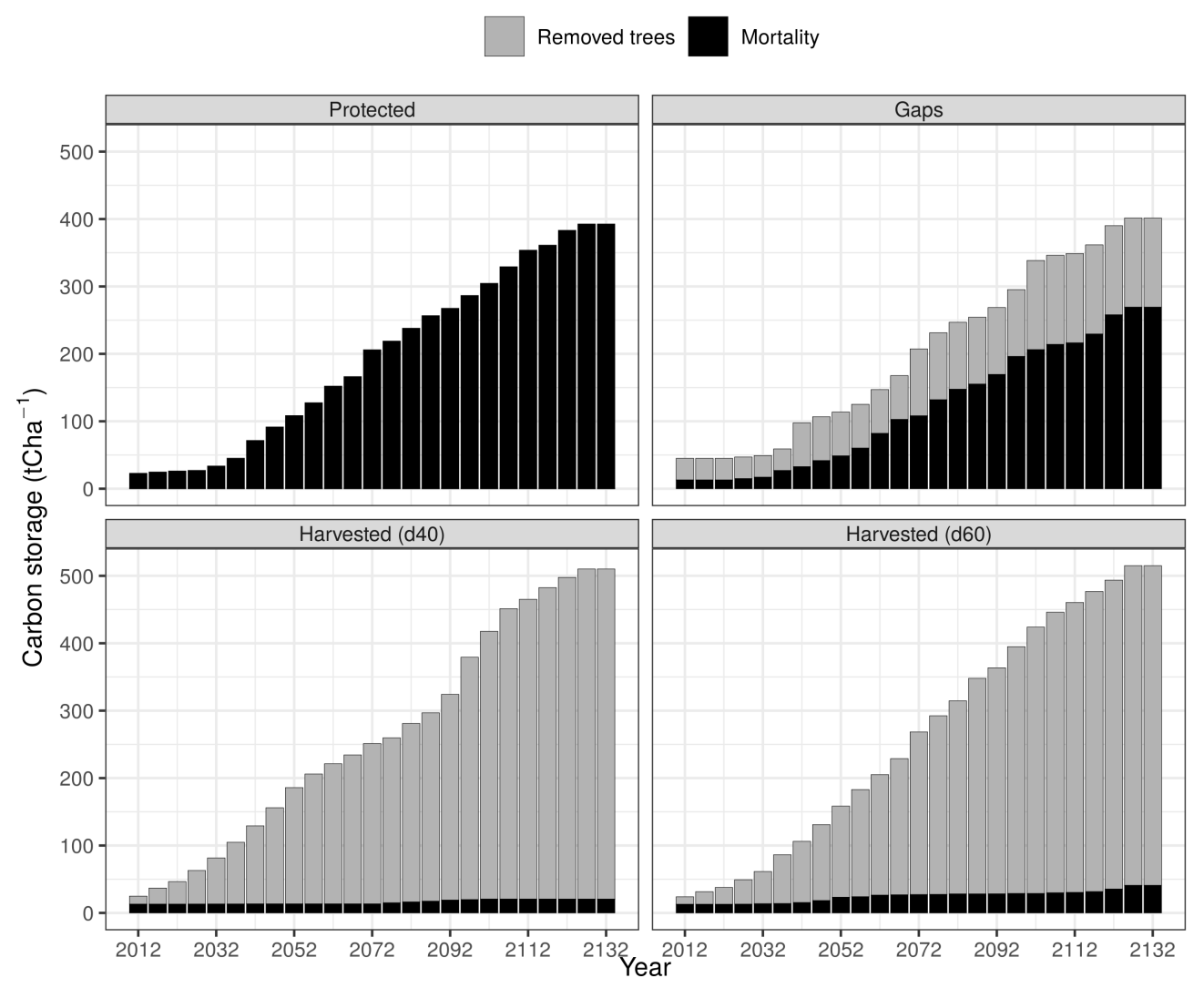

Figure 6.7: Cumulative carbon from removed trees and mortality. The estimates of these cumulative results do not include any decay rate. Therefore, the graph is most useful for visualizing how much carbon was stored in the dead and removed trees from the beginning to the end of the simulation period.

Harvest (d60) scenarios respectively. In these Harvest scenarios tree mortality was replaced by the silvicultural treatments, and it can be seen that these treatments slightly reduced tree mortality in the Harvest (d40) scenario compared to the Harvest (d60) scenario.

\subsubsection{Substitution effects}

In this research we have found that the most beneficial aspect of carbon harvesting relies on substitution effects. Figure 6.9 shows the carbon contribution by scenario, with information of carbon content by component. We included only the live trees for comparison purposes. With the substitution effects, the contribution was dominated by the Harvest scenarios with a mean of $788 \pm 181$ and $792 \pm 146 \mathrm{tCha}^{-1}$ for the Harvest (d40) and Harvest (d60) scenarios respectively. The Gaps scenario 


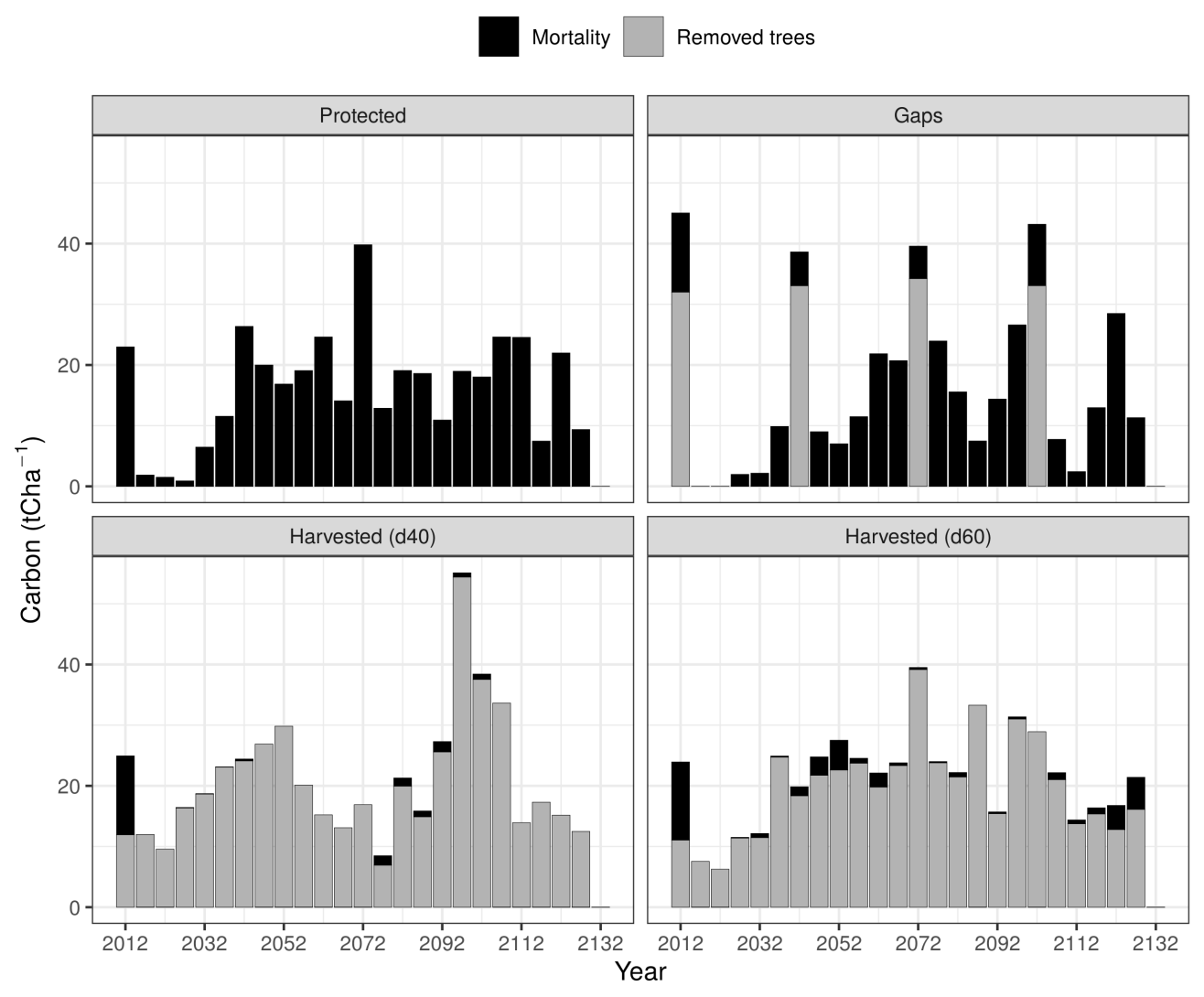

Figure 6.8: Carbon from mortality and removed trees by simulation scenario.

also exhibited substitution effects, with $225 \pm 14.7 \mathrm{tCha}^{-1}$.

In general, the substitution effects added up to the total carbon contribution. The Harvest (d60) scenario showed the highest amount of carbon with $1003 \pm 174$ $\mathrm{tCha}^{-1}$, followed by the Harvest (d40) scenario with $964 \pm 205 \mathrm{tCha}^{-1}$, and the Gaps scenario with $487 \pm 46.4 \mathrm{tCha}^{-1}$ (Figure 6.9). Table 6.3 shows the results of substitution effects by stand.

Overall, although the amount of carbon stored in live trees is larger in the Protected scenario, silvicultural treatments provided another important contribution. In particular, our results showed that substitution effects are a key element in understanding the role of forest management in above-ground carbon dynamics. Forest protection alone did not contribute to the reduction of fossil fuel emissions or to the avoidance of carbon-intensive materials. 


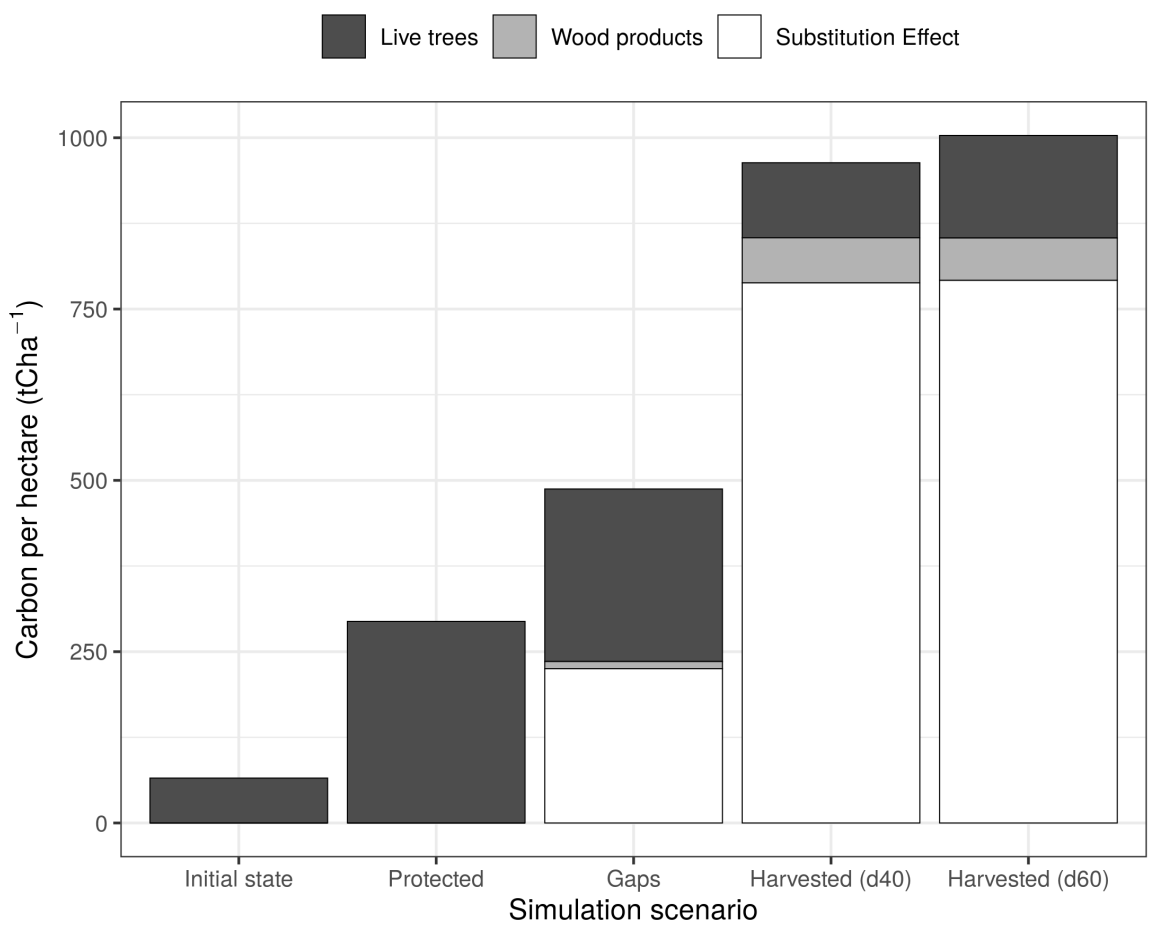

Figure 6.9: Mean carbon content by scenario and component. The figure shows the differences between the beginning (2012) and the end of the simulation period after 120 years (2132).

\subsection{Discussion}

The general direction of the results showed that carbon storage differed between scenarios. According to our objectives, carbon storage was larger when no management actions, other than forest protection, were carried out. When natural disturbances were emulated by silvicultural treatments, carbon stored was lower in both live and dead trees compared to the Protected scenario. However, with traditional silvicultural treatments, carbon storage decreased compared to the other two scenarios. Nevertheless, silvicultural treatments, in most cases, did not reduce the initial carbon stock at the end of the simulation period.

In the following subsections we discuss whether storing carbon in situ is the best forest management strategy for Mexican temperate forests. On the one hand, protecting forests from natural disturbances, such as fires, can maximize carbon storage in forests. However, fire suppression in fire-adapted ecosystems often leads to changes in the forest fuel bed, and such changes may promote more 
Table 6.3: Carbon content and substitution effects by stand, treatment and product class in $\mathrm{tCha}^{-1}$.

\begin{tabular}{|c|c|c|c|c|c|c|c|}
\hline \multirow[b]{2}{*}{ Treatment } & \multirow[b]{2}{*}{ Year } & \multirow[b]{2}{*}{ Dead trees } & \multirow[b]{2}{*}{ Live trees } & \multirow[b]{2}{*}{ Substitution } & \multicolumn{3}{|c|}{ Product Class } \\
\hline & & & & & 1 & 2 & 3 \\
\hline \multicolumn{8}{|l|}{ UMF2108P007 } \\
\hline Initial state & 2012 & 0.0 & 87.9 & 0.0 & 0.0 & 0.0 & 0.0 \\
\hline Protected & 2132 & 422.6 & 284.0 & 0.0 & 0.0 & 0.0 & 0.0 \\
\hline Gaps & 2132 & 281.2 & 256.9 & 224.8 & 1.0 & 0.8 & 9.2 \\
\hline Harvested (d40) & 2132 & 27.1 & 126.3 & 792.3 & 8.2 & 5.3 & 48.8 \\
\hline Harvested (d60) & 2132 & 28.5 & 111.1 & 893.6 & 8.3 & 5.6 & 55.8 \\
\hline \multicolumn{8}{|l|}{ UMF2108P010 } \\
\hline Initial state & 2012 & 0.0 & 88.6 & 0.0 & 0.0 & 0.0 & 0.0 \\
\hline Protected & 2132 & 442.2 & 328.9 & 0.0 & 0.0 & 0.0 & 0.0 \\
\hline Gaps & 2132 & 319.4 & 297.8 & 240.3 & 1.1 & 0.9 & 9.9 \\
\hline Harvested (d40) & 2132 & 30.1 & 127.2 & 1041.4 & 8.9 & 6.1 & 63.0 \\
\hline Harvested (d60) & 2132 & 68.9 & 201.6 & 938.1 & 7.9 & 5.0 & 46.6 \\
\hline \multicolumn{8}{|l|}{ UMF2108P041 } \\
\hline Initial state & 2012 & 0.0 & 38.5 & 0.0 & 0.0 & 0.0 & 0.0 \\
\hline Protected & 2132 & 285.3 & 264.8 & 0.0 & 0.0 & 0.0 & 0.0 \\
\hline Gaps & 2132 & 169.6 & 229.4 & 205.3 & 0.7 & 0.6 & 7.5 \\
\hline Harvested (d40) & 2132 & 5.1 & 86.0 & 641.8 & 9.4 & 5.8 & 50.9 \\
\hline Harvested (d60) & 2132 & 1.7 & 87.5 & 640.0 & 10.6 & 6.3 & 49.2 \\
\hline \multicolumn{8}{|l|}{ UMF2108P048 } \\
\hline Initial state & 2012 & 0.0 & 47.2 & 0.0 & 0.0 & 0.0 & 0.0 \\
\hline Protected & 2132 & 333.9 & 298.9 & 0.0 & 0.0 & 0.0 & 0.0 \\
\hline Gaps & 2132 & 189.2 & 223.0 & 230.4 & 0.9 & 0.7 & 8.5 \\
\hline Harvested (d40) & 2132 & 3.0 & 98.5 & 677.6 & 7.8 & 4.9 & 43.8 \\
\hline Harvested (d60) & 2132 & 26.9 & 198.1 & 696.4 & 7.1 & 4.4 & 40.0 \\
\hline
\end{tabular}

intense and severe fires. On the other hand, silvicultural treatments modify forest structure, thus promoting resilience to droughts and wildfires. In addition, forest management favors carbon sequestration by maintaining forest productivity and providing the substitution effects of wood products.

\subsubsection{Forest structure}

The forest structure generated by the different scenarios is related to the management alternatives. The stand structures created by the Protected and Gaps scenarios 
are typical of old-growth forests, where tree competition often creates bimodal diameter distributions, and differentiates the stand into social cohorts (Prodan et al., 1997; van Laar and Akça, 2007). In the study of Kara (2021) the bimodal distribution of managed forests are attributed to the selection cuttings aimed to release suppressed trees in lower and middle stories. Rubio-Camacho et al. (2015) observed a partial bimodal diameter distribution of pines in a protected forest, characterized by a potential fire regime of frequent and low-severity fires (Jardel-Peláez et al., 2009; Rodríguez-Trejo, 2008).

Unimodal distributions are usually observed in young even-aged forests (Bettinger et al., 2010; Prodan et al., 1997; van Laar and Akça, 2007). In this study, the diameter distributions created by the Harvest scenarios exhibited unimodal curve, positive or right-skewed from normality explained by the thinning and harvest treatments. On the one hand, release thinnings that promote growth of crop trees caused a positive skewness by removing competitors, thus resulting in fewer trees in classes under 40 and $60 \mathrm{~cm}$ of the Harvest d40 and Harvest d60 scenarios respectively. On the other hand, the planting strategy could explain the higher number of trees in the smaller and intermediate classes, because in the simulation, the planting phase started only when there was enough space in the canopy.

\subsubsection{Carbon dynamics}

Carbon stored in live trees. After 120 years of carbon accumulation in live trees, the Protected scenario stored more carbon, around $250 \mathrm{tCha}^{-1}$. This is in part due to the high productivity of the analyzed stands, and to the growth models used in the simulation process. Besides, the Protected scenario kept old-growth big trees that usually store more carbon (Stephenson et al., 2014). Comparable results are shown in other studies carried out in Mexico and other countries. QuinteroGradilla et al. (2020) reported 347.5 $\mathrm{Mg} \mathrm{ha}^{-1}$ of biomass (approx. $173.8 \mathrm{tCha}^{-1}$ ) stored in live trees after 60 years of recovery from a stand replacement fire. In the simulation study of Pukkala (2018), the carbon stored in living biomass was maximized around $200 \mathrm{tCha}^{-1}$ in Boreal forests. Moore et al. (2012) simulated different silvicultural scenarios for carbon sequestration in Southern Appalachian Spruce-Fir forests, it was documented up to $242 \mathrm{tCha}^{-1}$ in an unmanaged scenario. 
The Gaps scenario showed a similar trend to the Protected scenario in terms of carbon storage in live trees. This could be explained by the fact that the Gaps scenario also has carbon stored in large and old trees, but also distributed in intermediate and small size classes (Figure 6.2). Besides, the silvicultural interventions were carried out every 30 years, removing about $30 \mathrm{tCha}^{-1}$ on each of them. The purpose was to mimic the effects of mixed severity disturbances, while creating structural complexity including biological legacies and structural retention (Franklin et al., 2007; Palik and D'Amato, 2019).

The Gaps scenario was designed to emulate the effects of disturbances such as low-severity frequent fires (Agee, 1993; Pickett and White, 1985; Rodríguez-Trejo, 2008), or the drought-driven tree mortality (see chapter four), since both are common disturbances in the study region. In other countries such as Canada, fire regime emulation is an accepted forest management practice, and many experiments are focused on stand replacement fires, i.e. performing clearcuts to mimic wildfires (McRae et al., 2001). However, the pine ecosystems in study area, such as many pine forests in Mexico has a potential fire regime of lowseverity frequent fires (Jardel-Peláez et al., 2009; Rodríguez-Trejo, 2008). Therefore, simulating small gaps seemed to be a more appropriate harvest alternative (Palik and D'Amato, 2019).

The Harvest scenarios were designed to remove biomass from the forest without reducing the initial stock. Both Harvest scenarios ended with less carbon stored in live trees compared to the Protected and Gaps scenarios, but with more carbon compared the initial stock, 1.65 and 2 times for the Harvest $d 40$ and the Harvest $d 60$ respectively. Differences between these two scenarios might be explained by the chosen target diameter, the Harvest $d 60$ let trees to grow larger before cuttings (diameter $>=60 \mathrm{~cm}$ ), thus storing more carbon in larger trees.

In general, Harvest scenarios could be consider the better management alternative. Both scenarios have environmental benefits, as the harvesting process prevents the accumulation of biomass in situ, thus avoiding catastrophic fires. In addition, the economic impact is bigger because the harvested timber can be sold and more profits can be obtained compared to the other scenarios.

Carbon stored in dead trees. Silvicultural treatments prevented carbon accumulation from dead trees in the stands. At the end, the Protected scenario 
outperformed the rest of the simulation scenarios with respect to carbon from mortality. The Gaps scenario, compared to the Protected scenario, showed 30\% less carbon from mortality. However, tree mortality was drastically reduced in the Harvest scenarios compared to the Protected scenario. The Harvest $d 60$ and Harvest $d 40$ scenarios showed $90 \%$ and $95 \%$ less carbon from mortality respectively. This was an expected result, since one of the purposes was to use classical silvicultural treatments to avoid tree competitive mortality or self-thinning (Oliver and Larson, 1996). These results have different implications in terms of forest management, as they reduce the risk of forest fires.

Biomass accumulation in forest ecosystems could lead to more extensive and severe fires. In fire-adapted forests, biomass accumulation is related to fire frequency, i.e., the time interval between fires (Agee, 1993; White and Pickett, 1985). The longer the time without fire, the larger the amount of forest fuel or biomass accumulated in the forest, which increases the risk of catastrophic fires (Swanson et al., 1994). Therefore, strict protection of these ecosystems is not always the best management option, as in the long term this strategy would create less resilient forests (Stephens et al., 2018).

\subsubsection{Substitution effects}

One of the main goals of this simulation study was to evaluate the substitution effects under different management scenarios. In general, as the substitution effect is a cumulative process, the use of wood products instead of carbon-intensive materials provided a better alternative for forest carbon storage. The substitution effects were larger in the Harvest scenarios, both showing a similar amount of carbon contribution. These results are consistent with other research works about substitution effects.

In a similar study, Wördehoff et al. (2017) analyzed the effects of silvicultural treatments on carbon storage. They used ForestSimulator and a 140-year-old beech stand to compare a harvest scenario vs a non-use scenario. After 70 years of simulation, the substitution effects in the harvest scenario contributed about 480 $\mathrm{tCha}^{-1}$, i.e. a mean annual contribution of $6.9 \mathrm{tCha}^{-1}$. In our research we have found a similar carbon mean annual contribution of about $6.6 \mathrm{tCha}^{-1}$ after 120 
years in both Harvested scenarios.

An interesting result was that of the Gaps scenario, due to substitution effects, it provided a better carbon contribution compared to the Protected scenario. Therefore, the Gaps scenario represents an interesting alternative to traditional silvicultural methods and to strict forest protection, especially in ecosystems adapted to a certain type of disturbances. Although the purpose of the Gaps scenario was rater ecological than economical, it turns out that it also has an economic impact, as it can prevent extensive and severe fires, which represent a high economic cost, and landowners could benefit from the sale of timber. This management alternative is particularly important when aiming to emulate the ecological processes that generate heterogeneous stand structures (Franklin et al., 2007; Palik and D'Amato, 2019).

\subsubsection{Recommendations}

This research may have limitations that could be addressed in future works. First, we used tree mortality model from Germany developed for pine trees. Although this might not have a major impact on our results, since tree mortality is difficult to predict, in future studies it is recommended to integrate mortality models for Mexican species. Second, we recommend to parameterize in-growth models and include them in the ForestSimulator software, so the outputs would not rely only on planting. Third, we did not take into consideration the carbon stored in the soil because our purpose was to evaluate the effects of silvicultural treatments on trees. However, it is worth to mention that carbon stored in soils could be addressed to have a broader perspective of carbon dynamics. Fourth, we did not include a decay rate to estimate carbon stored in dead trees because we were aiming to quantify the total amount of carbon at the end of the simulation period. Nonetheless, in later studies this could be a problem if it is not clearly stated, otherwise a decay rate should be incorporated.

Finally, we recommend using larger stands and include other tree species. The plots in this study are relatively small $\left(900 \mathrm{~m}^{2}\right)$, we believe that by using larger stands it would be possible to analyze more silvicultural alternatives, particularly when the goal is to emulate natural disturbance regimes. To gain 
a clearer understanding of the carbon dynamics, and to evaluate performance of the Mexican version of ForestSimulator, we decided to use only pure stands of Pinus patula. Nevertheless, pure stands of Pinus patula are scarce, thus we believe that other genera, such as Quercus, Abies and other Pinus species could be included in future simulation studies.

\subsection{Conclusions}

This research has investigated the above-ground carbon dynamics by exploring four different management scenarios. Our findings let us to conclude that protecting the forest allows to store more carbon in live and dead trees, but might not be the best management strategy due to the high risk of severe and extensive wildfires. Emulating natural disturbance regimes might be a better option, as it provides stand structural complexity while reducing forest fuel loading. However, silvicultural treatments could be complemented with prescribed burning, as harvesting alone would not be sufficient to mimic the effects of natural fire regimes.

Evidence from this study suggests that the major carbon contribution occurred when the forest was systematically harvested. In addition, thinning and harvest regimes did not include a final cut and maintained the initial carbon stock. In this case, a continuous forest cover was induced throughout the simulation, and the accumulation of biomass from dead trees was avoided. In addition, tree harvesting provides more socioeconomic benefits to landowners. Finally, this study provides an overview of the use of forest simulators to test different forest management alternatives. With these results we hope to promote the use of these important tools in Mexican forestry. 


\section{Literature}

Agee, J.K., 1993. Fire ecology of pacific northwest forests. Island Press, Washington D.C.

Bellassen, V., Luyssaert, S., 2014. Carbon sequestration: managing forests in uncertain times. Nature 506, 153-155. URL: http://www.nature.com/news/ carbon-sequestration-managing-forests-in-uncertain-times-1.14687, doi:10.1038/ $506153 a$.

Bergman, R., Puettmann, M., Taylor, A., Skog, K.E., 2014. The carbon impacts of wood products. Forest Products Journal 64, 220-231. URL: https://www.fs.usda. gov/treesearch/pubs/47306, doi:10.13073/FPJ-D-14-00047.

Bettinger, P., Boston, K., Siry, J.P., Grebner, D.L., 2010. Forest Management and Planning. Academic Press. URL: https://books.google.com.mx/books?id= XXbE7KJHN1kC.

Castellanos-Sotomayor, J., 2005. Caraterísticas Mecánicas y Clasificación de la Madera de 150 especies Mexicanas. Technical Report. Universidad Michoacana de San Nicolás de Hidalgo. Morelia, Michoacán, México.

Choat, B., Brodribb, T.J., Brodersen, C.R., Duursma, R.A., López, R., Medlyn, B.E., 2018. Triggers of tree mortality under drought. Nature 558, 531-539. URL: http: //www.nature.com/articles/s41586-018-0240-x, doi:10.1038/s41586-018-0240- $x$.

Ciccarese, L., Pellegrino, P., Pettenella, D., 2014. A new principle of the European Union forest policy: the cascading use of wood products. L'italia forestale e montana 69, 285-290. doi:10.4129/ifm.2014.5.01.

Crow, T.R., Dey, D.C., Riemenschneider, D., 2006. Forest productivity: producing goods and services for people. Gen. Tech. Rep. NC-246. Technical Report. U.S. Department of Agriculture, Forest Service, North Central Research Station. St. Paul, MN. doi:https://doi.org/10.2737/NC-GTR-246.

Duda, H.A.A., 2006. Vergleich forstlicher Managementstrategien. Umsetzung verschiedener Waldbaukonzepte in einem Waldwachstumssimulator. Ph.D. thesis. Georg-August-Universität in Göttingen. URL: https://ediss.uni-goettingen. de/bitstream/handle/11858/00-1735-0000-0006-B0F0-A/duda.pdf? sequence=1.

FAO, 2016. Forestry for a low-carbon future: integrating forests and wood products in climate change strategies. Technical Report. URL: FAOForestryPaperhttp: //www.fao.org/3/i5857e/i5857e.pdf.

Franklin, J.F., Mitchell, R.J., Palik, B.J., 2007. Natural disturbance and stand development principles for ecological forestry. Technical Report. Department of Agriculture, Forest Service, Northern Research Station. Newtown Square, PA: U.S. URL: http://www.nrs.fs.fed.us/pubs/3293. 
Gustavsson, L., Pingoud, K., Sathre, R., 2006. Carbon dioxide balance of wood substitution: Comparing concrete- and wood-framed buildings. Mitigation and Adaptation Strategies for Global Change 11, 667-691. URL: https://link. springer.com/article/10.1007/s11027-006-7207-1, doi:10.1007/s11027-006-7207-1.

Hansen, J., Nagel, J., 2014. Waldwachstumskundliche Softwaresysteme auf Basis von TreeGrOSS - Anwendung und theoretische Grundlagen. Universitätsverlag Göttingen, Gottingen, Germany. URL: https://www.univerlag.uni-goettingen.de/ handle/3/isbn-978-3-86395-149-8.

Harmon, M.E., 2019. Have product substitution carbon benefits been overestimated? A sensitivity analysis of key assumptions. Environmental Research Letters 14, 1-8. URL: https://doi.org/10.1088/1748-9326/ab1e95, doi:10.1088/ 1748-9326/ab1e95.

Heinselman, M.L., 1981. Fire intensity and frequency as factors in the distribution and structure of northern ecosystems, DC: U.S. Department of Agriculture, Forest Service, Honolulu, Hawaii. pp. 7-57.

Jardel-Peláez, E., Alvarado-Celestino, E., Morfín-Rios, J., Castillo-Navarro, F., Flores-Garnica, J., 2009. Regímenes de fuego en ecosistemas forestales de México, in: Flores-Garnica, J. (Ed.), Impacto ambiental de incendios forestales. 1 ed.. Mundi-Prensa, México, pp. 73-100.

Kara, F., 2021. Comparison of tree diameter distributions in managed and unmanaged Kazda fir forests. Silva Balcanica 22, 31-43. URL: https://silvabalcanica. pensoft.net/article/58020/, doi:10.3897/silvabalcanica.22.e58020.

van Laar, A., Akça, A., 2007. Forest Mensuration. volume 13 of Managing Forest Ecosystems. Springer Netherlands, Dordrecht. URL: http://link.springer.com/10. 1007/978-1-4020-5991-9, doi:10.1007/978-1-4020-5991-9.

Leskinen, P., Cardellini, G., González García, S., Hurmekoski, E., Sathre, R., Seppälä, J., Smyth, C.E., Stern, T., Verkerk, H., 2018. Substitution effects of wood-based products in climate change mitigation. From Science to Policy 7. URL: https://efi.int/publications-bank/ substitution-effects-wood-based-products-climate-change-mitigation, doi:https://doi. org/10.36333/fs07.

Leturcq, P., 2020. GHG displacement factors of harvested wood products: the myth of substitution. Scientific Reports 10,1-9. URL: https://doi.org/10.1038/ s41598-020-77527-8, doi:10.1038/s41598-020-77527-8.

Martínez-Domínguez, A., Ruiz-Aquino, F., Santiago-García, W., Antúnez, P., López-López, M.Á., Valenzuela-Encinas, C., Feria-Reyes, R., 2020. Allometric equations to estimate aboveground and belowground biomass of Pinus patula Schiede ex Schltdl. \& Cham. Forest Science and Technology 
16, 161-170. URL: https://www.tandfonline.com/doi/full/10.1080/21580103.2020. 1801526, doi:10.1080/21580103.2020.1801526.

McRae, D.J., Duchesne, L.C., Freedman, B., Lynham, T.J., Woodley, S., 2001. Comparisons between wildfire and forest harvesting and their implications in forest management. Environmental Reviews 9, 223-260. URL: https:// cdnsciencepub.com/doi/abs/10.1139/a01-010, doi:10.1139/a01-010.

Mitchard, E.T., 2018. The tropical forest carbon cycle and climate change. Nature 559, 527-534. URL: https://doi.org/10.1038/s41586-018-0300-2, doi:10.1038/ s41586-018-0300-2.

Moore, P.T., DeRose, R.J., Long, J.N., van Miegroet, H., 2012. Using Silviculture to Influence Carbon Sequestration in Southern Appalachian Spruce-Fir Forests. Forests 3, 300-316. URL: http://www.mdpi.com/1999-4907/3/2/300, doi:10.3390/ f3020300.

Nagel, J., 2003. TreeGrOSS: Tree Growth Open Source Software. URL: http: //treegross.sourceforge.net/.

Oliver, C.D., Larson, B., 1996. Forest stand dynamics. Wiley, New York.

Ontl, T.A., Janowiak, M.K., Swanston, C.W., Daley, J., Handler, S., Cornett, M., Hagenbuch, S., Handrick, C., Mccarthy, L., Patch, N., 2020. Forest Management for Carbon Sequestration and Climate Adaptation. Journal of Forestry 118, 86-101. URL: https://academic.oup.com/jof/article/118/1/86/5648951, doi:10.1093/ jofore/fuz062.

Palik, B.J., D'Amato, A.W., 2019. Variable retention harvesting in Great Lakes mixed-pine forests: emulating a natural model in managed ecosystems. URL: https://ecologicalprocesses.springeropen.com/articles/10.1186/ s13717-019-0171-y, doi:10.1186/s13717-019-0171-y.

Pickett, S.T., White, P.S., 1985. The ecology of natural disturbance and patch dynamics. Academic Press.

Pingoud, K., Pohjola, J., Valsta, L., 2010. Assessing the integrated climatic impacts of forestry and wood products. Silva Fennica 44, 155-175. doi:10.14214/sf.166.

Prodan, M., Peters, R., Cox, F., Real, P., 1997. Mensura forestal. Serie de investigación y educación en desarrollo sostenible, GTZ/IICA-Agroamerica, San José, Costa Rica.

Pukkala, T., 2017. Does management improve the carbon balance of forestry? Forestry 90, 125-135. URL: https://academic.oup.com/forestry/article-lookup/doi/ 10.1093/forestry/cpw043, doi:10.1093/forestry/cpw043. 
Pukkala, T., 2018. Carbon forestry is surprising. Forest Ecosystems 5, 1-11. URL: https://forestecosyst.springeropen.com/articles/10.1186/s40663-018-0131-5, doi:10.1186/s40663-018-0131-5.

Quintero-Gradilla, S.D., Cuevas-Guzmán, R., García-Oliva, F., Jardel-Pelaéz, E.J., Martínez-Yrizar, A., 2020. Post-fire recovery of ecosystem carbon pools in a tropical mixed pine-hardwood forest. Forest Systems 29. doi:10.5424/fs/ 2020291-14984.

Rodríguez-Trejo, D., 2008. Fire Regimes, Fire Ecology, and Fire Management in Mexico. AMBIO: A Journal of the Human Environment 37, 548-556. URL: http: //www.bioone.org/doi/abs/10.1579/0044-7447-37.7.548, doi:10.1579/0044-7447-37. 7.548 .

Rodríguez-Trejo, D., Fulé, P., 2003. Fire ecology of Mexican pines and a fire management proposal. International Journal of Wildland Fire 12, 23-37. URL: http://www.publish.csiro.au/paper/WF02040.

Rubio-Camacho, E.A., González-Tagle, M.A., Alanís-Rodríguez, E., ChávezDurán, A.A., Aguirre-Calderón, O.A., 2015. Analysis of the structure and diameter distribution in temperate forests under the perspective of the potential fire regime. Revista Chapingo Serie Ciencias Forestales y del Ambiente 3, 282-294. URL: http://www.scielo.org.mx/pdf/rcscfa/v21n3/v21n3a4.pdf, doi:10.5154/r.rchscfa.2014.10.053.

Sathre, R., O'Connor, J., 2010. Meta-analysis of greenhouse gas displacement factors of wood product substitution. Environmental Science and Policy 13, 104-114. doi:10.1016/j.envsci.2009.12.005.

Soriano-Luna, M.d.l.Á., Ángeles-Pérez, G., Martínez-Trinidad, T., PlascenciaEscalante, F.O., Razo-Zárate, R., 2015. Estimación de biomasa aérea por componente estructural en Zacualtipán, Hidalgo, México. Agrociencia 49, 423-438. URL: http://www.scielo.org.mx/pdf/agro/v49n4/v49n4a6.pdf.

Stephens, S.L., Collins, B.M., Fettig, C.J., Finney, M.A., Hoffman, C.M., Knapp, E.E., North, M.P., Safford, H., Wayman, R.B., 2018. Drought, Tree Mortality, and Wildfire in Forests Adapted to Frequent Fire. BioScience 68, 77-88. URL: https: //academic.oup.com/bioscience/article/68/2/77/4797261, doi:10.1093/biosci/bix146.

Stephens, S.L., Fry, D.L., Franco-Vizcaíno, E., 2008. Wildfire and Spatial Patterns in Forests in Northwestern Mexico: The United States Wishes It Had Similar Fire Problems. Ecology and Society 13,1-13. URL: http://www.ecologyandsociety. org/vol13/iss2/art10/, doi:10.5751/ES-02380-130210.

Stephenson, N., Das, A., Condit, R., et al., 2014. Rate of tree carbon accumulation increases continuously with tree size. Nature 507, 90-93. URL: https://www. nature.com/articles/nature12914, doi:10.1038/nature12914. 
Swanson, F., Jones, J., Wallin, D., Cissel, J., 1994. Natural variability implications for ecosystem management, in: Jensen, M., Bourgeron, P. (Eds.), Volume II: Ecosystem management: principles and applications.. (USDA). Forest Service, Portland, OR. General Technical Report PNW-318, pp. 80-94. URL: https: //www.for.gov.bc.ca/hfd/efp/uneven\{_laged/toc/sec03\{_\}03.pdf.

UNECE/FAO, 2010. The forest sector in the green economy. Geneva timber and forest discussion paper 54. United Nations Economic Commission for Europe, Food and Agriculture Organization of the United Nations, Geneva, Switzerland. URL: https://sustainabledevelopment.un.org/content/documents/807DP-54.pdf.

Vargas-Larreta, B., Corral-Rivas, J.J., Aguirre-Calderon, O.A., Lopez-Martinez, J.O., De los Santos-Posadas, H.M., Zamudio-Sanchez, F.J., Trevino-Garza, E.J., Martinez-Salvador, M., Aguirre-Calderon, C.G., 2017. SiBiFor: Forest Biometric System for forest management in Mexico. Revista Chapingo Serie Ciencias Forestales y del Ambiente 23, 437-455. doi:10.5154/r.rchscfa.2017.06.040.

White, P.S., Pickett, S.T., 1985. Natural disturbance and patch dynamics: an introduction., in: The ecology of natural disturbance and patch dynamics. Academic Press, pp. 4-13. doi:10.1016/b978-0-08-050495-7.50006-5.

Wördehoff, R., 2016. Kohlenstoffspeicherung als Teilziel der strategischen Waldbauplanung erläutert an Reinbeständen verschiedener Baumarten in Niedersachsen. Ph.D. thesis. Georg-August Universität Göttingen. URL: https://ediss.uni-goettingen.de/handle/11858/00-1735-0000-0028-87F3-1.

Wördehoff, R., Schulz, C., Nagel, J., 2017. Nutzung oder Nutzungsverzicht aus Sicht des Klimaschutzes. AFZ/Der Wald 72, 30-32. URL: https://wwww.nw-fva. de/fileadmin/nwfva/publikationen/pdf/wordehoff_2017_nutzung_oder.pdf. 


\section{Chapter 7}

\section{Conclusion}

The aim of this work was to contribute to the knowledge about forest stand dynamics and to link this knowledge to sustainable management of Mexican temperate forests. This was attempted by developing stochastic models for different species in central Mexico and by integrating them in ForestSimulator. Besides, through this software it was possible to infer about the contribution of forest management for carbon and climate change benefits.

A notable contribution of this thesis was the inclusion of random effects in mixed-effects models. This was carried out applying linear and nonlinear regression techniques, process that was challenging because the fitting, validation, and calibration is different from that of the usual ordinary least squares (OLS) regression models. Mixed-effects models presented in this work are an important advance in forestry science in Mexico since this approach has scarcely been applied in the country. The inclusion of random effects led to more accurate and reliable models by adding an error component at specific levels. Furthermore, it offers a solution to deal with the independence assumption of OLS.

All of the models described and developed in this research can be used in two different ways. Users can apply the models through the software ForestSimulator or through other sources. So far, the models are included in the software and can be used automatically for prediction of, for example, tree diameter increment or stand basal area increment, as well as to simulate new stands from scratch. However, potential users can also take the models outside of ForestSimulator and apply them in a different context, for example, using Excel spreadsheets or even 
using a pocket calculator. This represents a real advantage when users want to reduce the costs of forest inventories, as they do not need to measure all variables to obtain accurate estimates of tree height, or crown width.

Spatial point pattern analysis provided useful insights regarding forest stand dynamics. Following the spatial distribution during 20 years produced relevant information about tree mortality and its relationship to disturbance regimes. In fact, the knowledge generated through the point pattern analysis was the foundation of the Gaps scenario, which turned out to be better than the Protected scenario regarding carbon sequestration and environmental benefits. Tree mortality in temperate forests is a dynamic process that changes over time and space, and understating such process is fundamental to design sustainable forest management strategies.

Simulating the above-ground carbon dynamics through ForestSimulator led to the conclusion of harvesting forests is a better option for temperate forests of the study area. However, these findings do not imply that all forests in Mexico should be harvested in order to have the socioeconomic and environmental benefits. Users must be aware that forest management plans should be adapted to the specific forest stand conditions. There is no unique treatment applicable to all forest stands and the use of ForestSimulator should be viewed as an aid to foresters, but the final decision has to be made based on technical experience and scientific basis.

The integration of forest models in the ForestSimulator software was motivated by the need of forest technologies in Mexico. The Mexican version of ForestSimulator for temperate forests was developed with the intention of helping Mexican foresters, scientists, and decision makers. Therefore, the ideal case would be that the Mexican forest community adopt this software and integrate it into management activities. However, there are still several challenges and a long way to go in order to consolidate the use of ForestSimulator in the country.

First, Mexican foresters need to be trained in the use of the forest simulator. In this context, short courses can be offered to teach potential users. Aspects such as software installation, calibration, database management, and reporting would need to be covered. This also applies to the academic environment, i.e., as the simulator is useful to understand how the forest can be managed to obtain the 
desired objectives, it could be convenient to incorporate the use of the software in forestry schools. In this way, students could adopt and promote the software when they enter the professional field. Another solution could be the drafting of a comprehensive user manual in the full Spanish language. However, both approaches can be addressed.

Second, the software must be calibrated for other regions and ecosystems. To be widely adopted, the software should also be promoted, when possible, by state institutions, such as INIFAP and CONAFOR. If commitment can be reached by these institutions, the implementation of the simulator could be facilitated.

In this sense, future work could be focused on developing single-tree models to adapt ForestSimulator to other regions. The optimal solution would be to promote a national project in terms similar to SIBIFOR but including the following equations:

- Single-tree BAI or tree diameter increment models using tree size indicators, site characteristics, and competition metrics as predictor variables

- Single-tree crown width models

- Single-tree crown base height models

- Tree mortality models

- Ingrowth models

- Diameter distribution models

- Tree $h-d$ relationship models

- Biomass models

In addition, it would be necessary to generate information about stand dynamics in forest ecosystems. In general, Mexican forest ecosystems have evolved along with certain disturbances such as fire, drought, or plagues. For instance, some temperate forests have a specific fire regime with which tree species have developed mechanisms such as serotinous cones that release seeds after fires. Understanding these natural drivers would enable forest managers and decisionmakers to design management strategies that are coupled with socioeconomic and environmental factors.

This lack of knowledge could be solved by establishing long-term observational plots. These plots should be large enough to capture the natural stand 
dynamics and to make it possible to measure the effects of disturbances on forest structure, e.g., the gaps created by tree mortality. Besides, it would be optimal to have research stations where silvicultural treatments could be designed and tested using ForestSimulator.

Historically forest management in Mexico has had both successes and counterpoints. Community-based forest management can be considered as a success since it allowed the Ejidos and indigenous communities to manage their own land. However, the lack of knowledge and novel technologies in forestry sector have delayed the progress towards sustainable forest management. Mexican local communities have historically demonstrated their capacity to manage their forest in a more integrated way by establishing different levels of organization. However, in general, it is still necessary to link the knowledge generated by researchers with forest management programs. In this sense, the ForestSimulator represents a user-friendly tool not only for forest management and silviculture, but to be applicable in teaching and research projects.

The results of this work represent a way to support sustainable forest management in Mexico by integrating models with forest growth simulators for climate change and socioeconomic benefits. Therefore, the application of the knowledge and technologies presented here could help Mexican foresters, scientists, and decision makers to manage, analyze, and regulate forest ecosystems. 